\title{
MULTIFUNCTIONALITY AS A STRATEGY TO DECREASE RESOURCE USE IN BUILDING ENVELOPES
}

By

Clara H. Gerhardt

\author{
A thesis \\ submitted to the \\ Victoria University of Wellington \\ in fulfilment of the requirements for the degree of \\ Master of Architecture
}

Victoria University of Wellington

2009 


\section{$\underline{\underline{A B S T R A C T}}$}

The growing use of renewable and non-renewable resources by human society is increasingly seen as one of the root causes of the occurring imbalance in the global ecosystem. The effects are inter alia made responsible for a severe disruption in climate, loss of biodiversity, water shortage and a looming energy crisis that combined threaten human prosperity and livelihood. As a response to the occurring problems, global commitment to sustainable development is envisaged. In this context the building industry has a great responsibility as it's leverage as one of the biggest stakeholders in global material flows is significant. It will increasingly have to provide credible solutions and strategies to not only qualitatively change the composition of the triggered material flows, but to reduce the absolute consumption of raw and refined materials and generation of material flows to a sustainable level. The research presented in this thesis therefore analyses different strategies that can lead to the reduction of resource use in architecture, focussing on multifunctionality. A discussion of constructional principles of the building envelope analyses how multifunctionality can be achieved. A material intensity analysis using the material input per service unit concept (MIPS) quantifies the potential of multifunctionality to reduce resource use by comparing the material flows of a conventional and a multifunctional envelope. The case study shows that multifunctionality has the potential to reduce the resource use of building envelopes, if synergistic effects are created and if life-cycle wide resource flows are taken into account at the design stage. Both the theoretical first part and the case study in the second part of the thesis underline that the success of multifunctionality in contributing to resource flow reductions is highly dependent on the designer's awareness of the importance of material flows in the built environment and willingness to approach the topic with flexible design solutions. Furthermore it is underlined that only a combination of different strategies which address the topic at different leverage points will lead to the necessary absolute reduction in material flows. 



\section{ACKNOWLEDGEMENTS}

First of all, I thank my supervisor, Prof. Brenda Vale, for many insightful conversations during the development of the ideas in this thesis and for her continuous support during the last year, which made studying as a distant student a very pleasant experience.

For the generous financial support I received along with the Bruno-Taut-Award, I thank the German Chamber of Architects, the commissary of the German government for Culture and Media and the German Academic Exchange Service (DAAD), which made this year of research possible. I hope that the award and the scholarship will be re-established in the future as it truly serves its purpose of enabling graduate architects to orientate themselves in the first years as professionals without having to agonize about funding.

Furthermore I would like to express my gratitude to Michael Ritthoff of the Wuppertal Institute for Climate, Environment and Energy for his personal support in sourcing some of the data used for the material intensity analysis.

Thank you also to Tracey Peryman for taking time to discuss green walls with me and for taking me to Landcare Research in Auckland to visit the green wall and roof testing facilities there.

I am also indebted to Felix Jerusalem, who so kindly sent drawings and photos of the straw house in Eschenz he designed and who answered the technical questions I had concerning the structural and thermal properties of the pressed straw panels he used.

Many thanks also to all those other people that patiently replied to my email queries often in much detail.

Frederik, thank you as well! Especially for putting up with me and my various efficiency-increasing measures at home.

Probably unusual, but nevertheless truly felt is my gratitude to my mother-in-law, Stephanie WeisGerhardt, an environmentalist of almost 40 years, who inspired me to investigate sustainable architecture in the first place.

However, this thesis is dedicated to my parents who were the ones that instilled an unconditional love for nature in me. 



\section{TABLE OF CONTENTS}

NOTATION

XIV

PART A: FUNDAMENTALS AND DISCUSSION

1

1

INTRODUCTION

3

1.1 THE NEED FOR SUSTAINABLE MATERIAL FLOWS 3

$1.11 \quad$ IMPACT OF MATERIALS FLOWS 4

1.1.2 ECOLOGICAL OVERSHOOT- THE LIMIT OF THE PLANET'S BIO-CAPACITY 5

1.2 SUSTAINABLE DEVELOPMENT AND SUSTAINABILITY 10

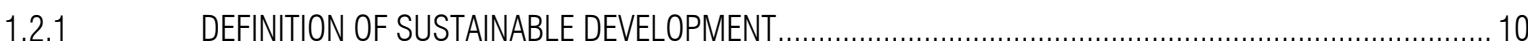

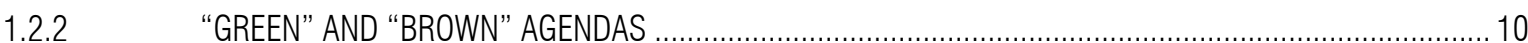

1.2.3 WEAK AND STRONG SUSTAINABILITY ……………………………………………………….... 12

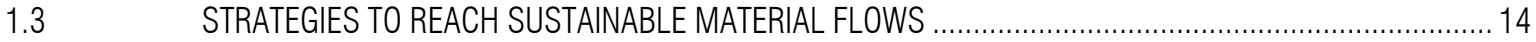

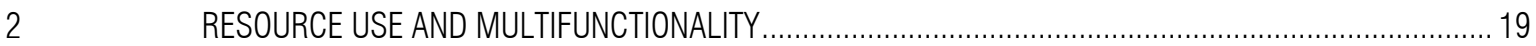

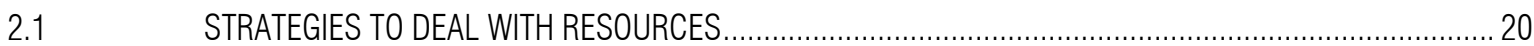

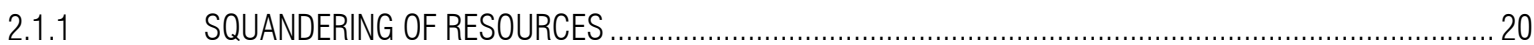

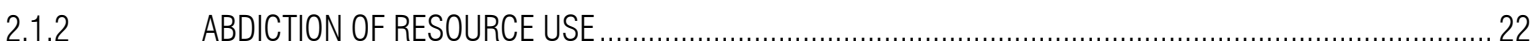

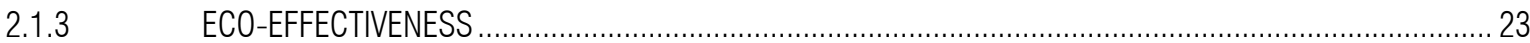

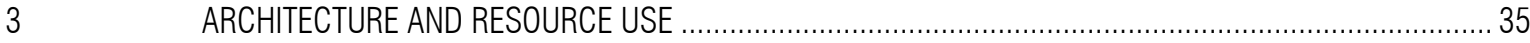

3.1 THE GLOBAL IMPACT OF BUILDINGS AND CONSTRUCTION ……...............................................

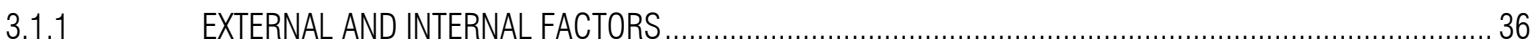


4.1 THE ELEMENTS OF THE ENVELOPE

R.2 REQUIREMENTS, FUNCTIONS AND UNDERLYING PHYSICAL PRINCIPLES ......................................42

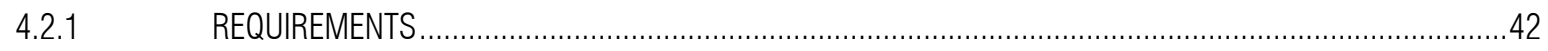

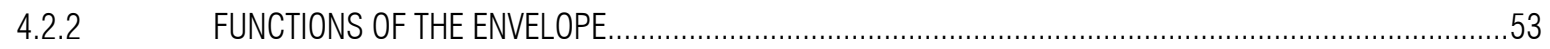

4.2.3 PHYSICAL PARAMETERS AS A MEASURE OF APPROPRIATENESS ……........................................

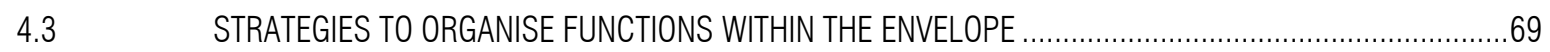

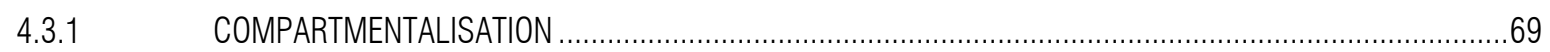

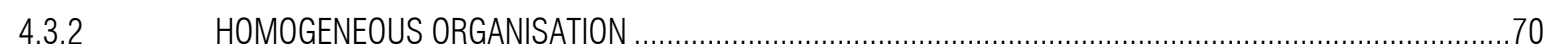

4.3.3 ORGANISATION IN LAYERS

PART B: CASE STUDY

5 REDUCING RESOURCE USE OF ENVELOPES BY INCREASING THEIR FUNCTIONALITY ..........................75

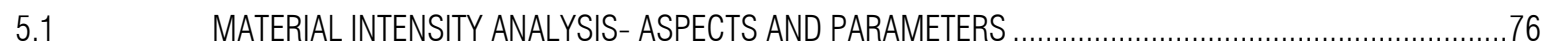

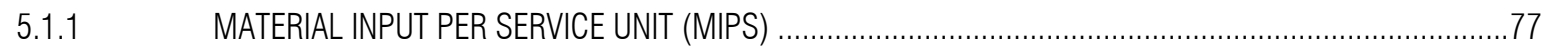

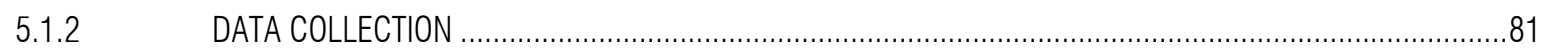

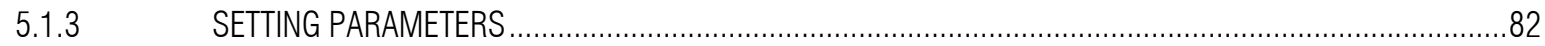

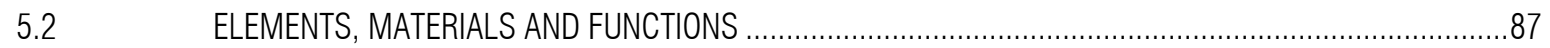

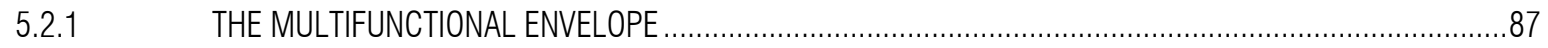

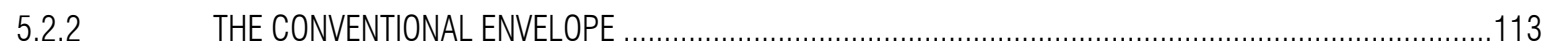

E.3 ENERGY PERFORMANCES OF THE TWO ENVELOPES 
5.3.3 ELECTRICITY

5.4 RESULTS: RESOURCE USE OF THE TWO CASE STUDIES

5.4.1 SCOPE, ASSUMPTIONS AND BOUNDARIES.

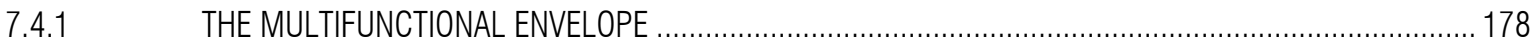

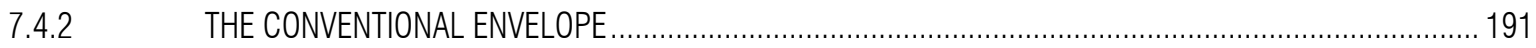

8

REFERENCES 



\section{LIST OF FIGURES}

Figure 1: Open pit diamond mine located in Mirny, Eastern Siberia and rainforest destruction in Borneo. 5

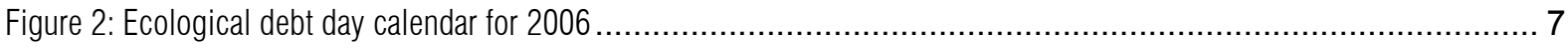

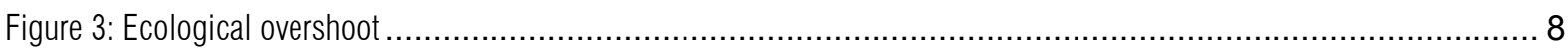

Figure 4: Share of world's private consumption of resources, 2005 ........................................................... 11

Figure 5: Strong sustainability model and weak sustainability triple bottom line model ............................................ 13

Figure 6: Relationship between material need and resource use in current ecological overshoot situation....................... 15

Figure 7: Possible actions to be taken to change relationship between material need and resource use .......................... 15

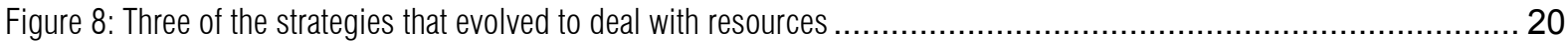

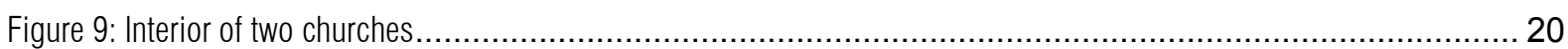

Figure 10: Cover of ICON magazine, November 2008 issue and a poster of the buy-nothing-day .................................. 22

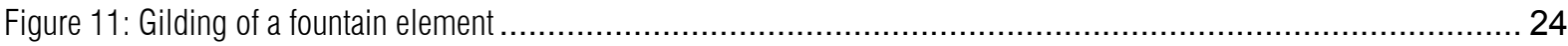

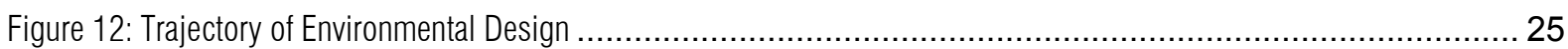

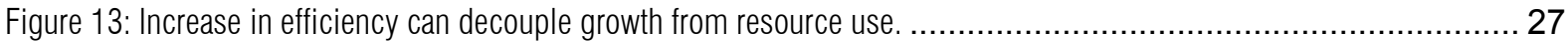

Figure 14: Computers, large and very expensive, have become small, faster and affordable ...................................... 29

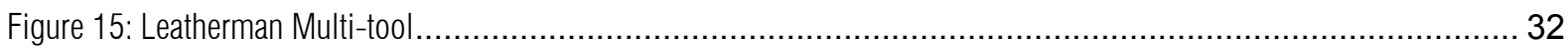

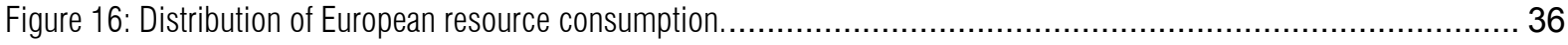

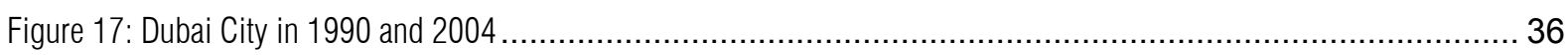

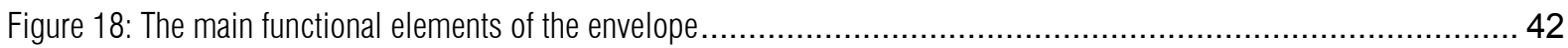

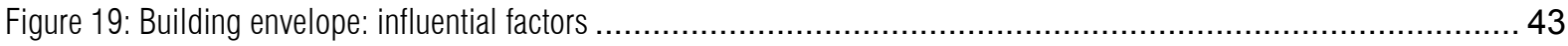

Figure 20: Glenn Murcutt's Marika Alderton House, Northern Territory, Australia. ..................................................... 44

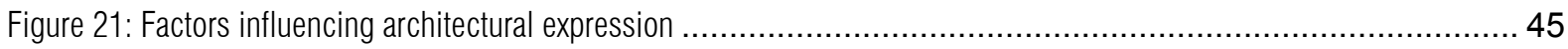

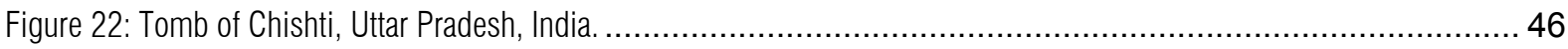

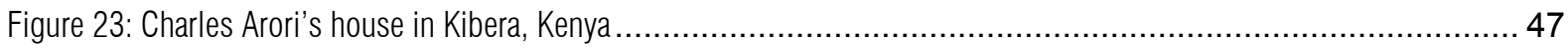

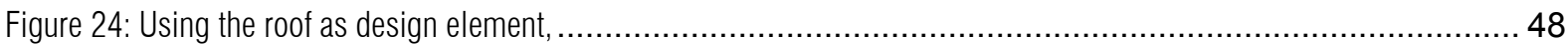

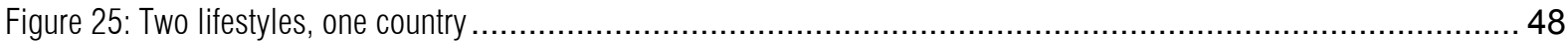

Figure 26: Cologne's main railway station from 1894 and Schloss Neuschwanstein in Bavaria from 1884 ...................... 50

Figure 27: Mies van der Rohe's high-rise designs 1919 and 1922 and Mies at Lake Shore drive in Chicago ................... 51 
Figure 28: German Architects in Beijing and Japanese Architects in Germany

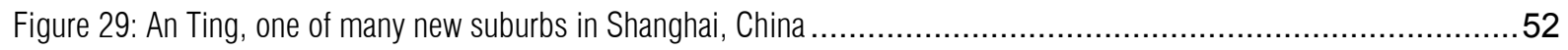

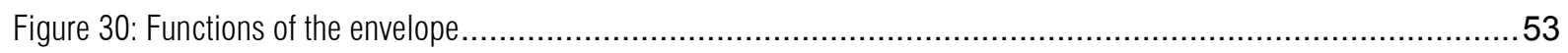

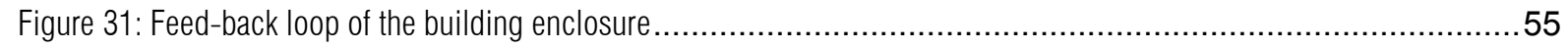

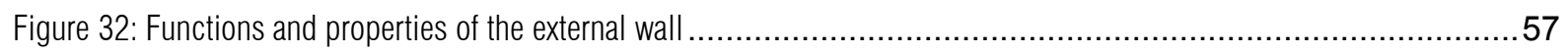

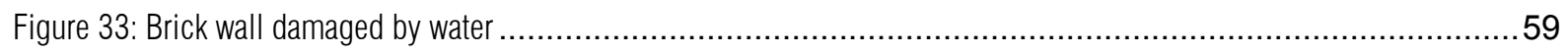

Figure 34: Illustration of compressive, tensile and shear forces ...................................................................62

Figure 35: Influence of thermal mass on temperature within the enclosed space .................................................64

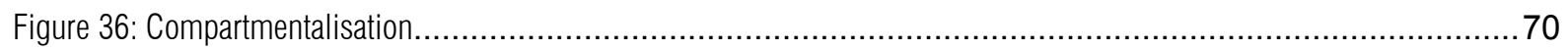

Figure 37: Traditional clay building (Kasbah in Morocco) and modern clay house in Austria .......................................70

Figure 38: The opening as an example of filtering internal and external influences................................................. 72

Figure 39: Multifunctional and conventional envelope slices that were compared in the case study ...............................76

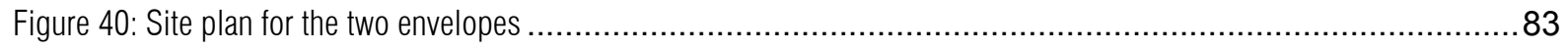

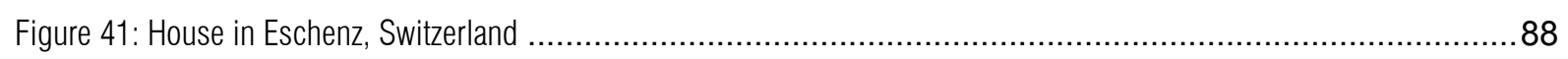

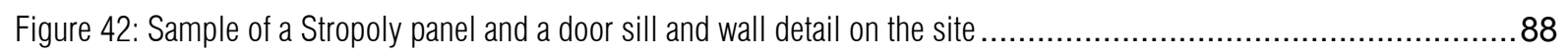

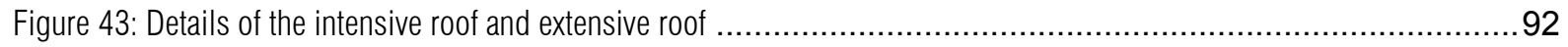

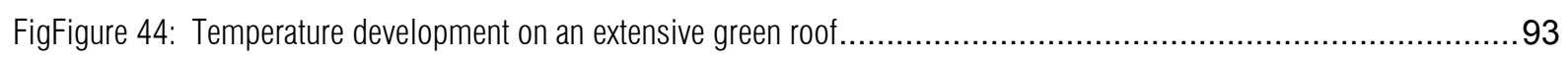

Figure 45: Extensive Roof and Intensive roof-top gardening in the USA.........................................................93

Figure 46: Shading provided by climbing plants and traditional patio in Cordoba, Spain ..........................................95

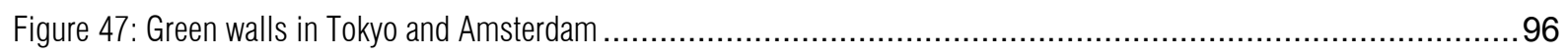

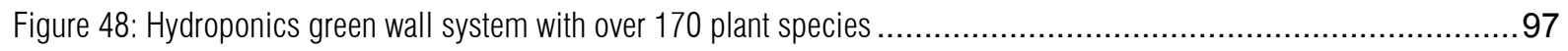

Figure 49:Close-up of a green wall and food project of the Urban Farming organisation in Los Angeles..........................97

Figure 50: Panels of stainless steel and aluminium in two different depths, drawings by manufacturer ...........................98

Figure 51: Installation of a vertical garden panel system and irrigation system ....................................................99

Figure 52: View of a green wall using panels, and section through the green wall.................................................99

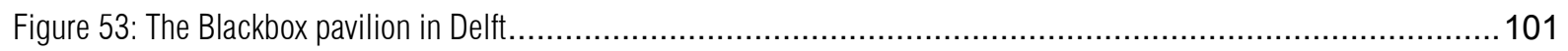

Figure 54: Image of the black box envelope and section through the green wall ..................................................101

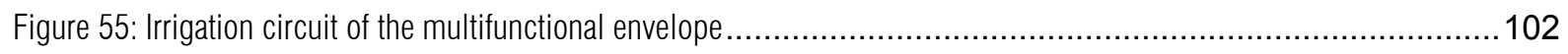

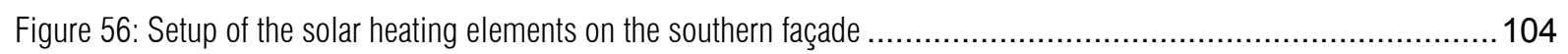

Figure 57: Elevation and Schematic organisation of pipes and flow directions of the thermal heating system .................. 105 
Figure 58: Circuit diagram of the heating system

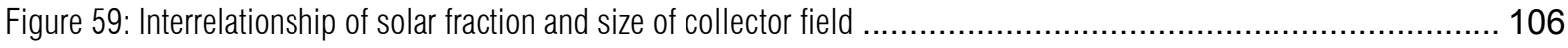

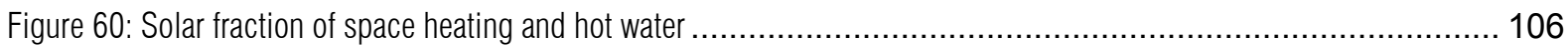

Figure 61: Cross section through the wall with the integrated solar heating .................................................... 107

Figure 62: Amorphous silicon thin film cells and microcrystalline silicon bottom cells integrated in glazing .................. 109

Figure 63: Section through a window with integrated amorphous silicon thin film module. ...................................... 110

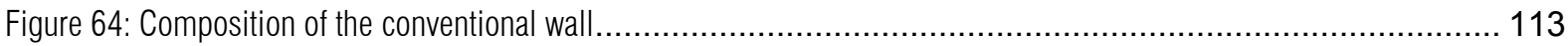

Figure 65: Detail of the conventional roof and image of a similar roof ........................................................... 114

Figure 66: Annual solar radiation in Graz dependent on module tilt, snow reflection and azimuth................................ 119

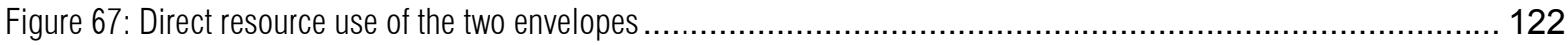

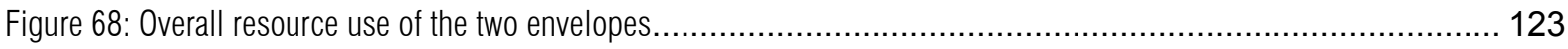

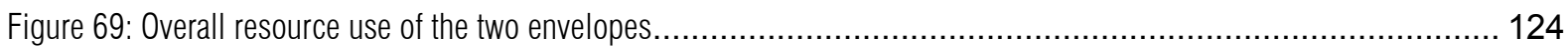

Figure 70: Overall resource use of the optimised versions of the two envelopes ................................................. 126

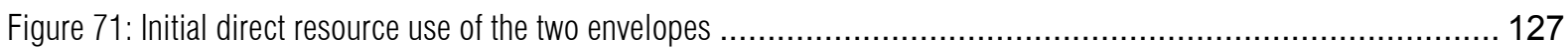

Figure 72: Direct resource use of the two envelopes over 60 years.............................................................. 128

Figure 73: Abiotic and biotic indirect resource use of the two envelopes ...................................................... 130

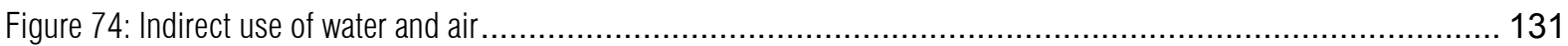

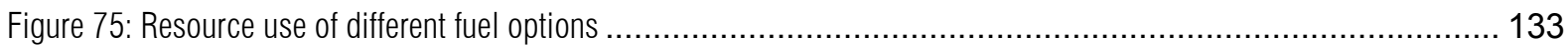

Figure 76: Resource use of the multifunctional envelope with (right) and without (left) solar thermal elements ................ 134

Figure 77: Resource use of the multifunctional envelope (in tonnes) with solar thermal elements .............................. 135

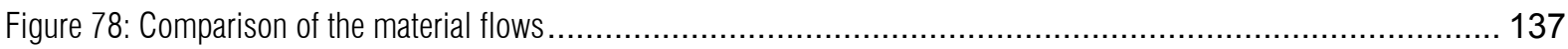

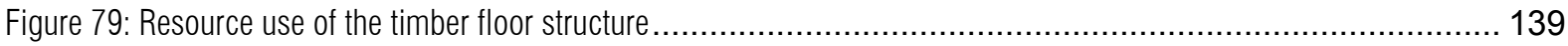

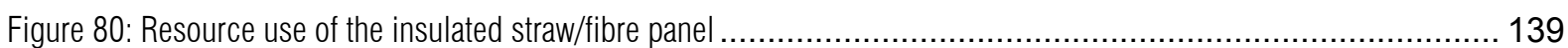

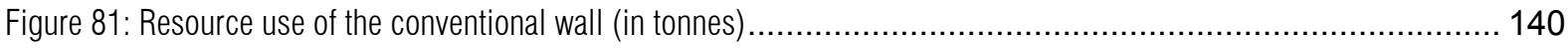

Figure 82: Direct and indirect resource use of the solar thermal wall ........................................................... 141

Figure 83: Direct and indirect resource use of the solar thermal wall ............................................................. 142

Figure 84: Direct and indirect resource use of the four green wall systems..................................................... 143

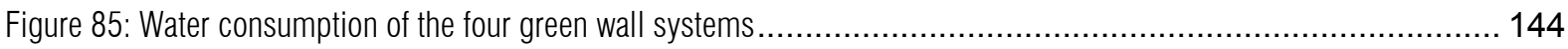

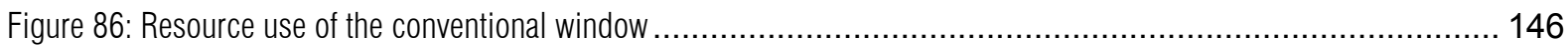

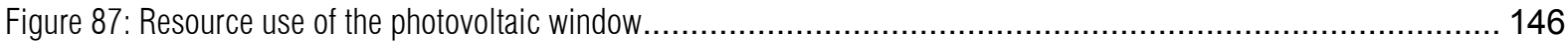


Figure 88: Resource use of the conventional roof with zinc-cladding..... 148

Figure 89: Resource use of the alternative conventional bituminous roof 148

Figure 90: Resource use of the roof structure of the multifunctional envelope without the green roof..... 149

Figure 91: Resource use of the green roof of the multifunctional envelope...... 149

Figure 92: Surface use per square metre greened area of green wall systems, roofs and gardens...... 152

Figure 93: Resource use in tonnes of 1 square metre of green wall panels, green roof and greened façade. 154

Figure 94: Water use in tonnes during production and maintenance of 1 square metre of green wall panels. 154

Figure 95: Section and schematic Floor Plan of the multifunctional envelope 159

Figure 96: Detailed section and reference numbers of the multifunctional envelope. 160

Figure 97: Section and schematic Floor Plan of the conventional envelope. 161

Figure 98: Detailed section and reference numbers of the multifunctional envelope. 162

Figure 99: Alternative roof solution, conventional envelope. 163

Figure 100: Part of the heating system providing hot water and space heating..... 175 


\section{NOTATION}

Latin symbols

$a_{i}$

$A_{B}$

$A_{f l n e t}$

$A_{g}$

A panel

$A_{p v}$

$A_{R}$

$A_{\text {th }}$

$A_{w}$

$A_{w l}$

C

C

$\mathrm{C}_{\mathrm{a}}$

$\mathrm{C}_{\mathrm{p}}$

d

E

$E_{p v}$

$f$

$f_{s}$

$g_{w}$ con

$g_{w p v}$

HGT $_{-12 / 20}$ numerical parameter to calculate usable heat gains

$[-]$

coefficient of appropriateness

$[-]$

surface of envelope

$\left[\mathrm{m}^{2}\right]$

gross floor area

$\left[\mathrm{m}^{2}\right]$

net glazed area

$\left[\mathrm{m}^{2}\right]$

photovoltaic panel size

$\left[\mathrm{m}^{2}\right]$

area of photovoltaic panel

$\left[\mathrm{m}^{2}\right]$

roof area

$\left[\mathrm{m}^{2}\right]$

net collector area

$\left[\mathrm{m}^{2}\right]$

window area

$\left[\mathrm{m}^{2}\right]$

wall (all four sides) area

$\left[\mathrm{m}^{2}\right]$

relevant thermal capacity

$\left[\mathrm{Wh} / \mathrm{m}^{3} \mathrm{~K}\right]$

heat capacity

$[\mathrm{J} /(\mathrm{kg} \cdot \mathrm{K})]$

specific heat capacity of air

$[\mathrm{J} / \mathrm{kgK}]$

specific heat capacity

$\left[\mathrm{kJ} /\left(\mathrm{m}^{3} \mathrm{~K}\right)\right]$

day

energy

$[\mathrm{kWh} / \mathrm{a}]$

efficiency photovoltaic element

correction factor heat loss

$[-]$

$[-]$

$[-]$

$[-]$

[K d] 


\begin{tabular}{|c|c|c|}
\hline $\mathrm{HT}_{12}$ & heating days per year & [d] \\
\hline$I_{d}$ & diffuse radiation on photovoltaic module & {$\left[\mathrm{W} / \mathrm{m}^{2}\right]$} \\
\hline $\mathrm{Ig}_{\mathrm{g}}$ & global radiation & {$\left[\mathrm{kWh} / \mathrm{m}^{2} \mathrm{a}\right]$} \\
\hline $\ln$ & solar radiation on horizontal plane & {$\left[\mathrm{kWh} / \mathrm{m}^{2} \mathrm{a}\right]$} \\
\hline$I_{N}$ & solar radiation on vertical plane (oriented north) & {$\left[\mathrm{kWh} / \mathrm{m}^{2} \mathrm{a}\right]$} \\
\hline lo/w & solar radiation on vertical plane (oriented east/ west) & {$\left[\mathrm{kWh} / \mathrm{m}^{2} \mathrm{a}\right]$} \\
\hline$I_{s}$ & solar radiation on vertical plane (oriented south) & {$\left[\mathrm{kWh} / \mathrm{m}^{2} \mathrm{a}\right]$} \\
\hline $\mathrm{k}$ & thermal conductivity & {$[\mathrm{W} /(\mathrm{m} \mathrm{K})]$} \\
\hline$L_{v}$ & ventilation loss index & {$[\mathrm{W} / \mathrm{k}]$} \\
\hline M & mass & {$[\mathrm{kg}]$} \\
\hline Mat $_{\mathrm{i}}$ & material input & {$[\mathrm{kg}]$} \\
\hline $\mathrm{n}$ & air change rate per hour & {$[1 / \mathrm{h}]$} \\
\hline$P$ & required energy & {$[W]$} \\
\hline $\mathrm{P}_{0}$ & heat loss through transmission & {$[\mathrm{W}]$} \\
\hline $\mathrm{P}_{\mathrm{A}}$ & specific heat loss through ventilation & {$[\mathrm{W}]$} \\
\hline$P_{\text {annum }}$ & energy use per annum & {$[\mathrm{kWh} / \mathrm{a}]$} \\
\hline$P_{\text {eff }}$ & effective energy use per annum & {$[\mathrm{kWh} / \mathrm{a}]$} \\
\hline $\mathrm{P}_{\text {pip }}$ & heat loss cold water pipes & [W/person] \\
\hline$P_{\text {spec }}$ & overall specific heat loss & {$\left[\mathrm{W} / \mathrm{m}^{3} \mathrm{~K}\right]$} \\
\hline$P_{t}$ & specific heat loss through transmission & {$\left[\mathrm{W} / \mathrm{m}^{3} \mathrm{~K}\right]$} \\
\hline$P_{\text {tot }}$ & overall heat loss $=$ heating load & {$[W]$} \\
\hline$Q_{\text {peo }}$ & heat gain from people with $12 \mathrm{~h} / 24 \mathrm{~h}$ absence & [W/person] \\
\hline $\mathrm{Q}_{2}$ & overall heat gains & {$[\mathrm{kWh} / \mathrm{a}]$} \\
\hline Qannum & usable heat gains per annum & {$[\mathrm{kWh} / \mathrm{a}]$} \\
\hline$Q_{\text {appl }}$ & heat gain from appliances & [W/person] \\
\hline Qeff.pv & effective power output of photovoltaic element per year & {$[\mathrm{kWh} / \mathrm{a}]$} \\
\hline Qenv & energy produced by envelope per year & {$[\mathrm{kWh} / \mathrm{a}]$} \\
\hline
\end{tabular}


$Q_{m p p}$

maximal power output according to Standard test conditions (STC)

$Q_{p v}$

$Q_{\mathrm{s}}$

$Q_{\text {start }}$

Qth space

$\mathrm{R}$

$\mathrm{R}_{\mathrm{re}}$

$\mathrm{R}_{\mathrm{s}}$

Su

$\mathrm{T}_{\text {int }}$

$\mathrm{T}_{\mathrm{ne}}$

$\mathrm{T}_{\mathrm{av}}$

U

V

$\mathrm{V}_{\mathrm{mpp}}$

$\mathrm{V}_{\mathrm{N}}$

$\mathrm{V}_{\mathrm{oc}}$

Greek Symbols energy gains from photovoltaics

solar heat gains

max. initial power of photovoltaic element

energy gains from solar heating

thermal resistance

albedo

coefficient to transform direct solar radiation

on horizontal plane into vertical plane

$[-]$

tilt of photovoltaic module

$\left.{ }^{\circ}\right]$

solar fraction

[\%]

service Unit

$[-]$

normalised inside temperature

$\left[{ }^{\circ} \mathrm{C}\right]$

normalised outside temperature

$\left[{ }^{\circ} \mathrm{C}\right]$

average temperature

$\left[{ }^{\circ} \mathrm{C}\right]$

heat transmittance

$\left[\mathrm{W} /\left(\mathrm{m}^{2} \mathrm{~K}\right)\right]$

gross heated volume

$\left[\mathrm{m}^{3}\right]$

voltage at maximal power point

[V]

net ventilated volume

$\left[\mathrm{m}^{3}\right]$

off load voltage temperature difference

ratio of heat gains and heat loss

load factor

density

density of air

time constant of thermal inertia
[K]

$[-]$

$[-]$

$\left[\mathrm{kg} / \mathrm{m}^{3}\right]$

$\left[\mathrm{kg} / \mathrm{m}^{3}\right]$

[h] 
Subscripts

\begin{tabular}{|c|c|}
\hline a & air \\
\hline appl & appliances \\
\hline B & building \\
\hline con & conventional \\
\hline $\mathrm{E} / \mathrm{W}$ & east/ west \\
\hline eff & effective \\
\hline elec & electrical \\
\hline env & envelope \\
\hline $\mathrm{fl}$ & floor \\
\hline g & glazed, global \\
\hline $\mathrm{h}$ & horizontal \\
\hline heating & space heating \\
\hline hw & hot water \\
\hline int & internal \\
\hline $\mathrm{N}, \mathrm{n}$ & net, north \\
\hline ne & normalised outside \\
\hline $\mathrm{p}$ & person \\
\hline peo & people \\
\hline pip & pipes \\
\hline pv & photovoltaic \\
\hline $\mathrm{r}$ & roof \\
\hline s & shade, solar, solubility, sound, south \\
\hline spec & specific \\
\hline $\mathrm{t}$ & transmission \\
\hline th & thermal heating, thermal \\
\hline tot & Overall, total \\
\hline$v$ & ventilation \\
\hline w & window, weighted, water \\
\hline $\mathrm{wl}$ & wall \\
\hline
\end{tabular}



PART A: FUNDAMENTALS AND DISCUSSION 



\section{INTRODUCTION}

"Many of the problems that threaten mankind's survival on the planet result from increased consumption of energy, water, raw materials, the increased production of waste and emissions and the increased human use of land area."

(Giljum et al., 2009, p. 5)

SUMMARY:

This chapter analyses the scale of human resource use and its impact on the ecosphere. It establishes why sustainable material flows are needed and gives a definition of sustainable development. It then touches briefly on strategies that can be applied at different levels in order to move to sustainability. The chapter cannot portray the interrelated existing problems in all their complexity nor do justice to all the strategies that exist to solve them, but should be understood as an introduction to the context in which resource-efficiency increases and mutlifunctionality are set.

\subsection{THE NEED FOR SUSTAINABLE MATERIAL FLOWS}

\section{SUMMARY:}

Globally accelerating material flows have diverse causes. Increasing population pressures, cultural and psychological changes that reinforce consumerism in rich nations and make it a goal in developing ones, as well as an economic system that requires continuous growth in order to maintain the current level of prosperity are all contributing factors. The following sections will analyse these causes and describe their impact on the global ecosystem. It will be shown that current human needs and wants are met at high social, environmental and cultural costs. They will have to be increasingly restricted rather than encouraged on a planet that is, even if its resources and possibilities once seemed 
to be unlimited, a closed system, requiring an equilibrium to sustain the favourable conditions that allowed humans to develop and survive as a species.

While the first voices questioning the compatibility of a finite planet and ever increasing global resource demand in the middle of the last century named resource limits as the probable main cause of decreasing human prosperity and livelihood in the future, it seems today that the ability to absorb the waste generated by current and past resource use (in the form of liquid, gaseous and solid pollutants that remain in the system) is the bottle neck that society will have to get through while hitting the first frontiers of resource depletion. Resource use is no longer only a question of preventing ecological overshoot and depletion of non-renewable resources. It has become increasingly clear how deeply complex and dynamically interactive the feedback mechanisms are that effect climate, surface properties, and the biological and cultural diversity of this planet. It is also clear these have been changed through increasing human exploitation of resources.

\subsubsection{IMPACT OF MATERIALS FLOWS}

Human life relies on the use of materials, water, energy and fertile land. To harvest resources, interference with natural systems and even their disruption is necessary. In prehistoric times these interruptions were small and local due to the absence of machinery and technology. Humanity relied on its own physical strength and skills to gather resources and increase its prosperity. A smaller population size reduced the impact of the changes to the natural environment to a level that was much less important than naturally occurring changes, so that it could recover from human interventions. However, since antiquity population growth, land reclamation, agriculture, logging and urbanisation have slowly accelerated and significantly changed parts of the globe.

Since industrialisation the growth of the global economy has speeded up, as fossil fuel and the invention of increasingly powerful machinery made ever increasing material flows technically achievable and economically viable (Fischer-Kowalski,M., 2006). With the technological changes came a cultural change increasing the global desire for consumer products, which further fuelled resource use.

Non-renewable energy carriers, available in large quantities, have triggered materials flows. They make widespread global distribution and trade of resources, goods and waste products possible. Globalised markets also trigger globalised production chains. In her book "The Travels of a T-Shirt in the Global Economy", Rivoli for example traces the journey of an ordinary T-shirt bought in the USA showing that its components are transported back and forth between five continents (Rivoli, P., 2005). Individual and yet typical examples like this add up to an enormous and increasing volume of consumer goods passing through the world trade routes. Today's anthropologic materials flows have not only quantitatively surpassed natural ones (Schmidt-Bleek, 1993, p.20) but have changed the ecosphere on a global scale, as they go along with building infrastructure, vessels and houses, sealing off land, mining, transporting goods, cultivating crops and harvesting biomass for human consumption and animal feed and consequently destroying natural habitat. The planet's capacity to recover from these alterations and degradations is in many cases exceeded and although barely noticeable for 
many people, species vital for the undisrupted functioning of life on earth are disappearing quickly (WWF, 2008, p. 14).
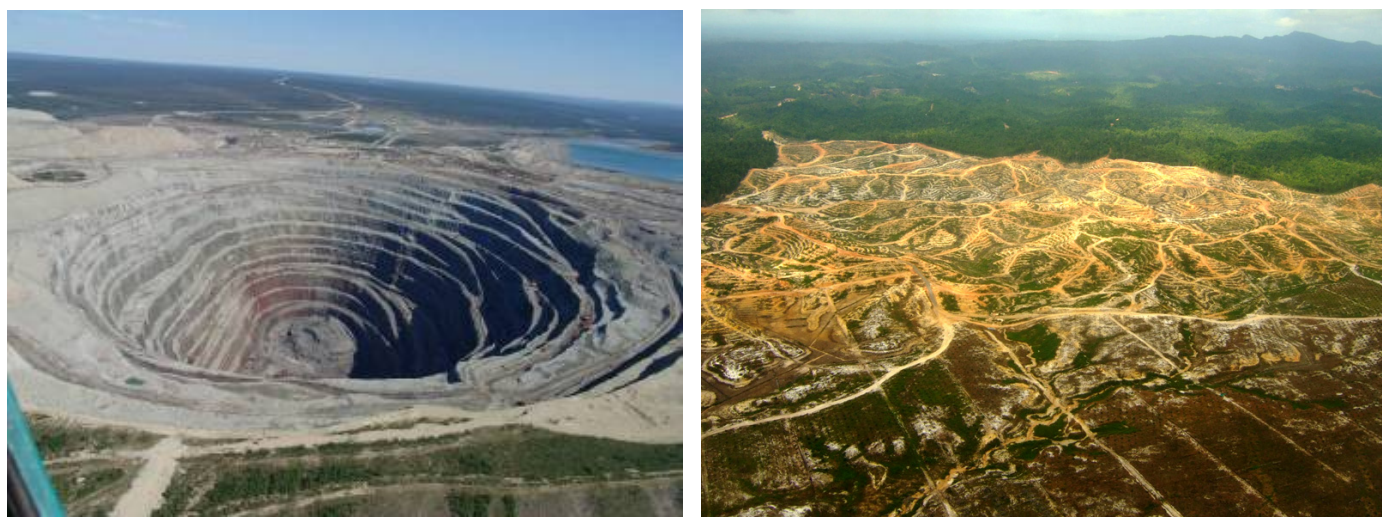

Figure 1: Open pit diamond mine located in Mirny, Eastern Siberia and rainforest destruction in Borneo.

The mine is $525 \mathrm{~m}$ deep and has a diameter of $1200 \mathrm{~m}$.

The current crisis might become even more pressing if the forecasted exponential growth of the economy, population pressure and resource exploitation all occur. The United Nation Environmental Panel (UNEP) for example currently forecasts a $30 \%$ increase of land area directly impacted by exploitation of resources and infrastructure by 2032 (up from 45\% in 2002) (UNEP, 2002, p. 353).

Although the reduction of material flows is urgent in terms of global ecology, it is a fact that ever increasing materials flows are the source and cause of the increased material wealth around a quarter of human society is experiencing (Giljum et al., 2009, p.5). As the current globalised "throughput economy" that produces this unprecedented wealth depends on increasing resource flows to allow for ongoing investment, a fundamental dilemma ensues between the economic interests of some and environmental interests of all.

\subsubsection{ECOLOGICAL OVERSHOOT- THE LIMIT OF THE PLANET'S BI0-CAPACITY}

For a long time it had not been acknowledged that the earth is a closed system and as such can only provide a limited amount of matter, surface area and natural sinks for anthropological debris. Religious beliefs, limited scientific knowledge, a very different level of experience as well as no or limited evidence all contributed to delayed realisation of resources being exhaustible through human consumption. The human population used to be very small and not very powerful (pre industrialisation) in comparison to the landmass and richness of the globe. Meadows et al. were some of the first to describe the antagonism of exponential growth in a finite world during the initial thinking about energy and resources in 1972. At that time they published the report Limits to Growth, which they updated in 2004. They developed a mathematical model of the five main interacting parameters influencing human development: accelerating industrialisation, population growth, food production, reliance on nonrenewable resources and resulting environmental deterioration. They summarised the outcome of their research in 1972 as follows:

"If the present growth trends in world population, industrialisation, pollution, food production, and resource depletion continue unchanged, the limits to growth on this planet will be reached sometime 
within the next one hundred years. The most probable result will be a rather sudden decline in both population and industrial capacity." (Meadows et al.,1974, p.24).

What they described is called "die-off" in ecology, the decline of a population of a species after it reached the ecological limits or the carrying capacity of its territory. In human societies this can be triggered by overconsumption, population growth, the destruction of livelihood (e.g. by eroding soils or by crop failure) or by a combination of these factors. The time between reaching the ecological limits and before the collapse occurs is called the ecological overshoot, essentially describing the state where vital resources needed to maintain the population in the future (such as seeds) are used to fulfil the needs of today (Catton, W. 1982). Therefore overshoot should be avoided in order to rule out a dangerous spiral of overconsumption that often leaves no options but to consume the last resources available.

However, on a local scale the limits of natural capital were often reached in various human societies and places. This either led to ecological overshoot

- the decline of natural capital by consuming more, than the biosphere could produce or assimilate as waste, in turn triggering erosion of overgrazed pastures, depleted fisheries, deforestation (ecological deficits) and finally disease and famine resulting in population decrease or even extinction, as in the case of the Maya and Easter Island populations (Diamond, J., 2005);

or to mitigation of resource shortage

- either by peaceful trade with others who still had sufficient natural resources or

- by securing resources from other areas with brute force e.g. colonisation.

Today developed countries continue to mitigate domestic ecological deficits. The surface of such countries is occupied by infrastructure, urban settlements and industry, leaving little area for food production. They therefore use the fertile surface and buy the resources of developing countries to accommodate their needs (GRAIN, 2008). But even countries with large areas of arable land like China, increasingly face food deficits. In China $28 \%$ of the land mass has been eroded and turned into desert mainly through use of inappropriate agricultural techniques under Mao (Kuchelmeister, 2006, p.16). China mitigates its food deficit for example by securing farm land in Africa and South America (GRAIN, 2008, p.2-3). As the sheer extent of this "land-grab" threatens the livelihood of local populations different international organisations such as the World Bank, the Food and Agriculture organisation and the UN conference on Trade and Development (UNCTAD) try to limit the "aggressive moves to buy vast tracts of agricultural land" (Mathiason, N., 2009, p.4).

Figure 2 illustrates local overshoots of selected countries graphically. 


\section{Ecological debt day calendar 2006}

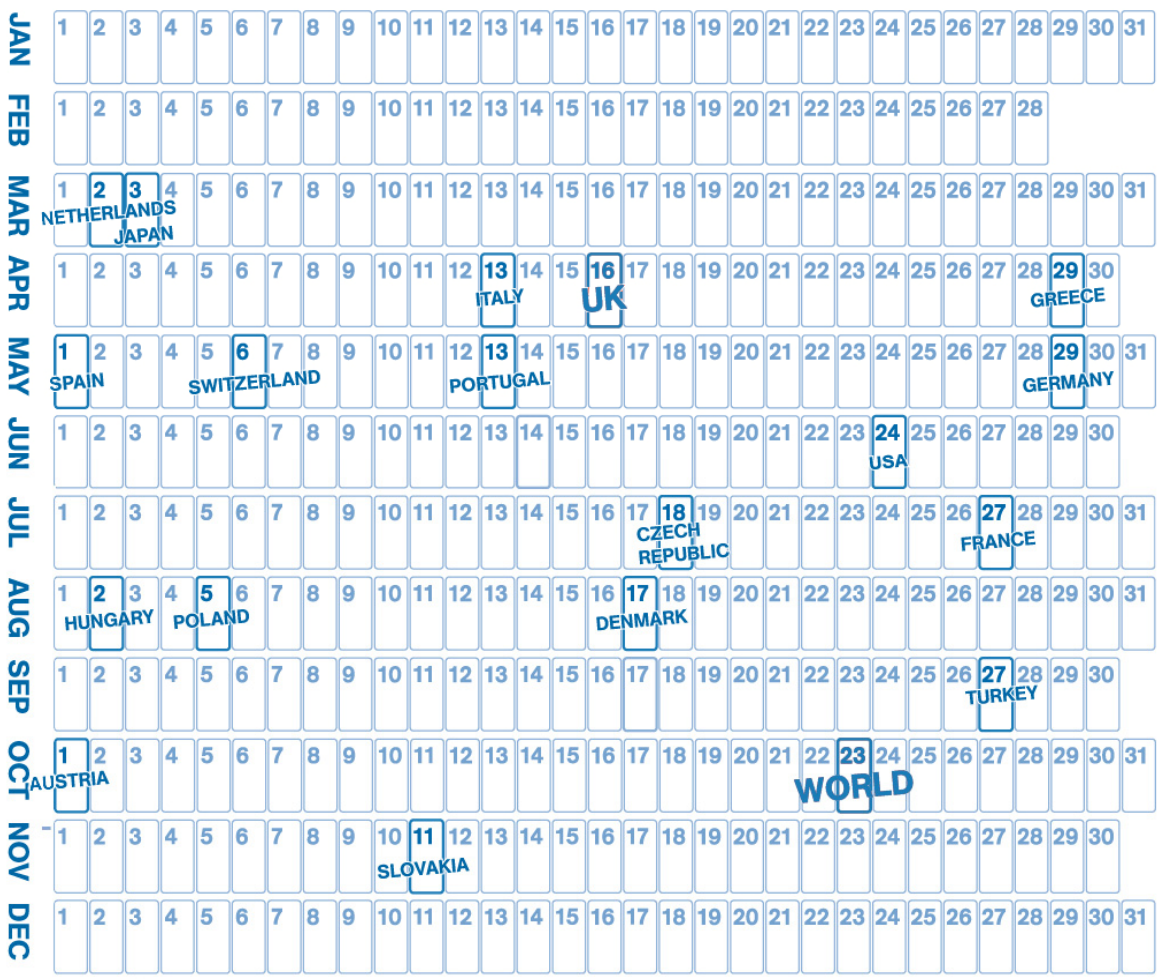

Figure 2: Ecological debt day calendar for 2006

The calendar shows the date when, in effect, different countries stopped relying on their own natural resources, and started to live off the rest of the world. At current levels of natural resource use the average person in the UK for example, begins living beyond his or her environmental means and goes into ecological debt on 16 April. As the total consumption in the UK grows, that date becomes ever earlier in the year. In 1961 it was 9 July, advancing to 14 May in 1981 (Simms, A. et al., 2006, p. 34).

Globally, overconsumption cannot be mitigated, as a shift to new markets or securing meaningful amounts of resources from other planets are fiction. Wackernagel states that: "Overshoot is a vastly underestimated threat to human well-being and the health of the planet, and one that is not adequately addressed." (Wackernagel, M., 2009)

Today it is estimated that the first time global ecological overshoot occurred was in 1986 as illustrated in Figure 3. In that period human consumption of biomass surpassed the annual re-growth of biomass of the entire globe for the first time, slightly lowering the amount of biomass available for the next year. The ecological overshoot has grown exponentially ever since, reaching $15 \%$ in 1996 and $40 \%$ in 2008. This means humanity used $40 \%$ more resources in 2008 than the ecosphere was able to regrow within 12 months. The $40 \%$ overshoot consisted of biotic products, such as fish that did not live long enough to reproduce, overgrazed pastures that turned into eroded land, trees that were not replaced at the same pace as they were cut down, all resulting in fewer fish and trees to harvest in 2009. Consumption levels have virtually turned renewable resources into non-renewable ones, which reduces the natural capital of the planet as Daly states: "Economic growth may already be making us poorer, rather than richer." (Daly, 2008, p.47) However, the overshoot shown in Figure 3 does not even reflect the use of abiotic matter such as fossil fuels or metals that are virtually not replaced by nature. 


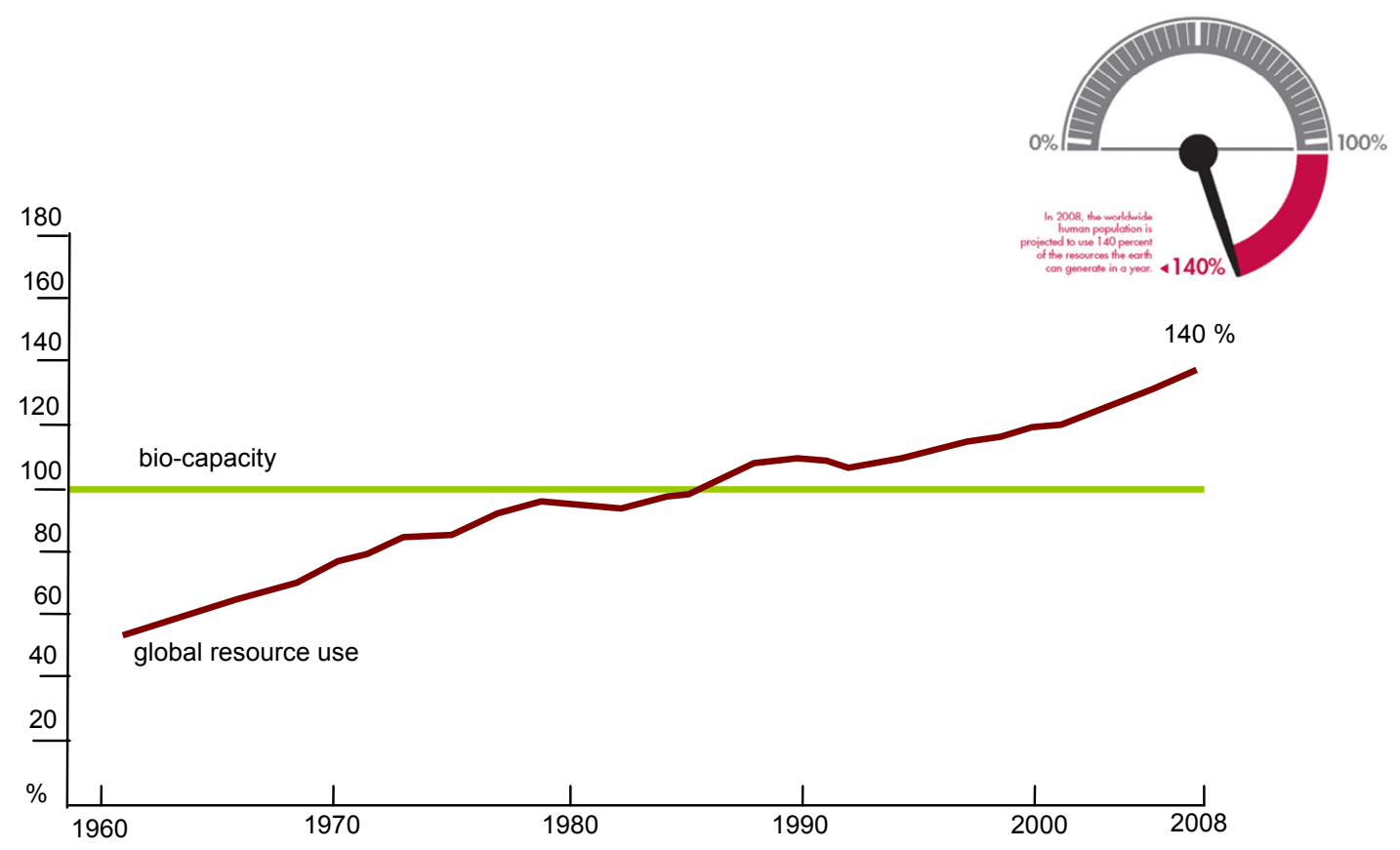

Figure 3: Ecological overshoot

It first occurred in the late 1980 s and reached $40 \%$ in 2008.

While the planet tolerates local overshoot without environmental collapse, the global overshoot, which shows that humanity is now living beyond the regeneration capacity of its ecosystems, causes longterm environmental degradation.

As a result of local and global overshoot, decline in bio-diversity, fisheries collapse, desertification, deforestation and resource scarcity are being witnessed, especially in developing countries, and are at least acknowledged by a part of the industrialised and urbanised societies, even though these occurrences feel unreal to many people. This is partly because environmental health has often been improved locally, as heavy industry shifted from industrialised to developing countries and also because the global economy does not reflect the loss of bio-capacity in its pricing of goods and services. 


\section{To summarise:}

The current extent of anthropological material flow

1. surpasses natural occurring flows quantitatively;

2. per year is increasing exponentially surpassing the amount of material nature can provide within 12 months, causing deterioration and collapse of the system if not counteracted;

3. relies on and largely consists of non-renewable materials;

4. increases wasteland, deserts, urban and sealed land;

5. diminishes significantly fertile land surface needed to meet the nutrition needs of current and future populations;

6. threatens the remaining bio-diversity that relies on undisturbed natural habitats such as forests and wetlands:

7. causes pollution in the form of solid waste, air pollution, and water pollution resulting in 4.6. and causing and intensifying severe problems such as climate change, ozone depletion, ocean acidification and decrease in human health as natural sinks fill up;

8. will continue to increase if the current economic system relying on growing material flows prevails, which will enforce 1.-7. 


\subsection{SUSTAINABLE DEVELOPMENT AND SUSTAINABILITY}

Given the complexity and size of the crisis at hand, it becomes clear that a global response is needed. In this context, sustainable development is seen as a solution to avoid a forced decline in human prosperity caused by continuing to ignore ecological limits. It stands as a goal for a human development that respects ecological limits to material and energy throughput in order to prevent the collapse of the very system it relies upon. However, it requires a shift in current culture, before this degrades human habitat beyond repair and makes conditions for human life less favourable.

The United Nations is committed to sustainable development and aspects of the interrelated problem of human caused disequilibrium on earth (such as climate change, ozone depletion, water shortage or desertification) are being addressed by world leaders with mixed results. However, although the current and predicted consequences become harder to ignore or deny, the degree of commitment to an organised downscaling of the human impact on earth and methods to achieve it are part of an ongoing debate, as will be discussed in the following section.

\subsubsection{DEFINITION OF SUSTAINABLE DEVELOPMENT}

Sustainable development has been defined by the World Commission on Environment and Development as "development that meets the needs of the present without compromising the ability of those in the future to meet their own needs." (WCED, 1987, p.43) The same definition appeared in Agenda 21, the conference document of the successor United Nation Commission on Environment and Development (UNCED) held in Rio de Janeiro in 1992 and chaired by Gro Brundtland, then Prime Minister of Norway.

Although it has been criticised for its lack of clarity and precision, it remains one of the most commonly used definitions of sustainable development as it introduces three key concepts, the concept of "needs", the concept of "limitation" (imposed by technology, social organization and the ecosystem's ability to meet present and future needs) and the concept of social responsibility for future generations. Sustainable development could therefore also be defined as the process of managing the diverse needs of current and future generations while facing the hard physical limits and accepting the soft ecological limits of the planet.

\subsection{2 "GREEN" AND “BROWN" AGENDAS}

The somewhat ambiguous definition accepted by Agenda 21 is the result of a political debate and represents the lowest common denominator between two environmental agendas. These are the "Green agenda for sustainable development" of developed countries focussing on more dispersed, delayed, inter-generational needs such as adjusting politics and society to the limits of the planet, and the "Brown agenda for sustainable development" of developing countries prioritising responses to immediate local needs that affect the current generation (Mc Granahan, G., Satterthwaite, D., 2000). These two agendas are caused by the inequities that currently exist within human society and that 
deeply influence the debate on environmental policies. The main difference between the Green and Brown agendas was summarised by Purvis and Grainger as follows (2004, p.100):

"In a context where the basic economic and social needs of the vast majority of the population are already met, sustainable development is characterized chiefly as a drive for greater environmental quality and efficiency. This is intended to reduce the environmental damages inflicted by human activity, ultimately to the point where a society comes to live within the limits of its environmental carrying capacity. It is acknowledged that such changes should be secured without unacceptable losses of the socio-economic benefits associated with environmental transformations; but less attention is focused explicitly on quality of life or social equity issues. In this, the Green agenda contrasts with the Brown agenda of the developing world, under which the present necessity for economic growth to alleviate poverty, secure livelihoods and fund investment in health and welfare services may take priority over concerns for the future condition of the global environment."

The environmental problems addressed by the Brown Agenda are typically associated with poverty, such as sanitation, urban pollution, lack of waste collection, and local land and water use that leads to erosion, while the Green Agenda is often focussed on problems associated with affluence such as water over-use, over-consumption of resources, land consumption and soil-sealing (DANIDA, 2000). Considering that the national income of Japan alone overtook the combined income of the then 3.8 billion people living in developing countries in the 1990s, it is not surprising that environmental policies take a quite different shape around the globe (Schmidheiny, 1992, p.2).

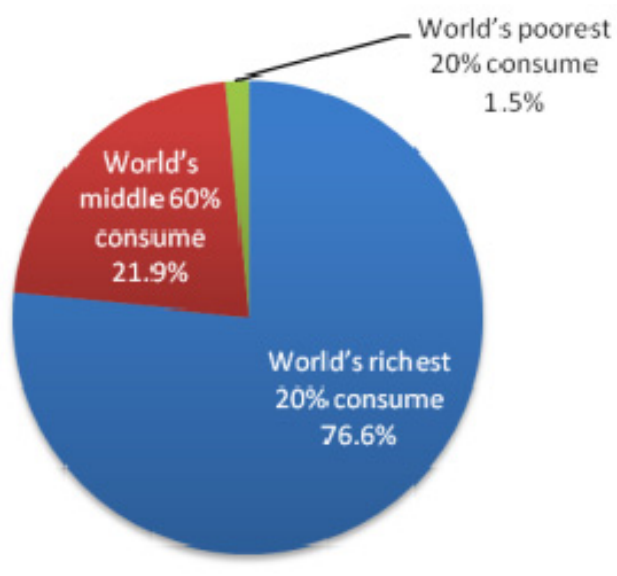

Figure 4: Share of world's private consumption of resources, 2005

In the context of development aid, increasing global material flows are often seen as a precondition for allowing all of humanity to develop to an adequate standard of living. However the current imbalance in people's access to resources seems rather a question of distribution, caused by the structure of the system favouring those already living in affluence, than a question of availability of resources (Meadows, D.H. et al., 2004, p.41), (Simms, A., 2008, p. 49-50), (Jackson, T., 2009). Simms states that: " the current world trade system helps support substantial inequalities in the distribution of the use of natural resources. This raises important questions for global justice." (2008, p.3), (refer also to section 1.4.3.3.4). 
In the light of the Brown and Green agenda discussion it becomes apparent that the terms "sustainable development" and "sustainability" although often used interchangeably, can have slightly different connotations. In his contribution "Forecasting urban futures" to Exploring Sustainable DevelopmentGeographical Perspectives, Mitchell points out that sustainability often has a more restricted meaning: "as the goal of constraining human impacts on the environment in order to protect the life support system of the earth. It is therefore a necessary, but not sufficient condition for sustainable development" (Purvis, Grainger, 2004, p.8).

\subsubsection{WEAK AND STRONG SUSTAINABILITY}

While Brown and Green agendas present two different viewpoints of the definition of "needs" of people, weak and strong sustainability are two terms that are used in the economists' debate over the role of natural capital in reaching and maintaining sustainable development.

Weak sustainability can be interpreted as a modernisation of neoclassical economics. Natural capital is not seen as a precondition to any economical activity but as a tradable commodity. As long as the decrease in natural capital is compensated by an increase of non-declining man-made capital, a sustainable situation is reached. "Weak sustainability is built upon the assumption that natural capital is either abundant or substitutable both as an input into the production of consumption goods and as provider of direct utility. This means that natural capital can be safely run down as long as enough man-made capital is built up in exchange." (Neumayer, E., 2002, p. 1)

Neumayer (2002, p. 23 and p.44) summarizes the paradigm of weak sustainability as:

- natural resources are super-abundant;

- or the elasticity for substituting man-made capital for resources in the production function is equal to or greater than utility, even in the limit of extremely high output-resource ratios;

- or technical progress can overcome any resource constraint;

- resource constraints are overcome by other resources or by increasing prices.

Strong sustainability by contrast perceives the services nature provides as fundamentally nonsubstitutable through other form of capital (e.g. by technology) and as a precondition for human prosperity and even survival. Weak sustainability is not an opposing concept to strong sustainability but is seen by many environmental economists as a first, but insufficient step towards a sustainable economic model which will require strong sustainability.

The reasons why natural capital is seen as not replaceable can be summarised based on Turner, Pearce and Spash (Turner, R., Pearce, D., 1992, p.7), (Spash, C. 1993, 2002):

- people are largely uncertain and ignorant about the detrimental consequences of depleting natural capital.

- natural capital loss often is irreversible.

- some forms of natural capital provide basic life-support functions. 
- individuals cannot be compensated for any environmental degradation via increased consumption opportunities.

As current and past levels of material flows are regarded as not sustainable in the future by most proponents of strong sustainability, the following set of rules defining the sustainable limits of material and energy flows developed by Daly (1990) summarize their approach to resource use:

1. Renewable resources such as fish, soil, and groundwater must be used no faster than the rate at which they regenerate. That is, harvest only at the maximum sustainable yield.

2. Non-renewable resources such as minerals and fossil fuels must be used no faster than renewable substitutes for them can be put into place.

3. Pollution and wastes must be emitted no faster than natural systems can absorb them, recycle them, or render them harmless.

Non-renewable resources can hence be used according to this set of rules but must be accompanied by investing in research on alternative renewable solutions.
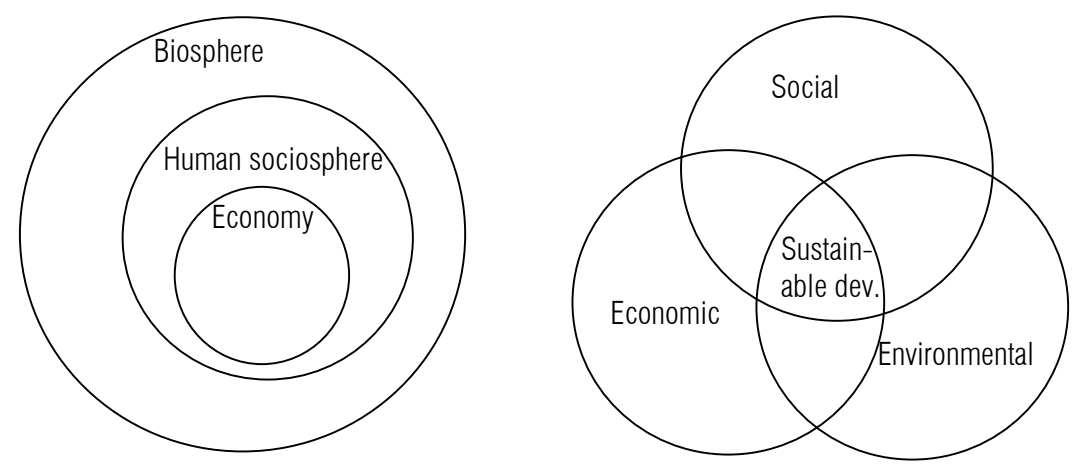

Figure 5: Strong sustainability model and weak sustainability triple bottom line model

Figure 5 shows two commonly used models to describe strong and weak sustainability. The first shows the human sociophere contained within the biosphere using the fact the earth is a closed or self-contained system except for sunlight received, heat reflected into space, and external gravitational effects. Thus, all of human life and actions are contained within the biosphere and are part of it. The economy, as a subset of human actions, is part of the sociosphere (SANZ, UNESCO, 2009).

The other model asserts that what is needed is an appropriate balance between economic, environmental and cultural (or social) outcomes. Only the intersection of the three circles represents the possibility of sustainability. Although social and economic aspects certainly need a more equal consideration, the model ignores the ultimate limits imposed by the environment (biosphere) on economic and social activity. "This makes it wrong in terms of fundamental science and therefore dangerously misleading as a framework for human policy" (SANZ, UNESCO, 2009, p. 6). However, this model underpins most of the discourse and policymaking in 'sustainable development', 'environmental protection' and 'sustainability' debates.

Although weak sustainability seems to be the avenue taken by many countries, others (such as the United Kingdom) do tentatively investigate in greater detail the possibilities of a steady, sustainable economy based on strong sustainability that might provide not only a solution for achieving a balance 
between human consumption and nature's provision of resources but maintain human prosperity (Jackson, T., 2009).

Whether a healthy life-supporting environment is seen as a precondition for sustainable development and human prosperity or more as an important element inter alia, measures to stop its degradation will have to become more important in political decisions and economic system thinking.

In sustainable architecture and urban planning, both models seem to be of great importance both to define the quality and the quantity of further development. The strong sustainability model could help to put the absolute amount of resources used by the building sector into perspective and help to find a sustainable limit to infrastructure and urbanisation (see also chapter 0 ), while the weak sustainability model can be used as a guideline to the importance of social and environmental issues in relation to the economic considerations that largely drive developments.

\subsection{STRATEGIES TO REACH SUSTAINABLE MATERIAL FLOWS}

Having discussed the impact of overconsumption above, this section will now touch on different strategies established to reach sustainable material flows.

Strategies deal with overconsumption through:

- a systematic approach

- addressing and reducing the demand for material flows (focussing on the source)

- reducing and changing the material flow itself

- regenerating and increasing the supply.

Within these, multifunctionality is part of strategies that try to focus on changing and reducing the material flows by introducing design changes as will be discussed in the next chapter.

Before describing aspects of the strategies mentioned above, Figure 6 shows a simplified presentation of the current relationship between material needs, resource use, physical and overstretched ecological limits of the planet, and feedback paths.

Figure 7 then illustrates where the strategies apply to the given problems.

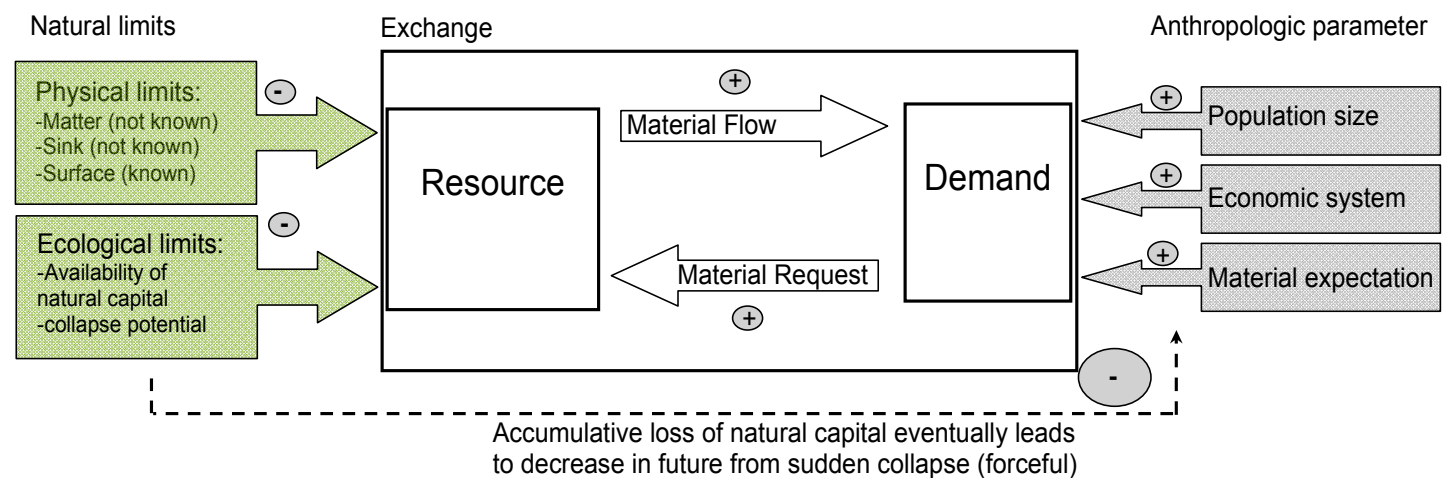




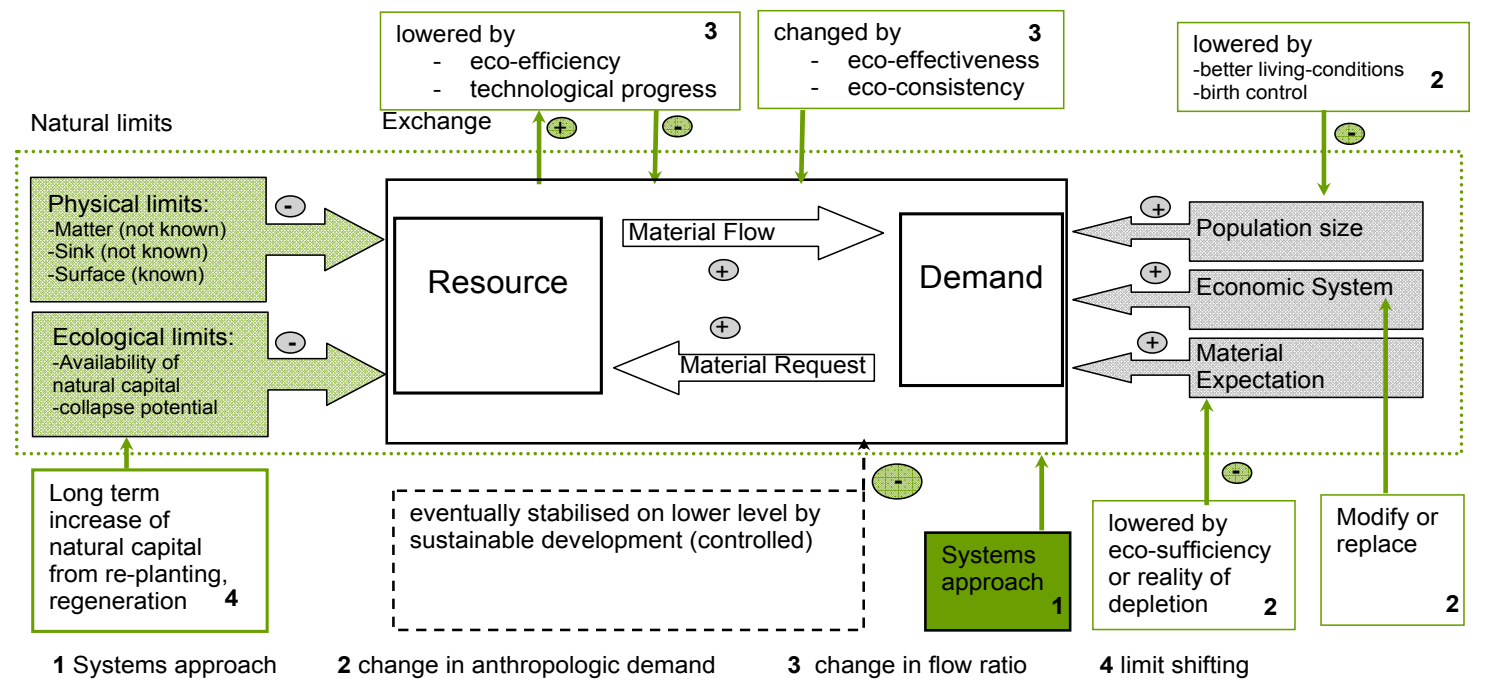

Figure 7: Possible actions to be taken to change relationship between material need and resource use

to create sustainable development

A systems approach (1) may focus on the overall relationship between resource use and demand, making the complex chains of effects more widely known or visible and implementing tools to measure these to allow people to trace their impact on the ecosystem.

Strategies that focus on demand (2) opt to facilitate change in anthropological parameters by focussing on

- stopping exponential population growth. This is certainly one of the most effective measures. However, there seem to be only two ways to stem population growth and both are hard to implement for political and social reasons. The first is breaking the cause-and-effect chain of inequity, poverty and overpopulation which would have a positive impact on almost all the limits and would help to increase overall human welfare (Meadows et al., 2004, p.124). The alternative is population control, with all its negative implications.

- modifying the globalised throughput economy or replacing it. The throughput economy is often seen as the driver and reason for unsustainable material flows, while all other factors such as materialistic ideology, availability of cheap fossil fuel, poverty and inefficiency are either fuelling it, are resulting consequences, or both. Different authors have researched options to modify or replace the capitalist economic system with a varying degree of realism and detail. Jackson argues convincingly that a steady state economy based on human prosperity rather than growing material wealth can provide a solution for the social, environmental and economic recession (Jackson, 2009, p.16). 
- changing values in affluent societies in line with change to the economy, from a narrow view of material wealth to eco-sufficiency (Winterfeld, v. U., 2007), (Scherhorn, G. in Schaffer et al., 2008) or the "the concept of satisfaction" (Vale, B., Vale, R., 2000, p.39), by defining human prosperity more broadly (Jackson, 2009, p.35). A change in values is certainly much needed as systematic change would require a broad commitment to a less materialistic lifestyle. But urban, industrialised societies, relatively sheltered from the first signs of declining natural capital and the consequences of unfair resource distribution, tend to largely underestimate the consequences of the situation and often react with indifference. (The architect Peter Eisenman summarised this mood quite precisely in an interview: "To talk to me about sustainability is like talking to me about giving birth. Am I against giving birth? No. But would I like to spend my time doing it? Not really. I'd rather go to a baseball game..." (Hawthorne, C., 2001 )).

A third set of strategies seeks to implement change in flow ratio (effective catalysts) which depends on technical and design changes. Material flows have to change both:

- quantitatively by reducing consumption e.g. through efficiency increase (life span, weight reduction, recyclability and multifunctionality of materials, services and products)

- qualitatively by eco-consistency (reduction of toxic substances) (Huber, J., 2000) and ecoeffectiveness (designing sustainable services and products instead of improving existing processes) (Mc Donough, W., Braungart, M, 2002) and recyclability.

The fourth and last group of strategies focuses on the regeneration or protection of natural resources from depletion through overconsumption or bad practice. Protection of fishing stocks and the rain forest, together with organic farming or the permaculture movement that try to establish an agriculture that does not degrade soils and deplete ground water levels needed by future generations, can be seen as such strategies.

As the proposed strategies intervene at different points in the system, they have different leverages (Meadows, D. H., 1999, p.2). There seems to be a hierarchy of leverage points going from the structural level (change in system approach) down to solutions focussing on optimisation of details (change of flow ratio).

The higher leverage points can effectively influence the whole system, triggering change, while a lower point, though important, hardly has any influence if the higher one is left unaddressed. Change in flow ratio for example can hardly reduce materials flows if anthropologic demand is increasing and the economy requires increasing material flows to maintain growth, as will be discussed in chapter 3 . It seems that the most effective change occurs at a higher level of the system (structural change of the system or change in anthropologic demand) as this will trigger a change in the system itself. Therefore mutlifunctionality does not represent the only or even most effective strategy to reduce the overall material flows. However, the different strategies proposed influence each other and will have to be addressed in conjunction to provoke the necessary changes towards sustainable development.

Sustainable architecture seems naturally inclined to search for design solutions to trigger social change as well as find technological solutions for material flow ratios. This thesis is therefore no exception as it will primarily deal with issues revolving around strategies that focus on flow ratios, quantitative aspects of material flows and technical and design solutions that try to increase resource productivity. However, for architects, it seems very important to realise that qualitative aspects and a 
broader understanding of the ecological and social problems the world is facing is just as central. In architecture, the composition of physical and measurable elements influences qualitative aspects, such as human well-being and prosperity and should represent the interface of economic, social and environmental aspects both in affluent and poor societies. 


\section{RESOURCE USE AND MULTIFUNCTIONALITY}

"To demonstrate this fantastic improvement in performance, we witness that one communications-relaying satellite of only one quarter of one ton of material is now outperforming the transoceanic communications message capacity and fidelity capacity of 175000 tons of copper cable. This constitutes a seven-hundredthousand-fold step-up in communications performance per pound of invested resources."

(Buckminster-Fuller, R., 1969)

\section{SUMMARY:}

Having shed light on the impact of overconsumption of resources and surface as well as on strategies to reduce the current consumption to a more sustainable level in the first chapter, this chapter narrows the focus of the discussion down to the reduction of material flows. Abdiction and resource squandering will be introduced as strategies that deal with resources in general, together with eco-effectiveness as a strategy that focuses on flow reduction. Eco-effectiveness will be discussed in detail with different subordinate aspects such as resource efficiency, multifunctionality and the concept of dematerialisation. The "decoupling" of economic growth and resource use as one of the conventional responses to the dilemma of growth will be assessed and its limits as a solution to overconsumption will be examined. Furthermore a material intensity analysis using the Material input per service unit (MIPS) concept, an analytic tool to quantify resource use, will be introduced as it will become an important tool in the case study at the end of the thesis. 


\subsection{STRATEGIES TO DEAL WITH RESOURCES}

This section focuses on three strategies that evolved to deal with resources. First the two antithetic strategies of resource squandering and resource abdiction will be discussed briefly, before reviewing eco-effectiveness as a strategy that tries to satisfy human needs while minimising the impact of these needs on the ecosphere. Figure 8 illustrates the relationship of the three strategies with subordinate aspects.

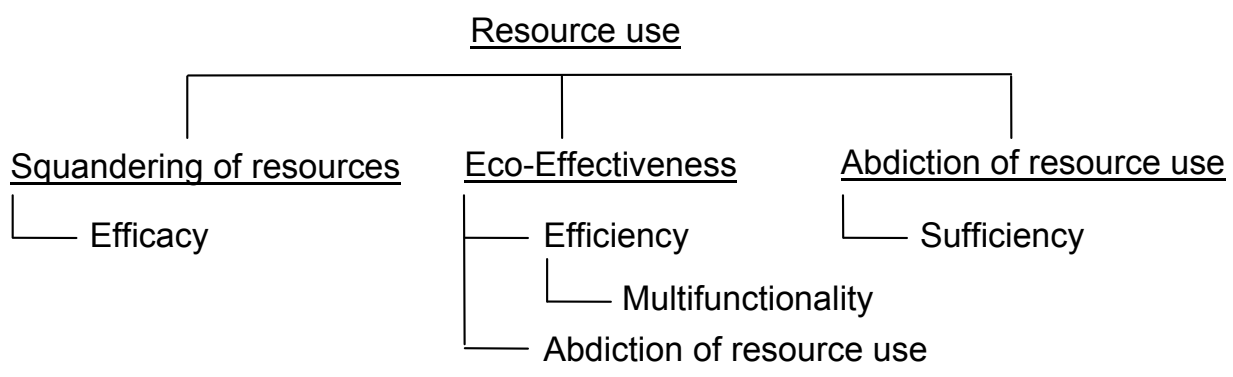

Figure 8: Three of the strategies that evolved to deal with resources

\subsubsection{SQUANDERING OF RESOURCES}

"Wasting" or squandering of resources is not a new phenomenon, but its scale and the reasons behind it have changed over time. The amount of material flows and the exponential increase of their ecological rucksacks due to fossil-based transport and harvest technology, has transformed squandering resources from a cultural and inequity question to one that is decisive for the future.

Traditionally many resources were scarce, as harvesting, mining and distribution were laborious and time consuming. Squandering of resources therefore used to be limited by availability of resources and was often a symbol of individual wealth and institutional power, such as that of kings, nobility, and important merchants. It was mainly used to reinforce the social and religious order in the society as can be seen in Figure 9. Where larger parts of society could afford to turn to resource squandering, such as the Romans in the final centuries of their empire, the energy to extract the resources necessary was gained by forced labour.
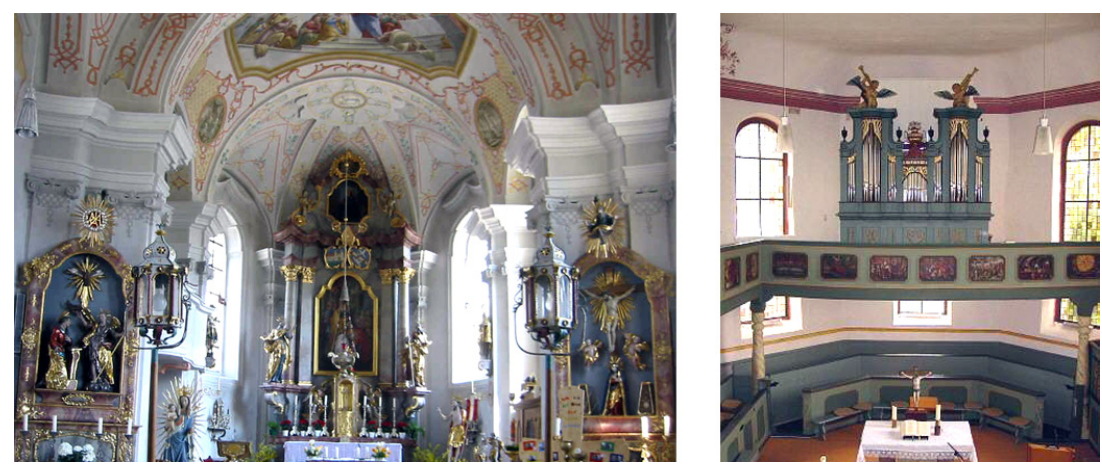

Figure 9: Interior of two churches

Catholic St.Remigius in Schleching, Bavaria, built in 1758 and protestant St.Michaelis in Oberkleen, Hesse, build in 1767. Protestants despised catholic materialism, which translated into architectural language. 
While slavery certainly made resource use financially more affordable and more achievable, fossil fuels made large scale resource extraction possible for the first time due to their high energy density (one barrel of refined oil equals the amount of energy required in 12 years by one physically hard working male adult (Bartlett, R., 2005, p. H2391)). Hence, the advent of the fossil-fuel driven economy made larger quantities of most resources available to more people. "The industrial revolution was in reality a revolution of the use of energy. It offloaded from human and animal power into the use of fossil energy" (Chu, S., 2009). The cause of modern squandering is therefore different from the traditional. Firstly, the over-consumption of resources can now be afforded by individuals and resources can be extracted all over the planet. Secondly, as resource use was suddenly more affordable, entire societies developed around consumerism, where material wealth is equated with emotional, physical and moral aspects of human prosperity and where increasing resource use is the basis to maintain the economic system (Jackson, T., 2009, p. 30). Squandering resources has therefore become the rule not the exception in affluent societies, which cause roughly $80 \%$ of global material flows as Figure 4 illustrates.

Figure 8 showed that efficacy is one subordinate strategy of resource squandering. It describes the causation of a given amount of output regardless of input or cost (Polimeni, J. et al., 2008, p.13). In modern societies it seems that the cost for a given amount of output does not sufficiently reflect the long-term cost of the input. This leads to the third aspect of modern over-consumption, which is largely caused by inefficient systems (e.g. distribution) that continue to operate on cheap energy, where squandering is a by-product that society can temporarily and, as discussed in chapter 1 , only financially afford (Jackson, T., 2009, p. 38). Table 1 gives one small example of inefficient practices or ecologically wasteful trade, showing import and export of different goods in the UK in 2005.

Table 1: Example of traded products in the UK after (Simms, A. et al., 2006, p. 3), (uktradeinfo, 2005)

\begin{tabular}{|l|l|l|}
\hline Product & Import (tonnes) & Export (tonnes) \\
\hline Gingerbread & 465 & 460 \\
\hline Fresh boneless chicken & 44000 & 51000 \\
\hline Chocolate covered waffles & 17200 & 17600 \\
\hline Milk and cream & 10200 (to France) & 9900 (from France) \\
\hline Potatoes & 1500 (to Germany) & 1500 (from Germany) \\
\hline
\end{tabular}

But not only energy use is not optimised, resource use is inefficient as well. Schmidt-Bleek states that $90 \%$ of global material flows are by-products of goods and services. Only $10 \%$ of all flows reach people in form of commodities and have the potential to satisfy demand and needs (2000b, p.1). 


\subsubsection{ABDICTION OF RESOURCE USE}

Abdiction of resources describes an antithetic mindset to squandering of resource use and can almost be seen as a countermovement. Just as the squandering of resources is not a recent phenomenon, the voices that criticise overconsumption can be found in many societies such as Seneca's criticism of the Roman decadence or Luther's questioning of the extreme wealth of the catholic church. This criticism was often based on equity issues, asking for a fair intra-generational distribution of resources and fighting against the associated exploitation of labour and the decline of communal values at the expense of individual wealth and pleasure. Today, concerns about inter-generational distribution are added, as people realise that resource use has risen to an extent where it is not only distributed unevenly in and between nations but threatens the prospect of the next and future generations to meet their needs, as discussed in section 1.2.

Abdication of resource use can be found as a form of moderation or as a reconsideration of values and needs in affluent societies (Layard, R., 2005, p.3), (Callenbach, E., 1973), (Schumacher, E.,1973). Given that resource use has reached a critical level, it is no longer seen as an extreme or anticapitalist position, but actually as an important paradigm shift society has to undergo.
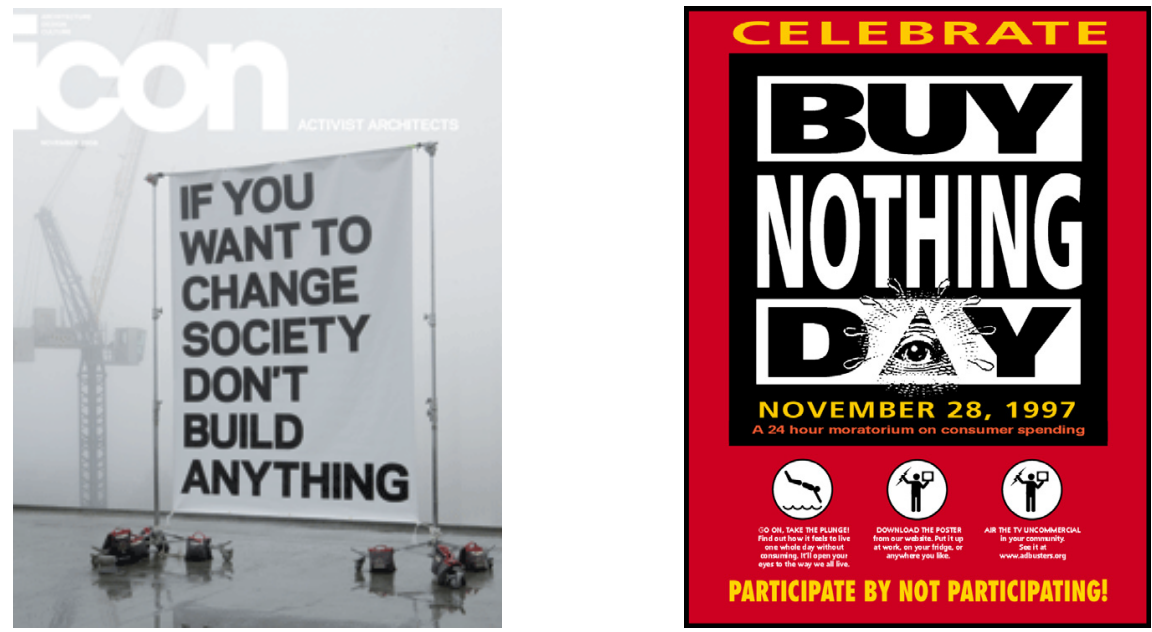

Figure 10: Cover of ICON magazine, November 2008 issue and a poster of the buy-nothing-day

Winterfeld and Scherhorn for example see abdiction of resource use and value changing in affluent societies from materialism to eco-sufficiency as a precondition for a more sustainable lifestyle (Winterfeld, v., U., 2007), (Scherhorn, G. in Schaffer et al., 2008). Moderation is certainly required as "It is not life which occasions our shortages-not even the "good" life; but the constantly better life as measured by increasing use of resources...which brings us to the limit of resources." (Thomas, W.,1956, p.1080. However, as discussed in chapter 1 , abdiction is at odds with an economic system that requires increasing resource use. Therefore it can often be observed that commitment to environmental practice in business falls short of limiting resource use substantially. In the architectural business for example sustainability is often perceived as a marketing tool or as an opportunity to optimise energy efficiency or user comfort. Although these steps are important and can reduce resource use, they might be only cosmetic changes in the face of the reduction of material flows required in the building industry overall (also refer to chapter 0). Furthermore it can be observed that architects' profits in many countries are based on overall construction costs. More material flows therefore mean more profit. 
However, architecture has always been the interface between meeting basic needs (of housing) and the art of representation (of cultural values and power with associated material flows). Sustainable architecture must therefore redefine but not destroy the fine balance between responsible resource use and its function as the material representation of cultural values.

\subsubsection{ECO-EFFECTIVENESS}

The relationship between an individual and material flows seems to be characterised by two major aspects. On the one hand, a person wants to gain as much satisfaction (or service) from a resource as possible, e.g. food, gold or electrical power, but on the other hand a person usually has to budget time, labour and the resource itself to get the service. If people benefit from a balance between the two aspects, they use as few resources as possible and as much as necessary. Different strategies have evolved to find the balance between resource use and service, multifunctionality being one of them.

Strategies seem to focus on:

- decreasing the amount of input (resource, labour, time, money) while maintaining a satisfactory outcome (e.g. gilding, Figure 10):

- increasing the service of a resource while keeping the input at least constant.

The strategies can be divided into

- strategies prioritising quality or output

- strategies prioritising quantity or input

Both types are of interest for environmental sustainability as they might help to reach an appropriate resource use.

These strategies are also employed by businesses, if they benefit from clever resource use or are penalised for excessive use. As this is currently often not the case, one promising avenue to reduce resource use and waste is to encourage the natural interest of balance in businesses by internalising social and environmental costs through policy changes.

In the light of the discussion in chapter 1, the question arises whether multifunctionality has the potential to reduce resource use significantly and on a big scale. To answer this, strategies that deal with quantitative and qualitative materials flows will be analysed in the following sections. 


\subsubsection{DEFINITION OF ECO-EFFECTIVENESS}

Eco-Effectiveness can be defined as a design strategy that focuses on adequate measures to accomplish a purpose or to achieve the overall goal (the effect) and reduce the global resource use to a sustainable level (eco). Eco-Effectiveness prioritises the absolute reduction of resource use e.g. of a product, rather than the reduction of resources going into every single element. It is a strategy of compromise or flexibility making innovation possible and encouraging system-wide considerations to achieve goals. It asks for careful assessment of goals and steps taken to reach the intended or expected result. Eco-Effectiveness can be adopted as an independent strategy, but in the context of resource use it can incorporate other strategies such as:

1. efficiency of resource use

2. abdication of resource use

Which of these strategies will be used depends greatly on the task:

Efficiency has a much narrower scope than effectiveness. It suggests doing the most with least, therefore prioritising quantity. Reduction of material input in processes is a much vaunted concept for sustainable resource use, partly because its results can be quantified and measured easily, which is important for policy making and businesses.

Abdication of resource use often requires reconsideration of overall goals. Often people base their decisions on narrow, set outcomes, instead of considering their need to use resources in the first place.

Schmidt-Bleek's example of a fridge will illustrate the difference between the strategies (SchmidtBleek, F., 1993, p.136). A fridge fulfils the function of cooling perishable products in the household. An efficient approach would opt to optimise the ratio of energy and materials used in common fridge types. An effective approach might go further, questioning the concept of the fridge altogether, possibly creating a better concept (such as using old fashioned earthenware cooling systems for butter and milk) or even resort to abdication. Tischner for example developed a new effective concept and designed a cooling chamber that realised a 4-8 fold decrease in resource use compared to common energetically optimised fridges (Tischner, U., 2003). Abdiction would be chosen if the whole concept of storing cool food at home is perceived as ineffective and shopping every day to avoid the need to cool food at home occurs.

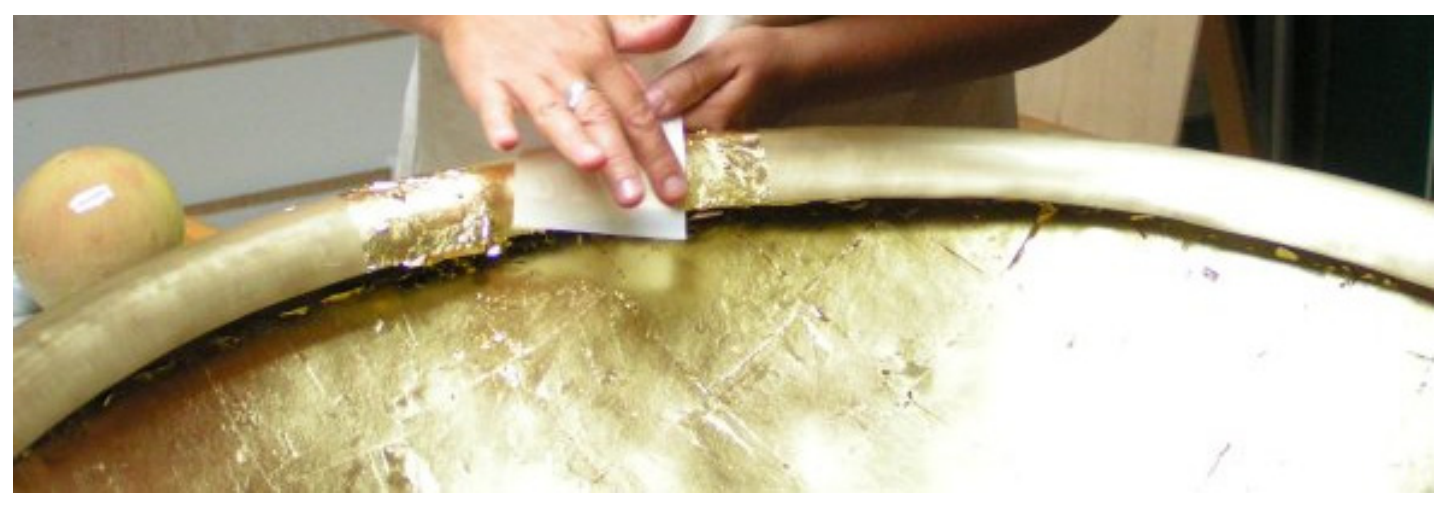

Figure 11: Gilding of a fountain element

Effective, efficient or simply clever: This is an example of a compromise between enjoying the aesthetic qualities of gold, while keeping the amount of gold to a minimum. 
It is often not possible to draw a distinct line between all these strategies. Together they are helpful as it remains clear that the global quantity of resource use has to decline and at the same time change qualitatively. Which strategy will be used is not only a question of numbers and facts, but will largely be influenced by perceived needs and the willingness of the user to innovate as well.

While this thesis proposes to treat efficiency as part of an eco-effective strategy, Reed considers efficiency and effectiveness as parts of a design progress as shown in Figure 12 (Reed, B.; 2006, p.12). Here, efficiency is a quantitative strategy, aimed at "making things better" leaving conventional practice goals behind and aiming for green goals.

\section{Regenerative Approach}

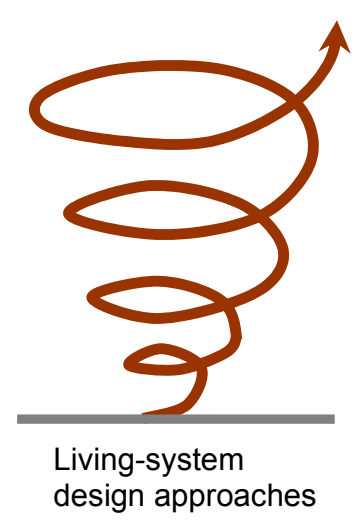

Systems approach

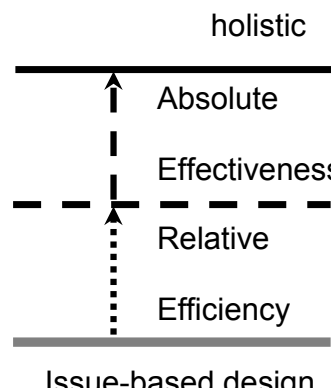

approaches
Regenerative Approach

Improvement through design

Sustainablitiy Targets

neutralise impact

Green Goals

limiting damage

Conventional Practice Goals

Figure 12: Trajectory of Environmental Design

Effectiveness then is described as "making better things" and "seeing things differently", in order to reach sustainability targets. The highest step of the learning hierarchy transcends sustainability targets and aims at a holistic design approach, that not only neutralises the impact of resource use, but improves the situation through "healthy relationships through co-evolution" (Reed, B., 2006, p.15.). Reed criticises effectiveness as a change that falls short of introducing a paradigm shift, although: "The shift from a fragmented worldview to a whole systems mental model is the significant leap our culture must make - framing and understanding living system interrelationships in an integrated way" (Reed, B., 2006, p.2).

By contrast, Mc Donough and Braungart define eco-effectiveness as this holistic, regenerative approach: "An eco-effective solution maximizes compatibility of products with biological systems and their performance simultaneously. It combines economy, equity and ecology in an integrated quality mix of products and services." (Braungart, M., EPEA, 2009) They think that eco-effectiveness can provide the necessary changes as it can lead to innovation: "taking an eco-effective approach to design might result in an innovation so extreme that it resembles nothing we know, or it might merely show us how to optimize a system already in place." (Mc Donough, W., Braungart, M., 2002, p.84).

Presuming that the overall goal of a designer is to reduce resource use, eco-effectiveness, being a flexible strategy gives freedom to trade-off inefficient elements for increased overall resource performance. A systems approach seems to be a precondition that makes effectiveness a valuable design strategy that can deal with both quality and quantity components of resource use. 


\subsubsection{ECO-EFFECTIVENESS AND ECO-EFFICIENCY}

The term eco-efficiency was proposed by the World Business Council for Sustainable Development (WBCSD, 2000a, p.1), in 1991. It combines efficiency as a quantitative strategy with qualitative strategies. As such it has much in common with eco-effectiveness, as it acknowledges that sustainability requires quantitative and qualitative change to material flows. This is particularly true for toxic substances that can be highly dangerous in small quantities. Eco-efficiency interconnects environmental aspects with economic development. It is a concept of industrial ecology, an interdisciplinary field that focuses on the sustainable combination of environment, economy and technology. The concept of eco-efficiency was defined as :"...creating more goods and services with ever less use of resources, waste and pollution" and further specified as "Eco-efficiency is achieved by the delivery of competitively-priced goods and services that satisfy human needs and bring quality of life, while progressively reducing ecological impacts and resource intensity throughout the life-cycle to a level at least in line with the earth's estimated carrying capacity." (WBCSD, 2000b, p.7)

Ultimately the goal of the WBCD remains as de-coupling growth from resource use and not eliminating economic growth itself.

Critical aspects of eco-efficiency include quantitative aspects such as:

- reduction in the material intensity of goods or services,

- reduction in the energy intensity of goods or services,

- increased service intensity of goods and services

and qualitative aspects such as

- reduced dispersion of toxic materials,

- improved recyclability,

- maximum use of renewable resources and

- greater durability of products

As a term eco-efficiency seems to be misleading, as it incorporates quality aspects that can neither be deduced from the term "eco" nor from the term "efficiency" and remains focussed on increasing efficiency. The term eco-effectiveness by contrast does incorporate efficiency, as it is a much more flexible strategy. However, eco-efficiency is widely used by institutions such as the OECD, as it is closer to the common business thinking of economic efficiency.

\subsubsection{EFFICIENCY-QUANTITATIVE IMPROVEMENTS IN RESOURCE USE}

Efficiency, which is very prominent is, as discussed above, a subordinate strategy of ecoeffectiveness. Increasing efficiency through changes in production and technological innovations seems the main item on the political agenda in order to limit the rate of materials flows for individual products. Its huge potential is in creating a window of opportunity where structural changes can be 
made without threatening human welfare. However, if it is misinterpreted as a problem solver, it will curtail the expectations of those who ignore the underlying principles:

\subsection{THE HUGE POTENTIAL OF RESOURCE EFFICIENCY TO REDUCE MATERIALS FLOWS}

Resource efficiency describes the creation of goods and services with ever less use of resources. It has huge potential and is attractive to policy makers and businesses alike as it can break the vicious cycle that usually accompanies decreasing material flows: recession, unemployment and loss of human welfare. So far absolute decoupling has not been achieved. However, if it could be achieved, it could prove to be a win-win strategy for the environment and the economy as it decouples resource use from economic growth, which translates into cost savings and reduction in environmental stress. In any case increasing efficiency has its limits and careful policy-making is required in order to create positive net effects for the environment, as the next two sections will discuss:

\section{- THE POINT OF MAXIMUM EFFICIENCY}

Dematerialisation (the decrease of resource use $\sim$ the increase of resource efficiency) is a powerful transitional tool for reducing resource use as illustrated in Figure 13.

As long as efficiency gains can be obtained, economic growth will be stable and de-linked from resource use, which will decline (stage 1). If technological and design solutions have been employed to reduce material flows to a point where further optimisation does not improve the efficiency of a service significantly or solutions are no longer economically viable, dematerialisation will no longer have great leverage. This point can be defined as "maximal efficiency", the situation where no more material output can be obtained without increasing the level of material inputs (stage 2). Once this point is reached, economic growth will by definition result in increasing resource use (stage 3 ).

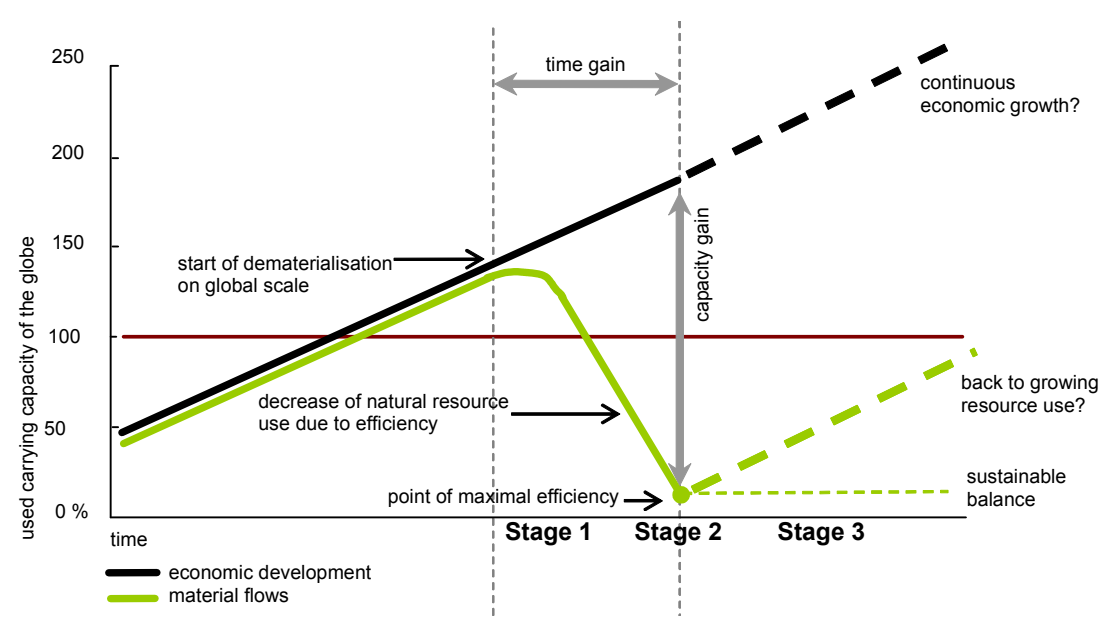

Figure 13: Increase in efficiency can decouple growth from resource use.

Once maximal economic viable efficiency is reached, economic growth will result in increase in resource use.

Due to increasing demand, humanity is currently far from maximum efficiency. On the contrary absolute throughput is in actual fact on the rise, although material intensities have declined significantly during the last three decades, across the OECD countries in particular (Jackson, T., 2009, p.48). 
Therefore the OECD considers it necessary to push for measurements to increase resource productivity even faster (WBCSD, 2000, p.10). An increase in resource productivity by a factor 4-10 seems necessary and achievable (Weizsäcker, v., E., 1997), (Schmidt-Bleek, F., 2000a, p.3). If it will be enough to translate into an absolute reduction in throughput is a question that divides economists as it seems that slow implementation of dematerialisation objectives (relative decoupling) is only partly causing the lack in absolute decoupling. Jackson, one of the sceptics of absolute decoupling, states that: "The message here is not that decoupling (of resource throughput and production) is unnecessary. On the contrary, absolute reductions in throughput are essential. The question is, how much is achievable? How much decoupling is technologically and economically viable? With the right political will, could relative decoupling really proceed fast enough to achieve real reductions in emissions and throughput, and allow for continued economic growth? These critical questions remain unanswered by those who propose decoupling as the solution to the dilemma of growth." (2009, p. 52) He therefore underlines efficiency gains as a temporary achievement but cautions that "it is entirely fanciful to suppose that "deep" emission and resource cuts can be achieved without confronting the structure of market economies." (2009, p.57) However, even if a less pessimistic outlook is adopted and absolute decoupling be achievable, it will not prove to be a long-term solution in a throughput economy, as the linkage of resource use and growth will be re-established. Reducing resource use will once again lead to decline in human welfare, as has proved inherent in the current economic system. Nevertheless, increasing efficiency opens a window of opportunity, as it can help to gain time and capacity that should be used to address the alternative economic strategies described in 1.3. Future generations will find efficiency central and helpful to achieving an acceptable welfare level with limited resources once a sustainable economic equilibrium is established as proposed by Jackson (2009) and others (Daly, 1991).

\section{- $\quad$ THE JEVONS PARADOX OR REBOUND EFFECT}

Apart from slow implementation of dematerialisation targets, the rebound effect or Jevons paradox has influence on absolute resource use. It describes the effect increasing efficiency has on an unregulated market. Jevons stated that: "It is a confusion of ideas to suppose that the economical use of fuel is equivalent to a diminished consumption. The very contrary is the truth....As a rule, new modes of economy will lead to an increase of consumption..." (Jevons, W., 1866, p.123). This means that increasing resource efficiency saves costs that, if translated into price reductions of products, will either lead to an increase in product sales, resulting in an overall increase of resource use, or will allow people to use the saved money to spend on other products or services that might be even more resource intensive (Polimeni, J., et al., 2008, p. IX). The Jevons paradox can be observed particularly well in communications technology. As telephones became smaller and more resource-efficient, they became more affordable as well, resulting in ever increasing numbers of phones. At the beginning of the twentieth century there were 2 million phone lines worldwide, the numbers increased to 20 million in 1922, 50 million in 1950, 75 million in 1950 and 263 million in 2005, plus an additional 2.16 billion mobile phones (Huurdeman, A., 2003), (ClA, 2008). A similar development has occurred with computers since 1950, as shown from the comparisons in Figure 14. The total material flows triggered by computers increased as well. If the rebound effect of efficiency is so strong that the increase in per- 
unit efficiency is out weighed by the number of consumed units, a backfiring effect is created (Polimeni, J. et al., 2008, p.8).
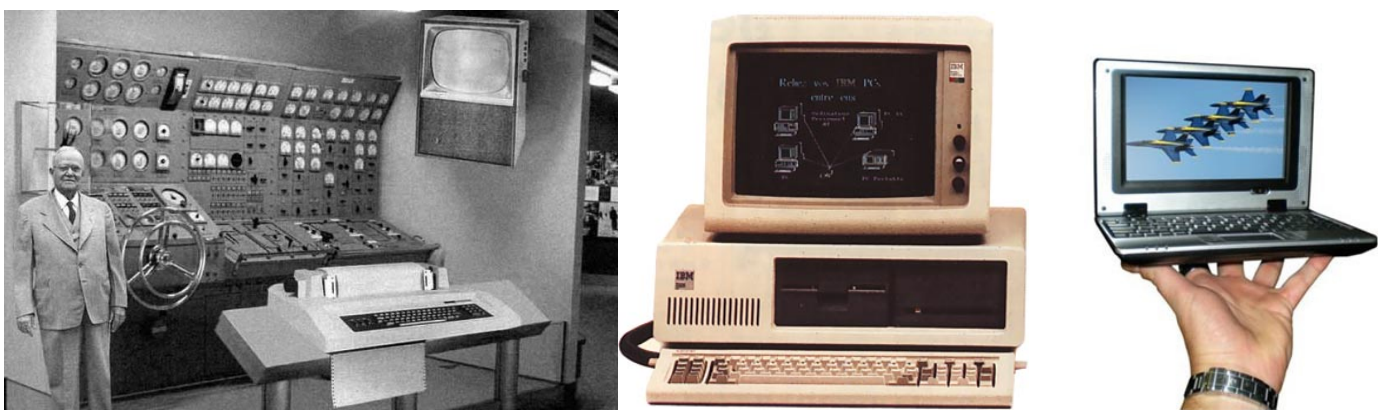

Figure 14: Computers, large and very expensive, have become small, faster and affordable 2 billion are expected to have a personal computer in 2014.

According to Tainter, the key to avoiding the Jevons Paradox is to adopt the principle that neither efficiency improvements, nor any other approach to reducing resource use (including voluntary conservation), can be allowed to reduce the cost of consumption (Polimeni, J. et al., 2008, p. XV). Hence, policy changes have to go hand in hand with increasing efficiency in order to benefit from its potential to reduce material flows.

Having discussed the difference between relative and absolute decoupling of resource use and economic growth, the following section will turn its focus on strategies that increase resource efficiency.

\subsection{STRATEGIES TO INCREASE RESOURCE EFFICIENCY}

Resource efficiency describes a ratio between material input and functional output.

The link between resource productivity and material input can be described as:

$$
\text { Resource Efficiency } \sim \frac{\text { Function }}{\text { Material Input }}
$$

Resource efficiency is high if the material input per function is low. The reciprocal is called material intensity. The aim of increasing resource efficiency is therefore to lower the material intensity of products.

Strategies to increase resource efficiency in product design and architecture include:

- decrease in weight (light-weight products): lower material input by using fewer new materials

- design for re-use / re-cycle, lower material input by using already sourced materials (Hinte, v., E., 2007)

- increase of service-life: lower ratio of material flows by prolonged service-life of products

- increase product functions (multifunctionality), increase service while decreasing overall material input

All of these are very important issues in sustainable architecture, and all have their limits and potentials. 


\subsection{MEASURING EFFICIENCY-THE MATERIAL INTENSITY INDICATOR MIPS}

In order to make increasing efficiency a powerful strategy, it is important to have methods that quantify overall materials flows. In chapter 0 , the resource use of a multifunctional and conventional building envelope will be compared in detail. This section forms an introduction to the indicator used and the relevant terminology.

Two of the most important material flow-based indicators on the product level for the European Union are Material Input per unit of Service (MIPS) and Surface Input per unit of Service (SIPS) used in the Material Intensity Analysis (MAIA) (Bargigli, S. et al., 2005, p. 353). They were proposed by the Wuppertal Institute for Climate, Environment and Energy in the 1990s as indicators able to provide a solid estimation of the ecological stress potential of goods and services (Ritthoff, M. et al., 2002, p. 9).

The assumption behind MIPS/ SIPS is that the environmental stress potentials of a product are linked and can be deduced from the life-cycle wide material input. The greater the resource use, the greater the change in a certain ecosystem or natural flow, the higher the potential environmental damage and degradation. MIPS and SIPS measure scarcity of resource components indirectly by presuming that a scare material will require a larger indirect material flow than an abundant one. Toxicity is not registered by MIPS and SIPS. It has either to be avoided during planning/design or be measured using another indicator calculating the impact of a given product/ building element. MIPS is currently used by many European governments, Japan and New Zealand (Ministry for the Environment, NZ, 2002). MIPS is described in more detail in chapter 1.10.1., p. 77.

MIPS and SIPS describe the link between eco-efficiency and material input/ surface input as follows.

Resource Productivity=Material Input/ Service Unit $R P=\frac{S_{u}}{M a t_{i n}}$

Resource Productivity=Surface Input/ Service Unit $R P=\frac{S_{u}}{\text { Area }_{\text {in }}}$

Material Input refers to the lifecycle wide input of resources that will have to be moved, consumed and refined during production, use and recycling or disposal of a product (Schmidt-Bleek, F., 1993). In order to derive a meaningful estimate, material inputs are differentiated into abiotic raw materials such as fossil fuel energy carriers or mineral raw materials such as sand, biotic raw materials such as biomass, earth movement such as erosion or mechanical earth movement, water use, meaning use of ground or surface water, and air.

Surface Input is the surface used to mine, grow and harvest the resources required. It is equivalent to the product footprint used by WWF and The Global Footprint Network (WWF, 2008).

Service Unit is a service provided by products that will have to be defined by the user, for example transportation of two people from point A to point B. MIPS is useful for comparing the material associated with the provision of a service unit by different means.

When comparing material alternatives, often only the Material Input (MI) will be calculated. Unlike lifecycle assessments where data for many products is already published, material inputs often have to be calculated from scratch. However, calculations have been carried out for many standardised proc- 
esses and have been published as MI factors in literature (Wuppertal Institute for Climate, Environment and Energy, 2003), (Bergmann, I., Weiss, W., 2002), (Schmidt-Bleek, F., Manstein, C., 1999). $\mathrm{MI}$ in relation to weight is defined as Material Intensity (MIT =Material input in relation to weight unit, with units $\mathrm{kg} / \mathrm{kg}$ ). Material Intensity of energy carriers or transport will be indicated by the respective units $\mathrm{kg} / \mathrm{MWh}$ or $\mathrm{kg} / \mathrm{tkm}$. If the MIT is related to the service provided it will indicate the global environmental impact of that service. The MIPS indicator can therefore provide quantitative information on indirect resource use or the resource efficiency of a product.

Furthermore, it is important to define system boundaries and cut-off criteria. As the MAIA is focussed on resource flows caused by human action (or their technology), the system boundary between nature (ecosphere) and the technical-economic activities of humankind (technosphere) has to be defined. The technosphere (human activities) is imbedded in the ecosphere (nature's system), which means that all sourced resources will be released into the ecosphere at some point deferred in time and space and often in altered form. The authors of the MIPS concept defined the following conventions for the system boundaries between technosphere and ecosphere (Schmidt-Bleek, F. et al., 1998, p.38):

System boundary (Input): The boundary between ecosphere and technosphere is given by the active sourcing or moving of materials by machinery or tools. This boundary is therefore primarily a functional boundary and only secondarily a geographical or special limit.

System boundary (Output): The system boundary of the output is defined by:

- translocation of natural resources to land fills

- emissions during production or use, as well as disposal of the product itself

- dissipative losses

Recyclables do not leave the technosphere and are therefore not counted again as inputs, although their Material Intensity does consist of the necessary resource flows triggered by their recovery (e.g. collecting, cleaning, melting, and redistribution).

\subsection{DEFINITION OF MULTIFUNCTIONALITY}

The term multifunctionality was first coined for free trade negotiations. Here, it summarizes the idea that agriculture has many functions in addition to producing food and fibre, e.g. environmental protection, landscape preservation, rural employment and food security and therefore also fulfils nontradable functions (WTO, 2009). It was used as an argument by industrialised countries to justify the introduction of financial subsidies which protect their agriculture sector against a the free market that threatened to undercut its viability.

In the context of resource use multifunctionality describes materials or products that have been designed to fulfil more than one function. Many products can fulfil different functions. However, multifunctional products are designed and optimised to fulfil all their functions to a high extent. The appropriateness of a product to fulfil a function will later be referred to as $a_{i}$, the coefficient of appropriateness. A sheet of paper for example can be used to write on and can cut skin. However, it would not be 
called multifunctional for this, as paper would not be an appropriate replacement for a knife. This was also described by Buckminster-Fuller in his book Operating Manual for Spaceship Earth: "If you are in a shipwreck and all the boats are gone, a piano top buoyant enough to keep you afloat that comes along makes a fortuitous life preserver. But this is not to say that the best way to design a life preserver is in the form of a piano top." (Buckminster-Fuller, 1969, p.1). Multifunctionality is therefore best described as a design strategy used to increase the number of functional units of products and materials. It focuses on functionality and performance, not on the material input. However, it can be used to meet a series of requirements, while decreasing the amount of space, components and resources needed.

\subsection{EFFICIENT MULTIFUNCTIONAL PRODUCTS}

Multifunctionality can contribute to efficient resource use, but to do so, it has to create synergetic effects. This means that a multifunctional product must be designed in such a way, that the overall material input of the multifunctional product is smaller than the sum of its different functional parts if designed as monofunctional products. The Leatherman Multi-tool (Figure 15) is a good example of a multifunctional tool creating synergies. It consists of 19 tools that are fixed to one single handle. Each tool consists of at least one function or Service unit (SU) and adds a certain material input (Mi) to the whole.

Leatherman tool $=\frac{S_{U 1}}{M_{i 1}}+\frac{S_{U 2}}{M_{i 2}}+\ldots \frac{S_{U 19}}{M_{i 19}}$

The pliers for example fulfil the function (SU) of nipping or pinching and contribute a material input to the gripping jaws, the pivot and the handles. The handles of the pliers are now used as handles for all the other tools, such as the knife, the screwdriver or the tin opener. Here synergy is created, enabling reduced material input as one handle is used for 19 tools. The material input is ergo reduced by 18 handles if the tool is compared with 19 separate tools. Another form of synergetic effect can be observed at the awl, where another tool, the thread loop, is created by cutting a hole into the awl, changing the ratio between resource use and service output even further.

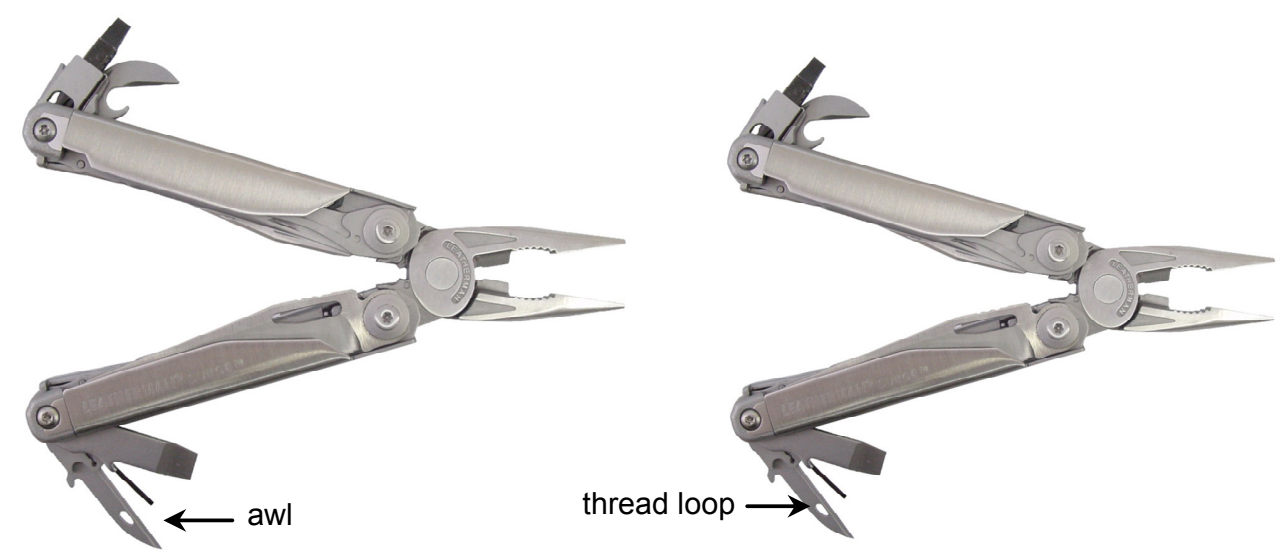

Figure 15: Leatherman Multi-tool

It incorporates 19 tools weighing only 129g. measuring direct + indirect flows and qualitative aspects. 
The MIPS indicator can also be used to measure resource efficiency of multifunctional products. The service units will simply increase faster than the material input resulting in a higher resource productivity, shown by the following:

$$
\mathrm{RP}_{\text {multifunctinal }}=\frac{\sum_{\mathrm{i}} \mathrm{S}_{U} \cdot \mathrm{a}_{\mathrm{i}}}{\sum_{\mathrm{i}} M \mathrm{at}_{\mathrm{i}}}
$$

$\mathrm{a}_{i}=$ coefficient of appropriateness

It will be influenced by $a_{i}$, which is the coefficient of appropriateness. If it is low, the service output will decrease. To use the example given in 1.4.3.3.4 again, a sheet of paper would get a service output equivalent to 1 for the service: to write on, but would get a service output below 1 for: to cut skin resulting in a worse ratio than the Leatherman tool would have, as all its tools are optimised for their functions. 


\section{ARCHITECTURE AND RESOURCE USE}

"In efforts by the global community to achieve real sustainability, probably no industrial sector has as great a potential as building and construction."

Steve Halls $(2003$, p.3)

SUMMARY:

Having discussed measures to reduce material flows in general in chapter two, this chapter explores the role of the building sector in global resource use and discusses more specific measures to decrease its impact on overall material flows. It provides a transition to the analysis of multifunctional envelopes that follows in chapter four. The following analysis will briefly touch on the subject, attempt to position multifunctionality within the strategies used to reduce material flows in architecture and will also seek to clarify the role of the envelope in this context. 


\subsection{THE GLOBAL IMPACT OF BUILDINGS AND CONSTRUCTION}

Looking at vast and increasing global material flows, the question arises, what role the building and construction industry plays and if improvements in resource effectiveness in this field have any leverage at a global scale.

Data give evidence that the building industry is in actual fact the single largest force driving resource depletion and waste production and is a major contributor to climate change. $50 \%$ of the global resource use is generated by the direct and indirect material flows of the building and construction sector. According to UNEP it also accounts for roughly $50 \%$ of all waste generated in industrialised countries, as well as for $40 \%$ of global greenhouse gas emissions and $40 \%$ of global energy use (Halls, S., 2003, p.3). A reduction in material flows in this sector would therefore have the potential to influence the global situation significantly. Figure 16 shows that housing and infrastructure account for $31 \%$ of resource consumption in Europe.

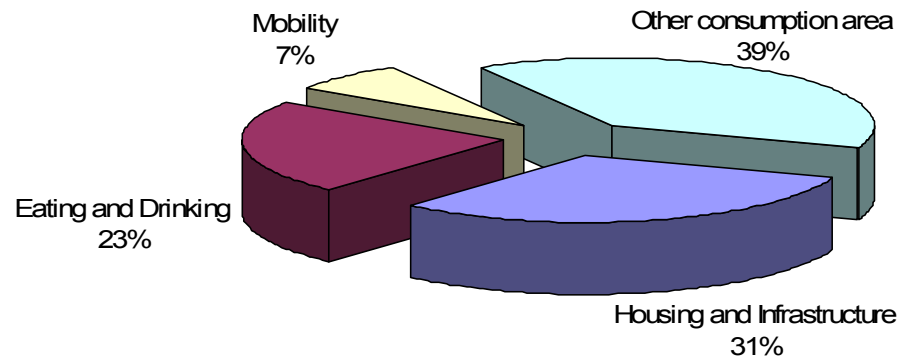

Figure 16: Distribution of European resource consumption.

Apart from contributing to unsustainable material flows, human building activities (both by houses and infrastructure) are increasingly expanding. Roughly $22 \%$ of the global land area was covered by buildings and infrastructure in 2002 and this is forecasted to increase globally to $30-40 \%$ in 2032 (Halls, S., 2003).
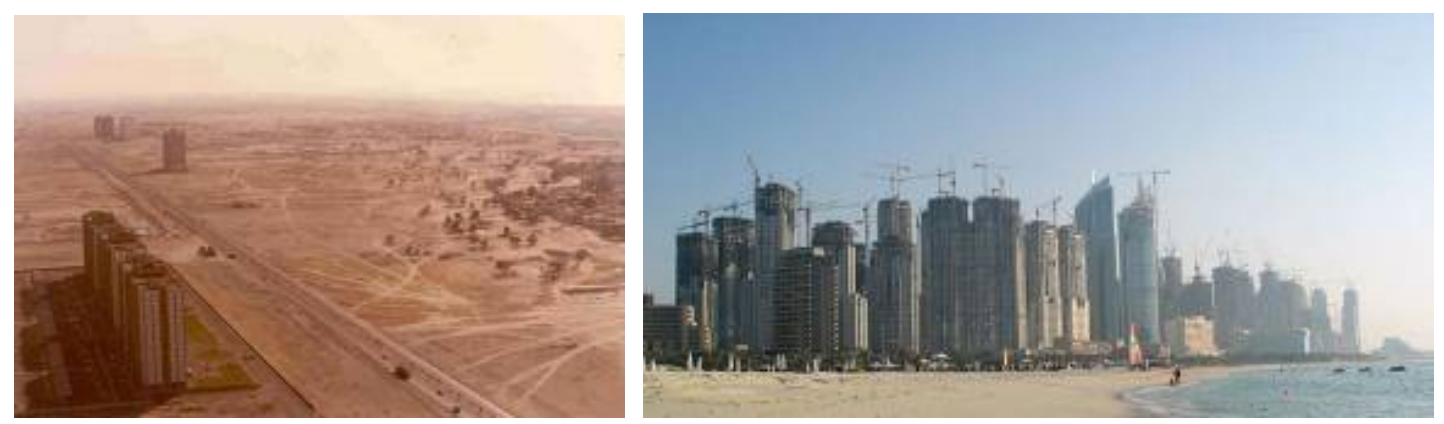

Figure 17: Dubai City in 1990 and 2004

One of the most famous and fastest urban developments, every aspect of life in this modern desert city relies on fossil fuel.

\subsubsection{EXTERNAL AND INTERNAL FACTORS}

The UNEP prognosis is influenced by a variety of external factors that are not directly linked to construction and buildings, such as global population size which is predicted to increase, increasing surface requirements to feed and house the projected population, increasing infrastructure and transportation to distribute food, as well as the global trend towards urbanisation and industrialisation that also 
triggers direct and indirect material flows. In industrialised countries changes in social structures contribute to the increasing number of small private households that in turn increase the demand for infrastructure and appliances. In Germany alone for example the number of single households increased by $5.1 \%$ (ca. 3.5 million additional single households) between 1991 and 2007 (German Federal Statistical Office, 2008). This is a development worth noting, as a single person requires up to $50 \%$ more natural resources than two people sharing a household (Schmidt-Bleek, F. et al.,1999, p. $14)$.

In addition there are factors within the building industry that contribute directly to material flows such as unsustainable urban planning goals, insufficient codes and regulations, as well as a lack of awareness or concern for the material intensities of chosen materials and alternatives. The biggest driver however remains the interconnection between financial markets and buildings. Real estate is one of the few real (in the sense of not virtual) financial assets and hence internationally traded as a security and investment by funds and banks. Building activity (or ownership) is therefore no longer dictated by needs only but reinforced by the financial market. Even in countries with declining populations such as Germany, which declines by $-0.4 \%$ per annum (already mitigated by $+0.3 \%$ of immigration), the annual rate of land claim for infrastructure and construction is not static and exceeds $400 \mathrm{~km}^{2}$ per annum (0.11\% of the overall surface area) (German Federal Statistical Office, 2007, p.8), (Hoffmann-Mueller, R., Lauber, U., 2008, p.334).

\subsection{MEASURES TO REDUCE RESOURCE USE IN ARCHITECTURE}

As in other sectors the reason for enormous resource uses in the building industry are manifold and so are the measures to reduce material flows. However, there are a number of general strategies (useful in most climates) that have proven to contribute to reducing resource use if correctly applied. Careful urban planning, appropriate insulation levels, material choice, form, positioning on the site, the level of recyclability, flexibility and durability of its components, as well as its fit out with appliances have a direct impact on the overall operating and embodied material flows a building generates during its service life. Table 2 shows measures that can decrease the resource use of buildings and infrastructure. Awareness of these parameters can reduce the resource use of buildings significantly.

Table 2: Measures to reduce resource use in urban design and architecture and type of resulting reduction based on (Halliday, S., 2008, chapter 5).

\begin{tabular}{|c|c|}
\hline Regional level: & \\
\hline Measure & Resulting significant reduction* in use of \\
\hline avoid urban sprawl, increase density ${ }^{* *}$ & $\begin{array}{l}\text { surface, soil, indirect: biotic, and abiotic materials and air } \\
\text { (energy, infrastructure, transport, emissions) }\end{array}$ \\
\hline introduce green corridors for wildlife and plants & $\begin{array}{l}\text { natural capital, increase resiliency, cooling equipment } \\
\text { due to heat island effect }\end{array}$ \\
\hline improve waste water management and urban ecology & water, soil and air \\
\hline Consider prevailing winds that ventilate the city & abiotic materials, air \\
\hline
\end{tabular}




\section{Building on site:}

passive design: Orientation of the building and openings to optimise solar gains in winter, shade in summer and shading from wind, minimise heat-loss

all resources as expenditure on building services (e.g. cooling and heating) can be reduced, abiotic and biotic materials for operational throughput

(native) landscaping to shelter from wind

soil, water, abiotic and biotic resources for operational throughput

\begin{tabular}{|l|l|}
\hline storm water retention & water and soil \\
\hline limit sealing of land & water and soil \\
\hline
\end{tabular}

\section{Building form:}

surface to volume ratio in order to minimise envelope

all resources as material flow decreases, abiotic and biotic resources for operational throughput

limit building depth: allow for cross-ventilation, natural light

abiotic resources, minimise need for mechanical ventilation and artificial light

\begin{tabular}{|l|l|}
\hline simplicity & all resources as material flow is voluntarily limited \\
\hline avoid over sizing & all resources as material flow is voluntarily limited
\end{tabular}

\section{Building layout:}

design for flexibility

all resources by extending useful life of elements and avoiding new material inputs

energy conservation, capture and storage ( e.g. energy-efficiency by insulation, thermal mass, minimising heating, cooling requirements, solar hot-water, solar electricity )

abiotic resources, however embodied energy or toxicity of some components can put benefits into question (e.g. batteries $)^{\star \star \star}$

lighting and appliance efficiency,

abiotic resources, water

attention to power source (renewable)

design for recycling and compartmentalisation

all resources by avoiding down-grading and high energy input in order to recycle

\section{(multifunctionality)}




\begin{tabular}{|l|l|}
\hline \multicolumn{2}{l}{ Materials: } \\
\hline local & $\begin{array}{l}\text { mainly abiotic materials (transport, energy) and air (emis- } \\
\text { sions) }\end{array}$ \\
\hline $\begin{array}{l}\text { design for operation and maintenance: use materials, components } \\
\text { and connections that can be dissembled and repaired e.g. screws } \\
\text { instead of glue }\end{array}$ & potentially all resources \\
\hline adequate durability & all resources \\
\hline waste management & all resources, specially soil and water \\
\hline recyclability and degradability of materials & all resources \\
\hline materials efficiency & all resources \\
\hline avoid toxic materials & air, water, soil \\
\hline
\end{tabular}

${ }^{*}$ most measures will impact indirectly on all categories of resources as a MIPS-analysis would reveal. However, this table only indicates the main impact.

** the degree of density has to be carefully established as a higher density can lead to the need to create buffer areas that surpass the area gained by increasing the building density (Lehmann, H., Stanetzky, C., 1999, p.17)

${ }^{* * *}$ Vale, B. and Vale, R. discuss the disadvantage of storing electricity in more detail (2000, p.122-128).

It seems to be important to adopt a systemic approach that integrates the different levels of building activities in order to achieve an overall sustainable and resource effective outcome (Hindrichs, D., 2006), (Hegger, M., 2007), (Schmidt-Bleek, F., 1999). A systemic strategy that allows for the coordination of all the different aspects and hierarchies is therefore required. As cities are made of buildings, which are assembled from components in turn made from diverse elements it is only natural that the different hierarchy levels are interdependent. Storm water retention might for example not be an issue on the building scale, if the community has a natural retention area where water from roofs and sealed-off land is collected and this might be a wetland area with its own eco-system. If not, water might be collected on site and be used for irrigation or if not possible a green roof might be an option to retain at least part of the rainfall.

Bearing in mind that planning for "resource minimised buildings always requires a systemic approach" and that "the planning has to be coherent in the overall design as well as within the elements"(Lehmann, H., Stanetzky, C., 1999. p.20), the focus of this research will now turn to multifunctionality, as one strategy that can reduce the resource use in buildings. The envelope lends itself to be studied in this context, as it is an element that is multifunctional by default as it has to fulfil many functions simultaneously. Therefore strategies to achieve multifunctionality can be discussed when analysing the envelope and its components. Furthermore the envelope represents a vital element of sustainable architecture as it is the interface between the external environment and the interior / conditioned space. 


\section{THE ENVELOPE AS A MULTIFUNCTIONAL ENTITY}

"Every facade fulfils a wide range of functions. These functions are defined by the location of the building and the conditions required by the users inside it. Among the functions are the provision of natural light, views out and in, solar screening, ventilation and energy generation. The conceptual design of the skin must consider the basic arrangements of the various functions within the skin-adjacent, behind each other, or combined. Depending on the requirements, positive synergetic effects may arise from the chosen arrangement." (Hausladen, G., 2006,

p.86)

SUMMARY:

Building envelopes are probably the oldest architectural elements created by humans. They are multifunctional entities that have to react to a wide range of physical, technological, social and cultural requirements. Given the fact that envelopes have a limited depth that can vary from a few millimetres (tent) to a few decimetres (stone wall), it is quite surprising how successful they are in doing so. The following chapter sets out to analyse which requirements and functions the envelope has to fulfil and how the envelope as an entity as well as its individual components are organised to meet these requirements successfully. Different multifunctional strategies will be explored in this context and their potential to reduce resource use of the envelope will be discussed. The chapter builds the theoretical basis for the material intensity analysis carried out in chapter 5 , which analyses the potential and limitations of multifunctionality to decrease resource use with the help of a concrete case study comparing two envelopes. 


\subsection{THE ELEMENTS OF THE ENVELOPE}

Most envelopes consist of four main elements: Floors, roofs, walls, and openings. Each of these four functional elements can be divided in further sub-elements. Being part of a greater entity, their functions as well as their individual structure influence each other in many ways and the performance of the envelope as a whole.

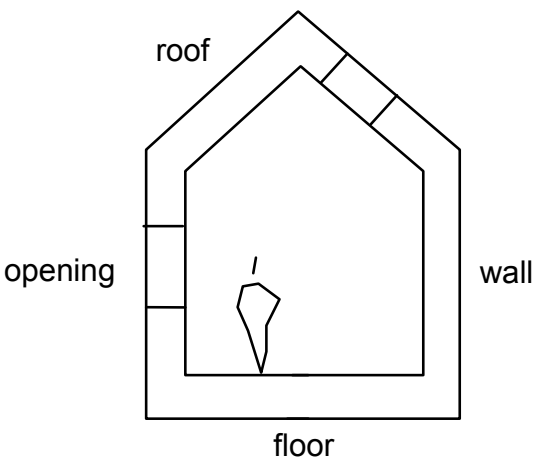

Figure 18: The main functional elements of the envelope

Roof, walls, floor and openings.

Their interdependence leads to a complex but highly effective building enclosure that can at the same time protect from external influences, filter those not wanted out and let those required through. The individual elements of the envelope are by nature multifunctional as each of them has to control air, water, vapour and thermal movements between the indoor (or conditioned) space and the exterior (or unconditioned space). Also in conjunction they often create synergetic effects as one element shelters the other (roof overhangs protect the wall from rain, which in turn allows for openings for ventilation).

\subsection{REQUIREMENTS, FUNCTIONS AND UNDERLYING PHYSICAL PRINCIPLES}

\subsubsection{REQUIREMENTS}

The envelope forms the physical separation between the environment and the interior spaces occupied by people. In the beginnings of human history, its main purpose was the creation of an effective protective barrier against enemies and wild animals as well as to shelter people and possessions from inclement weather.

Subsequently these protective functions were joined by diverse others that refined the basic envelope: provision of ventilation, light in the interior spaces and a visual relationship between inside and outside. Hence, the

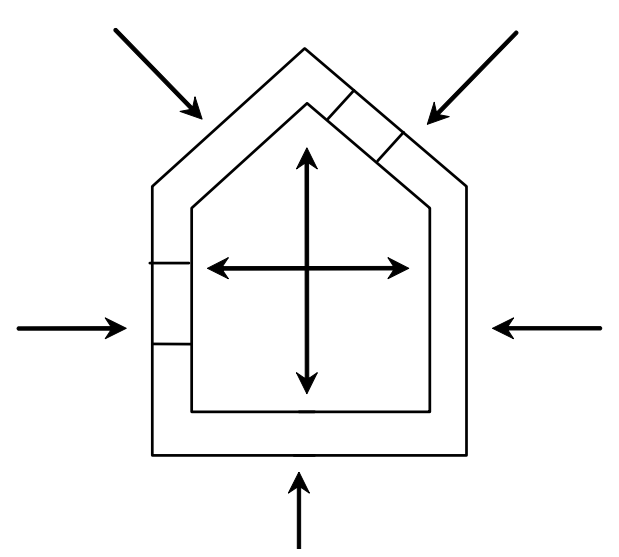
envelope evolved from a basic barrier with protective functions to a flexible filtering layer with additional control and regulatory functions (Herzog, T. et al., 2004, p. 19). Additionally the envelope took 
on representative functions and supported the generation of cultural conventions such as the differentiation between public and private realms.

Today, requirements (or services) of the envelope can be divided in three groups:

1. Requirements caused by external conditions specific to the location, which are more or less unchangeable by design (e.g. climate, built environment).

2. Requirements of internal conditions influenced by factors such as the intended use of the building, user comfort expectations and security requirements (e.g. required lighting levels for certain activities).

3. Requirements caused by the socio-cultural context which determines fashion, availability of materials and building techniques and again user expectations.

These requirements and functions are graphically illustrated in Figure 18. They are interwoven with the design of buildings and with the use and experience of buildings. The following sections will now analyse the role of these three influences (internal, external and socio-cultural) in more detail.

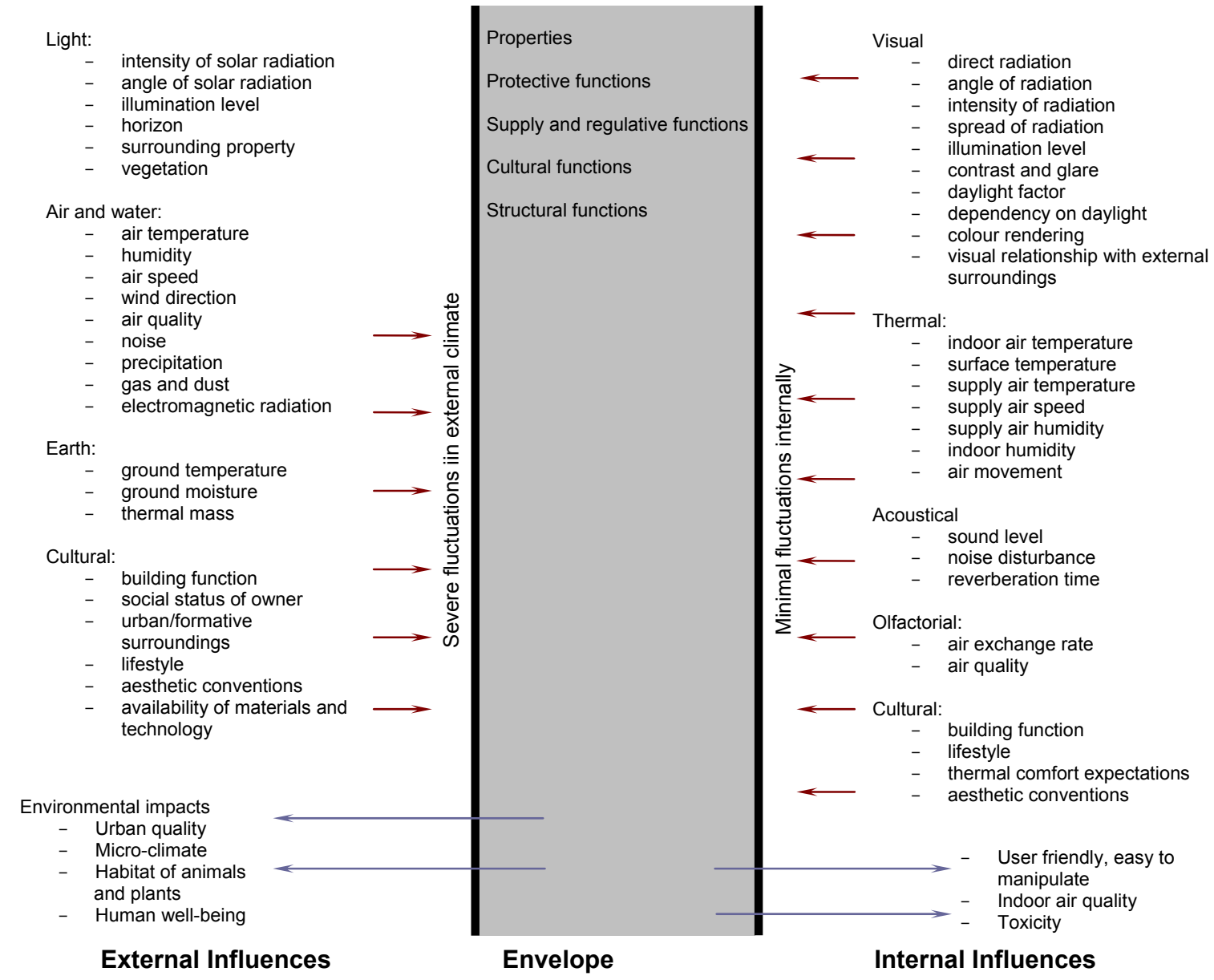

Figure 19: Building envelope: influential factors 


\subsubsection{EXTERNAL INFLUENCES}

External conditions are usually specific to a building site and vary in intensity and nature depending on the location, geographical region and continent. Micro- and macroclimatic conditions, pollution levels, shadowing by neighbouring buildings and existing vegetation are generally given parameters to the designer. In turn, a good wall design can impact positively on its environment e.g. by absorbing dust, reflecting light into surrounding buildings, or shielding existing buildings from a prevailing wind (refer also to the green wall section 1.11.1.3).

Climatic parameters such as temperature and humidity used to drive the evolution of construction techniques and lifestyle. In turn the use of an envelope has allowed humans to occupy most of the available land mass from permafrost regions to the desert, as people have learned to build dry shelter specialised to local conditions. In order to allow people to survive in extreme climates, envelopes have to either keep cold air and wind out or provide well ventilated rooms with good sun protection and low room temperature. People in each climatic zone developed their own architecture with astonishing similarities in physical properties in both hemispheres as described by Olgyay, V. (1963, p.6):

"Building styles are less defined by national frontiers than by climate zones. (...) Allowing for some variation in taste and tradition, the general forms of native habitation are born from the environment."

These envelopes evolved over thousand of years, and have been improved and diversified. The degree of consideration of climatic and external factors has varied over history but should always be a primary criterion in order to design envelopes appropriate to local climate and external conditions.

\subsubsection{INTERNAL INFLUENCES}

Requirements arising at the inside face of the envelope partly originate from cultural circumstances such as user expectations of comfort standards. Technical knowledge and the amount of available energy to meet these standards have an impact as well. However, many physical factors play a vital role in the creation of comfortable conditions inside a building. Thermal comfort is influenced by temperature and relative humidity of interior air, surface temperature of building components, airflow across the human body, and different gender of the users as well as their activity levels. The human body can maintain its core temperature of $37^{\circ} \mathrm{C}$ without internal thermo-regulation (shivering or sweating) if the external temperature is around $30^{\circ} \mathrm{C}$ for a naked and $25^{\circ} \mathrm{C}$ for a lightly dressed person. This temperature zone is called "thermo-neutral" (Kirschbaum, C., 2008).
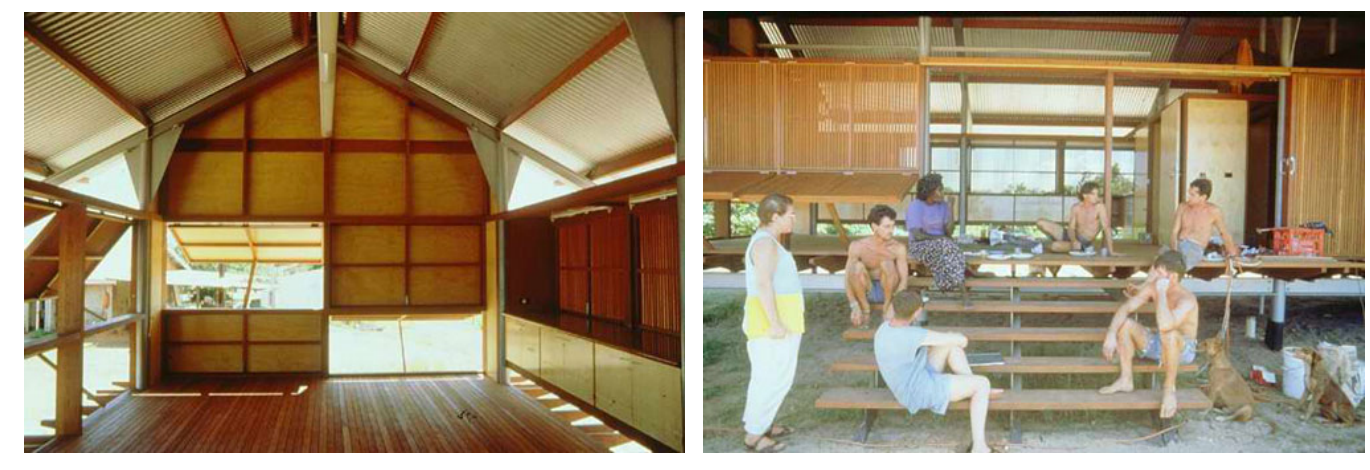

Figure 20: Glenn Murcutt's Marika Alderton House, Northern Territory, Australia.

Living in the tropics requires flexible facade elements, shading from sun and a building envelope that catches every breeze, yet protects the user from cyclone winds. Large roof eaves protect from sun as well as from tropical rain which can flood the area at times. Therefore the floor is elevated from the ground. No glazed openings are required. 
The greater the difference between the thermo-neutral zone and exterior temperature, the greater the technical undertaking to design an envelope that can provide ambient conditions in the interior of the building. In tropical zones, where temperatures are mostly thermo-neutral, the envelope is traditionally reduced to a minimal screen protecting only from wind, rain, sun and animals as can be seen in Figure 20.

\subsubsection{THE ROLE OF THE SOCIO-CULTURAL CONTEXT}

Three cultural aspects influence the appearance, performance and design of the envelope, these being:

- architectural function of the envelope

- Lifestyle

- technology and the availability of construction materials

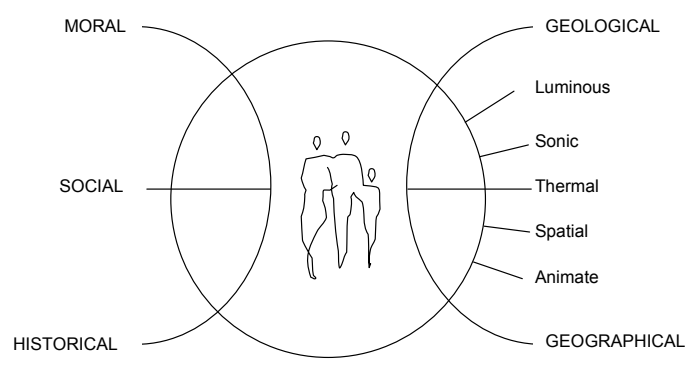

Figure 21: Factors influencing architectural expression

They will now be discussed in more detail:

\subsection{THE ARCHITECTURAL FUNCTION OF THE ENVELOPE (ART AND REPRESENTATION)}

The envelope is as much a cultural element as it is a functional one. It influences the appearance of a building more than any other architectural element and communicates with its surroundings.

In the cultural context there is a well established hierarchy between the different elements of the envelope. External walls, windows and to a certain extend roofs can be powerful messengers of the owner's taste, social status and financial power as they lend themselves to sending a message to their surroundings. The role of the floor as horizontal elements as elements of representation is often limited to the interior of a building. The decoration and representational functions of the enclosure constitute a source of cultural information, revealing much about historical tastes and aesthetical conventions of an era, and give evidence of the historical technical knowledge and building techniques of societies. The envelope is therefore more than the sum of its functions but can reflect values, conventions and habits of societies long after they have disappeared.

Another indicator for the importance of the envelope as a representative element is its often emphasized close figural relationship to the human skin and face. The envelope is called the building skin 
and walls become façades, which is equivalent to the French word for frontage or face. Emphasis is put on the cultural and social aspect of the walls as the face, the representative element of architecture, the one that not only defines the character of the building, but also has a huge influence on its environment (Herzog, T. et al., 2004, p.10), (Sack, M., 2003).

Investigating multifunctionality, the connotation of skin and face is also very interesting as the functions of both the human skin and the façade surpass the representation of a cultural or individual image, but are true interfaces between two different spheres. External walls are interfaces of architectural objects with the environment, just as the human face presents the main link between the inner self and the surrounding social and physical world. Interfaces are by nature multifunctional, as they simultaneously connect as well as separate inside and outside. The human face is specialised in receiving information (tactile, acoustical, visual, olfactory and taste) and incorporates organs to ingest vital substances such as food, air and information from its surroundings. At the same time it presents a dense area of outgoing information for other humans where verbal and silent expressions (language and mime) are located. Faces can be distinguished and recognized by people even after years of separation. The function of the facade is similarly complex and diverse as will be discussed.
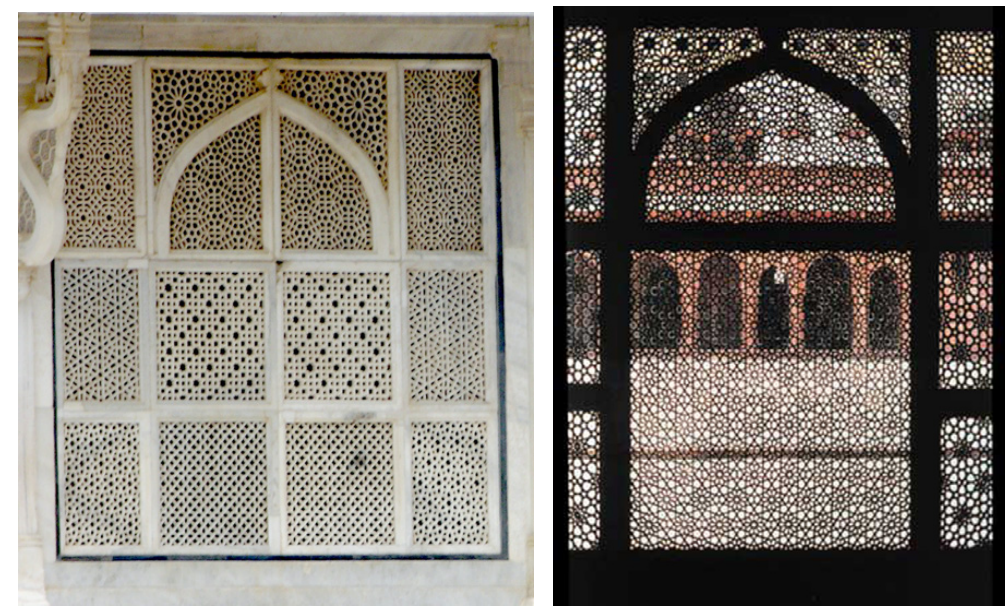

Figure 22: Tomb of Chishti, Uttar Pradesh, India.

Shade, privacy and decoration.

Another aspect of the envelope in the cultural context is that it lends itself to be decorated not only for representation but also for its beauty, which often can be enjoyed from the inside as well as the outside, as seen in Figure 22. An intrinsic part of civilisation is to add beauty and art to functional elements rendering them into both useful and delightful things. Bendiksen for example shows that the urge to mix the useful with beauty is not confined to affluent societies but can literally be found in the poorest hut. Figure 23 shows the $3.5 \mathrm{~m}^{2}$ home of Charles Arori and his 10 children in Africa's largest slum Kibera in Kenya, which he describes as follows: "As you can see on my walls, there are some daily newspapers that we have been reading, The Standard, People's Daily. I put these newspapers up to decorate my house -for their beauty. It makes the house look beautiful, and it makes you see anything -like cockroaches. When the papers are hanging you can see that this -this is a cockroach. Or that -that is an ant. So, you protect yourself' (Bendiksen, 2008, chapter 1). 

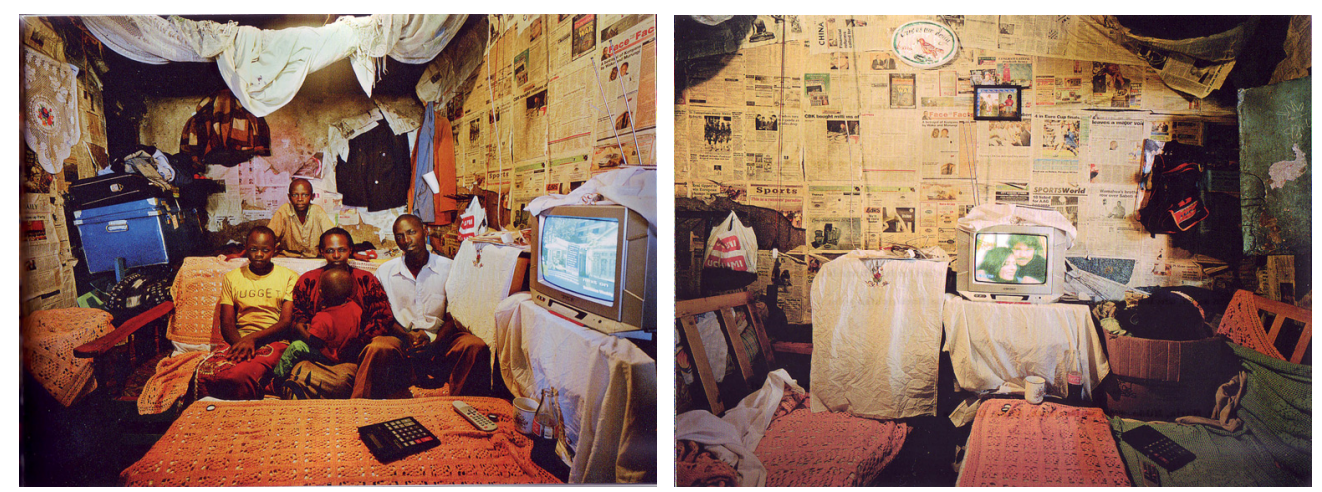

Figure 23: Charles Arori's house in Kibera, Kenya

This urge drives the continuous evolution of aesthetic conventions, with the result that sometimes former constructional elements turn into purely ornamental features. The ancient Greeks for example applied elements (rafters) of timber construction, which were no longer required, to stone temples and turned them into ornamental elements on their new stone façades. In turn there are examples that show that aesthetic consideration can also impact on the functionality of the envelope. In the architecture of the Renaissance, the climatic

principles were generally overridden by the requirements of proportion, symmetry and the correct use of the Orders (LEARN, 2004).

The influence of cultural context on the envelope can be illustrated by another example: the controversy over the flat roof which erupted in Germany at the beginning of the $20^{\text {th }}$ century. Starting from a neo-classical search for antique forms in the $18^{\text {th }}$ century, it was first perceived as a symbol of the cultural and aesthetic superiority of the universal (Ancient or Mediterranean) culture over the German vernacular building culture where houses traditionally had pitched roofs (Pommer, R., 1983, p. 159). Later it symbolised the new found universal language of modernist architecture searching for clear building lines and forms. As such it gained political explosiveness during the Third Reich, as its connotation with the left and liberal centre turned it into a symbol of opposition to the regime. This caused the Major of Berlin at the time to demand Wagner and Taut, architects of the Horseshoe Colony in Berlin-Britz, to build pitched-roof houses on threat of going to jail (Taut, B., 1936, p.204-214). The dispute lost its vigour only after the German proponents of the Modern Movement went into exile in the 1930s. In the 1960s and 70s the discussion over whether pitched or flat roofs were adequate for German culture and climate returned and this time "its industrial connotations were played down or suppressed (by architects) in favour of its abstract purity of line and plane" (Pommer, R., 1983, p.167). Maybe because of this long and often harsh debate the use of the roof as a design element in the residential sector is quite uncommon in German or Swiss culture compared to contemporary architecture in New Zealand or The United States of America, where the debate never had such a political edge. 

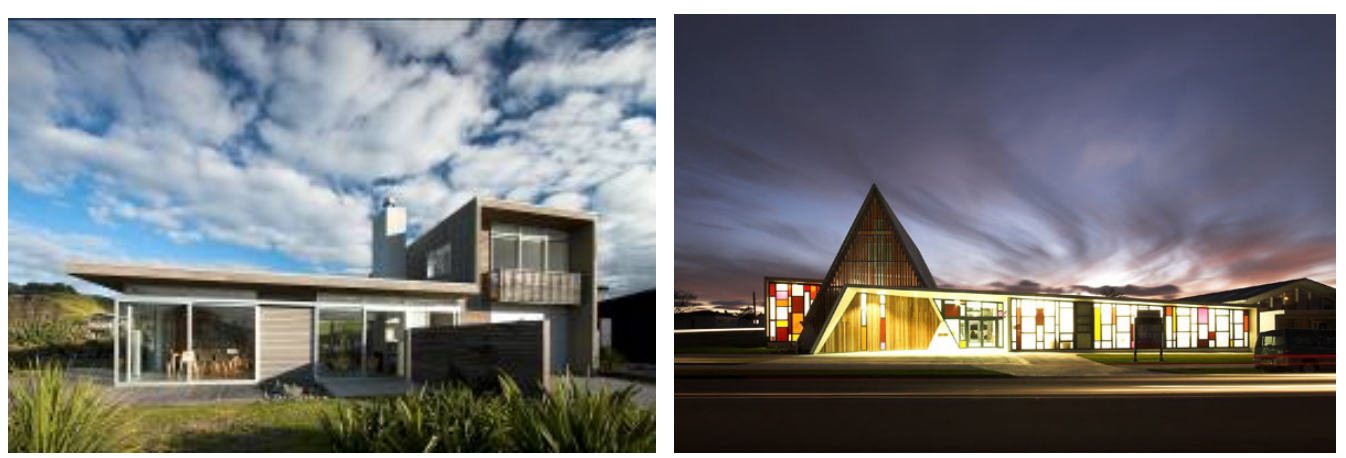

Figure 24: Using the roof as design element,

Harris bach, Omaha and Combined Churches in Waiuku, New Zealand

Given that the envelope has such an important role in the cultural context, it represents an individual challenge as well as a responsibility towards society for its designer. It can be argued that designers should embrace the challenge to create envelopes that are not just self-referencing but enrich the cultural space as ultimately "the aggregate of facades, in context, creates our urban landscape. If the façade fails, this public face is compromised."(Brock, L., 2005, p.5). Given its cultural importance, it is not surprising that building regulations exist in some countries to set strict, local standards for the design of facades.

\subsection{LIFESTYLE}

The second aspect influencing the envelope in the socio-cultural context is the lifestyle of its users. More than anything else, the lifestyle of people influences the kind of housing they inhabit (Knaack K. et al. 2007, p.14). Nomads require mobile, light construction that can be set up relatively quickly by a few people. Their houses need to be modular to allow for disassembly and transportation, which leads to separation of the wall and the structure.
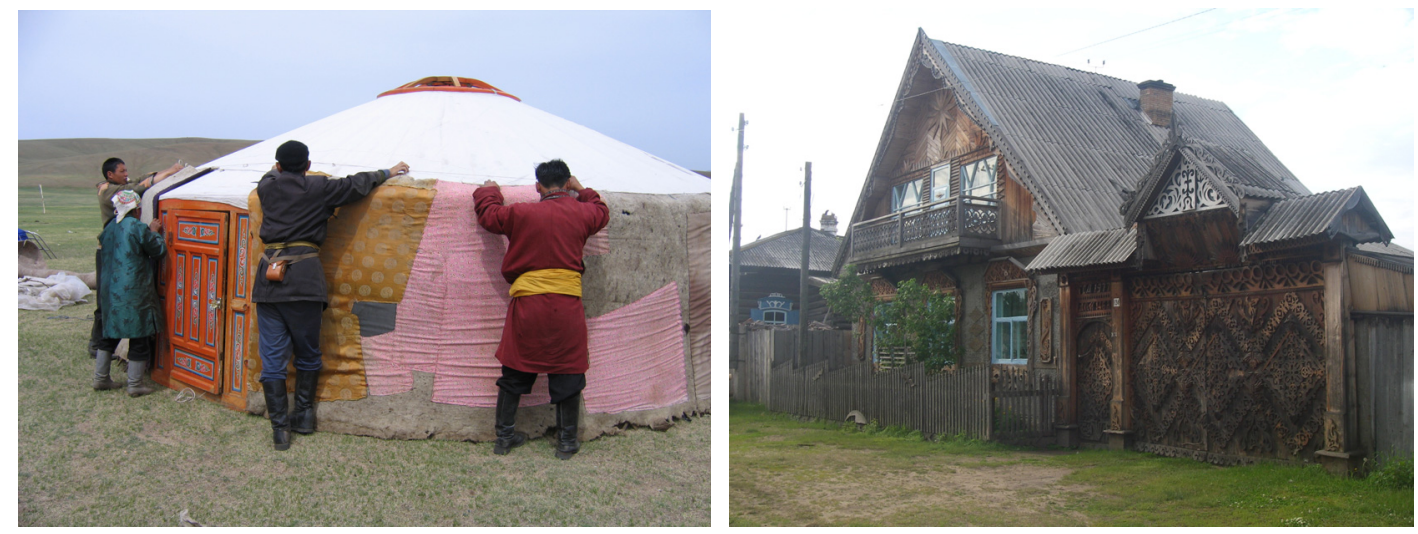

Figure 25: Two lifestyles, one country

Mongolians who were traditionally nomads living in Yurts (left), were made sedentary during Russian occupation and moved mostly into prefabricated concrete apartment buildings, while the Russians introduced their traditional Dachas (right) to the country

Sedentary people often chose long lasting, heavy, load-bearing materials. These can withstand decades of use, act as thermal mass, as safe storage for food and can be built from local sources. The most fundamental constructional distinction between envelopes is therefore if they are mobile or per- 
manent load-bearing structures. The lifestyle of a society in turn depends on diverse factors such as climate, energy and food supply.

\subsection{TECHNOLOGY AND THE AVAILABILITY OF CONSTRUCTION MATERIALS}

The third aspect of socio-culture context is the availability of materials and technology. It can be argued that they are influenced by external conditions and not so much by social parameters. However, it seems that technology and availability of construction materials are both reinforced and the same time propelled by cultural aspects, such as lifestyle changes and the development stage of a society. Therefore they will be discussed here.

Availability of materials used to drive certain construction techniques and structural principals, as some materials such as stone or clay lent themselves to the creation of homogenous solid walls that are load-bearing, while other materials are much more efficient when combined with each other, such as concrete or steel. Building techniques hence evolved according to the properties of the materials at hand and for most of human history the availability was restricted to local sources. These were used for domestic buildings, as even regional transport was often not an economic option as described by Clifton-Taylor: "It was the great difficulty of transporting heavy materials which led to all but the most affluent until the end of the eighteenth century to build with the materials that were most readily available near the site, even when not very durable...if a non-local stone were required, it was sometimes brought laboriously by wagon, but always at high cost." (Clifton-Taylor, A., 1987).

Mainstream architecture was therefore vernacular (Brunskill, R., 1978, p.22). Expense and effort to import materials were mostly reserved for religious architecture such as Greek temple and gothic cathedral architecture.However, societies that could delegate work to a cheap or unpaid workforce, such as the Indian, Roman or Egyptian, did not spare the effort of importing materials (marble, gold or diamonds) and people with technical knowledge from far away places to honour kings and gods with buildings.

The industrial revolution (which was as much a technical as a cultural revolution) changed transportation and the production techniques of building materials. Industrial production made materials and their transport much more affordable. Hence, the industrial revolution virtually removed availability as a limiting factor for building construction techniques. Formerly expensive or unavailable materials such as tiles or bricks gradually replaced many local materials such as earth and thatch. It also resulted in an increase in new processing techniques (Koch, W. ,2006, p.377). Steel and later concrete were mass produced. They were first only used to replace traditional materials such as timber or brick as structural elements but later made new building typologies such as railway stations and early high rises possible. However, mostly steel and brick were concealed behind historic and eclecticist facades. Construction techniques did not always translate into appearance as can be seen in Figure 26 . 

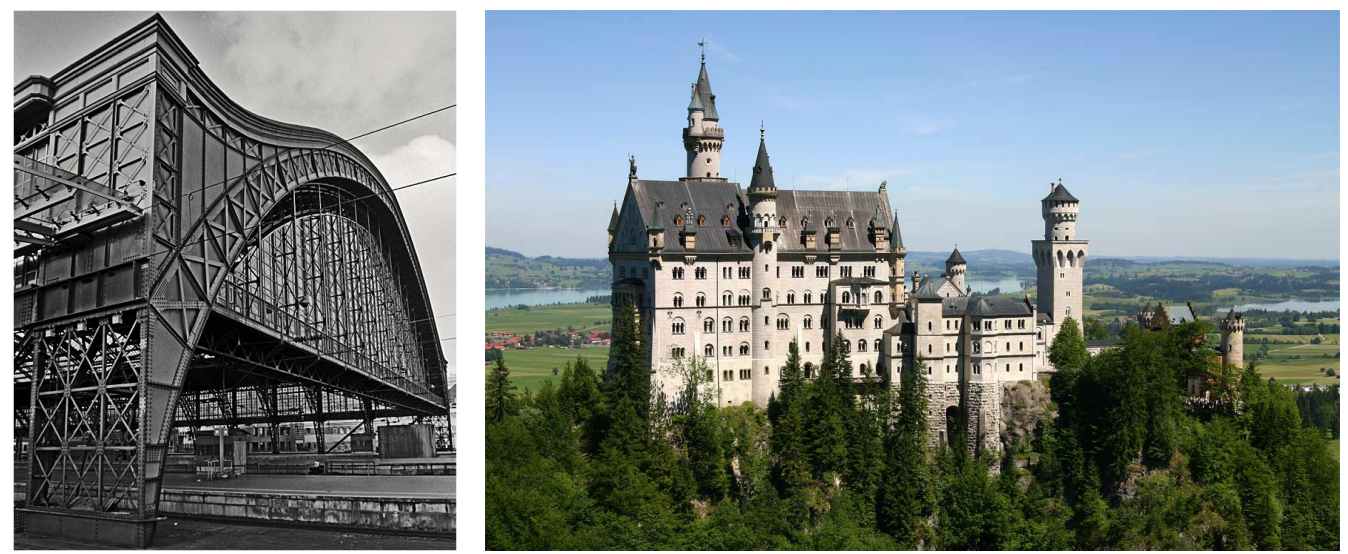

Figure 26: Cologne's main railway station from 1894 and Schloss Neuschwanstein in Bavaria from 1884.

The steel structure of the station spans $64 \mathrm{~m}$. The main hall has a length of $255 \mathrm{~m}$. The structure of the castle also consists of steel frames as well as load-bearing brick walls.

Modernist architects felt that the use of classical elements and architectural language for new building typologies such as offices, stations and factories as taught by the École de beaux Arts in Paris were unsatisfactory as they did not reflect the revolutionary new possibilities of the materials and available technology. Instead they asked for a new architectural canon which reflected the emerging building techniques, the materials' properties and mass production and called for the reunifaication of the education of engineers and architects. Sullivan synthesised the unease about this discrepancy between appearance and function as well as dominance of "foreign schools" over "native instinct and sensibility" and coined the great battle-cry of modernist architects "form follows function" (Sullivan, L., 1896).

Industrialisation is in actual fact a good example of the interconnectedness of external, internal and social-cultural conditions which impact on the envelope as well as on each other (refer back to 1.8.1). First a combination of social changes, urbanisation and new working environments raised the demand for new building typologies such as factories, offices and apartment blocks, changing social conditions. Then new envelope systems replaced the traditional ones that were highly adapted to the local external conditions as cooling and heating was now much more affordable. The availability of materials and resources made the new envelope systems possible, trading off adaptation to climate with the use of vast amounts of cheap energy which became available to run buildings. For a short period in architectural history, the design of the envelope seemed to become independent of external conditions as described by Le Corbusier: "Every country builds its houses in response to its climate. At this moment of general diffusion, of international scientific techniques, I propose: only one house for all countries, the house of exact breathing. (...)The Russian house, the Parisian, at Suez or in Buenos Aires, the luxury liner crossing the Equator will be hermetically sealed. In winter it is warm inside, in summer cool, which means that at all times there is clean air inside at exactly $18^{\circ} . "$ (Le Corbusier, 1930, p.65-66).

This drive to less adaptive architecture and building enclosure was also fuelled by the expansion of industrialisation to a global phenomenon and the emerging financial and cultural influence of the USA after the Second World War. The lifestyle and new building typologies developed in the USA, including their construction techniques, were introduced to most countries. The USA was predominantly perceived as a symbol of increasing wealth and development contrasting with the "underperforming" socialist world, which fuelled the desire in business owners and private people alike to exhibit the life style improvements by building accordingly as described by Berghahn (2007): 
"The images and happy-end stories that California's dream factories told on the silver screen influenced the attitudes of millions who went to the movies at least once a week and came away envisioning for themselves the better life that they had just seen and associated with the United States."
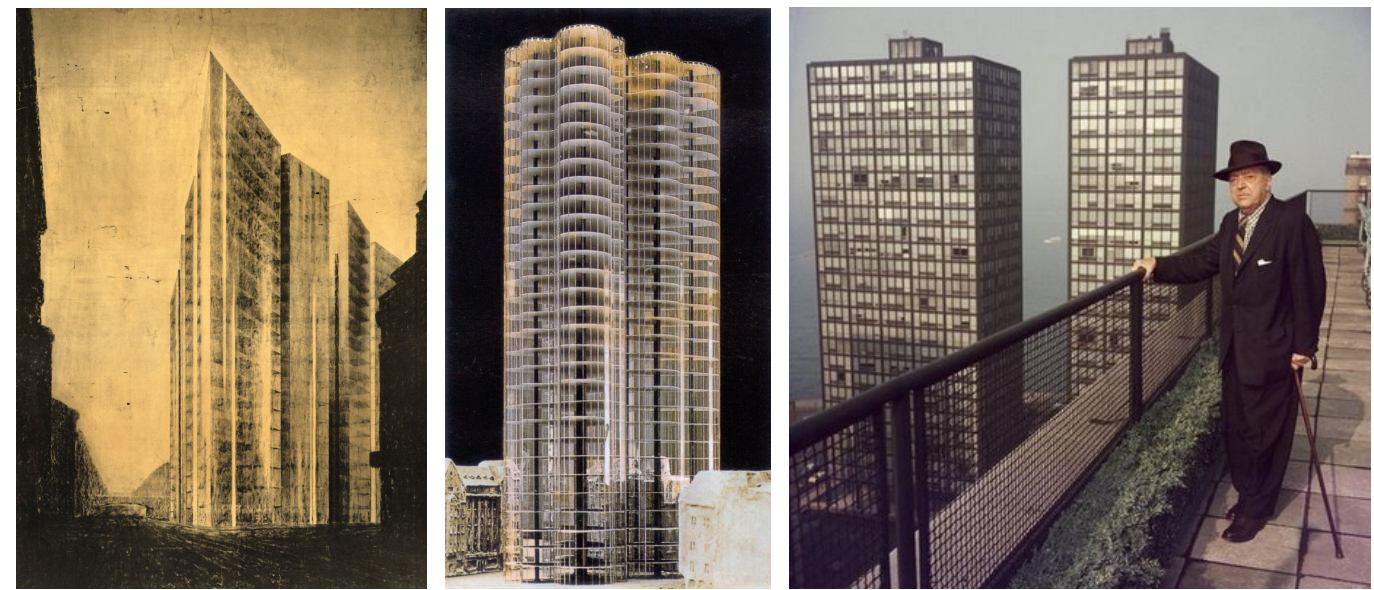

Figure 27: Mies van der Rohe's high-rise designs 1919 and 1922 and Mies at Lake Shore drive in Chicago

"The indigenous culture" became "subject to the powerful influence of "the idea of America" abroad" (Roper, J. 1996,p.12). For architecture and urbanism this meant that both were freed from a combination of local requirements, building techniques and local cultural conventions and aesthetics (Ward, S., 2003, p.83-106). The drive to fewer restrictions, more and more commercial big scale projects and less need for local knowledge, made possible the transformation of the building sector from a local trade of craftsman to an internationally operating industry of building specialists.
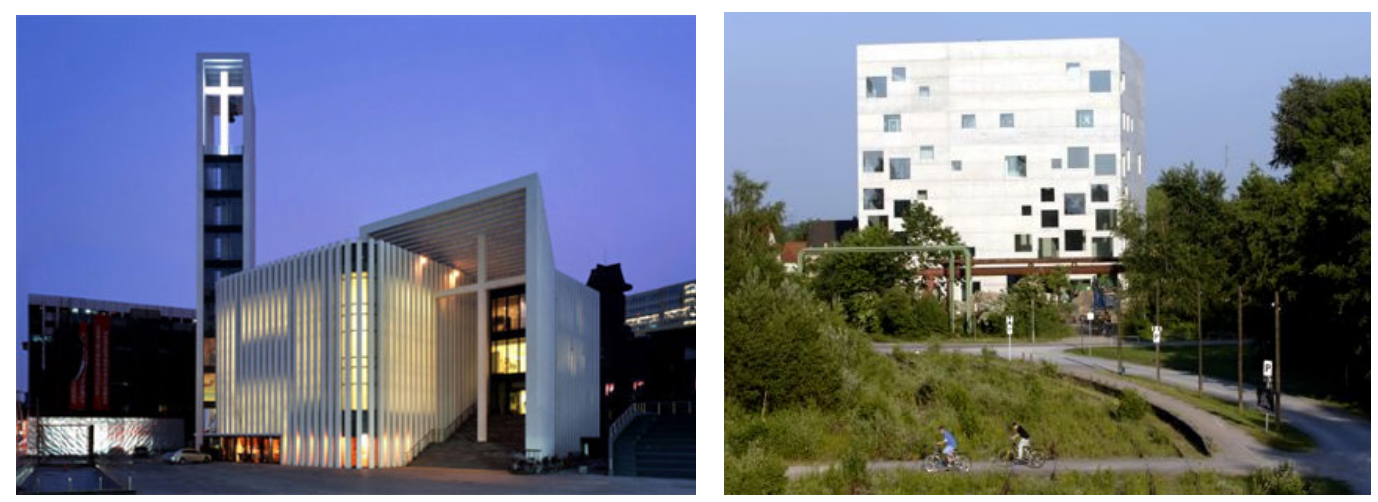

Figure 28: German Architects in Beijing and Japanese Architects in Germany

Christian Church Beijing by GMP architects and School of Management and Design Essen by Sanaa

However, although industrialisation changed the course of the evolution of building envelopes, it did not bring it to a halt. From the 1960s general awareness of ecological issues, resource depletion and the energy crisis increased in industrialised societies. Simultaneously the living standard also increased and with it the requirements for thermal comfort, which were often not satisfied by early modern architecture. Stricter regulations pushed architects and engineers to embark on a journey to find more economic and ecological answers to local climatic realities that made office and apartment buildings so inefficient in terms of energy use. A generation of architects (such as Behnisch, Foster, Herzog, Ingenhoven, Rogers) approached the topic from a technical side and pushed to optimise the office and high rise façade in terms of its energy efficiency and user comfort, introducing doublefacades, natural ventilation, sky-gardens etc. However, Davies criticises the fact they felt short of 
questioning the entire concept of the modern building envelope and developing a new system that could really fulfil all the requirements the new building typology imposed on the envelope. He accused architects and engineers of having instead resorted to using more materials to fulfil the functions appropriately (such as introducing double and triple glazing as a second façade layer): "We were caught admiring the concept (of modern architects) but with our technological panties around our knees." (Davis, 1981). The new façade systems Davies described increased in complexity, driven by the careful thermal separation of construction profiles followed by the consequent need to maintain this separation throughout window casements, drainage plains and jointing technology in order to prevent thermal bridges (Knaack, K. et al., 2007, p.11). These refined façade system can often capture energy, provide natural ventilation and almost act as a building skin (Hausladen, G., 2006). While they might be optimised to reduce the amount of operational energy, not all of these measures result in decreasing resource flows as will be seen in section 1.13. Furthermore it remains true, that the majority of these buildings do not reflect local climates or culture-specific values.
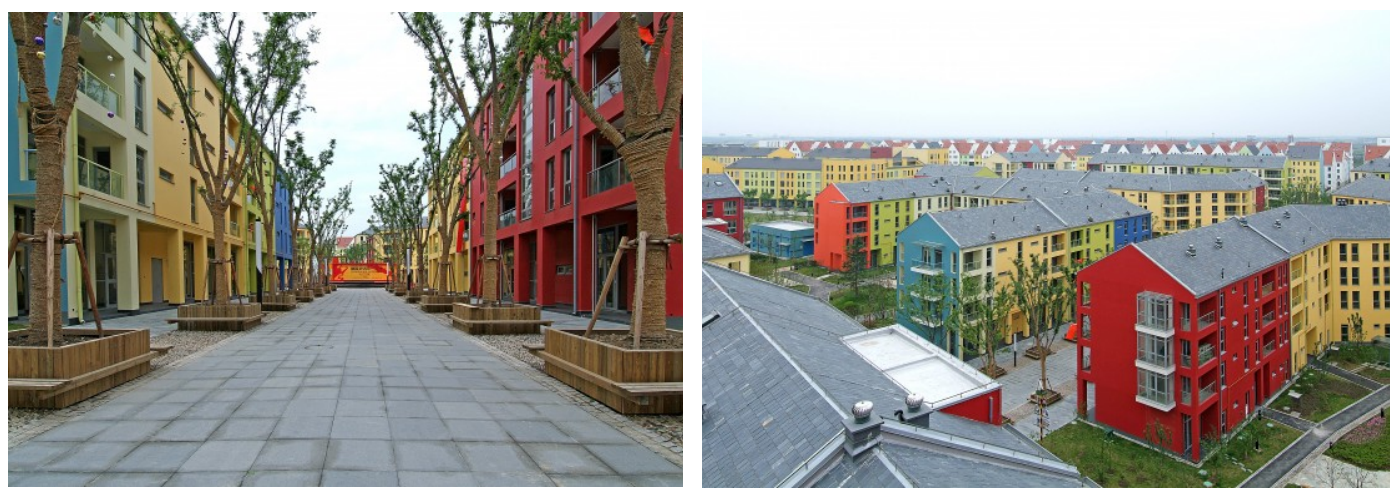

Figure 29: An Ting, one of many new suburbs in Shanghai, China

Contextless architecture also becomes more important in residential architecture

On a global scale only a very small minority of architects did challenge the new contextless office-, hospitality- and industrial architecture typologies as such. Reconsideration of entire building typologies tend to be found in small scale projects and residential works, where a small revival of climate-specific and vernacular building technologies occurred (Rael, R., 2008 ), (Halliday, S., 2008).

However, the drive to not only energy-wise, but also resource-wise urban planning, buildings and envelopes is essential, as building stock lasts a long time and resources to rebuild the entire environment to create spaces that require less or no operational energy, might not be available. Architects and engineers should therefore anticipate the resource and energy supply situation by resorting to as many as possible low-tech, low-resource options in all building typologies. 


\subsubsection{FUNCTIONS OF THE ENVELOPE}

The performance of the envelope is measured by its success in mediating between external and internal influences. Functions can be distinguished as those that completely prevent transaction across the wall (protective functions) and those that regulate the process (supply and regulative functions) (Hegger, M., 2007, p. 83), (Herzog, T. et al., 2004, p.18). Water, at least in its liquid form for instance should never penetrate the interior of a building, while many other elements, like sun, air and sound only require filtering or need to be actively supplied. Furthermore the envelope has to take on structural functions e.g. transferring its own weight or additionally the weight of other elements. Additionally the entire envelope is increasingly used for other environmental functions, such as energy production, water retention or $\mathrm{CO}_{2}$ sequestration. Figure 30 summarizes the functions and properties a building enclosure has to fulfil. These functions are direct responses to climatic and others factors such as air, heat, water, sound and light as illustrated in Figure 19. The shown functions will now be analysed in more detail.

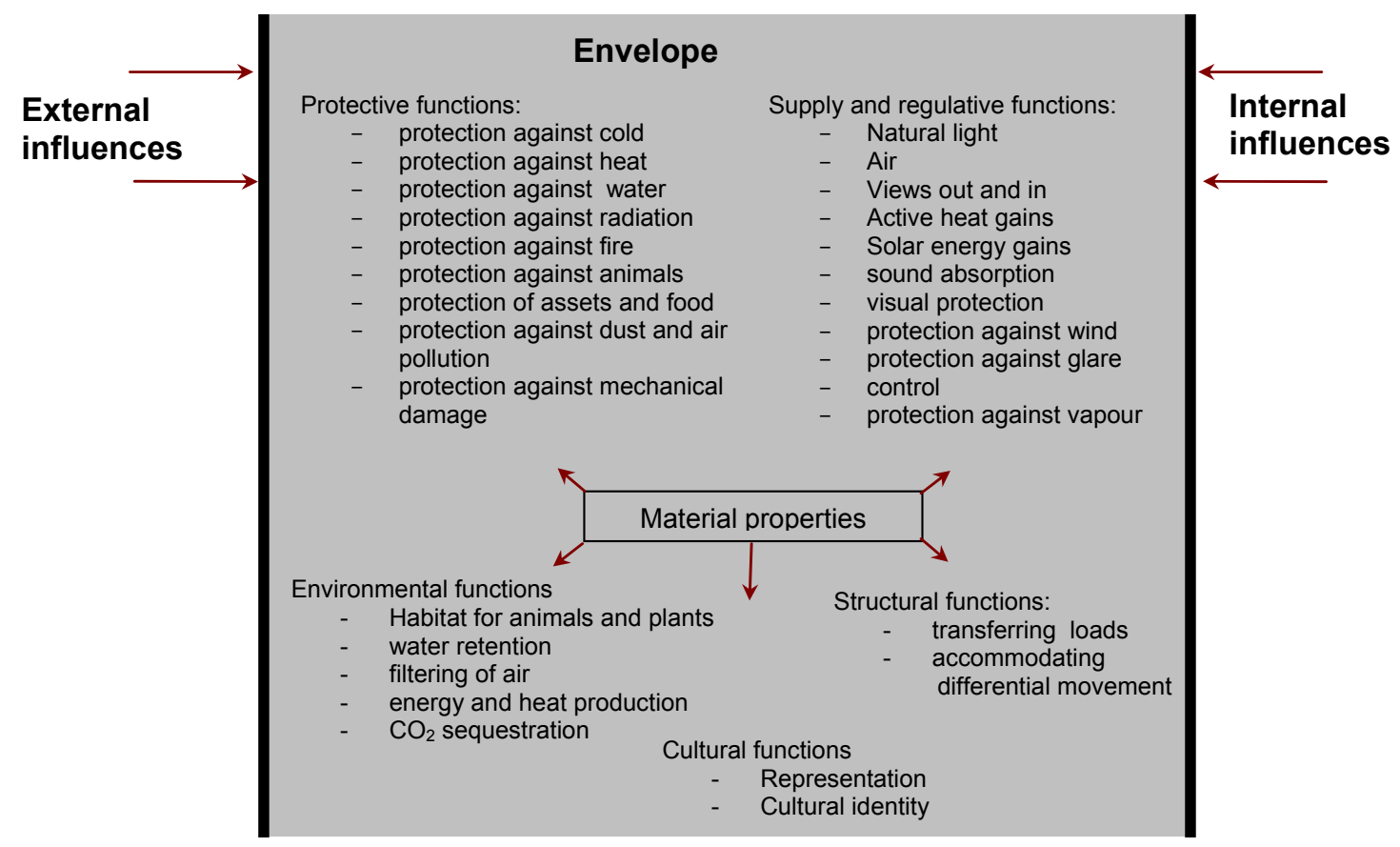

Figure 30: Functions of the envelope 


\section{- PROTECTIVE FUNCTIONS}

In general, protective functions are mandatory and are caused by essential physical needs. If not fulfilled by the envelope itself, usually other precautionary strategies will be established. These can be as varied as a hose kept to water down flammable facades to prevent flash over of fire or the keeping of dog packs to make up for the lack of physical protection of a textile enclosure in a nomadic lifestyle. As there is no such thing as the universal perfect envelope, envelope design ideally represents an appropriate combination of construction methods and a careful selection of materials according to their physical properties.

\section{- SUPPLY AND REGULATIVE FUNCTIONS}

Just as for protective functions, supply and regulative functions can sometimes be outsourced and fulfilled by other elements. Visual protection for example can be created by planting. However, compared to protective functions, they are more discretionary and can to a certain extend be traded off. They are influenced both by anthropologic aspects (user expectation, economic funding and architectural conventions) and by each other.

\section{- ENVIRONMENTAL FUNCTIONS}

The idea to attribute environmental functions to the wall is especially important for sustainable or regenerative approaches (refer to Figure 12). The wall is seen as an element that can improve people's health, generate solar power and provide habitats for plants and animals. It should always be considered carefully if additional functions are in the end beneficial for the environment (refer to chapter 5 ). Section 1.13.1.5.3 shows for example that green walls can certainly improve local micro-climate and the psychological well-being of a neighbourhood but do create a large demand for natural resources, which other available options do not.

\section{- STRUCTURAL FUNCTIONS}

Starting from the two major types of envelopes, the tent and the solid structure, two different approaches to deal with the structural functions of the wall can be distinguished. The former separated structural function to a skeletal structure that carried the weight of the sealing cloths; the later mostly assumed both structural and enclosing functions in the same element. 


\subsubsection{PHYSICAL PARAMETERS AS A MEASURE OF APPROPRIATENESS}

In section 1.4.3.3.5 the coefficient of appropriateness $a_{i}$ was introduced as a measure of how well materials or products fulfil their function. It was stated that multifunctional products are designed and optimised to fulfil all their functions to a high extent. For the envelope to be a multifunctional element, this means that its components fulfil the requirements described above to a high extent.

For the case study appropriateness will become important, as it becomes a precondition for all additional functions that are to be incorporated into the envelope. Only if they are appropriate in terms of their visual, architectural, and physical performance, does it makes sense to establish if they decrease resource use. The photovoltaic windows used in the case study are examples of elements where the question of appropriateness occured during the setup of the multifunctional envelope (refer to discussion in section 1.11.1.5).

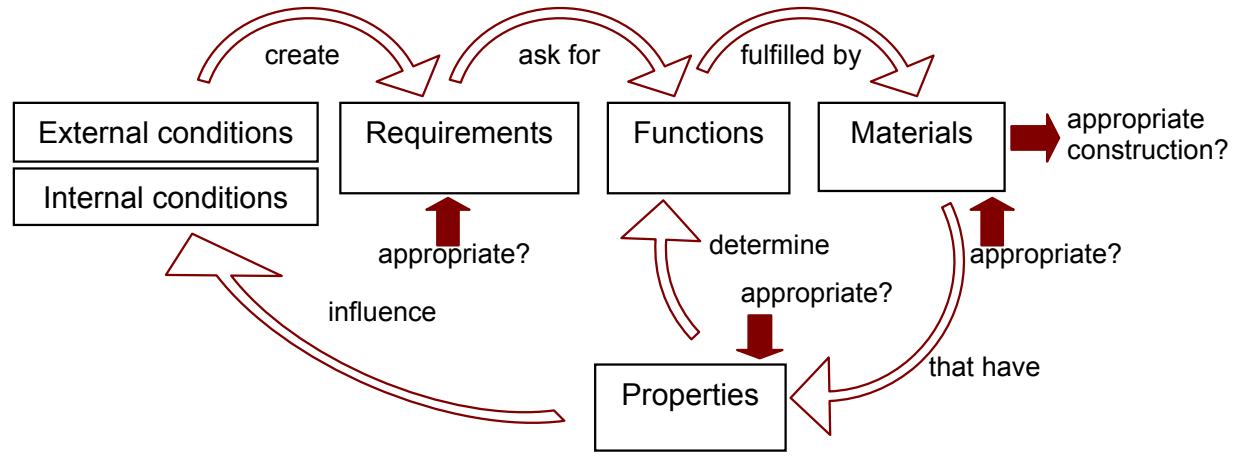

Figure 31: Feed-back loop of the building enclosure

Figure 31 illustrates how the question of appropriateness arises several times during the design of the envelope and feeds back into the design process.

Firstly it has to be established if the available materials are appropriate, if they can fulfil the requirements. If the answer is positive, then construction method and material selection have to be attuned. Lastly the properties of the chosen material have to be appropriate for fulfilling the required functions as material properties limit performance.

As the properties of different materials become important when comparing multifunctional walls, the following section will deal with relevant physical parameters building materials have to fulfil. In order to establish which functions of the wall are essential and the extent to which they can be manipulated, the underlying physical principles as well as the essential needs of the user have to be analysed. To clarify if the overall performance of a multifunctional wall is satisfactory, the different properties of its elements have to be analysed separately and in conjunction, as the combination of them always matters. (Ashby, 1992, p. 24) They act as coefficients of appropriateness $\left(a_{i}\right)$ and can hence help the analysis of the functionality of any material (and material combination) in regard to a certain profile of requirement.

Each requirement (e.g. thermal insulation) has its specific coefficient of appropriateness (e.g. thermal conductivity k). In order to establish these coefficients, a clear definition of appropriate performance profiles is fundamental. Although the appropriateness of requirements is partly discretionary and con- 
textual, it is largely dependent on scientific facts and is influenced by physical parameters. Often values of coefficients are recommended by regulations, although they usually only represent the lowest acceptable standard. In the European Union concerns about energy dependence and climate change have led to passing relatively high standards of energy saving regulations for buildings that define limiting values for most of the relevant property coefficients. The following is a summary of the most relevant physical parameters and coefficients. As resource effectiveness of multifunctional walls will be measured at a later stage, the recommended values of the European Union and its member states will be indicated using the German regulation Energieeinsparverordung (EnEv), to create an indicative guideline (EnEV, 2007). The following sections will summarise the most important requirements and indicate how their coefficient of appropriateness is established, they follow the logic of

Figure 32, which summarizes the relationship between the function of the envelope and its properties e.g. thermal conductivity, strength, fire resistance, insulation against sound and heat, pressure resistance, solidity etc. 


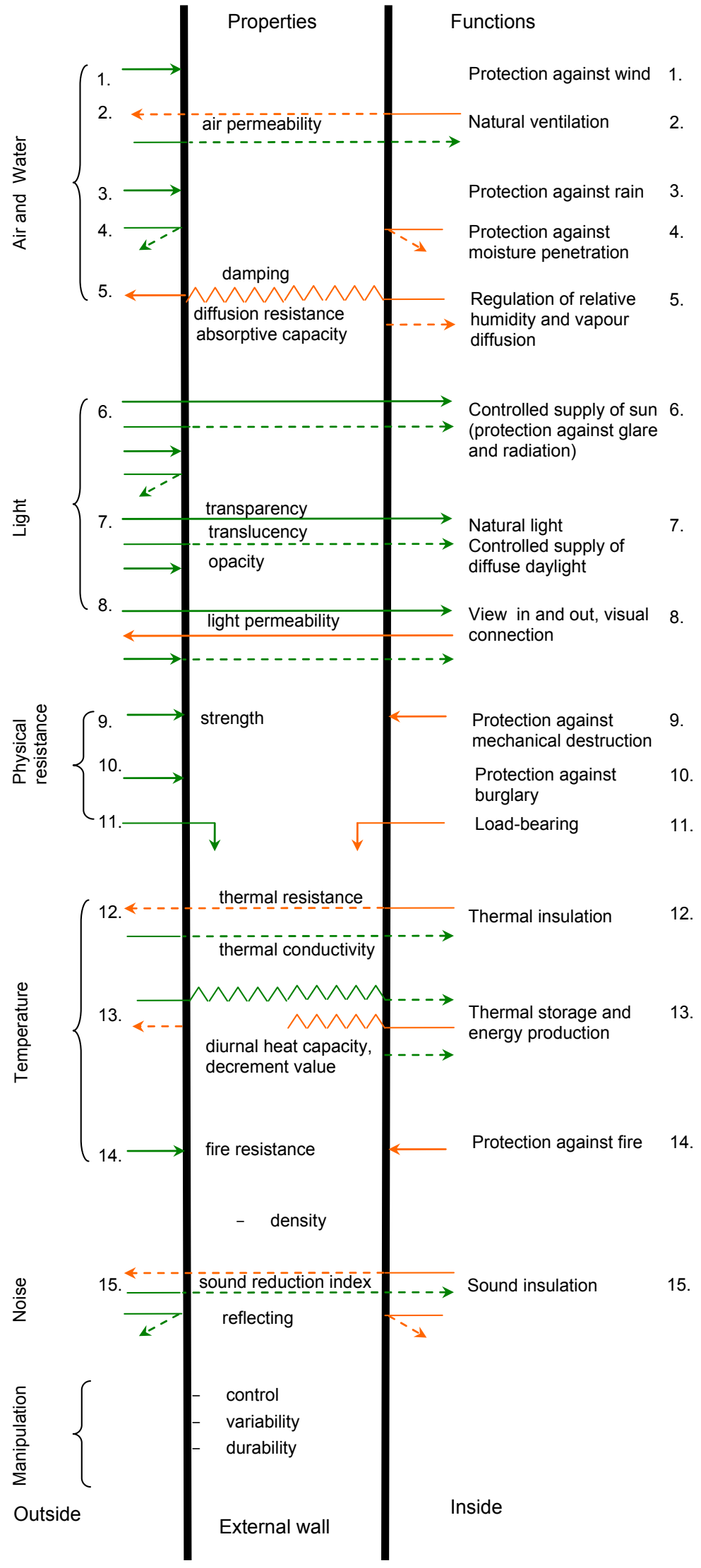

Figure 32: Functions and properties of the external wall 


\subsubsection{AIR AND WATER}

\subsection{WIND AND NATURAL VENTILATION}

Every building is affected by wind that can vary considerably in severity and direction. Left uncontrolled it can impact negatively on the thermal comfort of users in colder climates both by producing drafts and by sucking heat out of the building. Therefore all relevant building components should be as air

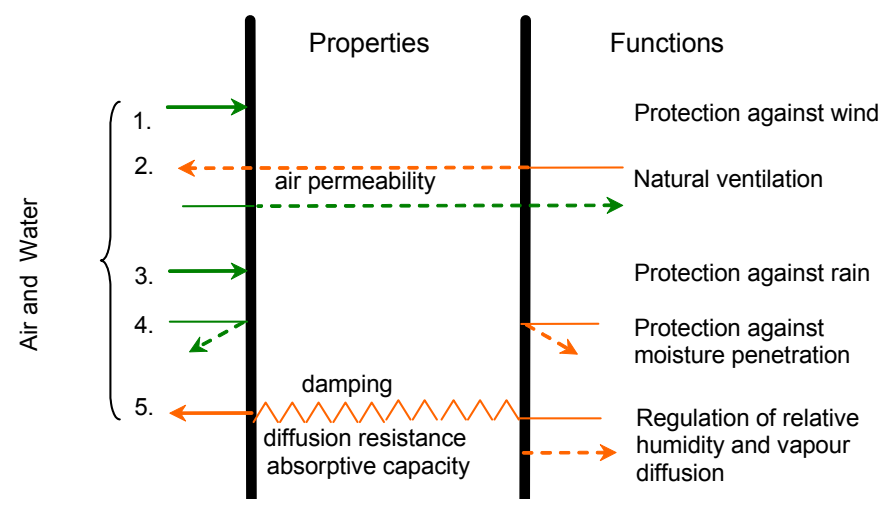
tight as possible. However, natural ventilation is essential to provide a building with fresh air, release moisture and excessive heat and prevent the potential build-up of toxic gases released by building elements. A sufficient air exchange rate can be guaranteed by controllable elements that can vary their air permeability such as windows and air ducts. Ideally the facade takes advantage of the physical principles of air movement and manipulates it accordingly. Air currents for example usually occur where there is a temperature gradient and a supply of fresh air that can be moved. As hot air is lighter than cold air it rises and can produce a draft. This is sometimes used to create a chimney effect in north facing (southern hemisphere) double facades which can avoid the need for mechanical ventilation to get rid of excess heat.

The following coefficients can be used to quantify the performance of the wall or its components in respect to air.

Coefficients:

- Air-exchange rate (ventilation) $n[1 / \mathrm{h}]$ :

The air exchange rate $n[1 / \mathrm{h}]$ indicates the air flow rate in relation to the volume of the space that needs ventilation. The recommended air-exchange rate varies locally. It depends on air volume of spaces, internal heat and pollution sources as well as use of rooms and number of occupants. The air-exchange rate is influenced by the air-tightness of the building, as leakage presents a form of involuntary air-exchange. The minimal hygienic air-exchange rate is, for example, given as 0.45/h by Din 1946-6 (DIN 1946-6, 2006)

- Air-tightness n50 [1/h]:

In general air leakage occurs mostly where materials are joined. It is therefore usually analysed in the context of the entire building or separate units of a building. For this purpose a negative or positive pressure of $50 \mathrm{~Pa}$ will be generated by a fan inside the sealed space and the influx and respective efflux of air will be measured (blower-door-test) as an indication of the air leakage rate. For energy efficiency reasons the entire building should be as air-tight as possible to avoid heat loss through drafts. EnEv 2007 requires a maximum air-leakage of $1.5 / \mathrm{h} n 50$ for buildings with an air-conditioning system and $0.6 / \mathrm{h} \mathrm{n50} \mathrm{for} \mathrm{zero} \mathrm{energy} \mathrm{housing}$ (EnEV 2007). Air-tightness of individual materials is not systematically measured. Absolute air-tightness does not exist, however most building materials are presumed to be sufficiently 
impermeable for building purposes with the exemption of textiles and perforated materials. Air-tightness of materials is dependent on size of perforations as well as thickness of material.

\subsection{PROTECTION AGAINST MOISTURE}

Some materials such as wood, bricks and some stones do absorb water which can lead to damage from rot or freezing. Clay and earth loose their structural integrity in direct and continuous contact with water. Protection of these materials against rain and flooding is therefore mandatory. Continuous exposure to water e.g. by a leaking down pipe can also damage materials that are generally not susceptible to moisture such as some hard baked bricks, refer to Figure 33.

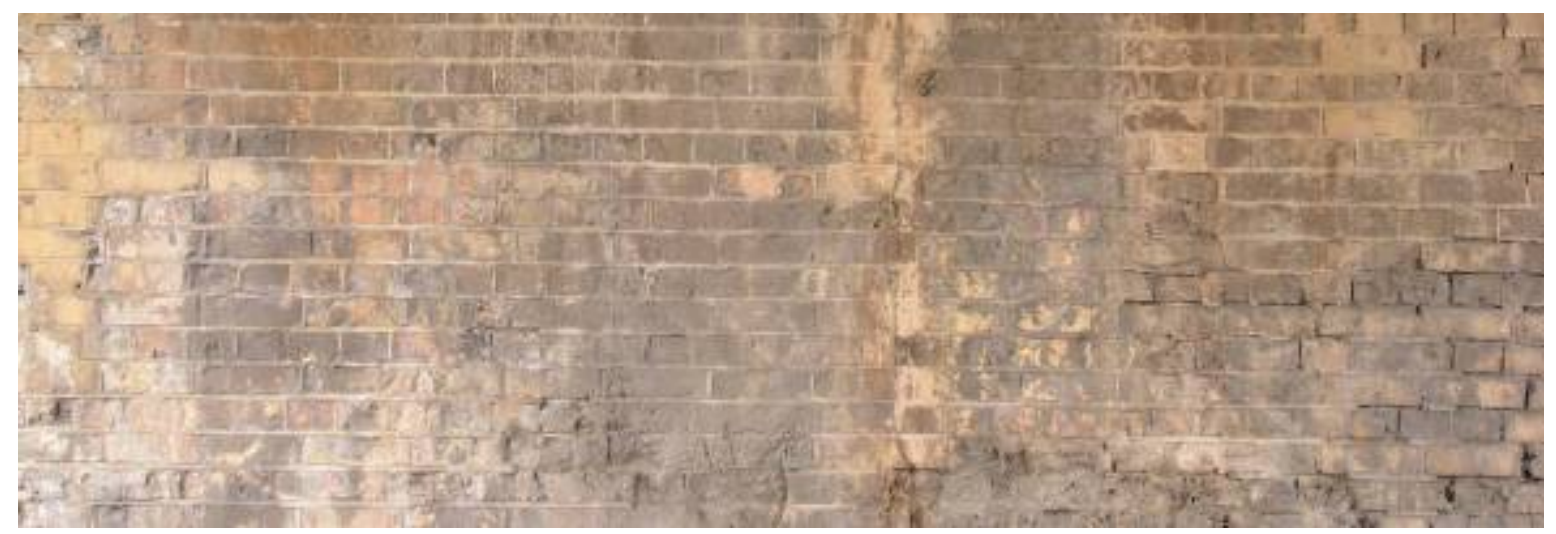

Figure 33: Brick wall damaged by water

Penetrating moisture can cause mould and should either be avoided (by water tight layers) or needs to be dried out from the wall from time to time. Insulation can loose its thermal properties when in contact with water. This is caused by the fact that water has at $15^{\circ} \mathrm{C}$ a $25 \mathrm{fold}$ higher thermal conductivity $(k=0.598 \mathrm{~W} / \mathrm{mK})$ than air $(k=0.024 \mathrm{~W} / \mathrm{mK})$. Hence, water reduces the performance of the thermal insulation significantly (Hegger, 2005, p. 135). Insulation materials must therefore be kept dry. The following coefficients can be used to quantify the performance of the wall or its components in respect to moisture.

\section{Coefficients:}

- Aqueous solubility $W_{s}[\mathrm{~kg} / \mathrm{l}]$ :

Aqueous solubility depends on the amount of water that coats the material. A continuous down pouring of water can destroy most materials in a relatively short time. Some materials however have so small a solubility rate that their abrasive wear is not indicated in $\mathrm{kg} / \mathrm{l}$ but in terms of years. Schuhmann for example gives the solubility of sandstone at an annual precipitation rate of $800 \mathrm{~mm}$ as follows.

1500 years if siliceous binder used

500 years if binder based on dolomite

150- 300 years if lime binder used (Schuhmann, H., 1987).

- Water absorption rate $\mathrm{w}\left[\mathrm{kg} /\left(\mathrm{m}^{2} \cdot \sqrt{h}\right)\right]$ : 
The water absorption rate is another important parameter as water penetration does impact on the health, bearing capacity, durability and insulation performance of the envelope.

A commonly used classification for the water absorption rate is:

$$
\begin{array}{ll}
\mathrm{w}>2 \mathrm{~kg} /\left(\mathrm{m}^{2} \cdot \sqrt{h}\right)=\text { priming } & \mathrm{w}<2 \mathrm{~kg} /\left(\mathrm{m}^{2} \cdot \sqrt{h}\right)=\text { hydrophobic } \\
\mathrm{w}<0,5 \mathrm{~kg} /\left(\mathrm{m}^{2} \cdot \sqrt{h}\right)=\text { water repellent } & \mathrm{w}<0,001 \mathrm{~kg} /\left(\mathrm{m}^{2} \cdot \sqrt{h}\right)=\text { water proof }
\end{array}
$$

The water absorption rate and the size of pores reveal how the material reacts to frost. The water absorption rate also acts as an indicator for the swelling power of a given material.

\subsection{RELATIVE HUMIDITY AND WATER VAPOUR PRESSURE}

Air absorbs water in the form of vapour. It reaches a saturation point which is dependent on temperature. At the same temperature moist air has a slightly lower density than dry air. If there is a severe temperature gradient between inside and outside, water will condense out of the air as soon as the dew point is reached. Water vapour flows from high vapour pressure to lower pressure. As inside and outside usually have a different temperature, humidity and hence vapour pressure, the wall either has to block the migration of vapour through itself (it could condense inside the wall and facilitate mould growth) or it has to be able to absorb vapour and release it again. The diffusion resistance depends on vapour diffusion coefficient $\mu$ and on the thickness of the material.

\section{Coefficients:}

- vapour diffusion coefficient $\mu[-]$

The vapour diffusion coefficient $\mu$ indicates how resistant a material is to vapour. The smaller the value, the smaller the amount of vapour that will be inhibited from passing from the warm to the cold site of the material. The basic unit $\mu=1$ means that a material has the same diffusion capacity as a layer of air of the same thickness. The vapour diffusion coefficient of most building materials is influenced by temperature and moisture content, therefore often limiting values are indicated e.g. oriented strand board $\mu=50 / 100$ (Hegger, 2005, p. 75).

Values below $\mu=10$ indicate a high vapour diffusion capacity.

Values between $\mu=10-50$ indicate a moderate diffusion capacity.

Values between $\mu=50-500$ indicate that the diffusion capacity is restricted.

Values between $\mu=500-15000$ indicate that the diffusion capacity is highly restricted.

Values above $\mu=15000$ indicates that the material presents a barrier to vapour

(Haerig et al, 2003, p.210, Oberrauch, B., 1992, p. 48, 49).

Whether a high or low value is appropriate depends on the construction strategy. Open pored constructions benefit from low values as dehumidification is less restricted and therefore fast. If wall materials are arranged in layers their vapour diffusion value should be decreasing from the inner building surface to the outside. This undermines the natural tendency of the vapour to migrate from the warmer inside to the colder outside. However, if water vapour does enter it 
would then be transported to the outside of the building. In constant hot and humid climate, vapour tightness is essential to prevent rot, as dehumidification of the wall is not possible.

\subsubsection{LIGHT}

Natural light can be separated into sunlight and daylight. Daylight is the desirable soft, indirect, diffused light that avoids glare, harsh shadows and heat gains. Daylight has a positive impact on people's health and performance and improves resourceefficiency, as it can reduce the opera-

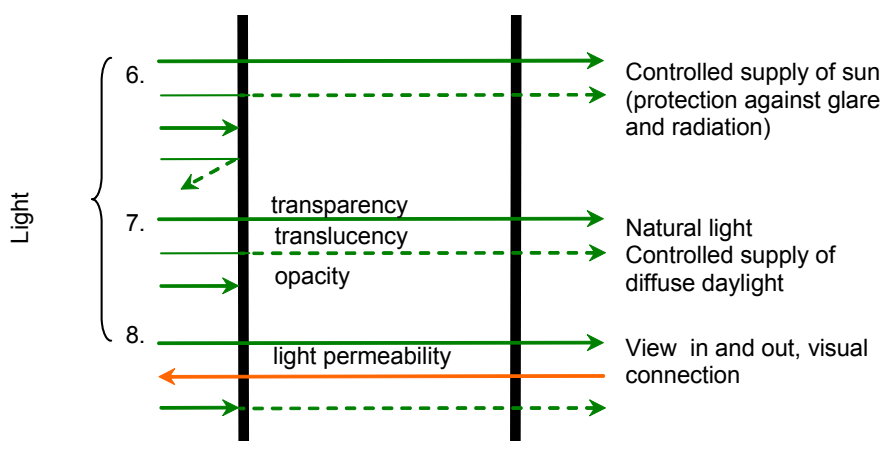
tion hours of artificial lighting.

Direct sunlight can cause the build-up of excessive heat and glare. It can also be undesirable due to its brightness and UV-radiation. Sun protection therefore is often required. In general sustainable design opts for maximising daylight and minimising direct sunlight in summer (Winchip, S., 2007, p. 169). However, in winter direct sunlight is often welcome, penetrating transparent wall elements in order to heat the interior passively.

The visual connection to the outside is another important aspect as it can give orientation and has a positive influence on people. It is mandatory for workplaces in many countries.

Coefficients:

- Visible transmittance $\mathrm{V}_{\mathrm{t}}[-]$

The visible transmittance is an optical property that indicates the amount of visible light transmitted. Visible transmittance theoretically varies between 0 and 1 . The higher the visible transmittance, the more light is transmitted vt $1=100 \%$.

- Illuminance $E_{v}\left[\mathrm{lux}=\mathrm{Im} / \mathrm{m}^{2}\right]$

Illuminance is the total luminous flux incident on a surface, per unit area.

Minimal illuminance levels at workplaces are regulated and depend on the activity carried out and age of staff.

- Light absorption coefficient $g_{\vee}[-]$

The light absorption coefficient is the measure of impenetrability of radiation, especially visible light. It describes the absorption and scattering of radiation in a medium, such as shielding material, glass, etc. The coefficient gives the rate of absorption of the radiation that is absorbed or scattered per unit distance along a ray of propagation. For a given material it has a numerical value that may range between 0 and infinity. In general $K_{v}$ depends on the frequency of the radiation, as well as the density, temperature, and composition of the material. 


\subsubsection{PHYSICAL RESISTANCE}

The hardness of selected building materials plays an important role in protection against mechanical destruction and burglary. Three different types of hardness can be
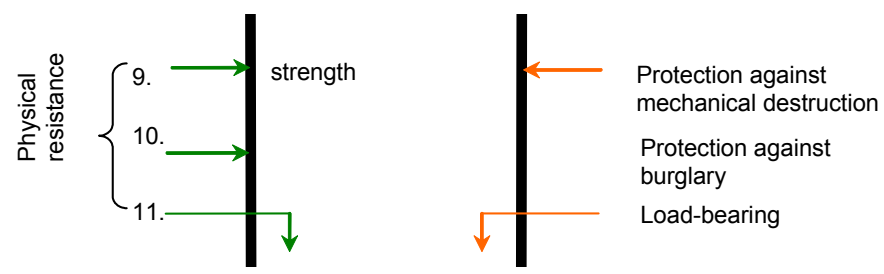
the distinguished:

- scratch hardness: Resistance to fracture or plastic deformation due to friction from a sharp object.

- indentation hardness: Resistance to plastic deformation due to a constant load from a sharp object.

- rebound hardness: Height of the bounce of an object dropped on the material, related to elasticity.

However, impact resistance is also influenced by mass and strength of materials.

Traditionally one of the main functions of the wall was to bear the weight of almost all building components. Today, the wall is often differentiated into facade and structure.

The stresses applied to the wall are caused by compressive, tensile and shear forces. They can originate from self weight, loads transferred from adjacent components such as walls, floors and roofs or from external elements such as snow or wind. Some materials can withstand all three stresses while others show different performance profiles for each of them (refer to section 1.11.1.1). The strength of a material refers to the material's ability to withstand an applied stress without failure. Yield strength refers to the point beyond which the material begins deformation that cannot be reversed upon removal of the loading. Yield and maximum stress are avoided by safety factors and careful dimensioning.
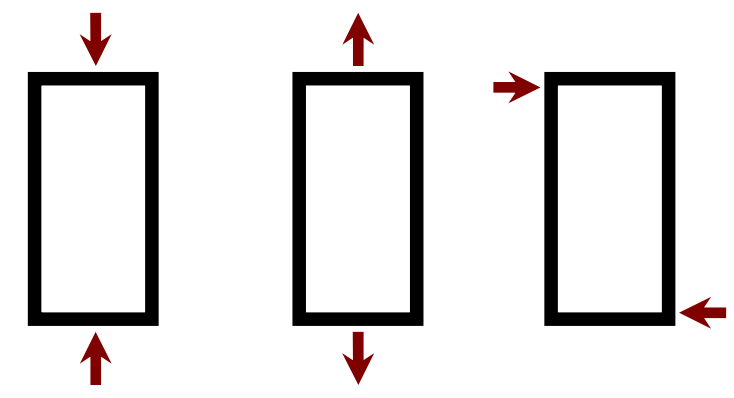

Figure 34: Illustration of compressive, tensile and shear forces

Coefficients:

- Hardness $\mathrm{H}\left[\mathrm{N} / \mathrm{mm}^{2}\right]$ covers several properties: resistance to deformation, and resistance to friction and abrasion. Several methods exist to measure the hardness of a material which leads to different coefficients named after the method used (Hegger, 2005, p. 264): 
Mohs-hardness HM [-]: the Mohs method tests scratch hardness. It is a relative coefficient with a scale of $1-10$, where one refers to the hardness of talc and ten to the hardness of diamond. Mohs-hardness is mainly used for minerals.

Brinell-hardness HB and Vickers-hardness HV [N/mm²] are used to test plastic deformation. The first is mainly used for soft and medium hard metals, wood and inhomogeneous building materials. Both methods indicate a ratio of used force and area of deformation.

- Compressive strength $f_{c}\left[\mathrm{kN} / \mathrm{mm}^{2}\right]$

The compressive strength defines the maximum compressive tension a material can absorb. It is defined as the quotient of maximum compressive force and the cross-section of the material tested.

- Tensile strength $f_{t}\left[\mathrm{kN} / \mathrm{mm}^{2}\right]$

The tensile strength describes the maximum tensile tension a material can absorb before breaking. It is defined as the quotient of maximum tensile force and the initial cross-section of the material tested.

- Shear strength $f_{m}\left[\mathrm{kN} / \mathrm{mm}^{2}\right]$

The shear strength of a material is defined by the quotient of the maximum bending moment and the section modulus of the material tested. It defines the maximum shear tension a material can withstand.

\subsubsection{ENERGY FLOW}

Heat will flow from a higher to a lower temperature through one, or any combination of the following three heat transfer mechanisms:

- Conduction

Conduction describes the trans-

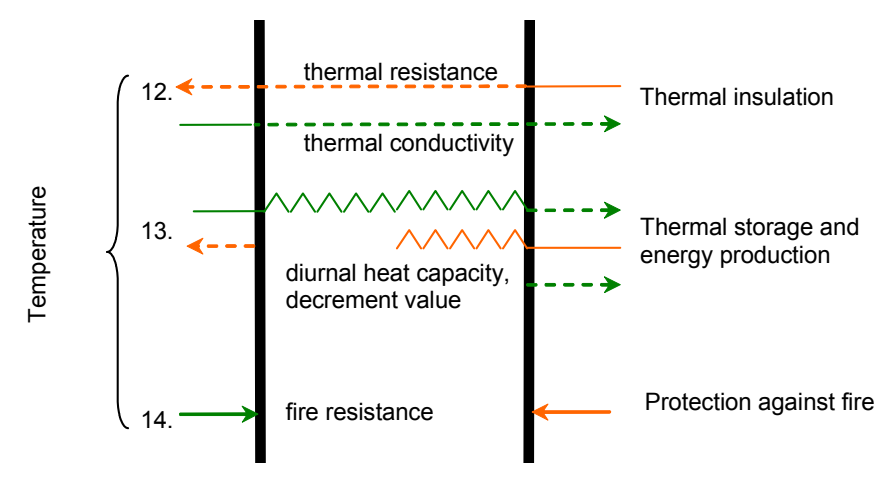
fer of heat through matter from a region of higher temperature to one of lower temperature.

\section{- Convection}

As described in section 1.8.3.1.1 air rises up and falls back down as it changes density when heated or cooled. These air movements, known as convection currents, can cause a significant amount of heat loss as they carry away the heat. Convection can only occur in fluids.

- Radiation. 
Heat energy may be radiated across space and then be absorbed by another body. Radiant energy from the sun is an example, as this energy may be absorbed as heat by the human body.

The heat transfer can be delayed by addressing one or several of the following mechanisms.

\subsection{THERMAL INSULATION}

The rate at which heat will flow through a material is dependent not only on the nature of the material, but also on the difference in temperature between the hot and cold sides. Comparisons of the effectiveness of insulation must be made on a basis which excludes the influence of variable factors such as thickness and the temperature differences.

Thermal mass $C_{T h}[\mathrm{~J} / \mathrm{K}]$

The amount of thermal mass in the building and its distribution in the envelope has a major impact on the effectiveness of the discharge of excessive heat and coolness and the amount of stored thermal energy. The concept takes advantage of the fact that heavy materials have a delay in absorbing and releasing the energy underlying temperature differences as can be seen in Figure 35, where the thermal performance of a light weight construction (green) is compared with one that has a high thermal mass (blue). Thermal mass can level temperature fluctuations throughout the day and night as it stores heat during daytime and releases it in the night and vice versa.
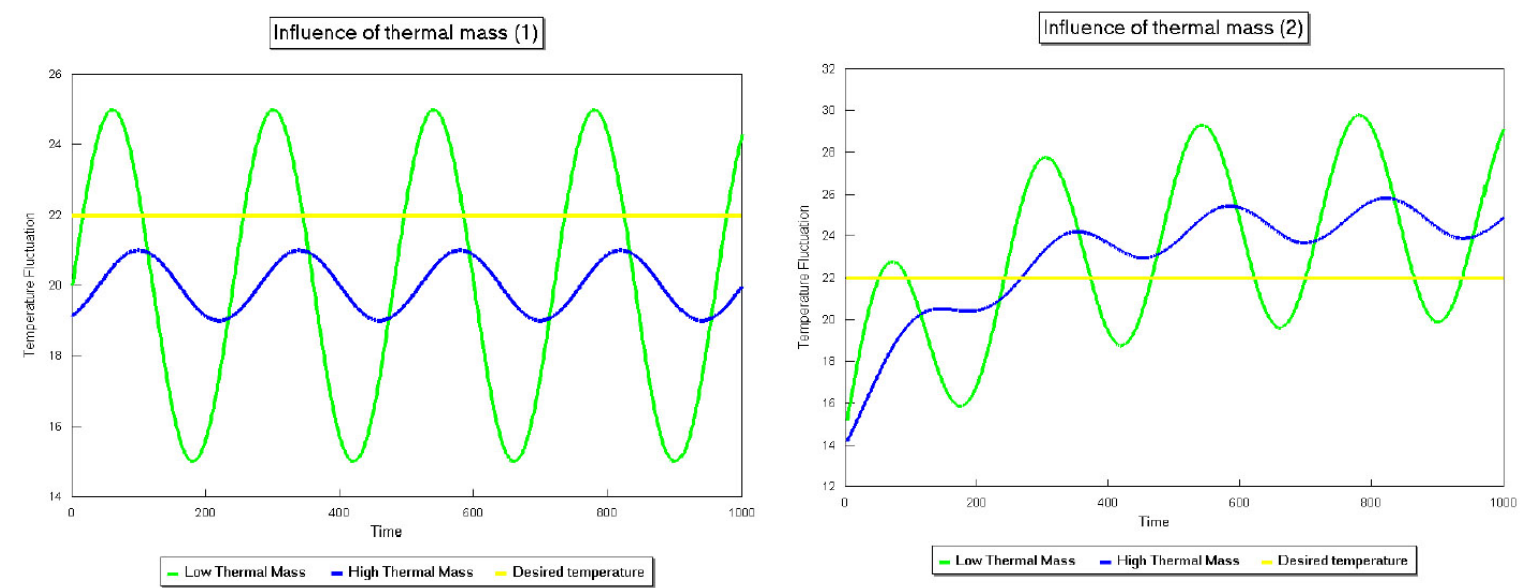

Figure 35: Influence of thermal mass on temperature within the enclosed space

Thermal mass delays temperature increases and levels them off.

Thermal mass is a concept that is suitable for climates where temperature changes exist between night and day as well as between seasons. In constantly hot or cold climates the effect can be detrimental because the thermal mass will tend towards maintaining the average daily temperature which is not necessarily within the comfort range. Therefore thermal mass is not used in tropical climates, where buildings are open and light-weight as illustrated in Figure 20.

Thermal mass or the heat capacity $C_{T h}$ of a material is a product of the mass $m$ and the specific heat capacity for the material $\left.C_{p}[\mathrm{~kJ} / \mathrm{kgK})\right]$. Thermal mass has to be combined with a good level of insulation to avoid cancellation of heat gains in winter and the build-up of excessive heat in summer. 
The following coefficients can be used to quantify the performance of the wall or its components in respect to energy flow.

Coefficients:

- Thermal conductivity $\mathrm{k}[\mathrm{W} /(\mathrm{m} \mathrm{K})]$

specifies the rate of heat transfer in any homogeneous material. If a material has a $k$ value of one, it means a one cubic metre of material will transfer heat at a rate of one $\mathrm{W}=\mathrm{J} / \mathrm{s}$ for every degree of temperature difference between opposite faces. The lower the value, the higher is the insulating ability of the material. Thermal conductivity excludes variable factors such as given thickness of material and temperature gradients and can therefore be used to calculate $\mathrm{R}$-value and $\mathrm{U}$-values of homogeneous materials. As moisture has a negative impact on thermal conductivity, only dry materials are measured as reference materials.

- Thermal resistance, $\mathrm{R}$-value $\left[\left(\mathrm{K} \cdot \mathrm{m}^{2}\right) / \mathrm{W}\right]$

R-value signifies the ability of a particular thickness of a material to resist heat flow. It is a measure of thermal resistance. The higher the R-value the greater the resistance to heat flow due to higher levels of insulation or material properties. The values of individual layers of materials can be added to give the overall resistance. Their reciprocal is the total U-value (heat transfer coefficient). When adding R-values, the heat transmittance resistance $R_{s}$ that exists between air and material has to be incorporated.

$$
U_{\text {wall }}=1 / \sum R_{\text {s outside }}+R_{\text {layer } 1}+R_{\text {layer } 2}+\text { etc }+R_{\text {s inside }}
$$

Table 3: heat transmittance resistance $R_{s}$ for the interior $\left(R_{s i}\right)$ and exterior $\left(R_{s e}\right)$ of walls independent of direction of heat transfer (EN ISO 6946)

\begin{tabular}{|c|c|c|c|}
\hline \multicolumn{4}{|c|}{ Direction of heat transfer } \\
\hline \multicolumn{2}{|c|}{ upwards } & horizontal & downwards \\
\hline$R_{s i}$ & 0.1 & 0.13 & 0.17 \\
\hline$R_{s e}$ & 0.04 & 0.04 & 0.04 \\
\hline
\end{tabular}

- Heat transmittance, U-value $\left[\mathrm{W} /\left(\mathrm{m}^{2} \mathrm{~K}\right)\right]$

$\mathrm{U}$-value is the overall heat transfer coefficient or heat transmittance. It indicates the amount of heat transmitted per second through one square metre of material with a temperature difference of one Kelvin between the two sides. The U-value is the reciprocal of the sum of all the $\mathrm{R}$-values in a wall.

$$
U=\frac{1}{R}
$$


Table 4: Required and recommended U-values for new residential houses (Kaufmann et al., 2002, p.6), (OIB, 2007, p.5), (SIA, 2009) and (EnEV, 2009).

\begin{tabular}{|c|c|c|c|c|}
\hline & $\begin{array}{c}\text { Passive house } \\
\text { Institute }\end{array}$ & $\begin{array}{l}\text { EnEv } 2009 \\
\text { (Germany) }\end{array}$ & $\begin{array}{c}\text { OIB } 6 \\
\text { (Austria), } 2008\end{array}$ & $\begin{array}{c}\text { SIA 380/1 } \\
\text { (Switzerland), } \\
2009\end{array}$ \\
\hline Elements: & \multicolumn{4}{|c|}{ Required U-Value $\left[\mathrm{W} /\left(\mathrm{m}^{2} \mathrm{~K}\right)\right]$} \\
\hline Roof & 0.1 & 0.2 & 0.2 & $0.17-0.2^{*}$ \\
\hline Wall & 0.15 & 0.24 & 0.35 & $0.17-0.2^{*}$ \\
\hline Window $\left(\cup_{w}\right)$ & 0.8 & 1.3 & 1.7 & 1.3 \\
\hline Floor & 0.15 & 0.3 & 0.4 & $0.17-0.2^{*}$ \\
\hline
\end{tabular}

* blow-door test required

- Specific heat capacity $C_{p}\left[\mathrm{~kJ} /\left(\mathrm{m}^{3} \mathrm{~K}\right)\right]$

The specific heat capacity indicates the amount of thermal energy needed to raise the temperature of one kilogram of a specific material by one Kelvin. The higher the value of $C$, the larger is the amount of thermal energy that can be stored.

\subsection{PROTECTION AGAINST FIRE}

Fire resistance of materials plays an important role in the causation and spread of fire. The European regulation (Din EN 13501-1) classifies materials according to their resistance to fire, as shown in Table 5.

Table 5: Fire resistance classification under European law, Din EN 13501-1 (after Hegger, 2005, p. 266).

\begin{tabular}{|c|c|c|c|}
\hline Building-authority terminology & $\begin{array}{c}\text { Additional requirements: } \\
\text { smoke }\end{array}$ & $\begin{array}{c}\text { Additional requirements: } \\
\text { dripping off }\end{array}$ & $\begin{array}{c}\text { Fire resistance class according } \\
\text { to DIN EN 13501-1 }\end{array}$ \\
\hline Non-flammable & $\bullet$ & $\bullet$ & A2 \\
& $\bullet$ & $\bullet$ & B1 \\
\hline Flame resistant & $\bullet$ & $\bullet$ & B2 \\
\hline Normally inflammable & & $\bullet$ & B3 \\
\hline Easily inflammable & & & \\
\hline
\end{tabular}




\subsubsection{DENSITY}

Density influences the performance of many functions indirectly e.g. insulation from unwanted sound. It does not relate to any function of the wall but is an important parameter when choosing construction materials. Also, the density of a material potentially impacts on incorporated energy e.g. for transportation.

Coefficient:

- Density $\rho\left[\mathrm{kg} / \mathrm{m}^{3}\right]$ :

Below $300 \mathrm{~kg} / \mathrm{m}^{3}$ a building material is classified as being light-weight. Densities above $2500 \mathrm{~kg} / \mathrm{m}^{3}$ will only be reached by stones and metals (König, H., 1997, p.225-227)

\subsubsection{NOISE}

\subsection{SOUND INSULATION}

Sound can be transmitted in various ways.

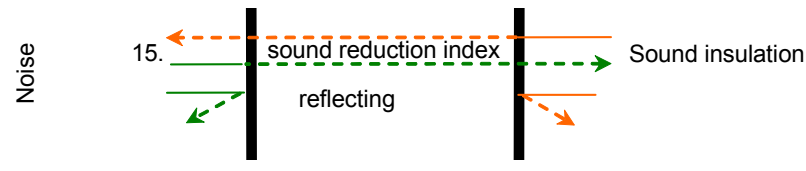

- Airborne transmission. Air tightness and structural isolation are important parameters in acoustic design of buildings to control airborne sound transmission. Doors and windows for example can have excellent sound reduction properties, but if left open only a few millimetres their effectiveness is reduced to practically nothing as the vibrating air has a clear path to carry the sound from one place to another. A noise source in one room can also send air pressure waves which induce vibration in one side of a wall or element of structure setting it moving such that the other face of the wall vibrates in an adjacent room. The most important acoustic control method here is adding mass into the structure, such as using a heavy dividing wall, which will usually reduce airborne sound transmission better than a light one;

- Impact transmission. A noise source in one room results from the impact of an object onto a separating surface, such as a floor and transmits the sound to an adjacent room. A typical example would be the sound of footsteps in a room being heard in a room below. Acoustic control measures usually include attempts to isolate the source of the impact, or cushion it. For example carpets will perform significantly better than hard floors;

- Flanking transmission. Resultant vibrations from a noise source are transmitted to other rooms of the building usually by elements of structure within the building. For example, in a steel framed building, once the frame itself is set into motion the effective transmission can be pronounced.

Soundproofing affects sound in two different ways: noise reduction and noise absorption. Noise reduction blocks the passage of sound waves through the use of distance and intervening objects in the sound path such as walls. Noise absorption describes the irreversible transformation of vibrations of fluids and matter into thermal energy. Noise absorption involves suppressing echoes, reverberation, resonance and reflection. Absorption relies on the damping characteristics of materials. Materials can be measured by the sound absorption coefficient. The moisture level in a medium can reflect sound 
waves, significantly reducing and distorting the sound travelling through it, making moisture an important factor in soundproofing.

Coefficients:

- Sound absorption coefficient $\alpha_{s}[-]$

The sound absorption coefficient describes the ratio of occurring vibration energy and not reflected energy. If this energy is completely absorbed by material $\alpha_{s}=1$, if completely reflected $\alpha_{s}=0$. The sound absorption coefficient depends on the frequency of sound and is usually measured for $100-5000 \mathrm{~Hz}$.

- Weighted Difference level $D_{w}[\mathrm{~dB}]$

This index is defined by measuring the noise level produced on each side of a building element under test (e.g. external wall) while noise is produced on the other side (e.g. outdoors). 


\subsection{STRATEGIES TO ORGANISE FUNCTIONS WITHIN THE ENVELOPE}

Having analysed requirements and functions the envelope has to fulfil in the previous sections, the following paragraphs will discuss different strategies that have evolved to incorporate all those requirements into the envelope. They are of interest as they essentially make the envelope multifunctional. They will therefore be discussed briefly and their potential to reduce material flows will be analysed.

The three strategies describing functional organisation of the envelope are:

- Compartmentalisation

- Homogenous organisation

- Organisation in layers

Compartmentalisation is the organisation of the envelope in different functional elements that fulfil diverse requirements independently or in conjunction with each other.

Homogenous organisation is the most basic strategy and describes the use and later refinement of one single building material that fulfils as many functions as possible. It is hardly ever found in entire envelopes but mostly applies to components and even to building materials. Some of the traditional envelopes that use this strategy are quite successful in fulfilling today's requirements, while others that have been used for centuries have been outperformed by modern systems.

Another strategy is the layering of materials of different properties. By organising them in layers, synergies do occur and often even conflicting requirements can be fulfilled.

\subsubsection{COMPARTMENTALISATION}

The most evident strategy found in envelopes to organise functions is compartmentalisation or the division of labour between different elements. Probably all modern envelopes and most of the vernacular envelope types show a degree of this by being organised in elements that can react to different requirements specifically. The differentiation between openings that allow for ventilation and natural light and the wall, which give structure and privacy, is one of the most basic forms of compartmentalisation. The only envelope type coming into mind that does not show any kind of differentiation is the igloo that is made completely from snow and does not have windows.

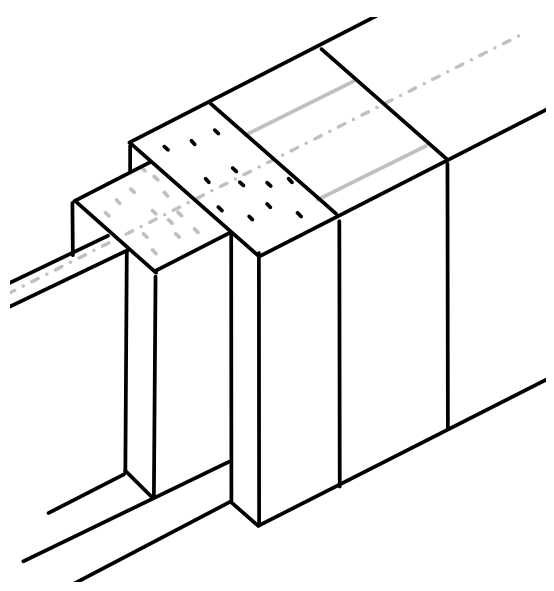

As can be seen in the illustration above, elements are organised at $90^{\circ}$ to the plane of the enclosure. The creation of synergies depends on their positioning relative to each other. Positioning windows adjacent to each other can for example reduce the amount of framing needed (refer to Figure 36). However, as the intention of specification of functional and constructional units is to organise functions 
independently, often synergies do not occur. A window for example is independent of the wall in that sense, in that it will always need some sort of a frame (as a structural support) and remains a functional unit, independent of its positioning on the wall. A classical synergistic benefit of this strategy is the creation of shade by (coming back to the example mentioned in section 1.7) the roof eaves, which could make additional sun protection in front of openings redundant.
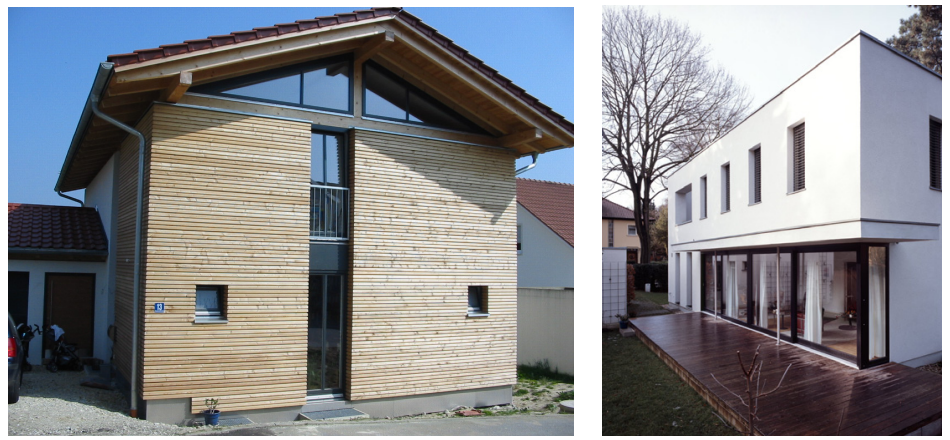

Figure 36: Compartmentalisation

windows are partly positioned independently and partly grouped together into larger units

Compartmentalisation can be seen as a way of organising contradicting requirements, such as structural support and flexibility (tent). It also is a superordinate strategy that incorporates the other strategies that will be described below. It occurs at the higher level (the envelope as entity), while the other two strategies are found in the elements of the envelope. Therefore an envelope can show compartmentalisation with both homogeneous elements and layered elements.

\subsubsection{HOMOGENEOUS ORGANISATION}

One strategy to create a multifunctional element is either to use a material that has properties that can fulfil many functions or to homogeneously mix different materials with dissimilar functions. The traditional load-bearing wall for example answers requirements for strength, water tightness and thermal insulation by being very thick. There is no separation between the wall and the structure. This strategy has many advantages as construction is simple and can often be done by non-professionals. Therefore it is probably one of the oldest strategies and can be found in traditional building typologies such as the straw and clay hut of central Africa,

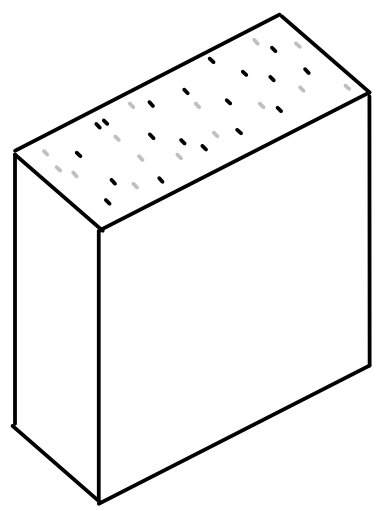
but also in contemporary reinforced concrete structures.
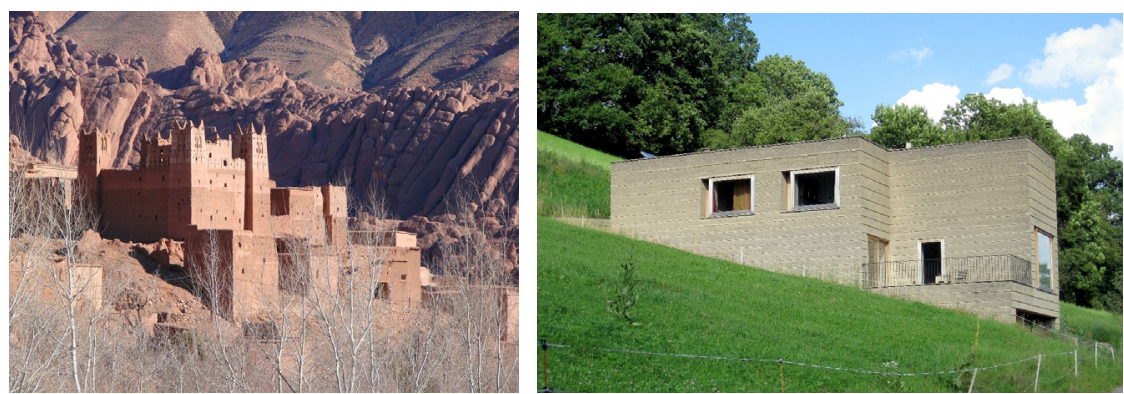

Figure 37: Traditional clay building (Kasbah in Morocco) and modern clay house in Austria 
The performance of the facade is determined by the properties of the materials used and the overall thickness which allows for a variety of materials to be used. One aspect that needs consideration when homogenous elements are chosen to fulfil functions in envelopes is that the coefficients of appropriateness of each of these functions are inevitably interconnected. This can under certain conditions lead to a suboptimal performance in certain aspects, or result in higher resource use as will be illustrated in the following example. In section 1.11.1.1, the compressed straw panels used in the case study are analysed in detail. These provide thermal insulation, structure, and air, water and vapour control at the same time. The required thickness is dependent on the load they have to carry as well as the insulation level they have to provide. Therefore, the ideal dimension to fulfil one requirement cannot be reached without interfering with the other.

On the other hand, the structural straw panel is a great example of the potential of homogenous organisation to reduce resource use as its structural layout makes it very strong compared to systems that are compartmentalised. Homogenous organisation leading to a decrease in resource use depends on the functions that have to be fulfilled as well as the elements and materials used.

\subsubsection{ORGANISATION IN LAYERS}

The last strategy organises materials or elements with different functions parallel to the plain of the enclosure. Each layer fulfils one or several functions such as thermal control, air control, water control or vapour control (Lstiburek, J., 2009, p.1). Materials will be combined or layered to reach a sufficient performance. As the different elements are layered, filtering of external and internal influences is often easier to achieve than with the other strategies. Elements can, for example, be layered in accordance with their ability to resist vapour diffusion, resulting in a wall that leads vapour away from the core of the element to the outside where it can be released.

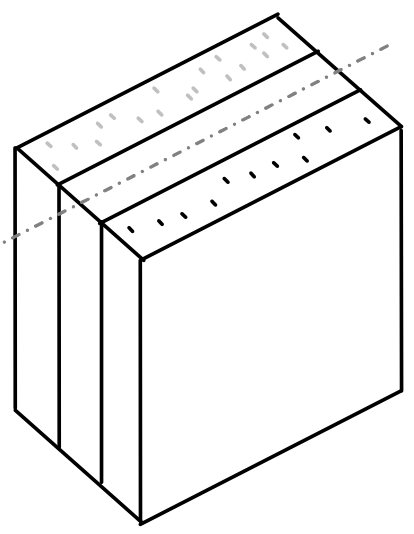

Another advantage of layering (apart from providing the opportunity to gradually reach the required performance) is that the concept can allow for flexibility, as layers can under certain conditions be moved. The classic example for this is the opening where different flexible and fixed layers help to modify the parameters such as sunshine, wind and temperature as illustrated in Figure 38. Curtains and blinds can be drawn to modify views and privacy. 


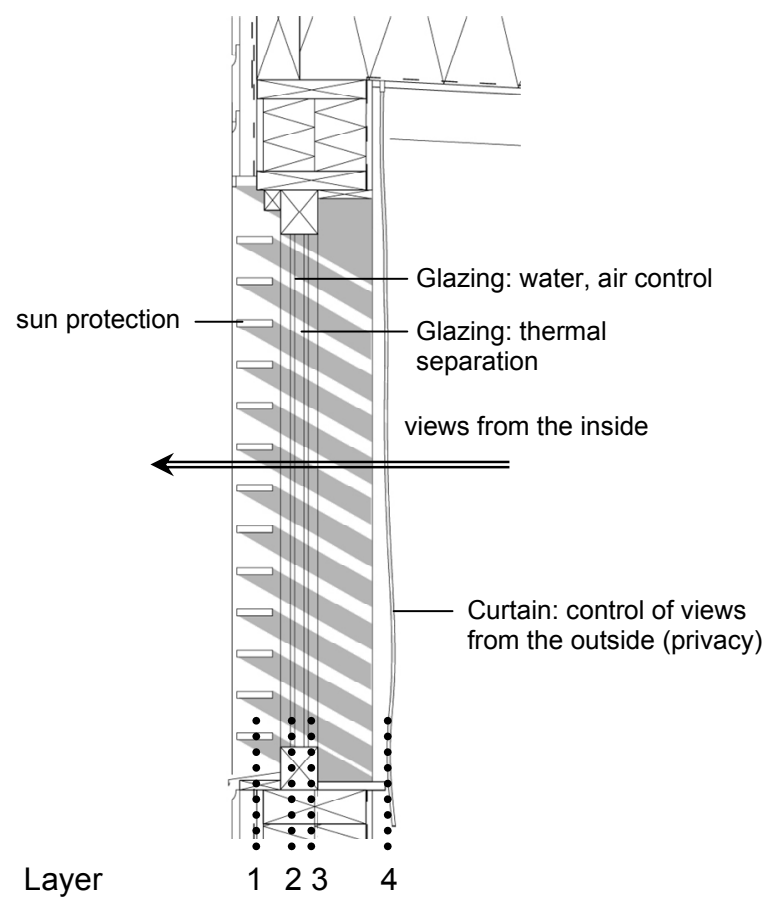

Figure 38: The opening as an example of filtering internal and external influences

Organising elements in layers can create synergies that can lead to a significant reduction in resource use. The green roof used in the case study (refer to section 1.11.1.2) is one example where synergistic effects considerably reduce the amount of overall resource use. The synergies that occur can be similar to the reductions reached in compartmentalisation where components share supporting structural elements, or can be created by the positive impact of one element's performance on another. The heat produced by the non-ventilated solar thermal heating system used in the wall case study (refer to section 1.11.1.4) for example reduces the amount of thermal insulation required and also impacts on the overall heating requirements due to the lower heat transmittance of the wall. If it were not part of the layered organisation of the wall but independently mounted on the side, it would still produce solar heat, but would create fewer benefits for the wall and would have no positive impact on the overall heat load of the building. 
PART B: CASE STUDY 


\section{REDUCING RESOURCE USE OF ENVELOPES BY INCREASING THEIR FUNCTIONALITY}

SUMMARY:

Having discussed strategies to achieve multifunctionality in building envelopes in section 1.9, this chapter sets out to measure the potential of multifunctionality to reduce the material flows associated with the construction and maintenance of building enclosures by comparing a conventional (but still multifunctional) envelope with one where additional functions are included (called multifunctional envelope hereafter). Including additional functions such as production of electricity, heating or water retention into the envelope increases both the functionality and in most cases the initial resource use of the enclosure. Therefore a life-cycle-wide material intensity analysis was carried out for both envelopes to see how this initial resource increase impacted on the absolute resource use over the service life. The chapter is organised in four main sections. First the methodology of the material intensity analysis (MAIA) is discussed and general parameters of the case study such as location and geometry of the envelope are established. This is followed by a description of the elements and materials used in the two envelopes and their functions. A third aspect discussed is the heat load of the envelopes and the resulting requirement for space heating and electricity. The last section describes the results of the MAIA and discusses the findings. 


\subsection{MATERIAL INTENSITY ANALYSIS- ASPECTS AND PARAMETERS}

In order to assess the potential of multifunctionality in reducing resource use in building envelopes a material intensity analysis was carried out comparing two envelopes. In the first one many additional functions and multifunctional elements were imbedded (hereafter called the multifunctional envelope), while the second (conventional envelope) was comparable in design and shape but fulfilled no additional functions to the usual requirements and was made from ordinary materials. The data needed to carry out the material intensity analysis was gathered from two sections through imaginary building envelopes with similar geometries, which were designed as part of this thesis. Figure 39 shows the two envelopes compared schematically. A set of drawings can be found in Appendix 1.14., p.159.

Envelope $\mathrm{A}$ is a multifunctional envelope incorporating several "additional" functions. It features an extensive green roof and a green wall, where vegetables can be grown, has photovoltaic elements imbedded into the glazing of the windows providing both shading and electrical energy and a solar water heating system integrated into one facade that acts as additional insulation and provides hot water. Furthermore, the main structure of the envelope consists of structural insulated panels (SIPS) made from compressed straw, which fulfils both structural and insulation purposes. As straw is a waste-product of agriculture, which is currently often burned or transported to land-fills (Mc Leod, B., 2004, p. 205), the envelope takes on the additional function of a waste sink.

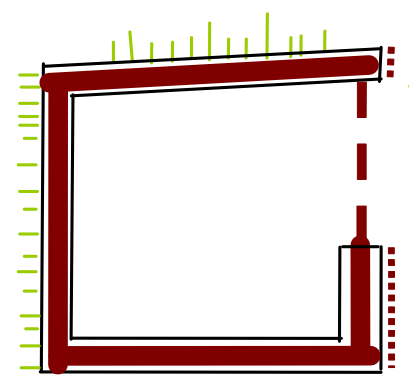

A

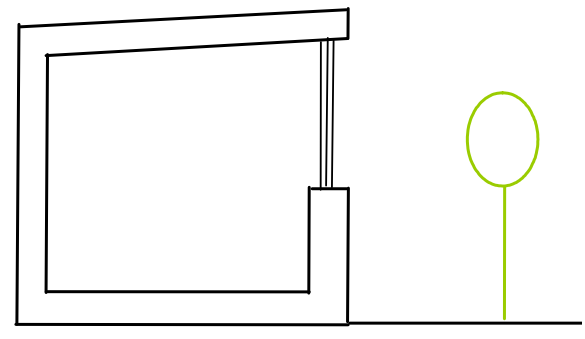

B

Figure 39: Multifunctional and conventional envelope slices that were compared in the case study

All these features can be found in green architecture and are commonly used, although they often occur as additions to the envelope, rather than being integrated within it. Various manufacturers and groups have promoted their use citing their environmental benefits, mostly without having assessed the life-cycle impact of these features (Cantor, L., 2008, p.18), (Dunnett, N., Kingsbury, N., 2004). Most manufacturers stress certain aspects of their product's performance (e.g. negative $\mathrm{CO}_{2}$ footprint or energy-efficiency) and often do not see the need for a full life-cycle wide assessment for the material flows triggered by their "green" products. Therefore a material intensity analysis seemed an essential step for this research as it can look at these elements more broadly and try to establish their full impact.

Envelope B is a well insulated "conventional" light-weight envelope using timber both as a cladding material and for structural purposes. In this set-up the insulated timber frame construction is clad with timber weatherboards fixed to timber cavity battens. Both envelopes have a slightly inclined roof $\left(2.9^{\circ}\right.$ pitch), resulting in a larger façade area facing the sun at noon. 
Table 6 summarizes the different components and services of the two envelopes.

Table 6: Components and services of the two envelopes

\begin{tabular}{|c|c|c|}
\hline & Envelope $\mathrm{A}$-multifunctional & Envelope B -conventional \\
\hline Floor & $\begin{array}{l}\text { Structural insulated panel, straw, on concrete } \\
\text { strip foundation }\end{array}$ & $\begin{array}{l}\text { Timber joisted, insulated on concrete } \\
\text { strip foundation }\end{array}$ \\
\hline Wall & $\begin{array}{l}\text { Vertical garden and non-ventilated solar ther- } \\
\text { mal heating facade producing hot water for } \\
\text { taps, shower and space heating }\end{array}$ & Timber frame, weatherboard \\
\hline Windows & $\begin{array}{l}\text { Insulated, double glazed windows, timber } \\
\text { frame, photovoltaic elements, thin-film ASI }\end{array}$ & $\begin{array}{l}\text { Insulated, double glazed windows, timber } \\
\text { frame }\end{array}$ \\
\hline Roof & $\begin{array}{l}\text { Roof pitch } 2.9^{\circ} \text {, Extensive Green Roof with } \\
\text { weed and grass vegetation on structural insu- } \\
\text { lated panel, straw, not accessible }\end{array}$ & Roof Pitch $2.9^{\circ}$, zinc clad \\
\hline
\end{tabular}

\subsubsection{MATERIAL INPUT PER SERVICE UNIT (MIPS)}

The Material Intensity Analysis (MAIA) presents a comparison of the quantitative material flows created directly or indirectly by the two different envelopes during their life-span. The analysis was carried out using the Material Input Per Service unit (MIPS) concept described briefly in section 1.4.3.3.3, p.30. The MIPS concept is based on the fact that "...there is a close relationship between resource use and environmental impacts and therefore the evaluation of resource use (and the related hidden flows) can be considered an aggregated indirect measure of ecosystem disturbance. The accounting of material flows, which are diverted from their natural pathways to support modern societal metabolism, is [therefore] of key importance for the evaluation of the related impacts on the environment, both on a local and a global scale." (Bargigli,S. et al., 2005, p.353).

A material intensity analysis enables comparison of the potential of products and materials to impact on and change the environment. Therefore all the material input, raw and refined, that has to be sourced from the environment or has been moved (stone, sand, earth) in order to produce a certain industrial product will have to be considered and summarised. This includes actions such as cutting trees or pumping off ground water that are only undertaken in order to retrieve a resource, or materials that are used to provide infrastructure or transport. Furthermore the proportionate amount of resources that are used to produce, to package, to maintain, to use, to repair, to recycle and to dispose of the analysed product also have to be taken into account. The sum of all these material flows, which are triggered by the final product or the service, represents the ecological rucksack of the product (or indirect resource use), which equals its material intensity (MI) minus the weight of the product (direct resource use). 
The classic MIPS analysis, described in detail by Ritthoff, M. et al. (2002) and by Bargigli et al. (2005, p.353), starts with the definition of a service unit to be compared.

The basic service unit of this material intensity analysis can be defined as a two metre wide building slice with the exact geometrical dimensions described in section 1.10.3.2, that provides shelter from climate, and fulfils the central European standards of thermal insulation, air tightness and protection against moisture. The means to provide these services differ for the two analysed envelopes. One uses a multifunctional approach, one a more conventional.

In the second step the amount of materials used for all the components of the product or service are established. Table 7 and Table 8 reflect the information required to analyse the material intensity of the multifunctional envelope and of the conventional envelope respectively. All elements and materials used in the case studies will be described in detail in section 1.11. For the analysis, the composition of all elements, their quantity, service life, operation energy requirements and materials used had to be established. A list of items can be found in Appendix 1.17. 
Table 7: Required data to calculate the Material Intensity of the multifunctional envelope

\begin{tabular}{|c|c|c|}
\hline Elements & Required information & Units \\
\hline green roof & $\begin{array}{l}\text { composition } \\
\text { retention capacity } \\
\text { amount of storm water re- } \\
\text { ceived }\end{array}$ & $\begin{array}{l}\text { dimensions, material, thickness, } \\
\text { density } \\
\text { litre per } \mathrm{m}^{3} \\
\text { litre per } \mathrm{m}^{2}\end{array}$ \\
\hline roof element & composition & $\begin{array}{l}\text { dimensions, material, thickness, } \\
\text { density }\end{array}$ \\
\hline roof parapet & composition & $\begin{array}{l}\text { dimensions, material, thickness, } \\
\text { density }\end{array}$ \\
\hline wall element & composition & $\begin{array}{l}\text { dimensions, material, thickness, } \\
\text { density }\end{array}$ \\
\hline $\begin{array}{l}\text { thermal solar collector } \\
\text { collector }\end{array}$ & $\begin{array}{l}\text { composition of absorber } \\
\text { heat carrier } \\
\text { absorber } \\
\text { energy gains of collector }\end{array}$ & $\begin{array}{l}\text { dimensions, material, thickness, } \\
\text { density } \\
\text { amount, material, density } \\
\text { dimensions, material, thickness, } \\
\text { density } \\
\text { amount }\end{array}$ \\
\hline primary heating system & $\begin{array}{l}\text { components, position, connec- } \\
\text { tion }\end{array}$ & $\begin{array}{l}\text { dimensions, material, thickness, } \\
\text { density, energy requirements }\end{array}$ \\
\hline wall behind collector & as wall element & \\
\hline $\begin{array}{l}\text { windows } \\
\sim \text { glazing } \\
\sim \text { frame } \\
\sim \text { photovoltaic element }\end{array}$ & $\begin{array}{l}\text { composition } \\
\text { composition } \\
\text { composition }\end{array}$ & $\begin{array}{l}\text { dimensions, material, thickness, } \\
\text { density } \\
\text { dimensions, material, thickness, } \\
\text { density } \\
\text { dimensions, material, thickness, } \\
\text { density }\end{array}$ \\
\hline $\begin{array}{l}\text { green wall } \\
\sim \text { substructure } \\
\sim \text { panels } \\
\sim \text { substrate } \\
\sim \text { vegetation } \\
\sim \text { pump and irrigation }\end{array}$ & $\begin{array}{l}\text { composition } \\
\text { composition } \\
\text { composition } \\
\text { retention capacity } \\
\text { composition } \\
\text { irrigation requirements } \\
\text { composition }\end{array}$ & $\begin{array}{l}\text { dimensions, material, thickness, } \\
\text { density } \\
\text { dimensions, material, thickness, } \\
\text { density } \\
\text { material, dimensions, density } \\
\text { litre per } \mathrm{m}^{3} \\
\text { material, dimensions, density } \\
\text { litre per } \mathrm{m}^{3} \\
\text { dimensions, material, thickness, } \\
\text { energy requirements }\end{array}$ \\
\hline floor element & composition & $\begin{array}{l}\text { dimensions, material, thickness, } \\
\text { density }\end{array}$ \\
\hline $\begin{array}{l}\text { remaining energy requirements } \\
\sim \text { heating } \\
\text { hot water } \\
\text { -electricity }\end{array}$ & energy carrier & efficiencies, quantities \\
\hline
\end{tabular}


Table 8: Required data to calculate the Material Intensity of the conventional envelope

\begin{tabular}{|c|c|c|}
\hline Elements & Required info & Units \\
\hline roofing & $\begin{array}{l}\text { composition } \\
\text { amount of storm water received }\end{array}$ & $\begin{array}{l}\text { dimensions, material, thickness, } \\
\text { density } \\
\text { litre per } \mathrm{m}^{2}\end{array}$ \\
\hline $\begin{array}{l}\text { roof element } \\
\sim \text { internal finish }\end{array}$ & $\begin{array}{l}\text { composition } \\
\text { composition }\end{array}$ & $\begin{array}{l}\text { dimensions, material, thickness, } \\
\text { density } \\
\text { dimensions, material, thickness, } \\
\text { density }\end{array}$ \\
\hline $\begin{array}{l}\text { wall element } \\
\sim \text { internal finish }\end{array}$ & $\begin{array}{l}\text { composition } \\
\text { composition }\end{array}$ & $\begin{array}{l}\text { dimensions, material, thickness, } \\
\text { density } \\
\text { dimensions, material, thickness, } \\
\text { density }\end{array}$ \\
\hline $\begin{array}{l}\text { external cladding } \\
\sim \text { substructure }\end{array}$ & $\begin{array}{l}\text { composition } \\
\text { composition }\end{array}$ & $\begin{array}{l}\text { dimensions, material, thickness, } \\
\text { density } \\
\text { dimensions, material, thickness, } \\
\text { density }\end{array}$ \\
\hline $\begin{array}{l}\text { window } \\
\sim \text { glazing } \\
\sim \text { frame }\end{array}$ & composition & $\begin{array}{l}\text { dimensions, material, thickness, } \\
\text { density } \\
\text { dimensions, material, thickness, } \\
\text { density }\end{array}$ \\
\hline floor element & composition & $\begin{array}{l}\text { dimensions, material, thickness, } \\
\text { density }\end{array}$ \\
\hline $\begin{array}{l}\text { energy requirements } \\
\sim \text { heating } \\
\sim \text { hot water } \\
\text { electricity }\end{array}$ & energy carrier & efficiencies, quantities \\
\hline
\end{tabular}

Apart from the quantification of all used materials, it is further necessary to establish the indirect energy requirements of the two envelopes. As will be seen, the two envelopes have a different insulation profile and the multifunctional envelope produces electrical energy as well as hot water and supports space heating, therefore the entire energy consumption during their service life has to be taken into account to allow meaningful comparison (refer to Appendix 1.16.1and 1.16.2.).

The next step is that the material intensity of all used materials will have to be established by looking at the production chain of all components or, if the data is not obtainable, an estimate has to be made on the basis of similar known products or materials. Another option is to use the already published data of Ml factors as will be discussed below (section 1.10.2.1). The published data is very valuable for complex case studies with many different components as the very time consuming research into all the different inputs during production and manufacture can be omitted.

A list of the relevant material intensities of the materials used can be found in Appendix 1.17, p.177.

The final step before drawing a conclusion is to categorise the results according to the five input groups:

- Abiotic materials,

including all anthropologically caused material flows of non-renewable materials such as ore, minerals, fossil fuels and their overburden. Hence, this category equals waste or by-products in other types of analysis. 
- Biotic materials,

including all flows of biotic materials in agriculture and forestry, or biotic resources taken from nature. Domestic animals do not count towards this category as they are defined as not forming part of the natural environment anymore (due to industrialised meat and dairy production) and are accounted for via their inputs (animal feed).

- Soil movement,

including erosion or mechanical earth movement caused by mining, agriculture, infrastructure etc.

- Water,

including both the use of ground or surface water for things like cooling and industrial use, as well as storm water run off.

- Air,

including all the oxygen that is changed through chemical processes. The amount of air is an indirect measure of the potential transformation of formerly solid matter such as coal into exhaust gases discharged into the air. This parameter is therefore closely linked to those processes that produce $\mathrm{CO}_{2}$. The used energy carrier and energy inputs can be recorded separately to allow the calculation of the overall energy input.

In most of the material intensity analysis only the three categories of abiotic material flows, air and water play a significant role (Schmidt-Bleek, F., Manstein, C., 1999, p.19). The results of the MAIA can be found in section 1.13 , p.121.

\subsubsection{DATA COLLECTION}

\subsubsection{AVAILABILITY OF MIPS DATA}

While there is data available of embodied energy and embodied $\mathrm{CO}_{2}$ for many building materials used in New Zealand, for example (Baird, G. et al, 1997) and (Alcorn, A. 1998), Material Intensity (MI) data has so far not been collected. However, MI data has been widely published in Europe (especially in German speaking countries) for example by (Bergmann, I., Weiss, W., 2002), (Schmidt-Bleek, F., Manstein, C., 1999), (Wuppertal Institute for Climate, Environment and Energy, 2003) and was used in this case study. This influenced the assessed material flows triggered by the different components of the envelopes, as for example wheat straw is more abundant in central Europe than timber and therefore requires less transportation than it would in New Zealand. As Austrian and mainly German data was used for the material intensity analysis, other underlying parameters such as building geometry and size were subsequently adapted to European standards in order to ensure the consistency of the case studies. Therefore both the envelopes and the material intensity of their components reflect local building standards and product intensities and are not immediately transferable to another climate or location, where transportation, energy mix, or simply production processes are different. However, an attempt was made to design envelopes that could be found in any OECD country using 
common construction methods and globally used materials. This would allow for a relatively uncomplicated new calculation for other countries, such as New Zealand, once more international MI-data becomes available. A summary of all the Material Intensities of the products and elements used for this case study can be found in section 1.17 .

\subsubsection{SETTING PARAMETERS}

The required data (material quantities) for the material intensity analysis was collected from the two alternative envelopes. Apart from the basic geometry and materials selection, a few additional parameters had to be defined in order to establish both the energy requirements (heating or cooling) of the internal spaces the two envelopes enclose and also the potential passive or active energy gains, especially from the multifunctional envelope. The two envelopes were presumed to be built in Graz, Austria and hence climatic data from Graz was used to calculate the heating requirements according to the Austrian standard (OIB, 2007). The location was mainly chosen for the availability of data from a solar heating test facility in Graz of the AEE, Austrian Institute for Sustainable Technologies. This institute has done extensive research on integrated solar heating elements and has also published a MAIA of several integrated solar heating systems (Bergmann, I., Weiss, W., 2003). As this presented an opportunity to add some real-life measurements to this case study, their data was used and modified according to the geometry of the case study at hand. Additionally, Graz does have a relatively high (compared to New Zealand) temperature difference between inside and outside, defined as $12^{\circ} \mathrm{C}$ outside and $20^{\circ} \mathrm{C}$ inside by the Austrian building code as Table 9, p. 82 shows. This was deemed interesting as the full potential of the multifunctional envelope to help with adaptation to harsh climates could be tested.

\subsubsection{CLIMATE AND TEMPERATURE}

Table 9 summarises the climatic data for the location as defined by the Austrian Institute of Construction Engineering (OIB). Heating degree days are defined as the sum of the daily measured temperature difference between inside temperatures $T_{i}$ and normalised outside temperature $T_{a}$ during the heating period which lasts for 211 days in Graz.

Table 9: Climatic data for Graz, Austria (OIB,1999, p. 26, Energiesparhaus, 2009)

\begin{tabular}{|l|l|}
\hline Height above sea level $[\mathrm{m}]$ & 353 \\
\hline Defined Inside temperature $\mathrm{T}_{\text {int }}\left[{ }^{\circ} \mathrm{C}\right]$ & 20 \\
\hline Defined outside temperature $\mathrm{T}_{\mathrm{ext}}\left[{ }^{\circ} \mathrm{C}\right]$ & -12 \\
\hline Temperature difference $\Delta \mathrm{T}[\mathrm{K}]$ & 32 \\
\hline Heating degree days $\mathrm{HGT}_{-12 / 20}[\mathrm{~K} \cdot \mathrm{d}]$ & 3515 \\
\hline
\end{tabular}




\begin{tabular}{|l|l|}
\hline Heating days $\mathrm{HT}_{12}[\mathrm{~d}]$ (Heating period starts when external temperature drops below $\left.12^{\circ} \mathrm{C}\right)$ & 211 \\
\hline Normalised external temperature $\left.\mathrm{T}_{\mathrm{Ne}}{ }^{\circ} \mathrm{C}\right]$ & -12 \\
\hline Average temperature $\mathrm{T}_{\mathrm{av}}$ & 3.34 \\
\hline Solar radiation during heating period on a vertical south-facing plane $\mathrm{I}_{\mathrm{s}}\left[\mathrm{kWh} / \mathrm{m}^{2} \mathrm{a}\right]$ & 456 \\
\hline Solar radiation during heating period on a vertical north-facing plane $\mathrm{I}_{\mathrm{N}}\left[\mathrm{kWh} / \mathrm{m}^{2} \mathrm{a}\right]$ & 171 \\
\hline Solar radiation during heating period on a vertical east or west-facing plane $\mathrm{I}_{\mathrm{o} / \mathrm{w}}\left[\mathrm{kWh} / \mathrm{m}^{2} \mathrm{a}\right]$ & 268 \\
\hline Solar radiation during heating period on a horizontal plane $\mathrm{I}_{\mathrm{h}}\left[\mathrm{kWh} / \mathrm{m}^{2}\right.$ a] & 440 \\
\hline Global radiation [kWh/m $\left.{ }^{2} \mathrm{a}\right]$ & 1300 \\
\hline Average annual rainfall [mm] & 867 \\
\hline Average annual sunshine hours [h] & 1900 \\
\hline Ground reflection (albedo), grass and gravel [-] & 0.2 \\
\hline Ground reflection (albedo), snow coverage in residential area [-] & 0.6 \\
\hline
\end{tabular}

\subsubsection{SITE AND BUILDING GEOMETRY}

Figure 40 illustrates the general setup for both envelopes. They are orientated east-west on a hypothetical site that is presumed to be flat, and free of any objects that give shelter from the wind or cast shadows on the envelope. The windows are oriented to the South, maximising solar gains for the photovoltaic panels and the solar heating in the case of the multifunctional envelope.

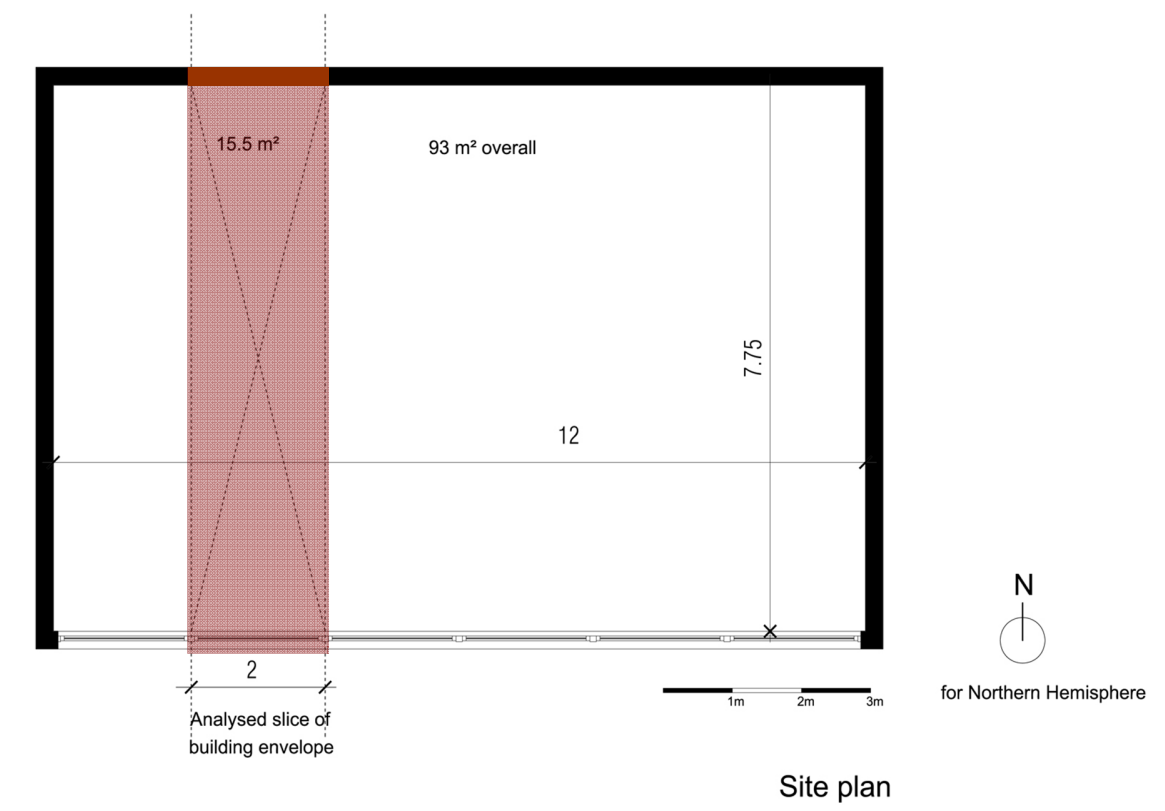

Figure 40: Site plan for the two envelopes

indicating the position of the analysed slice of the enclosure as well as the orientation of the buildings 
For the Material Intensity Analysis only a 2 metre wide slice of the envelope was analysed (indicated in pink). Hence, the east and west facing walls were neither defined nor incorporated in the material intensity analysis. It was felt that this approach would simplify the design process as corner details would be excluded from the analysis and would make both data gathering and interpretation of the results more straight forward without compromising the result too severely. Furthermore, the results thereby became independent of the overall size of the building, as they clearly indicate the resource use of a 2 metre wide section of the envelope and do not represent a percentage of a fixed building size. However, for heat loss calculations it was presumed that the east and west facing walls would have the same configuration as the north facing wall in the case of the conventional envelope. For the multifunctional envelope it was presumed, that the structural insulated panel would be clad by a ventilated plastic sheet, similar to the details of the straw house in Eschenz, Figure 41, p.88, described below.

Table 10 summarises the geometric data of the envelopes. Both envelopes have the same internal geometry with a room width of 7.75 metres and a ceiling height of $2.55 \mathrm{~m}$ to $2.95 \mathrm{~m}$ in order to facilitate the comparison of heating requirements (refer to set of drawings in Appendix 1.14). The dimensions were chosen to reflect typical building dimensions, although the ceiling height is higher than the Austrian required minimum of $2.3 \mathrm{~m}$. This takes into account the fact the case study envelope is an unfinished carcass and allows for floor construction or suspended ceilings that might be required to create a service area to run cables etc.

Table 10: Geometric data and services of the two metre wide section of the two envelopes

\begin{tabular}{|c|l|l|}
\hline & \multicolumn{1}{|c|}{ Envelope A -multifunctional } & Envelope B -conventional \\
\hline Internal width & $7.75 \mathrm{~m}$ & $7.75 \mathrm{~m}$ \\
\hline Internal length & $2 \mathrm{~m}$ (slice) $/ 12 \mathrm{~m}$ overall & $2 \mathrm{~m}($ slice $) / 12 \mathrm{~m}$ overall \\
\hline Floor Area & $15.5 \mathrm{~m}^{2} / 93 \mathrm{~m}^{2}$ overall & $15.5 \mathrm{~m}^{2} / 93 \mathrm{~m}^{2}$ overall \\
\hline Internal Height & $2.55 \mathrm{~m}-2.95 \mathrm{~m}$ & $2.55 \mathrm{~m}-2.95 \mathrm{~m}$ \\
\hline Internal Volume & $42.56 \mathrm{~m}^{3} / 255.36 \mathrm{~m}^{3}$ overall & $42.56 \mathrm{~m}^{3} / 255.36 \mathrm{~m}^{3}$ overall \\
\hline Window area & $2.62 \mathrm{~m}^{2} / 15.71 \mathrm{~m}^{2}$ overall & $2.62 \mathrm{~m}^{2} / 15.71 \mathrm{~m}^{2}$ overall \\
\hline
\end{tabular}

The two envelopes enclose an area of $93 \mathrm{~m}^{2}$ which gives them an internal volume of $255.36 \mathrm{~m}^{3}$. Again this size was chosen to reflect roughly the dimensions of an average house in central Europe: Switzerland (99 $\mathrm{m}^{2}$ in 2000), Germany (89 $\mathrm{m}^{2}$ in 2002) and Austria $\left(91 \mathrm{~m}^{2}\right.$ in 2006), (Wala, T., Lechner, J., 2006, p.49), (NZZ, 2008). This might be on the small side for other OECD countries such as Australia or the US, where average houses are closer to $230 \mathrm{~m}^{2}$ (NAHB, 2008) (Australian Bureau of Statistics, 2009). However, envisaging responsible resource use management in the future, the central European average seems more desirable where single family houses are concerned. This decision was also supported by the statement of the American National Association of Home builders which noted that the economic recession and higher energy prices are currently reversing the trend towards bigger 
houses in the USA and are predicted to continue to do so (Koch, W., 2009). Furthermore, the chosen size of $93 \mathrm{~m}^{2}$ seemed ideal for flexibly accommodating either a family or a single person, since the current average space per person in the USA and Australia is roughly $85 \mathrm{~m}^{2}$ (Hamilton, C., 2005, p. 17), compared to $38.8 \mathrm{~m}^{2}$ in Austria ( IFS, 2006).

\subsubsection{SERVICE LIFE}

The resource use of the two envelopes was calculated for a period of 60 years. Table 11 states the service life of the major components of the two envelopes and indicates where this data was sourced. Some of the specific life span information is also discussed below in section 1.11.

Table 11: Life span of the major components of the envelope in years. The italic numbers indicate a life span estimated by the author.

\begin{tabular}{|c|c|c|c|}
\hline \multicolumn{2}{|l|}{ Element } & Multifunctional envelope & Conventional envelope \\
\hline \multicolumn{2}{|l|}{ Roof } & $100^{*}$ (extensive) & $80^{*^{2}}$ \\
\hline \multicolumn{2}{|l|}{ Wall } & 60 & 60 (repaint every 5 years) \\
\hline \multicolumn{2}{|l|}{ Floor } & 80 & 80 \\
\hline \multicolumn{2}{|c|}{ PV-Elements/ window } & $20^{* 3}$ & $25^{*^{4}}$ \\
\hline \multicolumn{2}{|c|}{ Window frames } & 20 & 25 \\
\hline \multirow[t]{3}{*}{ Green wall } & PE panel & $15^{*^{5}}$ & - \\
\hline & $\begin{array}{l}\text { Aluminium/stainless } \\
\text { steel }\end{array}$ & $20^{* 6}-25$ & - \\
\hline & Felt & 10 & - \\
\hline \multicolumn{2}{|c|}{ Solar thermal heating elements } & $20 *^{7}$ & - \\
\hline
\end{tabular}

$\begin{array}{llll}* & \text { (Minke, G., 2006, p.86) } & { }^{*} 5 & \text { (Peryman, T., 01.07.2009) } \\ { }^{*} 2 & \text { (Hegger et al., 2005, p. 131) } & { }^{*} 6 & \text { (Eichmeyer, H., 1996, p.14) } \\ { }^{* 3} & \text { (Mercaldo, L. et al., 2009, p.1840) } & { }^{* 7} & \text { (Bergmann, I., Weiss, W., 2002, p. A 74) } \\ { }^{*} 4 & \text { (Kötz, D., 2009, p.8) } & & \end{array}$




\subsubsection{GENERAL CUT-OFF CRITERIA AND SYSTEM BOUNDARIES}

Clearly defined boundaries that constrain data gathering and analysis are critically important in comparative case studies. Results depend directly on boundary definition, which also determines whether the results may be compared with those of other studies. This study included data for raw material extraction and processing (for both product and process materials), transporting processed materials to manufacturing facilities, manufacturing and use. As the material intensities of most elements of the envelope were retrieved from literature and were hence not product-specific, the manufacturing location could not be established more specifically than by country (Wuppertal Institute, 2003-2009), (Schmidt-Bleek, F., Manstein, C., 1999), (Bergmann, I., Weiss, U., 2002). Therefore, the transport of all elements to the fictitional building site in Graz was excluded from the calculation.

All quantities were established on the basis of the $2 \mathrm{~m}$ wide envelope section which represents a $6^{\text {th }}$ of the entire building, described in section 1.10.3.2 , p.83. Electrical energy requirements, heating and hot water provision were first calculated on the basis of the entire envelope and the presumed number of inhabitants and then divided by 6 in order to match with the envelope slice.

As the two case studies consist of many different elements and several options will be presented and compared, boundaries, assumptions and scope will be described in each section of 1.13 separately and in more detail.

Conventions defined by the Wuppertal Institute for Climate, Environment and Energy concerning the Material intensities of products were respected (Schmidt-Bleek, F. et al., 1998). 


\subsection{ELEMENTS, MATERIALS AND FUNCTIONS}

Having discussed the general parameters of the two case studies, the two case studies will now be presented independently and their elements described in more detail.

\subsubsection{THE MULTIFUNCTIONAL ENVELOPE}

For the multifunctional envelope elements and materials were chosen that could deliver additional services, were globally available and that were claimed to be environmentally superior to their alternatives. The decision which product to choose was often a process of trial and error as some systems that seemed preferable at first, revealed flaws in terms

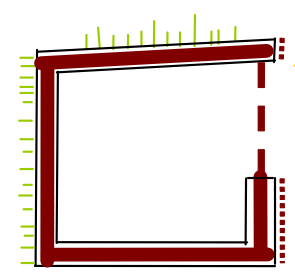
of functionality or had a very high life-cycle resource use compared to comparable products. Where appropriate, alternatives will be presented to make the decision making process more comprehensible.

\subsubsection{COMPRESSED STRAW FIBRE ELEMENTS}

Compressed straw fibre elements are an example of the organisation of several functions in a homogenous element (refer to section 1.9.2). Highly synergetic, these panels provide structural and insulating functions and are resistant to water and vapour. The following section will describe their performance in more detail.

The walls, flooring and the roof of the multifunctional envelope were all made from structural compressed straw panels which did not need a secondary structural system. Straw panels seemed to be a good alternative to traditional timber framed construction, as timber, although a renewable resource has a regrowth rate in decades and global demand is so high that it is sourced at unsustainable rates, causing loss of habitat both for wildlife and people (refer to Figure 1). Even the chipped wood used for many board and panel products, which is essentially a by-product of the timber industry, is not available in sufficient amounts due to the increasing use of timber in paper production and construction worldwide (Hayes, M., 2009). The use of straw in contrast seems to bring both environmental and social benefits, as it can help reduce the environmentally damaging burning and burying of the surplus, always has to be regionally sourced as its volume makes long transport routes uneconomic and it also provides a second source of income in the agriculture sector (Wilson, A., 2005). It could therefore act as an incentive for farmers to cultivate staple foods such as rice or wheat, instead of the otherwise more lucrative crops that are used in bio-fuel production. 

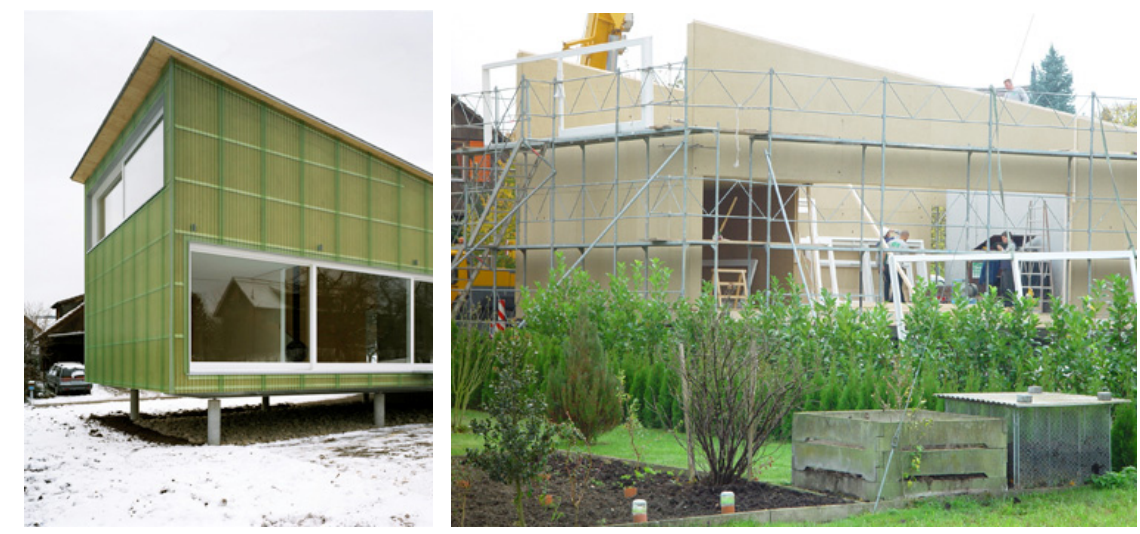

Figure 41: House in Eschenz, Switzerland

Stropoly Structural Insulated Panels completely made from straw were used and simply clad with translucent green plastic sheets

The possibility of producing straw panels and insulation made from wheat, rice or corn straw could help to make this product globally available and yet locally producible. However, the only company that produced structural insulated panels completely made from straw was the East German company Stropoly, which became insolvent in 2007. Although collecting data on this product was therefore more complicated it was decided to use the company's products, as the concept seemed globally employable and also environmentally superior to comparable products still available. In the USA for example, straw is used in the core of structural insulated panels as an insulation material, while the structural load is carried by oriented strand board facings made from timber. Although the material analysis carried out later revealed that the straw as an insulation material was the important part of the equation, the product completely made from straw was used (refer to section 1.13.1.4 for results).

The advantage of structural insulated panels over ordinary straw bale structures is that not only can they be used for walls but they can also be used as floors or ceilings without needing any secondary supporting structure such as joists, frames or rafters. This is achieved by the firm glue connection of the panels and the insulation, effectively giving the panel a structural configuration comparable to an Ibeam with the two load-bearing flanges on the outside and the connecting beam in the middle, as seen in Figure 42.
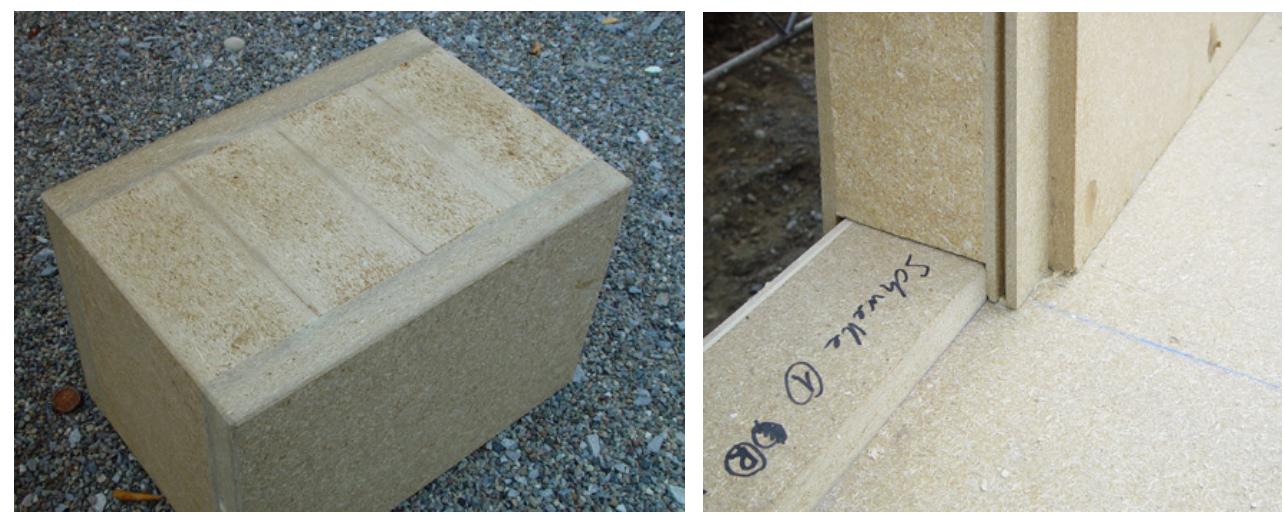

Figure 42: Sample of a Stropoly panel and a door sill and wall detail on the site

Just as for an I-beam the distance between the two panels or flanges is the most important parameter in defining the stiffness and load-bearing capacity of the overall panel.

The straw house in Eschenz, pictured above, for example, has $280 \mathrm{~mm}$ deep floor and roof panels which span $7.4 \mathrm{~m}$ without a secondary supporting system. However, in this example the actual re- 
quired depth would have been slightly thicker but the architect decided against increasing the floor panel to the structurally required depth and had additional compressed straw ribs integrated into the floor panels (Jerusalem, F., 05.07.2009), (Hegger, M.et al., 2007, p.216-218). As this measure kept the insulation layer to a reasonable thickness $(200 \mathrm{~mm})$ and prevented uneconomic resource use, it was used for the multifunctional element as well. Here it can be observed, that the great strength of this multifunctional element, being the characteristic interdependence of structural requirements and insulation levels in structural insulated panels, can possibly turn into a disadvantage in terms of resource use as it can result in use of a disproportionate amount of insulation. This is probably only critical if conventional insulation with a high material intensity, such as polyurethane foam, is chosen by the manufacturer. Table 12 summarises the basic data of the compressed straw fibre and the straw insulation.

Table 12: Data of the load-bearing compressed straw panels (Stropoly, 2007), (Hegger, M., et al., 2007, p.218).

\begin{tabular}{|c|c|c|}
\hline & Compressed straw panels & Straw insulation \\
\hline $\begin{array}{l}\text { strength, horizontal (roof or floor use) }\left[\mathrm{kN} / \mathrm{mm}^{2}\right] \\
\text { shear strength } \\
\text { compressive strength } \\
\text { tensile strength }\end{array}$ & $\begin{array}{l}8.3 \\
9 \\
1.2\end{array}$ & \\
\hline $\begin{array}{l}\text { strength, vertical (wall) }\left[\mathbf{N} / \mathbf{m m}^{2}\right] \\
\text { Shear strength } \\
\text { Drag } \\
\text { Compressive strength } \\
\text { Tensile strength }\end{array}$ & $\begin{array}{l}5.6 \\
5.6 \\
8.5 \\
4.8\end{array}$ & \\
\hline $\begin{array}{l}\text { stiffness horizontal }\left[\mathrm{N} / \mathrm{mm}^{2}\right] \\
\text { Young's modulus } \\
\text { modulus of rigidity }\end{array}$ & $\begin{array}{l}2400 \\
160\end{array}$ & \\
\hline $\begin{array}{l}\text { stiffness vertical }\left[\mathbf{N} / \mathrm{mm}^{2}\right] \\
\text { Young's modulus } \\
\text { modulus of rigidity }\end{array}$ & $\begin{array}{l}1400 \\
690\end{array}$ & \\
\hline $\begin{array}{l}\text { draft strength of point load (screws, hangers) } \\
{\left[\mathrm{N} / \mathrm{mm}^{2}\right]}\end{array}$ & 40.2 & \\
\hline density $\left[\mathrm{kg} / \mathrm{m}^{3}\right]$ & 600 & 224 \\
\hline thermal conductivity $\mathrm{k}[\mathrm{W} / \mathrm{mK}]$ & 0.12 & 0.04 \\
\hline vapour diffusion coefficient $\mu[-]$ & 300 & \\
\hline estimated life span* & $60-100$ years & $60-100$ years \\
\hline
\end{tabular}

* it was presumed that the lifespan would range between 60-100 years as this would be the presumed lifespan of the overall building. In theory the straw panels have a longer lifespan. 
Generally structural insulated panels can be used for multi-storey buildings and have a high loadbearing capacity. Calculations have shown that the chosen thickness for wall elements and the roof in this analysis could carry the weight of either an intensive or extensive green roof as well as the green wall system without needing a secondary structural supporting system such as studs or rafters. 


\subsubsection{GREEN ROOF}

In contrast to the straw elements, green roofs are examples of elements that are organised in layers. Each of them has a different form and materiality and a specific function assigned to it such as protection from water penetration, root protection, retention of standing water, plant nutrition etc. Together they create synergies with the roof structure, as they help to insulate the roof both in summer and winter. The following section analyses their benefits and describes the green roof system chosen for the case study.

Green roofs are elements that lend themselves to being used in a multifunctional case study since their functions are truly manifold. They can provide additional thermal insulation, and can decrease temperature peaks on the roof surface both in winter and summer, thereby helping extend the lifespan of the roof materials. They also retain water, increase wild life and biodiversity, bind dust, filter pollutants, sequester $\mathrm{CO}_{2}$, reduce the heat island effect of urban environments and can often be used as green space (Dunnett, N., Kingsbury, N., 2008). Although a new building of impervious materials and surroundings will still seal off surface, green roofs can partly compensate for this by creating a specific habitat which in the context of urbanised areas is often more valuable in terms of biodiversity and ecological benefits than the surface they replace. However, not all of the functions a green roof fulfils are quantitative and many do not contribute to decreasing resource use. The following section will primarily focus on those that do.

For the case study's green roof, a commonly found extensive green roof system was chosen. At first an intensive green roof was envisaged and designed as this seemed to provide the greatest service, as on top of increasing the longevity of the roof, acting as a buffer for extreme temperatures and thereby potentially reducing the urban heat-island effect, food-production could be envisaged. This would have meant applying a substrate layer of a minimum of $250 \mathrm{~mm}$ to the roof resulting in a substantial roof structure as shown in Figure 43. However, the idea of roof-top food production was abandoned and an extensive roof designed, based on Minke's suggestion that the envisaged cultivated plants would be unlikely to survive the harsh roof climate in the chosen location (mainly because of sun, wind speed and resulting water stress) and that yield would be poor as the roof did not provide shelter in the form of balustrades and hedges, as on bigger roof gardens (Minke, G., 26.05.2009). This posed questions as to the feasibility of the undertaking. As the case study was intended to be based on a functioning scenario it was felt that the additional measures that would enable a good crop, including allowing for appropriate roof access, an irrigation system, possibly water storage and wind shelter were excessive for the projected size of the case study. The second reason was that data showed that green roofs could maximise the thermal insulation of buildings if the vegetation layer was sufficiently thick and dense to provide a static air-layer (Minke, G., 2006, p.15). As cultivation of vegetables and crops would not provide this dense layer, they would diminish the thermal benefits both in summer and winter, and it seemed more appropriate to have food cultivation on the green wall system which was ventilated and hence could not provide much thermal insulation to the building. 

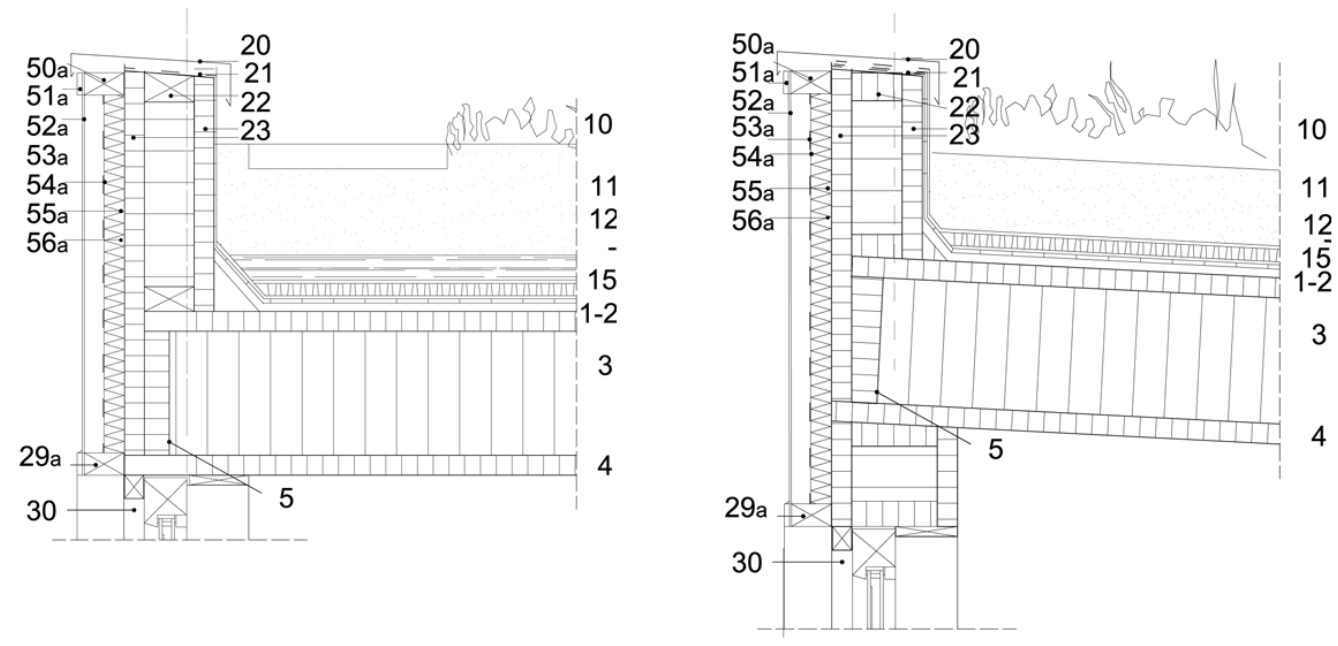

10 vegetation

$11250 \mathrm{~mm}$, substrate

12 water retention layer, stone wool

13 filter fleece, Polypropylen (PP)

14 drainage layer, Polystyrol (HIPS)

15 protective layer, Polythene (PE-HD)

Figure 43: Details of the intensive roof and extensive roof

Therefore instead of the intensive roof an extensive roof construction with a light-weight substrate of $150 \mathrm{~mm}$ was chosen. This meant the roof did not need extra irrigation and would not need access as no vegetable garden would need to be maintained. The roof could also be slightly pitched which facilitated the collection of run-off water. The envisaged vegetation layer consisted of the recommended fescues and herbs (festuca rubra genuia, ovina and commutata) to maximise thermal insulation benefits (Minke, G., 2006, p.21). Dürr indicates the thermal conductivity for a thick layer of grass is $k=0.17$ $\mathrm{W} / \mathrm{mK}$ and $\mathrm{k}=0.6 \mathrm{~W} / \mathrm{mK}$ for a moisture saturated substrate (Dürr, A., 1995).

Table 13 gives the heat transmittance of the conventional roof, the intensive green roof and the extensive green roof as shown in Figure 43.

Table 13: Comparison of overall heat load with different roof constructions

\begin{tabular}{|l|l|l|l|l|}
\hline & $\begin{array}{l}\text { Conventional } \\
\text { roof }\end{array}$ & $\begin{array}{l}\text { Multifunctional roof } \\
\text { without green roof } \\
\text { components }\end{array}$ & Intensive green roof & $\begin{array}{l}\text { Extensive } \\
\text { green roof }\end{array}$ \\
\hline $\begin{array}{l}\mathrm{U}-\mathrm{value} \\
{\left[\mathrm{W} / \mathrm{m}^{2} \mathrm{~K}\right]}\end{array}$ & 0.15 & 0.13 & 0.12 & 0.11 \\
\hline
\end{tabular}

The calculation of the heat transmittance (U-values) confirmed that the intensive green roof, while increasing the overall thickness of the roof by $320 \mathrm{~mm}$ and adding almost 4 tonnes of weight (excluding irrigation, water storage and access) to the 2 metre wide section of the envelope, only reduced the $\mathrm{U}$-value from $0.16 \mathrm{~W} / \mathrm{m}^{2} \mathrm{~K}$ to $0.14 \mathrm{~W} / \mathrm{m}^{2} \mathrm{~K}$. The extensive roof by contrast weighed 1.5 tonnes less than the intensive and reduced the overall weight by another 0.5 tonnes as, for example, the lower substrate height allowed for smaller parapets. The static $U$-value of the extensive roof was calculated at $0.13 \mathrm{~W} / \mathrm{m}^{2} \mathrm{~K}$.

The static U-value of the roof only takes the layer thickness and the thermal conductivity of the components of the roof into account. However, in reality the thermal resistance of the roof is higher than 
the static U-value suggests. In summer, the vegetation layer acts as a cooling element as water evaporates through its leaf surface. As roofs are normally not often trimmed their leaf surface is much bigger than that of other green spaces reaching $100 \mathrm{~m}^{2}$ of leaf surface per $\mathrm{m}^{2}$ roof area, outperforming public parks (with a leaf area of $10 \mathrm{~m}^{2}$ per $\mathrm{m}^{2}$ ) and other green urban areas by a factor 10 . However, in order to reach such a large leaf surface, roofs have to be planted with weeds and no sedum vegetation can be used (leaf area 1-5 $\mathrm{m}^{2}$ per $\mathrm{m}^{2}$ ) (Minke, G., 2006, p. 21). Furthermore a weed planted roof creates shade on the substrate layer and the space underneath which will not heat up as much. In winter the vegetation layer prevents heat loss through convection by sheltering the roof from wind and by reducing radiation loss from the envelope by partly absorbing heat and reflecting it back to the substrate. FigFigure 44 shows the temperature development of an extensive roof with a layer of $160 \mathrm{~mm}$ of substrate in Kassel, Germany in autumn and winter. While air temperature varies from $30^{\circ} \mathrm{C}$ to $14^{\circ} \mathrm{C}\left(44^{\circ} \mathrm{C}\right.$ difference), the difference on the surface of the substrate is only $26^{\circ} \mathrm{C}$ (from $22^{\circ} \mathrm{C}$ to -4 $\left.{ }^{\circ} \mathrm{C}\right)$.
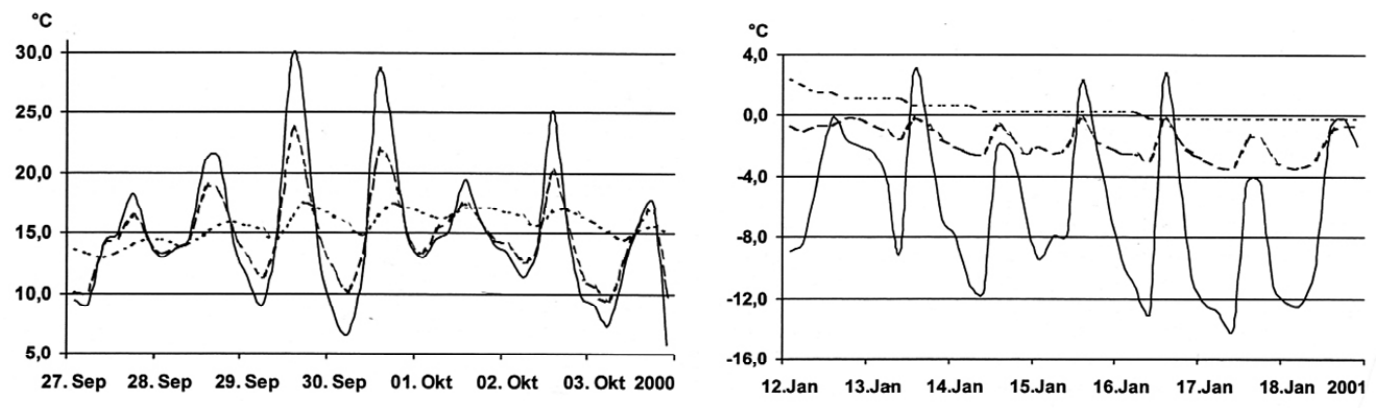

$$
\text { underneath vegetation _ _ _ underneath substrate }
$$

Temperature development on an extensive green roof

with a substrate layer of $160 \mathrm{~mm}$ in autumn and winter

Underneath the substrate this difference is further reduced to $17^{\circ} \mathrm{C}$ (from $17^{\circ} \mathrm{C}$ to $0^{\circ} \mathrm{C}$ ). Condensation of water vapour in the vegetation layer increases temperature marginally, as the condensation of 1 gram of water releases 530 calories (Minke, G., 2006, p.15). This implies that these effects combined would contribute to lower the effective U-value of the roof.

The reduced temperature maxima also have an implication for the lifespan of the roof. While EPDM roofs have a life span of roughly 50 years (Bastian, M., Dengel, U., 2004, p.3), the lifespan of extensive roofs is over 100 years, which is also influenced by the absence of UV radiation on the water proofing layers (Minke, G., 2006, p.86).

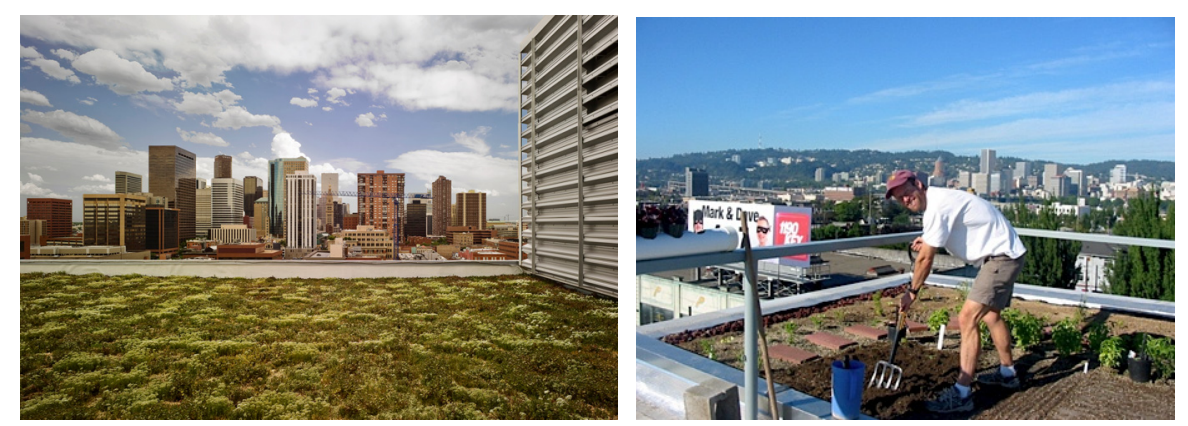

Figure 45: Extensive Roof and Intensive roof-top gardening in the USA

As storm water run-off counts towards the material intensity of the roof, it is also important to note that an extensive roof can retain most of the annual precipitation. According to the German standard (DIN 
1986, part 2) it can be assumed that a layer of substrate deeper then $100 \mathrm{~mm}$ will retain and evaporate $70 \%$ of the rainfall compared to $0 \%$ for most of the conventional roofs. Dürr states that a roof with a $200 \mathrm{~mm}$ substrate layer can retain 90 litres per square metre (Dürr, A., 1995, p.39). This is the equivalent of almost one and a half month's average precipitation in Graz. However, retention capacity varies from winter $(40-50 \%)$ to summer $(70-100 \%)$ as the amount of water that can be returned to the atmosphere through evaporation and transpiration is smaller in the winter months (Peck, S. et al., 1999).

Table 14: Annual amount of water retained by $2 \mathrm{~m}$ wide section of the conventional roof, the green roof and the green wall (described below)

\begin{tabular}{|c|c|c|c|}
\hline & Conventional roof & Green roof & Green wall \\
\hline area $\left[\mathrm{m}^{2}\right]$ & $\begin{array}{l}18.6 \text { (including over- } \\
\text { hang) }\end{array}$ & $\begin{array}{l}15.5 \text { (excluding para- } \\
\text { pet) }\end{array}$ & 7 \\
\hline $\begin{array}{l}\text { litres per year in } \\
\text { Graz depending on } \\
\text { roof size }\end{array}$ & $\begin{array}{l}867 \mathrm{l} / \mathrm{m}^{2} \times 18.6 \mathrm{~m}^{2} \\
=16126 \mathrm{I}\end{array}$ & $\begin{array}{l}867 \mathrm{l} / \mathrm{m}^{2} \times 15.5 \mathrm{~m}^{2} \\
=13438 \mathrm{I}\end{array}$ & \\
\hline $\begin{array}{l}\text { amount of water } \\
\text { retained/ needed }\end{array}$ & 01 & 9407 I (70\%) & $\begin{array}{l}7665 \text { I }\left(3 \mathrm{l} / \mathrm{m}^{2} / \mathrm{d}\right) \text { for sub- } \\
\text { strate panels } \\
12775 \text { । }\left(51 / \mathrm{m}^{2} / \mathrm{d}\right) \text { for hy- } \\
\text { droponic system }\end{array}$ \\
\hline $\begin{array}{l}\text { amount of water } \\
\text { released / lost }\end{array}$ & 16126 I (storm water) & $\begin{array}{l}4031 \text { I }(30 \%) \text { (used } \\
\text { for green wall) }\end{array}$ & 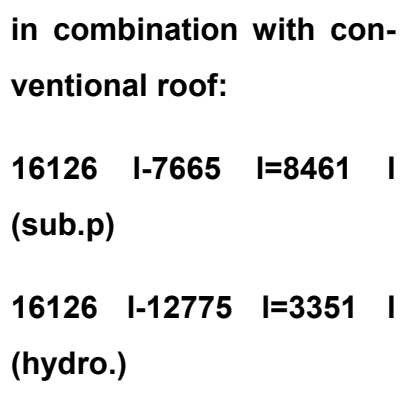 \\
\hline $\begin{array}{l}\text { amount of addi- } \\
\text { tional irrigation } \\
\text { water required }\end{array}$ & & & 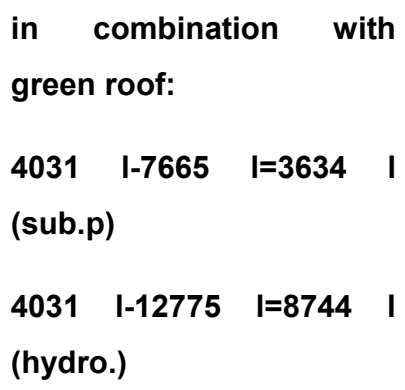 \\
\hline
\end{tabular}




\subsubsection{GREEN WALL}

Similar to the green roof, green walls are examples of organisation of functions in layers. However, the different layers of the wall are not directly connected to the green wall layers, but divided by an air gap. As they are placed in front, but not integrated into the wall, it seems that slightly less synergy occurs (in terms of thermal insulation for example). This section describes different green wall systems used in the case study and their requirements and benefits.

Over the last few years green walls have become popular. Developed in Japan, where urban green space is often limited due to dense urbanisation and high property values, the concept of bringing gardens into the vertical has proved successful. The benefits of the green wall are numerous and are comparable to the benefits of green roofs. They range from filtering water, cleaning air, and binding dust to cooling buildings and cities, and providing habitat for animals. Depending on the thickness of the vegetation layer they can provide some thermal and significant sound insulation (Dunnett, N., Kingsbury, N., 2008, p.9-11). While green roofs are mostly only accessible to a few people, a benefit of facade greenery is that it has a highly visual effect that can be enjoyed by a wide range of people. The modern green wall is different from the traditional greening of a facade where plants grow in the ground or pots and climb to grow over facades. Modern green walls systems by contrast bring the plant roots into the vertical and hence need irrigation systems. While this increases the installation complexity the advantage is that walls can be planted evenly and to a greater height. Plant diversity is potentially greater e.g. 170 species are used on the façade of the Musée du Quai Brantley (Allix, G. 2005). Compared to greened facades the variety of designs or patterns that can be achieved is larger, as Figure 48 illustrates. Distributors of green walls therefore often refer to the walls as "feature walls" highlightening their aesthetic potential. For contemporary architecture the green wall presents a combination of an unusual facade (pattern, material, texture, colour) which attracts attention to a building and at the same time symbolises a human, eco-friendly face. It is therefore ideal for public and sophisticated commercial clients who are looking for something unusual to create a green and innovative image. The sustainable aspect of green walls is not necessarily stressed by architects, but the public and manufacturers often equate green walls with sustainable solutions (or products).
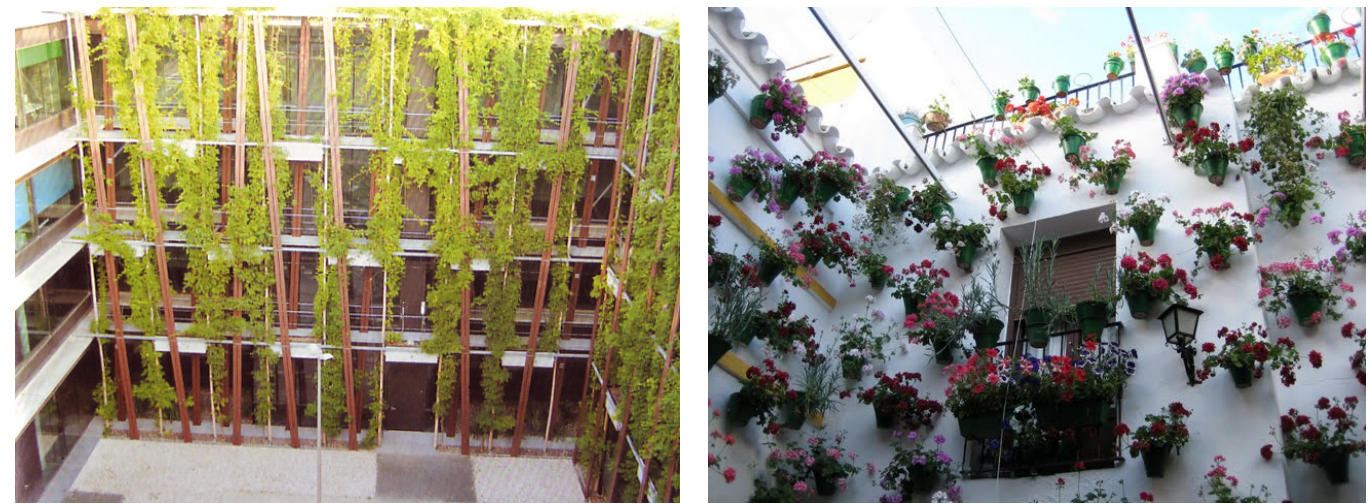

Figure 46: Shading provided by climbing plants and traditional patio in Cordoba, Spain

Vertically organised plants have been used since the Romans in Cordoba to provide a cool microclimate in the hot summer and to delight both inhabitants and visitors in the small outdoor spaces of the inner city houses. The patios are also used to grow vegetables in pots, keep chickens and act as the social centre of the house.

While any form of vegetation in the built-up urban environment has positive effects on micro-climate, animals and humans and is therefore welcome, it has to be analysed if the new trend for vertical gar- 
dens is as eco-effective as more established options like green roofs of greened facades. The following points have to be considered when choosing a vertical garden instead of a green roof or a greened façade:

- In general, it is important to prevent green walls being used as an excuse to shift baselines in urban design. Green walls have many benefits, but should not replace local parks which are less economical in land use but which provide green space of higher quality and are also important when it come to resiliency of a society as parks can easily be used as vegetable gardens (Hopkins, R., 2008). However where the urban environment is already extremely dense and land so expensive that local parks have long gone, green walls can make a difference as shown in Figure 47.
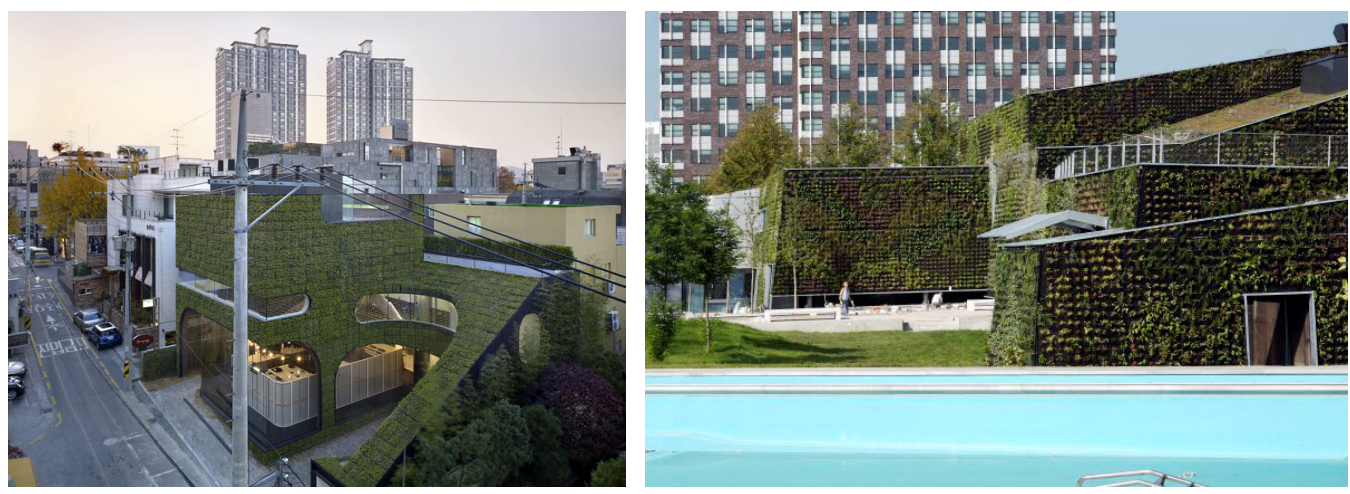

Figure 47: Green walls in Tokyo and Amsterdam

- As the concept always requires the transport and circulation of water adjacent to the wall, the green wall systems are always ventilated as this seems to be the safest way to exclude moisture and possible damage to the wall structure and the insulating layers. In summer green walls can prevent increasing temperatures on wall surfaces just as effectively as greened walls or roofs. In order to be beneficial during the warmer season they have to be orientated toward the building faces where the major solar radiation occurs. If greened walls or green walls are so orientated, they can reduce energy consumption for cooling by up to $30 \%$, which is similar to savings from having green roofs (Bass, B., Baskaran, B., 2001, p. 85). However, in winter, the green wall underperforms in comparison to a thick greened façade or grass roof as it cannot contribute as much to reducing heat loss. The slowly circulating air behind its construction will prevent the creation of a static layer of air that acts as an insulation layer in winter.

Another reason to be potentially sceptical about green walls as an enhancer of sustainability is the fact that a large number of pre-grown plants that are trained in hot houses is often used. Presuming that the average energy requirement per pre-grown plant is half of that of tulips grown in hothouses (4.4 MJ/plant), the energy requirement of one square metre of green wall vegetation (with an average of 15 plants $/ \mathrm{m}^{2}$ ) equates to $9.17 \mathrm{kWh} / \mathrm{m}^{2}$ which equals almost $10 \%$ of the annual energy required for space heating in the multifunctional case study (refer to section 1.12.1.) (Vringer, K., Blok, K., 2000, p.9). Although most roofs will be planted with pre-grown plants, the chosen species can be grown in open terrain as they are by definition not very delicate and can withstand dry spells as wells as periods of cold, frozen and wet soil. While in theory these plants could be used on a green wall, a tendency to use plants that are less robust and therefore raised in hot houses where irrigation, temperature and growing conditions are controllable can be observed. This is due to the fact that the extensive green roof and greened facade usually rely on naturally occurring rainfall, which, over time, reduces the vegetation choice to those plants that are best suited for the climate and microclimate. The green 
wall by contrast always requires additional irrigation (even if rainwater is used it has to be distributed), fertiliser and liquid nutrition for some systems. (Green walls can also be interior features). Therefore it is possible to use diverse and sometimes exotic plants that rely on a consistent level of water and nutrition. In actual fact these plant species often form part of the attraction of the green wall, which stays lush and green even in hot summers. It seems that the technological feasible and not the ecological sensible option is chosen in many cases when it comes to choosing plant species.

Herwig therefore criticises green walls and states that they act as a cosmetic disguise of the built environment with "eco-coats" rather than the result of a serious investigation of ecologically sensitive measures such as zero-energy houses or alternative storm water management.

"The main question remains. Do we only intend to camouflage our guilty conscience? Or do we want to start building not only greener but also more ecological houses?" (Herwig, O., 2008)
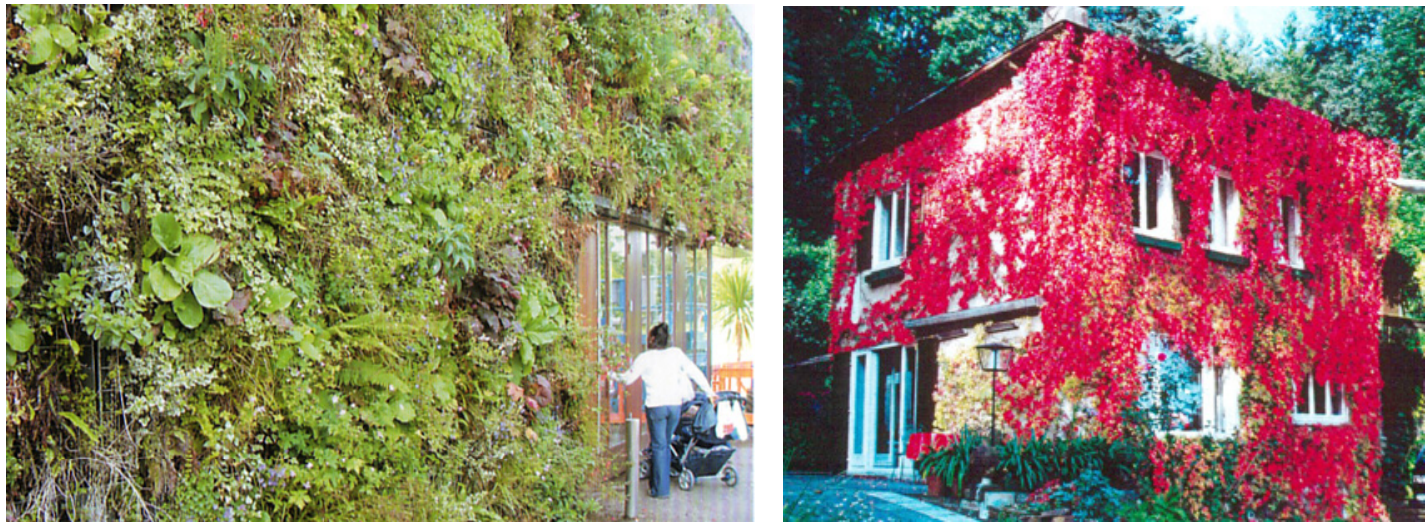

Figure 48: Hydroponics green wall system with over 170 plant species

and a house covered with Virginia creeper

The incorporation of a green wall seemed interesting for the case study as it could possibly answer the question as to whether and how far the ratio between environmental and aesthetic benefits and resource use would deteriorate when comparing it with traditional facade greening or a green roof in more detail (refer to section 1.13.1.5.3 for results).

Many different systems exist ranging from low- to high-tech solutions, with varying resource uses (Kaltenbach, F., 2009, p.1454-66). For the case study three panel systems and one substrate fleece system were analysed in more detail. They were chosen as they were low tech and easy to maintain and therefore the most realistic options for a residential envelope.
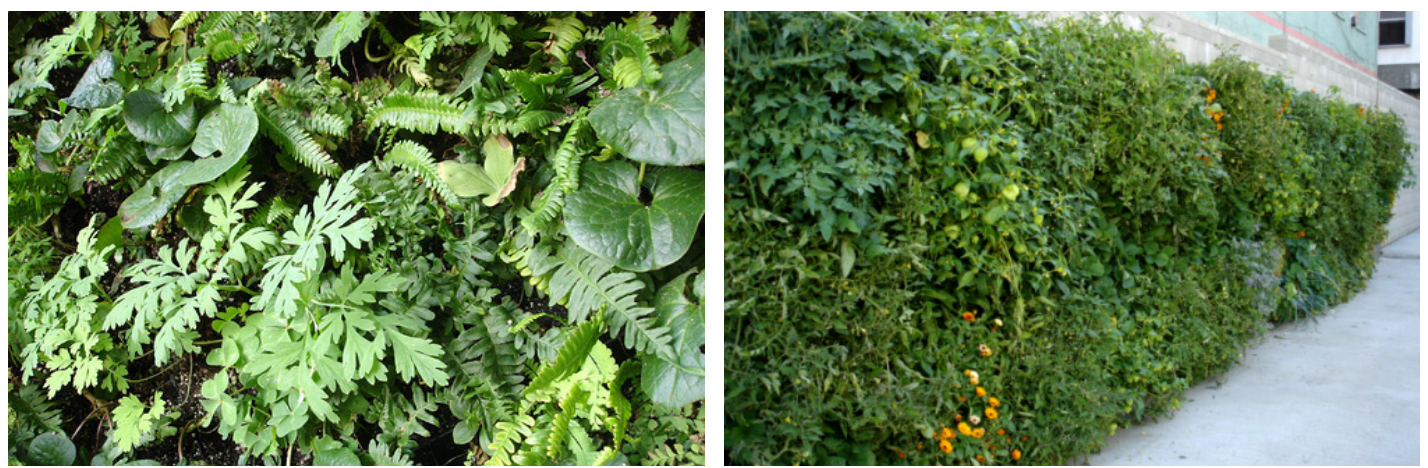

Figure 49:Close-up of a green wall and food project of the Urban Farming organisation in Los Angeles 
Panel systems, illustrated in Figure 50, function like shelves filled with soil. Water drips from the top and soaks the soil. Each self is perforated to allow for root growth as well as for water penetration. Run-off water is collected underneath the lowest shelf, filtered and pumped back into the water tank. The roots of the plants help fix the substrate which in theory becomes completely stable a few days after installation.
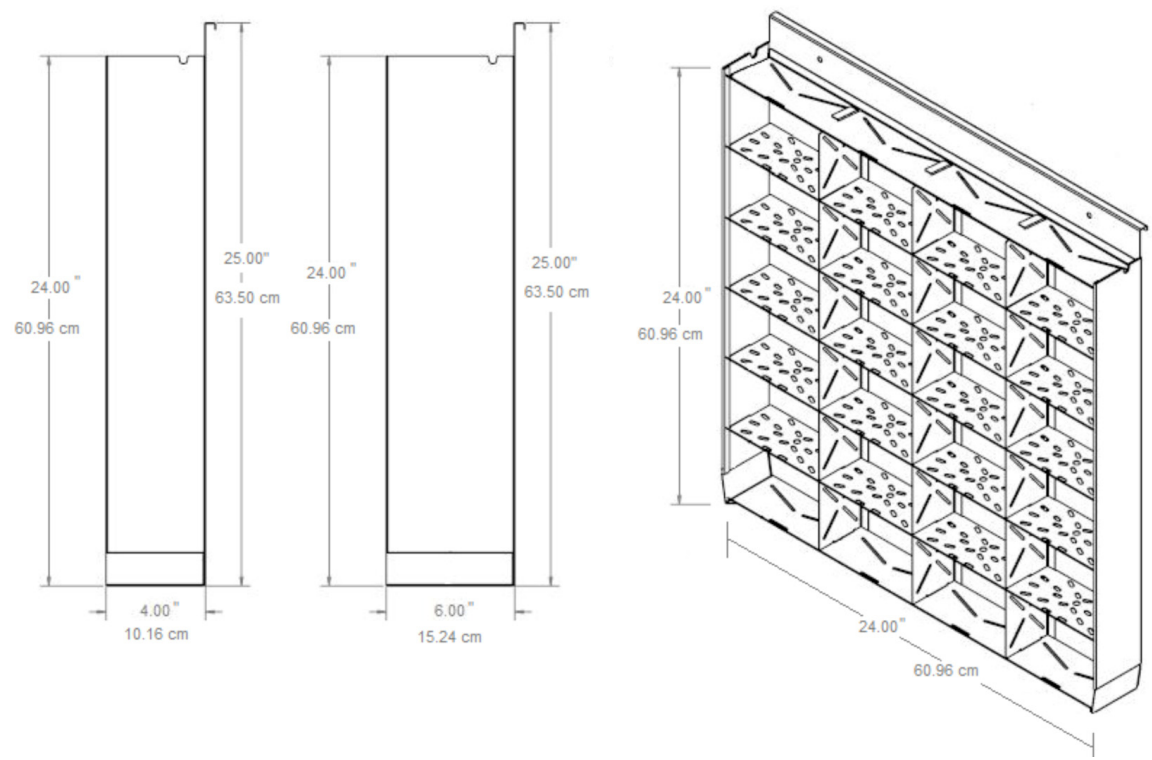

Figure 50: Panels of stainless steel and aluminium in two different depths, drawings by manufacturer

The first system considered is a food panel system which created great interest in the USA where people hoped it could provide an opportunity to grow local food in the urban context, where space for conventional gardening is often not available. The system was used by the Urban Farming organisation in the USA to produce fresh vegetables for homeless people in urban communities on the walls of car parks or supermarkets, as illustrated in Figure 49 (Urban Farming, 2009). It is made from stainless-steel and its depth is sufficient $(152.4 \mathrm{~mm})$ for food production. In order to incorporate it into the multifunctional envelope it was presumed that the northern side of the building where it was situated was actually receiving the solar radiation of the southern facade. The second option was the standard panel of the same manufacturer, a 101.6 millimetre deep aluminium panel filled with substrate that would allow the cultivation of grass, ivy and other decorative plants that would grow on the northern side of the building where only diffuse solar radiation is provided. The company's panels for food production were not made from aluminium as a precaution, since there exists an ongoing discussion about the link between aluminium, food and Alzheimers disease (Irwin, G., 08.06.2009), (Crapper, D. et al., 1976, p.67-80), (Netter, P. et al., 1989, p. 573-75). 

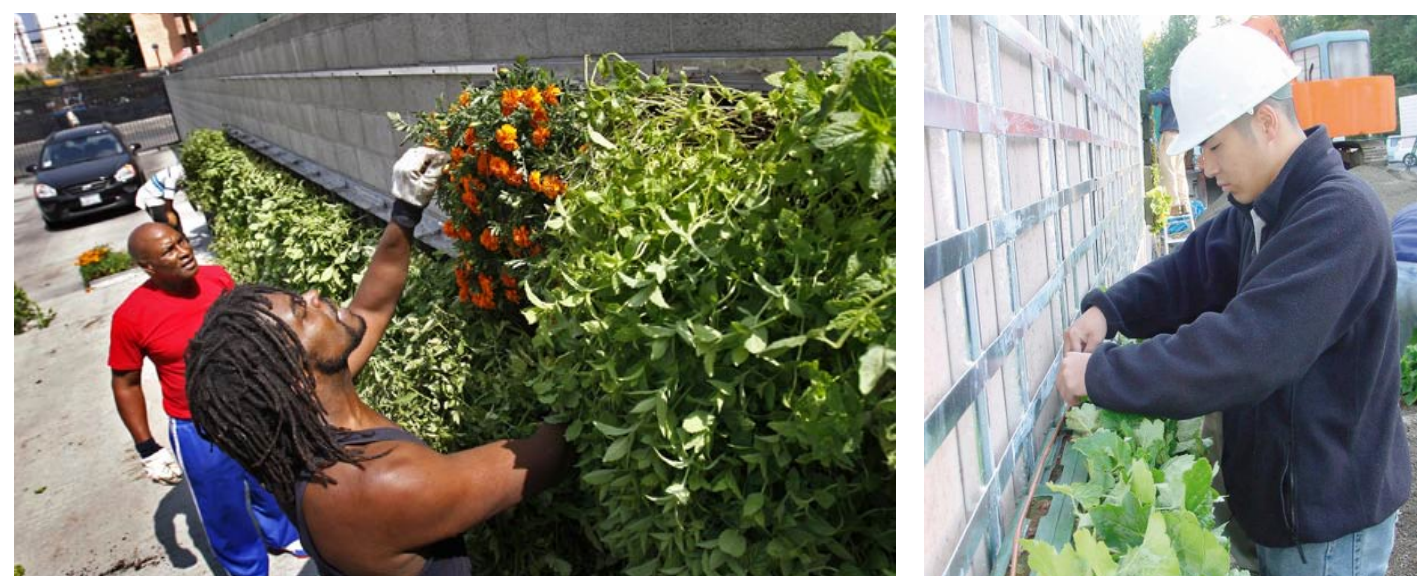

Figure 51: Installation of a vertical garden panel system and irrigation system

As maintenance of the crops was best done standing on the ground, the manufacturer suggested limiting the height of the panels containing food crops to 2 metres. Therefore only the lower area $\left(3.05 \mathrm{~m}^{2}\right)$ of the green wall would be used for vegetables while the upper part $\left(3.65 \mathrm{~m}^{2}\right)$ was used for other plants as indicated in Figure 95. In order to eliminate any potential heath risks linked to the use of aluminium in food production all panels, even those not planted with vegetables were made from stainless steel, as water would filter through the upper elements down to the vegetable elements. The material intensity analysis revealed that this system was the most resource intense system analysed.

Figure 52 shows a section through the green wall of the case study using the $154 \mathrm{~mm}$ deep stainless steel panels and gives an example of the appearance of the system. Even though the vegetation grows strongly, the rectangular shape of the panels is still perceptible in the upper parts.
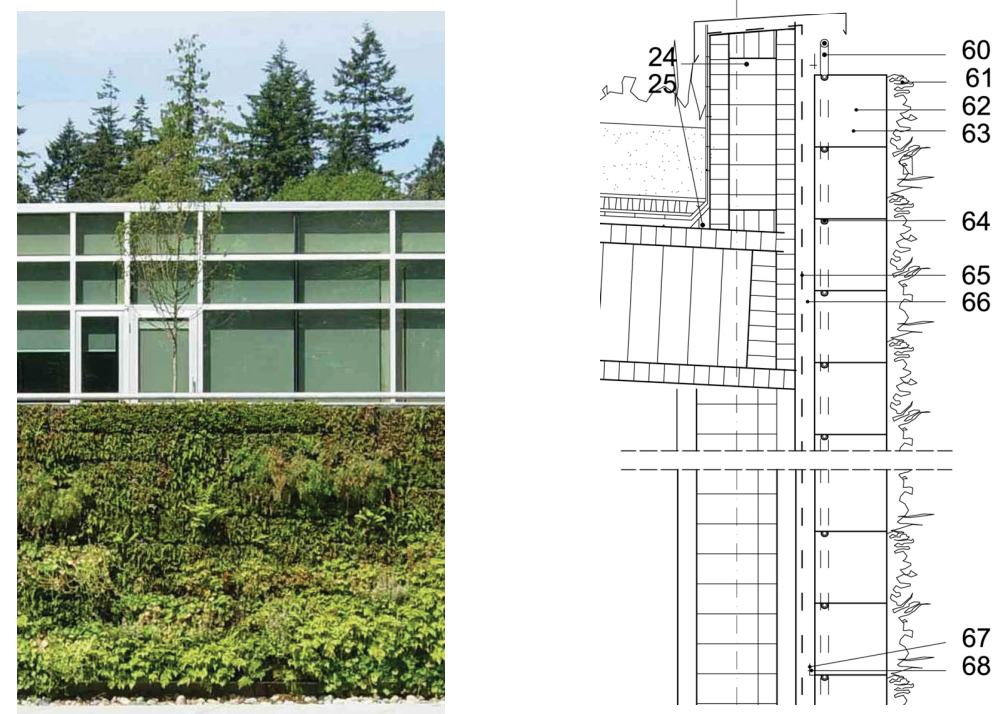
$6017 \mathrm{~mm}$ water supply
hose
$150 \mathrm{~mm}$ substrate
63 green wall perforated
stainless steel panels
$648 \mathrm{~mm}$ drip irrigation
65 water proofing
membrane, PE
66 spacer,HDPE, filled
with
polyethylene
67 mounting bracket,
aluminium
$686 \mathrm{~mm} / 50 \mathrm{~mm}$ flathead
pan
wood screw, stainless
69 batten $40 \mathrm{~mm} / 60 \mathrm{~mm}$
compressed straw-fibre

Figure 52: View of a green wall using panels, and section through the green wall

of the multifunction case study using the system

The third option analysed was a panel made from polyethylene, with a depth of $100 \mathrm{~mm}$. As the irrigation system of the plastic panels is basically identical to the aluminium and stainless steel systems a comparison of the three systems seemed useful as it would reveal both the importance of the choice 
of materials as well as their lifespan for the overall resource use. The plastic panel system was used for the calculation of the overall resource use of the multifunctional envelope in section 1.13.1.1.

Table 15 indicates the direct resource use of the three panel options.

Table 15: Three analysed panel systems used in the green wall (referring to the $2 \mathrm{~m}$ wide section)

\begin{tabular}{|c|c|c|c|c|}
\hline Direct material flow & $\begin{array}{l}\text { Stainless Steel } \\
\text { Food production }\end{array}$ & \multicolumn{2}{|c|}{$\begin{array}{l}\text { Aluminium } \\
\text { Decorative green wall }\end{array}$} & $\begin{array}{l}\text { Plastic } \\
\text { Decorative green wall }\end{array}$ \\
\hline Material & Stainless steel & \multicolumn{2}{|l|}{ Aluminium } & PE-HD \\
\hline Depth & $152.4 \mathrm{~mm}$ & $152.4 \mathrm{~mm}$ & $101.6 \mathrm{~mm}$ & $134 \mathrm{~mm}$ \\
\hline Weight of substrate & $\begin{array}{l}3400 \mathrm{~kg} \\
\left(250 \mathrm{~kg} / \mathrm{m}^{2}\right)\end{array}$ & $\begin{array}{l}3400 \mathrm{~kg} \\
\left(250 \mathrm{~kg} / \mathrm{m}^{2}\right)\end{array}$ & $\begin{array}{l}2260.33 \mathrm{~kg} \\
\left(166 \mathrm{~kg} / \mathrm{m}^{2}\right)\end{array}$ & $\begin{array}{l}1490 \mathrm{~kg} \\
\left(226 \mathrm{~kg} / \mathrm{m}^{2}\right)\end{array}$ \\
\hline Weight of Panels & $\begin{array}{l}442 \mathrm{~kg} \\
\left(67 \mathrm{~kg} / \mathrm{m}^{2}\right)\end{array}$ & $\begin{array}{l}292 \mathrm{~kg} \\
\left(44 \mathrm{~kg} / \mathrm{m}^{2}\right)\end{array}$ & $\begin{array}{l}233 \mathrm{~kg} \\
\left(35 \mathrm{~kg} / \mathrm{m}^{2}\right)\end{array}$ & $\begin{array}{l}118 \mathrm{~kg} \\
\left(18 \mathrm{~kg} / \mathrm{m}^{2}\right)\end{array}$ \\
\hline Weight total (panels + substrate) & $317 \mathrm{~kg} / \mathrm{m}^{2}$ & $294 \mathrm{~kg} / \mathrm{m}^{2}$ & $201 \mathrm{~kg} / \mathrm{m}^{2}$ & $244 \mathrm{~kg}$ \\
\hline Life span & $30^{*}$ & $20^{*}$ & $20^{*}$ & 15 years warranty \\
\hline
\end{tabular}

* (Eichmeyer, H.(ed.), 1996, p.14)

As loads and direct resource use were both relatively high for the green wall panel due to the mass of the substrate as well the amount of panel material needed, it was felt that a fourth option should be investigated which did not rely on substrate or panels. Comparing a light-weight green wall system would help to evaluate the indirect resource use findings and also help judge the ecological performance of green walls overall.

The chosen light-weight system was designed and built in 2006 by architectural students in Delft, the Netherlands, as the outer shell of an exhibition pavilion that would last for five years. Although it was a prototype, it was used as a basis for the case study as it was low-tech, light-weight and seemed therefore more realistic for residential use than the more expensive and sophisticated conventional systems available. 

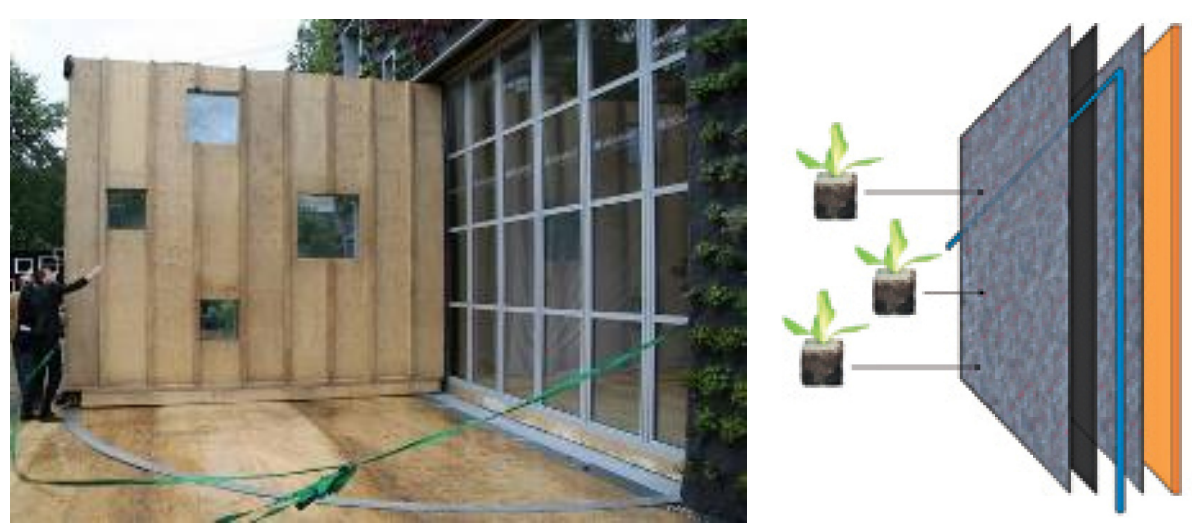

Figure 53: The Blackbox pavilion in Delft

The composition of the green wall is so light that it can be attached to openable facade elements. Felt is used instead of soil as the substrate

Instead of soil, plant roots grow between layers of felt made from recycled cloth and get all their nutrition from an agricultural drip irrigation system. The felt is attached to a water tight board which in turn is connected to cavity battens as illustrated schematically in Figure 53. The drip irrigation only soaks the layer of felt that is closest to the board with water containing fluid nutrients. The water then drips through this layer and is partly absorbed by the felt. The roots of the plants have to stretch out into the felt to get enough nutrients. This ensures that the roots do not spread into other layers, as these do not contain any nutrients.

The outer layer of felt keeps the plants packed to the façade. Small cuts in this layer create pockets where the young plants are placed when the façade is being planted. A thin layer of damp open plastic foil between the two felt layers ensures protection against evaporation in the summer and against freezing in the winter. The entire green wall system has a depth of $40 \mathrm{~mm}$ and weighs roughly 30 $\mathrm{kg} / \mathrm{m}^{2}$, adding $170 \mathrm{~kg}$ to the $2 \mathrm{~m}$ wide section of the case study envelope. The system's lifespan of 5 years is short for a facade element and the mainly determined by the organic felt material used that would rot over time. For the case study it was therefore replaced by a synthetic polyester needle felt that would last approximately 10 years.
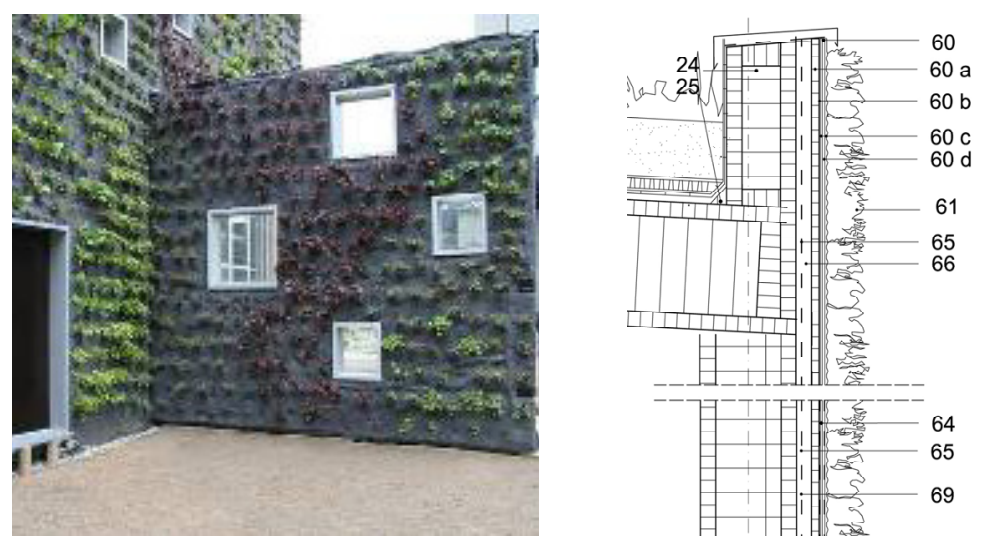
$60 \quad 17 \mathrm{~mm}$ water supply hose 60 a $200 \mathrm{~mm}$ compressed straw panel, water resistant
$60 \mathrm{~b}$ root protection layer, water tight
60 c $5 \mathrm{~mm}$ felt layer
$60 \mathrm{~d}$ drainage membrane, perforated $\mathrm{PE}$ vegetation $8 \mathrm{~mm}$ drip irrigation water proofing membrane, PE
batten $40 \mathrm{~mm} / 60 \mathrm{~mm}$ compressed straw-fibre

Figure 54: Image of the black box envelope and section through the green wall

Although this was still a short lifespan, it was deemed realistic to expect people to replace the hydroponic wall after that time, as the system functions as a ventilated rain-screen and is easy and not very expensive to replace. The wall might also require new planting from time to time anyway. The water circuit, pump etc. would not have to be replaced in this scenario. The irrigation system for all four options is similar. A pump circulates a mixture of rain water, tap water and nutrients into the drip irriga- 
tion that soaks either the soil substrate or the felt. Run-off water is filtered and returned into the cycle as shown in Figure 55. It shows all the irrigation components necessary to make any of the green wall systems work.

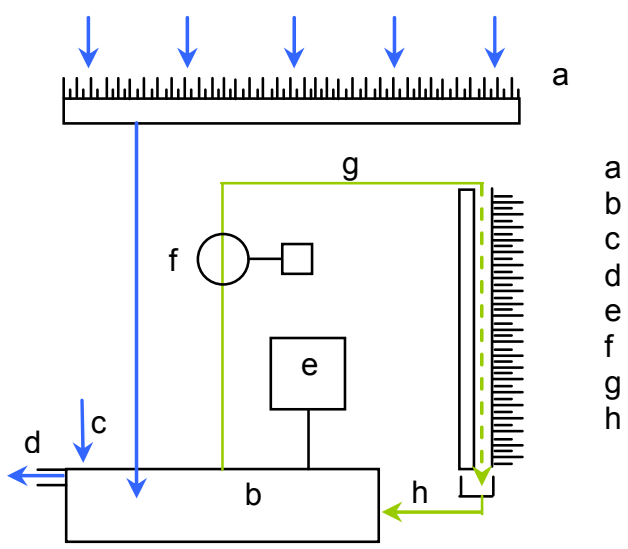

extensive green roof water tank irrigation water over flow fertiliser pump with control nutrient solution for plant facade return run

Figure 55: Irrigation circuit of the multifunctional envelope

Most of the components, such as the filter, the drip line irrigation system and pipe sizes were chosen according to one of the panel manufacturer's recommendations. Flow rates are either similar or the same for both the substrate based panel and the hydroponic systems. However, while soil based systems only require a boost of fertiliser from time to time, just as a garden would do, the hydroponic system needs a full nutrition feed on a daily basis which consists of many more components than the average fertiliser. The water pump for the irrigation system was chosen after the required power rating was calculated in relation to building height and flow volume. All systems need a pump with a rated power of 20 watts. 


\subsubsection{SOLAR THERMAL HEATING}

The following section describes the solar thermal heating system integrated into the southern wall of the case study. It is an example of an organisation of function in layers, where the outer layers form a functional unit that collects the heat of solar radiation which is then transported and used to condition the interior of the building and to provide hot water. Synergies ensue between the different layers of the solar collector and also between the collector and the wall, as it reduces the thermal transmittance of the wall. This reduction influences the amount of resources used to provide space heating indirectly, while the solar thermal system also impact on this resource use directly by providing part of the heat needed for hot water and space heating. Therefore its performance will be analysed in more detail here, as this data is needed for later calculation of overall requirements for heating.

As mentioned above the AEE (Austrian Institute for Sustainable Technologies) has undertaken a Material intensity analysis and done extensive research on solar thermal heating elements and their data was used and modified for this case study (Bergmann, I., Weiss, W., 2003). Their report "Fassadenintegration von thermischen Solarkollektoren ohne Hinterlüftung" (Integration of non-ventilated solar thermal collectors into the external wall) summarises the findings of a four year research project carried out for the Austrian Ministry for Transport, Technology and Innovation in which they elaborate the system-, structural- and building physics theories of non-ventilated solar thermal collectors. The performances of fourteen existing integrated solar thermal systems in Austria were monitored and analysed. Furthermore a series of standardised solar thermal systems were simulated and these can be used to assess the performance of built examples. The conclusions drawn from this part of the report then led to the design and construction of two case studies in Graz, Austria that were optimised in terms of performance, resource use and architectural integration. These were Testanlage 1 and Testanlage 2, one being a solar thermal collector integrated into a light-weight timber construction used for water heating and space heating of a two family house and one being integrated into a massive, heavy weight brick wall of an administration complex and used for water heating. The report details the monitored thermal performance, moisture levels and temperature development of the two case studies. Important for this thesis is that it concludes with an extensive Material Input Analysis of the two case studies using the MIPS concept in order to trace their resource use and to be able to compare the two optimised installations with the other fourteen monitored systems (Bergmann, I., Weiss, W., 2003, p. A 69-A 90). The design of the solar thermal heating component of the multifunctional wall is based on the case study, Testanlage 1 and Variante 5 of the report, a comparable timber frame light-weight structure with a solar heating collector integrated into the southern façade (Bergmann, I., Weiss, W., 2003, p. 72-100). Its heating medium is water-based and the system is used both for the production of hot water and for space heating.

Using the same design for the collector as Testanlage 1 seemed useful as a detailed Material Intensity Analysis was documented in the report which would significantly facilitate the gathering of exact data for the solar thermal system of the multifunctional envelope. However, Testanlage 1 has a different geometry from the multifunctional envelope as the total gross area of its collector surface is twice as big as the solar thermal collector of the multifunctional wall. Therefore the system behind the collector was too big and not suitable for the multifunctional envelope. The size of the solar storage, pumps and other elements were therefore adapted and calculated according to the size of the multifunctional envelope. 
The entire solar thermal system of the multifunctional envelope consists of the thermal collector which is integrated into the southern wall, two storage tanks, one for domestic hot water and one for hot water used in the space heating, several pumps, valves and controls.

Figure 56 shows the southern wall of the multifunctional envelope. The solar thermal collector is arranged around the windows and divided into four fields indicated in red. The total gross area of the collector is $25.60 \mathrm{~m}^{2}$.

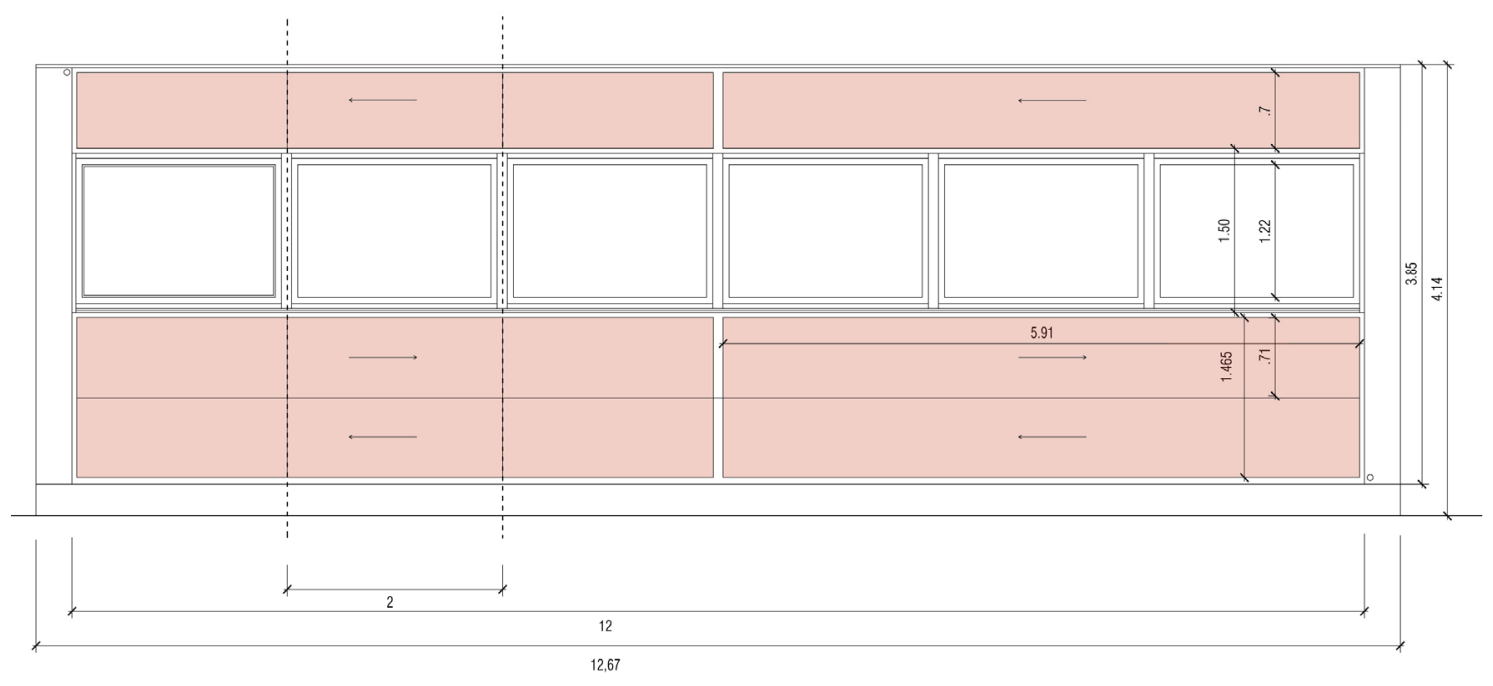

Figure 56: Setup of the solar heating elements on the southern façade

Panels are positioned above and underneath the windows.

The solar heating elements can be used both for space heating and the production of hot water. The chosen solar heater is a low flow water based system which typically reaches a rate of flow of $15 \mathrm{~kg} / \mathrm{m}^{2} \mathrm{~h}$ compared to $55 \mathrm{~kg} / \mathrm{m}^{2} \mathrm{~h}$ for a high-flow system. A high flow system creates temperature differences of $15 \mathrm{~K}$ average between the feed and the return of the system. The temperature rises slowly while water is pumped through the system in larger quantities. A low-flow system by contrast flows slower and therefore the water remains longer in the absorber. It reaches high temperatures and the water can be used instantly. As its performance is dynamic, it needs a stratified storage element. As the water in the system should be exposed as long as possible to the solar heat, the low-flow system requires a high hydraulic length $(+20 \mathrm{~m})$ in order to heat up to sufficient temperatures. The required length of the system is proportional to the diameter of the pipes used. Advantages of the system are that it requires less electric power to run the pump that circulates the transport medium, needs a smaller length of pipes with a smaller diameter and the need for supplementary heating can be reduced compared to the high-flow system (Bergmann, I., Weiss, W., 2003, p. 44-47). It is therefore potentially more resource-efficient.

Figure 57 shows a schematic organisation of the left half of the collector pipes in the multifunctional envelope. The right side of the wall is organised in the same way (although mirrored) as the system consists of two pipe loops that start in the outer corner of the façade and join each other in the central top of the wall. In order to avoid thermal bridges, pipes do not run between windows where crosssectional diameters are small, but connections between the upper and lower parts of the solar heating system are in the periphery of the facade. 


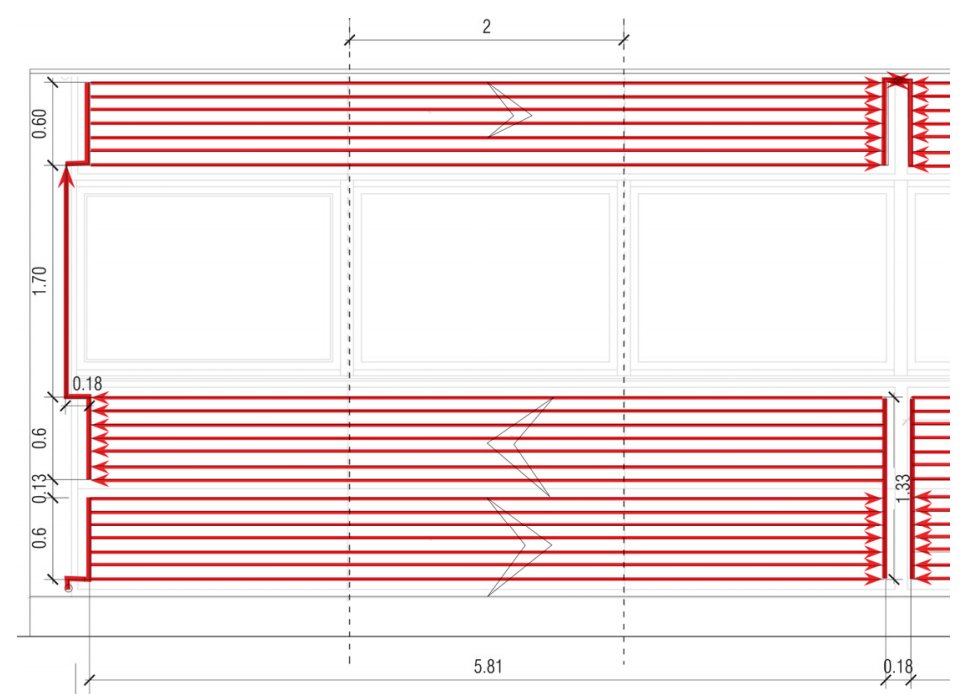

Figure 57: Elevation and Schematic organisation of pipes and flow directions of the thermal heating system

After being pumped through the collector field the water enters the heating system of the building. Figure 58 shows the circuit diagram for the provision of space heating and hot water for the multifunctional case study.
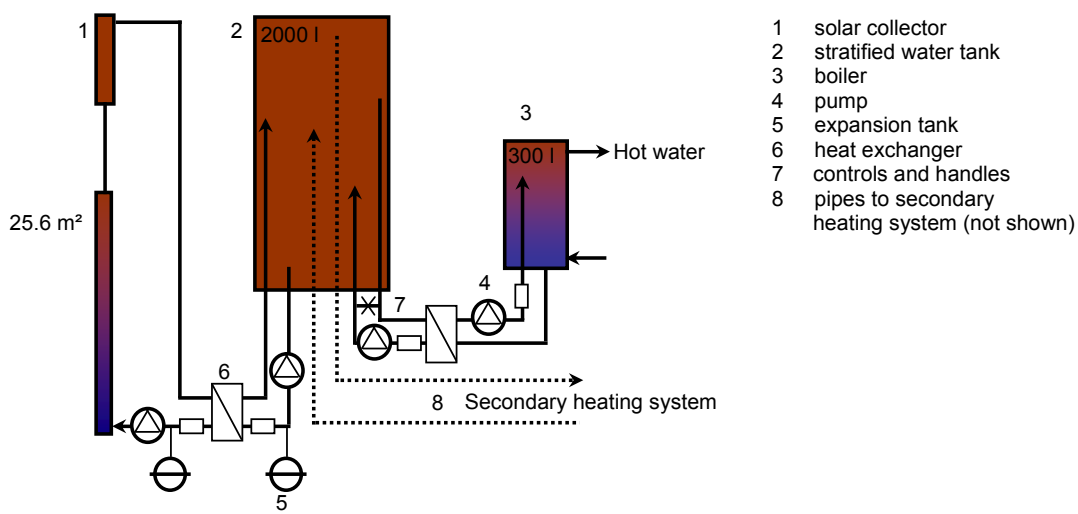

Figure 58: Circuit diagram of the heating system

The conventional space heating is not shown, only the part important for the solar thermal system.

Water is first pumped through the collector system and into a stratified water storage tank that can be heated by a secondary heating system fuelled by timber, coal, oil or gas, which is excluded from the diagram as it is not part of the case study. This 2000 litre tank is used to feed the space heating. The other tank (boiler) stores 300 litre of hot water, which can be directly used in the household. The size of these two tanks was established by the requirements of 4 people (401/d of warm water with a temperature of $50{ }^{\circ} \mathrm{C}$, and a surplus of $140 \mathrm{I}$ ) and was also used by Bergmann and Weiss for a $25 \mathrm{~m}^{2}$ collector system (Variante 5) (Bergmann, I., Weiss, W., 2003, p. 68-69). By keeping the design and setout of the solar thermal system of the multifunctional envelope consistent with Variante 5 , it was possible to derive a value for the solar fraction of the system (multifunctional envelope) using their published data. Figure 59 shows the performance of Variante 5, a vertical collector field orientated to the south with a 2000 l stratified solar tank and a 300 l boiler situated in Graz with different collector sizes. The multifunctional envelope with its $25.6 \mathrm{~m}^{2}$ collector field can cover $33 \%$ of its total energy needs from the solar thermal system. 


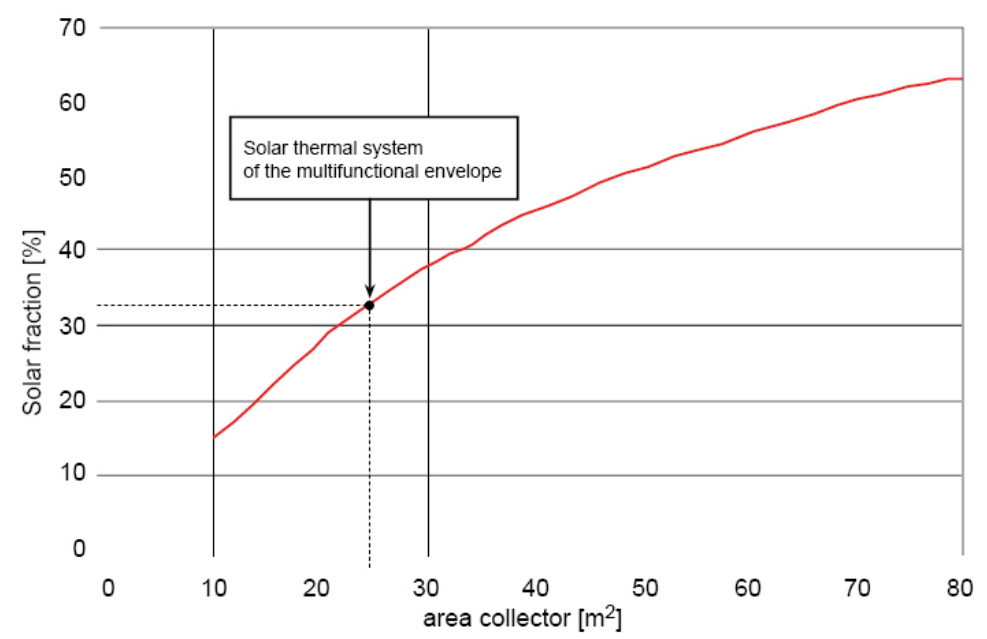

Figure 59: Interrelationship of solar fraction and size of collector field

for a system (Variante 5) used for space heating (2000l) and provision of hot water (300I). The graphed line refers to a vertically orientated integrated collector.

As the need for warm water is more consistent during the year than the need for space heating, which is roughly inversely proportional to the amount of solar radiation available to heat the solar thermal system, it can be anticipated that the solar fractions are different for hot water and space heating. Figure 60 shows different solar fractions for space heating and warm water in relation to different overall solar fraction gain using data published for Variante 5.

Interpolating between the graphs allows establishment of a solar fraction for hot water of $48 \%$ for the multifunctional envelope. The space heating fraction takes into account the fact the presumed heat load of Variante 5 is $8 \mathrm{KW}$ while the multifunctional envelope has a heat load of $3.8 \mathrm{~kW}$, as will be discussed in section 1.16.1.1.1, p.171.

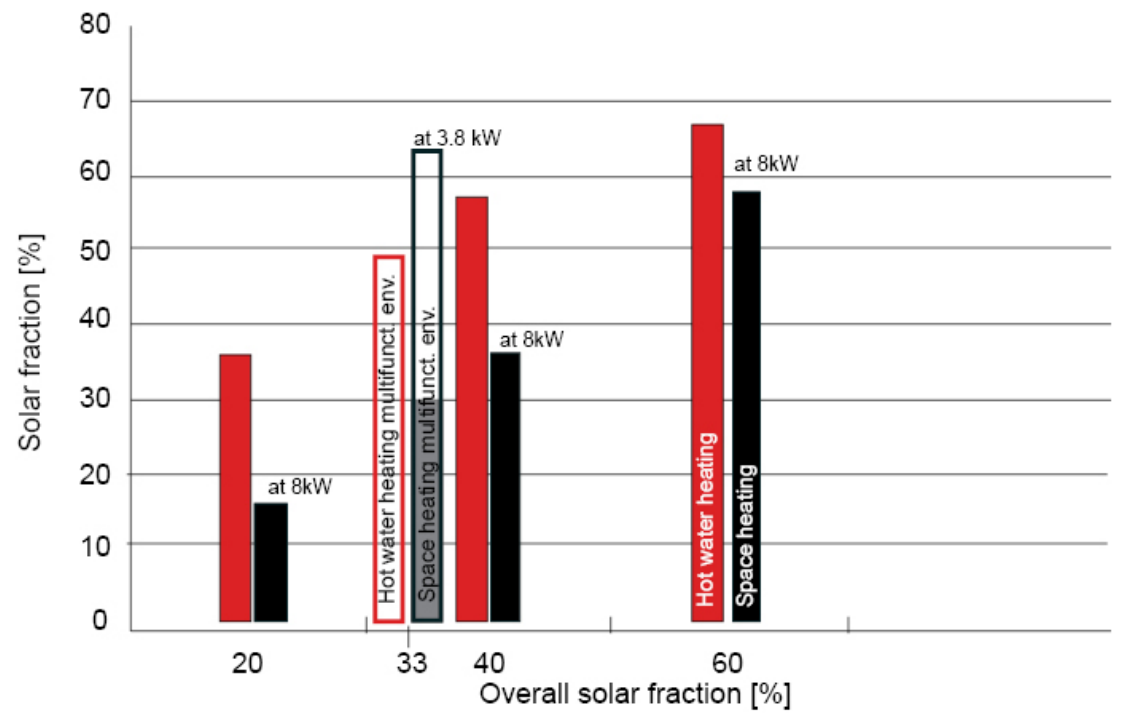

Figure 60: Solar fraction of space heating and hot water

of Variante 5 depending on overall solar fraction. The space heating fraction is based on a heat load of 8kW. For the multifunctional envelope the fractions were linearly interpolated and the fraction for the space heating doubled as the heat load of the multifunctional envelope is $3.8 \mathrm{~kW}$.

Therefore the solar fraction of the space heating does not only reach $30 \%$, which would be the result for Variante 5 at an overall solar fraction of $33 \%$ (shown in grey). Due to the smaller heat load, the solar thermal system of the multifunctional envelope covers around $63 \%$ of its heating requirements. 
Table 16 summarises the discussed data which will be important later for establishing the reduction in resource use that can be achieved by using the solar thermal heating system instead of conventional means to fuel the production of hot water and space heating (refer to section 1.12)

Table 16: Overall solar fractions of the solar thermal system, solar fractions depend on use and tank sizes

\begin{tabular}{|l|l|}
\hline Stratified storage tank [l] & 2000 \\
\hline Boiler hot water [l] & 300 \\
\hline Overall solar fraction [\%] & 33 \\
\hline Solar fraction space heating [\%] & 63 \\
\hline Solar fraction hot water [\%] & 48 \\
\hline
\end{tabular}

While the solar fraction of the entire solar thermal system is needed to establish the efficiency of the system, the collector also influences the thermal performance of the envelope directly and impacts on the overall heat load through this. As will be discussed in more detail in section 1.16.1.2.1, the heat load refers to the amount of energy needed to keep the inside temperature of the building at the comfort level, while the external temperature is low. The heat load is among other things directly dependent on the thermal transmittance of the enclosure of the building such as the collector and the wall behind it. Figure 61 shows a cross section through the southern wall and the collector. It consists from outside to inside of a layer of solar glazing, which has a low reflectivity, the aluminium absorber coated with a solar paint that absorbs solar radiation particularly well, absorber pipes that are pressed into the absorber sheeting and a layer of insulation which is directly attached to the wall element.

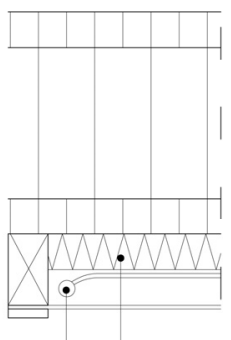

$55 \quad 56$

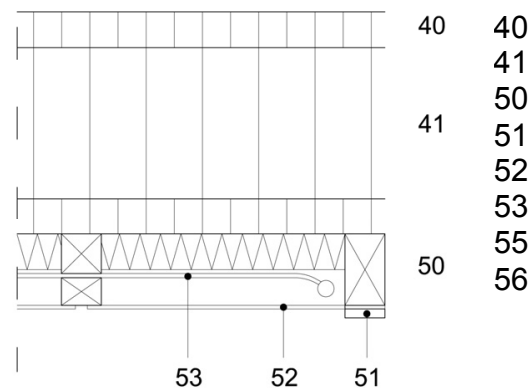

$40 \mathrm{~mm}$ compressed straw fibre $170 \mathrm{~mm}$ straw fibre insulation 45/80 mm timber frame, larch aluminium-rubber sealing $40 \mathrm{~mm}$, glazing absorber, aluminium, solar coating collector pipes, copper $40 \mathrm{~mm}$ themal insulation, rock wool

Figure 61: Cross section through the wall with the integrated solar heating

Small steel angles, positioned in the insulation, attach the wooden frame (50) of the solar heating elements directly to the wall (40). Bergmann shows that the effect of the thermal bridging on the performance of the wall and the collector is minimal (Bergmann, I., Weiss, W., 2003, p. 79).

The direct contact between the collector and the wall creates a synergetic effect in terms of thermal performance but on the other hand means that water vapour cannot migrate from the inside to the outside of the wall across the solar heating elements as the solar collector material is impermeable. However, Bergmann's and Weiss' measurements showed that no condensation occurs inside the wall in the weather conditions of Graz, but guidelines were formulated recommending the use of perfectly 
dry timber for construction. Furthermore the use of vapour barriers with sufficient permeability was recommended in order to allow any trapped moisture to dry out from the inside (Bergmann, I., Weiss, W., 2003, p. 85).

During the heating period the collector can reduce the effective thermal transmittance of the wall. In contrast to the static U-value which is a constant value influenced by layer thickness and the thermal conductivity $(\mathrm{k})$ of materials, the effective $\mathrm{U}$-value takes actual heat flows and internal and external temperature differences into account. Testanlage 1 for example, has a static thermal transmittance of $0.16 \mathrm{~W} / \mathrm{m}^{2} \mathrm{~K}$. Measurements of the effective thermal transmittance of the wall carried out between September 2001 and February 2002 at the site in Graz, basically the entire heating period, showed an improvement of $76 \%$ compared with the static $U$-value. The average thermal transmittance of the wall was measured as $0.04 \mathrm{~W} / \mathrm{m}^{2} \mathrm{~K}$ (Bergmann, l., Weiss, W., 2003, p. 86). The calculation of the thermal performance of the south wall of the multifunctional envelope was based on this value although an even lower effective $U$-value could be assumed since the static thermal transmittance of the multifunctional wall is lower than that of Testanlage 1 (U-value of $\left.0.12 \mathrm{~W} / \mathrm{m}^{2} \mathrm{~K}\right)$, due to slightly higher insulation levels.

It could be presumed that the low effective thermal transmittance of walls with integrated solar heating elements would allow the amount of insulation in the wall to be reduced but this is not the case. What helps in insulating the wall in winter can cause heat gains in summer when the collector produces high temperatures even if solar radiation is low. Therefore high insulation levels are required to stop buildings from overheating.

One advantage of integrating solar heating in the facade instead of the roof is that in summer solar radiation hits the vertical plane at a steep angle of incidence which basically reduces the efficiency of the collector when demand for hot water and space heating combined is low. In contrast, solar heating in the roof plane can result in an excess amount of hot water and the need to switch off the solar heating cycle which can have an impact on overheating as temperatures in stagnant solar heating can exceed $210^{\circ} \mathrm{C}$. In autumn and spring however the solar angle flattens, fully reaching the solar heating system in the wall (which has its highest efficiency in this period), which is ideal as additional energy is needed for space heating (Bergmann, I., Weiss, W., 2003, p. 44). Another advantage of integrating solar heating in the vertical plane, at least in regions with snow fall, is that reflected radiation from snow increases collection by $45 \%$ in a vertical plane compared to $5 \%$ in a roof with a $45^{\circ}$ pitch which means that yield is higher in winter as well (Bergmann, I., Weiss, W., 2003, p. 44). However, one of the disadvantages of solar heating in walls clearly lies in its increased susceptibility to shading by vegetation or the built environment. 


\subsubsection{THE PHOTOVOLTAIC WINDOW}

For the production of electricity the use of photovoltaic elements integrated into the windows was envisaged. Again this element is organised in layers as the photovoltaic element is basically sprayed onto the glazing of a window. In theory synergies ensue as the photovoltaic element not only provides electricity but also reduces the amount of direct sunlight that penetrates the building on the south and thereby reduces the risk of overheating. For this case study, it was however found that the multifunctional performance of the window was not entirely satisfactory, as will be discussed in section 1.13.1.6.

Photovoltaic (PV) modules convert solar energy directly into electricity using the so called photoelectric effect, whose description won Einstein the 1921 Nobel Prize in Physics. The photoelectric effect characterises the ability of light to act as a stream of particles that knock electrons out of a metallic surface resulting in an electrical flow. In the case of a photovoltaic element the surface is usually made of silicon. When a photovoltaic element is exposed to light, electricity is produced as a stream of electrons start flowing. The amount of electrons ejected from the element's surface is proportional to the intensity of light on it.

Two options were initially analysed, an amorphous silicon thin film element on a glass substrate and a mono-crystalline cell. Both options can be placed between two layers of insulating glazing and integrated in the windows as can be seen in Figure 62. The more common mono-crystalline photovoltaic cells, based on wafer technology, require a silicon thickness of $180-250 \mu \mathrm{m}$ to create a stable and strong enough element. However, only $20 \mu \mathrm{m}$ of its thickness is used to transform solar radiation into electricity (Diehl, M., Ternus, T., (6)2009). Thin film technology was developed to reduce the amount of silicon used.
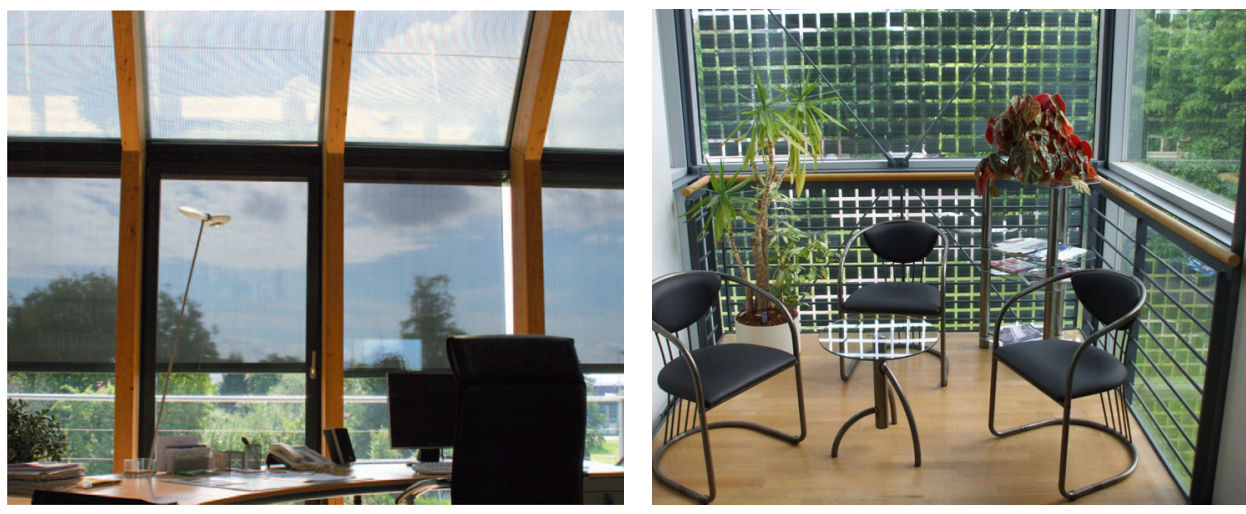

Figure 62: Amorphous silicon thin film cells and microcrystalline silicon bottom cells integrated in glazing

Amorphous silicon cells do not require the production of silicon crystals and are fabricated through the deposition of gaseous silicon on a flat substrate, such as glass or steel as shown in

Figure 63. Therefore thin films require much less silicon than wafer panels and a less resource intensive production process, reducing the amount of primary energy. The primary energy required for the fabrication of crystalline PV modules has been reported to be 2.9 to 3.8 times greater than the input for the same unit area of thin film modules (Pacca, S. et al., 2006, p.11). Primary energy requirements for manufacturing crystalline modules were found to range between 5,300 and $16,500 \mathrm{MJ} / \mathrm{m}^{2}$ for 
mono-crystalline (sc-Si) modules, whereas the manufacturing energy requirement for thin film modules ranges from 710 to $1,980 \mathrm{MJ} / \mathrm{m}^{2}$ (Alsema, E., 2000, p.17-25).

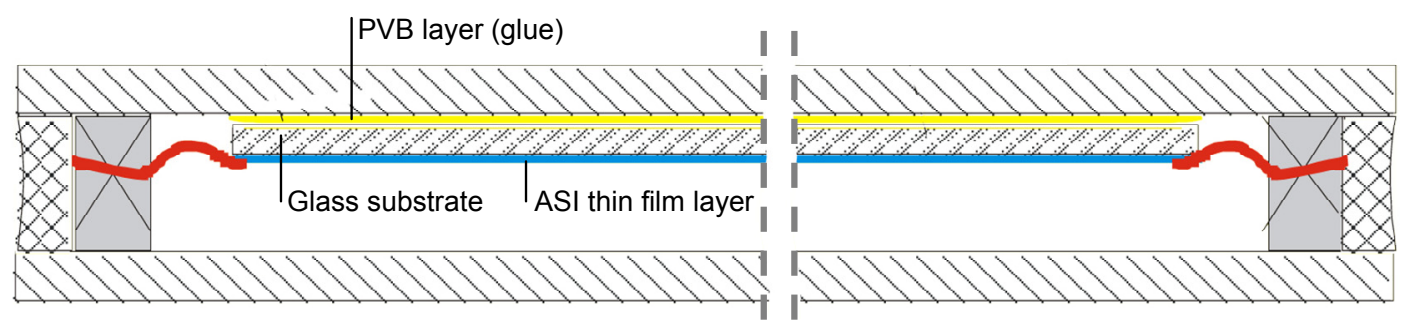

Figure 63: Section through a window with integrated amorphous silicon thin film module.

However, one disadvantage of amorphous silicon films is that they have a reduced solar efficiency of approximately $6-8 \%$ compared to common wafer-based crystalline silicon technology efficiencies which lie in the range of 10 to $20 \%$. The lifespan of both cell types is roughly 20 years (Mercaldo, L. et al, 2009, p. 1840). Some distributors of PV systems caution that amorphous thin film elements might not be the best option to decrease the reliance on fossil fuels in industrialised economies as only limited surface area is available on which to place photovoltaic elements, therefore these should be mono-crystalline modules with their higher yield.

However, this case study opted for amorphous thin film elements. Apart from the resource efficiency aspect, which seemed interesting, the visual appearance also played a role. Unlike microcrystalline silicon cells which produce a contrast of dark opaque and transparent light zones, the amorphous silicon elements produce a uniform visual effect in the glazing which is less disturbing although still not perfectly satisfying as illustrated in Figure 62. The amorphous thin-film was, therefore, presumed to be more suitable for residential glazing than the other option.

Initially there was hestitation about using a photovoltaic element in the glazing of the multifunctional envelope. This is mainly because windows hardly seem suitable elements for additional functions given their existing high level of multifunctionality.

Furthermore it is arguable whether the photovoltaic window is a likely or realistic choice for vertical residential glazing where it will impact on transparency, day light levels within the building and the amount of heat gains in winter as discussed in section 1.12.1, p. 116. However, the product also holds some adavantages. First of all it reduces the radiation transmittance of the glazing by $90 \%$ while providing electricity, which lowers the risk of overheating of the building in summer significantly. Secondly synergies are created as the photovoltaic element uses the window frame as its supporting structure instead of needing additional framing (as would be required for installation on a roof or the ground). As the energy contained in mounting structure would significantly affect the energy input into the photovoltaic systems, the attempt to integrate the photovoltaic element into the window seemed reasonable. According to Alsema, the energy pay back time for a PV system installed on a rooftop is typically 2.5 to 3 years, whereas the pay back time for a ground mounted system is 4 years due to the increased amount of structure needed. As different mounting options can double the energetic pay back times of the same photovoltaic modules, the importance of synergetic design solutions becomes apparent (Alsema, E., 2000, p.17-25).

The product chosen for the case study is called Voltarlux ASI THRU and is shown in 
Figure 63. Table 17 summarises the most important electrical data of the element as indicated by the manufacturer. The element has an efficiency of only $4 \%$. This is lower than the average $7 \%$ for amorphous PV modules, and is due to the fact the Voltarlux module is partly not covered with silicon in order to reach a higher transparency.

Table 17: Maximal performance of the Voltarlux ASI THRU element

\begin{tabular}{|c|c|c|c|}
\hline \multicolumn{2}{|l|}{ Amorphous thin film element } & \multirow{2}{*}{\begin{tabular}{|l|} 
\\
0.63 \\
\end{tabular}} & \multirow{2}{*}{\begin{tabular}{|l|} 
Units \\
{$\left[\mathrm{m}^{2}\right]$} \\
\end{tabular}} \\
\hline panel size & Apanel & & \\
\hline max. initial power & $Q_{\text {start }}$ & 31 & {$[\mathrm{~W}]$} \\
\hline off load voltage & $\mathrm{V}_{\mathrm{oc}}$ & 93 & {$[\mathrm{~V}]$} \\
\hline voltage at maximal power point & $V_{\text {mpp }}$ & 68 & {$[\mathrm{~V}]$} \\
\hline maximal power output according to *STC & $Q_{m p p}$ & 25 & {$[\mathrm{~W}]$} \\
\hline effective power output per year & $Q_{\text {eff.pv }}$ & 23.5 & {$[\mathrm{kWh} / \mathrm{a}]$} \\
\hline
\end{tabular}

*STC: Standard test conditions: $25^{\circ} \mathrm{C}, 1000 \mathrm{~W} / \mathrm{m}^{2}$ radiation at an $90^{\circ}$ angle, radiation spectrum 1.5

The maximal power output $Q_{m p p}$ is the amount of energy the module can produce under standardised test conditions which enable the comparison of different systems. However these conditions do not reflect the natural lighting and radiation levels to which the panels are exposed. The effective electricity output $Q_{\text {eff pv }}$ of a module depends on the maximal power output $Q_{m p p}$ and the amount of solar radiation that reaches the surface of the module. Therefore the position of the module with respect to the sun is important as well as its geographical location. The effective amount of electricity produced by the module depends on the orientation of the module's face, the angle with the horizontal plane and the amount of global and direct radiation. For the case study, the effective power output of each module was calculated at $75 \mathrm{KWh} / \mathrm{a}$. As the panel size of the Voltarlux panels differs from the one used in the case study (which is $2.01 \mathrm{~m}^{2}$ ), a factor of 3.19 had to be applied to derive an output for the multifunctional envelope. All six panels of the multifunctional envelope combined create $450 \mathrm{KWh} / \mathrm{a}$ electrical power as can be seen in Table 18. The calculation of the effective power output can be found in section 1.12.3.1, p.117.

Table 18: Summary of the electrical output of the PV modules

\begin{tabular}{|c|c|c|}
\hline Effective electrical output & Voltarlux ASI-ISO-E & $\begin{array}{l}\text { PV window case } \\
\text { study }\end{array}$ \\
\hline area photovoltaic element & 0.63 & 2.01 \\
\hline annual solar radiation & 587 & 1871 \\
\hline module's efficiency & 4 & 4 \\
\hline total effective electrical output (DC) per panel $Q_{\text {eff pv }}[\mathrm{KWh} / \mathrm{a}]$ & 23.5 & 75 \\
\hline for the entire envelope & & 450 \\
\hline
\end{tabular}

Balance of the system (BOS)

The balance of the system (BOS) comprises structures and equipment that are needed to support the modules and deliver the electricity to the local network. In most photovoltaic systems, the electrical output is fed to the mains grid and therefore needs to be converted from direct current (DC) generated by the PV modules into alternating current (AC) that can be used by the building. However, as described in section 1.12.3.2, in the case study the energy is directly used by the pumps of the solar thermal system and the green wall irrigation system that can run on DC currents. Therefore an inverter was not included in the case study. As mentioned above the PV module used in the case study 
is highly synergistic, giving it an advantage over other systems, which means that it does not require a huge amount of additional equipment. However, cables that connect the PV modules to the solar thermal system as well as the glazing substrate for the silicon were included in the calculation of the resource use in section 1.13 


\subsubsection{THE CONVENTIONAL ENVELOPE}

The design intention of the conventional envelope was to create an envelope that reflects a realistic envelope using common materials and construction methods that could be found in many parts of the world. The next step was to compare its performance to the multifunctional components of the other envelope. Hence, the chosen elements should facilitate and not complicate the comparison of the two enve-

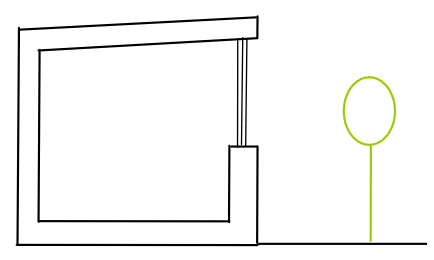
lopes. Therefore a few parameters were kept the same (or as similar as possible) regardless of their prevalence in residential housing, such as window size or roof form. The roof was first designed as a perfectly flat roof in order to accommodate the vegetable garden on the multifunctional envelope. When the roof top garden was abandoned in favour of an extensive green roof the flat roof was replaced by a slightly pitched roof which worked well for both envelope typologies. A set of drawings of the conventional envelope can be found in appendix 1.14.

\subsubsection{STRUCTURE AND CLADDING}

For the conventional envelope the intention was to use the most commonly employed materials. It was therefore decided that the conventional envelope should be a light-weight timber construction as this is a building typology which seems to be employed on a global scale, although not in Germany and Austria (where ironically the case study was presumed to be built) where only $13 \%$ of all buildings are made from timber (Ulrich, J., 2005). The external cladding was presumed to be timber boards which were then painted. In this case horizontally arranged weatherboarding as used in New Zealand or the USA was chosen, but any other form of timber cladding such as the vertical boards used in Sweden or the timber shingles used in alpine regions of Europe could have been used instead without materially affecting the result.

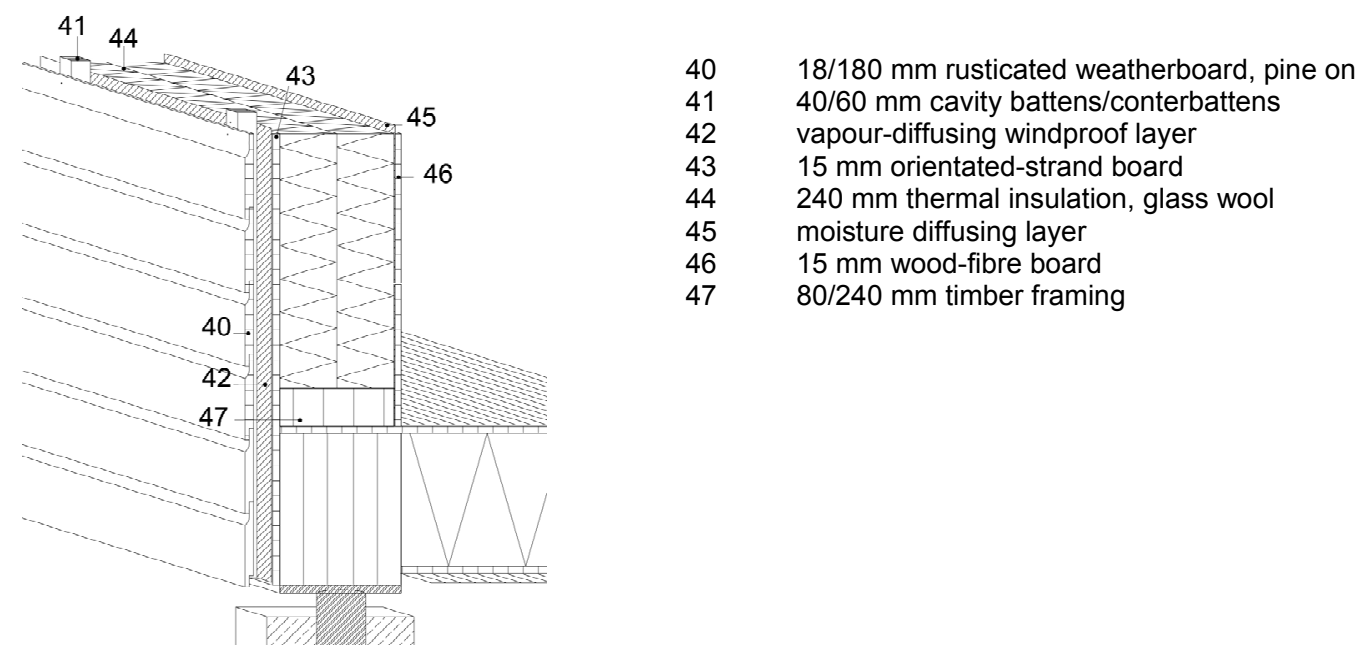

Figure 64: Composition of the conventional wall

Figure 64 shows the configuration of the conventional wall. The wall is structurally supported by a timber frame which is filled with two layers of $120 \mathrm{~mm}$ insulation (rock wool). Two layers of plastic sheets, one on the outside which is breathable and one on the inside as a vapour barrier prevent 
penetration of water into the timber construction and damage from subsequent condensation within the wall. The cladding is fixed onto cavity battens that allow for air to circulate between cladding and wall to aid the removal of moisture at this critical cold part of the wall.

\subsubsection{FLOORING AND ROOFING}

Although it would possibly have been more natural to use a concrete floor both to increase the thermal mass of the building and to make more use of solar gains, both the roof and the floor were presumed to be timber framed structures supported by timber joists. Again this was done to keep the two case studies comparable as the multifunctional envelope used the structural insulated straw panel as its floor element. To prevent rotting of the timber structure by continuous contact with splash water, the Austrian building code requires a gap of $300 \mathrm{~mm}$ between ground level and timber elements. It was therefore presumed that the timber floor was lifted slightly out of the ground.

Figure 65 illustrates the composition of the conventional roof. The roof is clad with zinc sheets, which are fixed to an oriented strand board sarking. A $60 \mathrm{~mm}$ air gap between the main roof structure and the cladding allows for ventilation and removal of moisture to prevent rot. Hegger et al. indicate a life span of 80 years for a roof that is clad with zinc sheeting (2005, p. 131), which makes it one of the only options that reaches a life span comparable to the green roof.

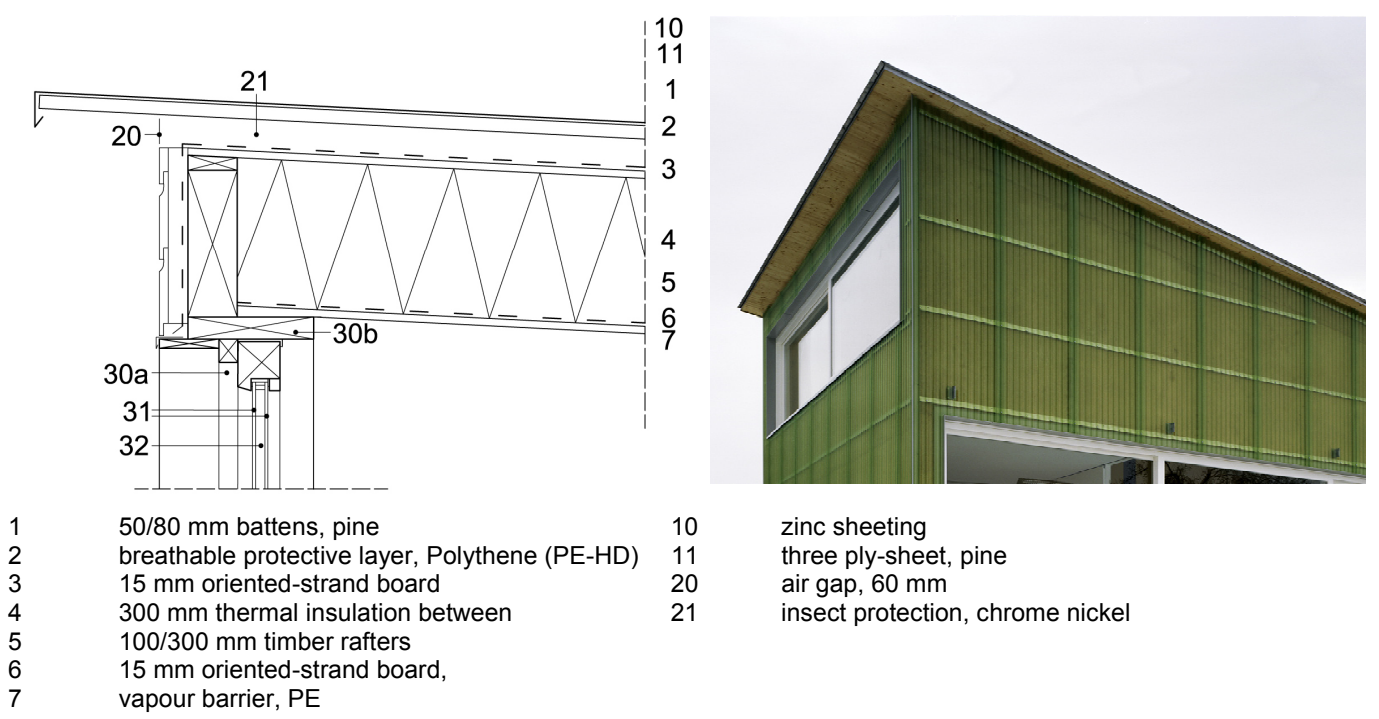

Figure 65: Detail of the conventional roof and image of a similar roof 


\subsection{ENERGY PERFORMANCES OF THE TWO ENVELOPES}

The knowledge of the thermal performance of the two envelopes is a precondition in establishing their indirect resource use during their life cycle. Initial resource savings in the envelope can for example translate into poorer thermal performance which increases operational resource use. Some of the multifunctional elements of the case study impact on the thermal performance of the envelope either by reducing transmission losses (green roof) as has been discussed in section 1.11.1, or by providing energy for space heating and hot water provision or by generating electricity (photovoltaic panels). The analysed solar thermal system is an example of a system that can fulfil several of these functions, reducing the transmission heat loss and providing energy for space heating and hot water as discussed in section 1.11.1.4 .

The following section is a summary and interpretation of the calculation of the energy requirements of the two cases studies. As the different active elements of the multifunctional envelope (solar thermal system and photovoltaic elements) either provide energy for the space heating (seasonal) or contribute to the provision of hot water (annual) or produce electricity, the section distinguishes between these three energy requirements. Furthermore the distinction was made as the generalisation of the required energy into a consolidated value would not have taken factors such as different efficiencies (to produce the same amount of electrical energy as heat energy requires considerably more energy) into account. These can have implications for resource use and hence the environment.

Table 19 summarises the performance of the two envelopes and shows data relevant for establishing the resource use of the case studies.

Table 19: Overview of the energy requirements of the two envelopes

\begin{tabular}{|l|r|r|c|}
\hline \multicolumn{1}{|c|}{ Heating requirements } & $\begin{array}{c}\text { Multifunctional } \\
\text { envelope }\end{array}$ & $\begin{array}{c}\text { Conventional } \\
\text { envelope }\end{array}$ & Units \\
\hline \multirow{2}{*}{$\begin{array}{l}\text { total energy for heating, } E_{\text {heating }} \\
\text { total energy required for hot water, } E_{\text {hw }} \\
\text { total electrical energy required, } E_{\text {elec }}\end{array}$} & 732 & 5268 & {$[\mathrm{KWh} / \mathrm{a}]$} \\
\cline { 2 - 4 } & 1524 & 2930 & {$[\mathrm{KWh} / \mathrm{a}]$} \\
\hline
\end{tabular}

The following paragraphs summarise the energy requirements. A detailed calculation of the energy requirements for space heating according to the European Standard EN 832, Thermal performance of buildings - Calculation of energy use for heating - Residential buildings and hot water provision can be found in appendix 1.16. In the following paragraphs the energy requirements were calculated for the entire envelope in a bid to make the calculation as clear as possible. For the calculation of the resource use in section 1.13, which only refers to the $2 \mathrm{~m}$ wide section of the envelope, these figures were then divided by 6 (as the analysed envelope section represented a $6^{\text {th }}$ of the overall building volume). 


\subsubsection{SPACE HEATING}

In order to establish the amount of energy $E_{\text {heating }}$ needed to heat the two case studies during the year, both the heat losses and the heat gains of the envelopes had to be calculated and in the case of the multifunctional envelope the amount of energy that was provided by the solar thermal elements had to be subtracted.

Table 20 summarizes the most important results for the energy requirements for space heating. A more comprehensive version can be found in sections 1.16.1.1.1 and 1.16.1.1.2.

Table 20: Summary of energy requirements in $\mathrm{KWh} / \mathrm{a}$

\begin{tabular}{|c|c|c|c|c|}
\hline \multicolumn{2}{|c|}{ Heating requirements } & $\begin{array}{l}\text { Multifunctional } \\
\text { envelope }\end{array}$ & $\begin{array}{c}\text { Conventional } \\
\text { envelope }\end{array}$ & Units \\
\hline \multirow{3}{*}{$\begin{array}{l}\text { heat loss per annum } \\
\text { usable heat gains per annum } \\
\text { effective energy use per annum }\end{array}$} & \multirow{3}{*}{$\begin{array}{l}P_{\text {annum }}=P_{\text {spec }} \cdot V \cdot H G T_{-12 / 20} \\
Q_{\text {annum }}=P_{2} \cdot \eta \\
P_{\text {eff }}=P_{\text {annum }}-Q_{\text {annum }}\end{array}$} & 9707 & 10162 & [KWh/a ] \\
\hline & & -2860 & -4894 & [kWh/a] \\
\hline & & 6847 & 5268 & {$[\mathrm{kWh} / \mathrm{a}]$} \\
\hline $\begin{array}{l}\text { energy produced by envelope for } \\
\text { space heating }\end{array}$ & $Q_{\text {th space }}$ & -6116 & 0 & [KWh/a] \\
\hline total energy for heating & $E_{\text {heating }}=P_{\text {eff }}+Q_{\text {th space }}$ & 732 & 5268 & [KWh/a] \\
\hline per square metre & & 8 & 57 & {$[\mathrm{KWh} / \mathrm{a}]$} \\
\hline
\end{tabular}

As can be seen annual heat losses of the two envelopes are relatively similar. They consist of heat losses through ventilation and transmission. As ventilation heat losses are identical for both envelopes (defined by the minimum air exchange rate), the higher number for the conventional envelope indicates that its insulation levels are a bit lower than those of the multifunctional envelope (refer also to Table 40 and Table 41). A bigger difference exists between usable heat gains which are considerably smaller for the multifunctional envelope. This is caused by the photovoltaic window elements that considerably reduce the amount of solar radiation penetrating into the building. Given that they effectively prevent the penetration of part $(58 \%)$ of the useful solar energy that could be otherwise trapped in the form of heat within the building, a discussion of whether these electricity producing elements are increasing the resource use of the case study instead of decreasing it, when compared to conventionally sourced electricity, can be found in section 1.13.1.3. As summarized in Table 16, the solar fraction of the solar thermal system amounts to 2320 Watt, representing $63 \%$ of the heat load of the multifunctional case study. This translates to $6116 \mathrm{kWh} / \mathrm{a}$ or $239 \mathrm{kWh} / \mathrm{a}$ per square metre of net collector surface. In total the energy needed for space heating is reduced to $732 \mathrm{kWh} / \mathrm{a}$ for the multifunctional and remains at $5268 \mathrm{kWh} / \mathrm{a}$ for the conventional envelope.

\subsubsection{HOT WATER PROVISION}

The amount of hot water required by the occupants of the case study was defined at 160 litres per day for 4 people. In the case of the multifunctional envelope the solar fraction for the 160 litres of hot water was established at $48 \%$, as discussed in section 1.11.1.4. The water temperature of the hot water was set at $55^{\circ} \mathrm{C}$ and the average temperature of cold tap water was identified to be $12^{\circ} \mathrm{C}$. The re- 
quired amount of energy $P_{h w}$ can be described as the product of the temperature difference $\Delta t_{h w}$ between hot and cold water, the thermal capacity of water $C_{h w}$ and the mass of the water to be heated:

$P_{h w}=\Delta t_{h w}[k] C_{h w}[K J / k g ~ k] \cdot m[k g]$

Inserting all the known and defined factors (refer to Table 39), $\mathrm{E}_{\mathrm{hw}}$ can be calculated as $28896 \mathrm{KJ}$, which translates into $2930 \mathrm{KWh} / \mathrm{a}$. As discussed in section 1.11.1.4, the multifunctional envelope can cover $48 \%$, or $1406 \mathrm{kWh} / \mathrm{a}$ of the required energy and thereby reduce the amount of energy that has to be provided by a secondary heating system to $1524 \mathrm{kWh} / \mathrm{a}$. The conventional envelope does not contribute to providing energy for hot water.

Table 21: Energy required for the provision of hot water and amount produced by the envelopes

\begin{tabular}{|c|c|c|c|c|}
\hline \multicolumn{2}{|c|}{ Hot water requirements } & Multifunctional & Conventional & Units \\
\hline \multirow{4}{*}{$\begin{array}{l}\text { energy required for hot water prod. } \\
\text { or } \\
\text { energy produced by envelope for hot } \\
\text { water } \\
\text { total energy required for hot water }\end{array}$} & \multirow[t]{2}{*}{$P_{h w}=\Delta t_{h w} C_{h w} \cdot m$} & 28896 & 28896 & {$[\mathrm{KJ}]$} \\
\hline & & 2930 & 2930 & [kWh/a] \\
\hline & $Q_{\text {th hw }}$ & -1406 & 0 & [KWh/a] \\
\hline & $E_{h w}=P_{h w}+Q_{t h ~ h w}$ & 1524 & 2930 & [KWh/a] \\
\hline
\end{tabular}

The calculations above do not include the energy required by the pumps that circulate the water in the thermal solar system. Their consumption was established as $352 \mathrm{KWh} / \mathrm{a}$ in total (refer to section 1.12.3). 


\subsubsection{ELECTRICITY}

According to the United Nations Statistics division the average electricity consumption (in residential houses) in Austria reached $2050 \mathrm{kWh} / a$ per capita in 2006. For the case study, with an occupancy of four, this means an overall electricity requirement of $8200 \mathrm{kWh} / \mathrm{a}$. The contribution of the photovoltaic thin-film element of the multifunctional envelope to cover the electricity use of the household represents roughly $5 \%$ as can be seen in Table 22 . The total electrical energy that has to be provided to the two case studies is therefore similar, reaching $8200 \mathrm{KWh} / \mathrm{a}$ for the conventional and $7750 \mathrm{kWh} / \mathrm{a}$ for the multifunctional envelope.

Table 22: Electrical energy requirements of the two envelopes and contribution of the photovoltaic element

\begin{tabular}{|ll|r|r|r|}
\hline \multicolumn{2}{|c|}{ Electricity requirements } & $\begin{array}{l}\text { Multifunctional } \\
\text { envelope }\end{array}$ & $\begin{array}{l}\text { Conventional } \\
\text { envelope }\end{array}$ & Units \\
\hline electricity required for 4 people & $P_{\text {elec }}$ & 8200 & 8200 & {$[\mathrm{kWh} / \mathrm{a}]$} \\
\hline electricity produced by envelope & $Q_{\text {env }}$ & -450 & 0 & {$[\mathrm{KWh} / \mathrm{a}]$} \\
\cline { 2 - 5 } total electrical energy required & $\mathbf{E}_{\text {elec }}=\mathbf{P}_{\text {elec }}+\mathbf{Q}_{\text {env }}$ & $\mathbf{7 7 5 0}$ & $\mathbf{8 2 0 0}$ & {$[\mathrm{KWh} / \mathrm{a}]$} \\
\cline { 3 - 5 }
\end{tabular}

\subsubsection{EFFECTIVE ELECTRICAL OUTPUT OF THE PHOTOVOLTAIC WINDOWS}

In order to derive the annual electricity produced by the solar modules of the multifunctional envelope or effective electricity output $P_{\text {eff pv }}$ several parameters have to be calculated. First of all it is necessary to know the total solar radiation that reaches the modules at the specific location Graz, with tilt angle of $90^{\circ}$, and south orientation. The total solar radiation on the module's surface $I_{g}$ combines the power from direct beams $I_{s}$, the diffuse radiation $I_{d}$, and the radiation reflected from the land surface back to the module's surface $R_{r e}$ (albedo) and is dependent on the tilt of the module $S$. Therefore it can be stated that:

$I_{g}=I_{s} \cdot R_{s}+I_{d} \cdot \frac{(1+\cos S)}{2}+\left(I_{s}+I_{d}\right) \cdot \frac{(1-\cos S)}{2} \cdot R_{r e}$

with

$\mathrm{I}_{g} \quad$ total solar radiation on the module

$\left[\mathrm{W} / \mathrm{m}^{2}\right]$

$\mathrm{I}_{\mathrm{s}} \quad$ direct solar radiation on horizontal plane

$\left[\mathrm{W} / \mathrm{m}^{2}\right]$

$\mathrm{R}_{\mathrm{s}} \quad$ coefficient to transform direct solar radiation

on horizontal plane into vertical plane

$[-]$

$I_{d} \quad$ diffuse radiation on module

$\left[\mathrm{W} / \mathrm{m}^{2}\right]$

S tilt of module

$\left[{ }^{\circ}\right]$

$\mathrm{R}_{\mathrm{re}} \quad$ albedo

$[-]$ 
While the ground albedo can be calculated by taking times of snow cover and the reflection of the plant covered ground into account (using the data of Table 9, p.82), the different forms of solar radiation have to be simulated. Figure 66 indicates the total annual solar radiation on a south facing vertical plane in Graz simulated by Bergmann and Weiss (2002, p. 56). As the case study was based on their work on solar thermal collectors (see also section 1.10.3, p. 82), it is possible to use their simulation directly. Taking the days with increased ground albedo (due to snow coverage in the cold months of the year) into account an annual radiation of $931 \mathrm{kWh} / \mathrm{m}^{2}$ can be assumed.

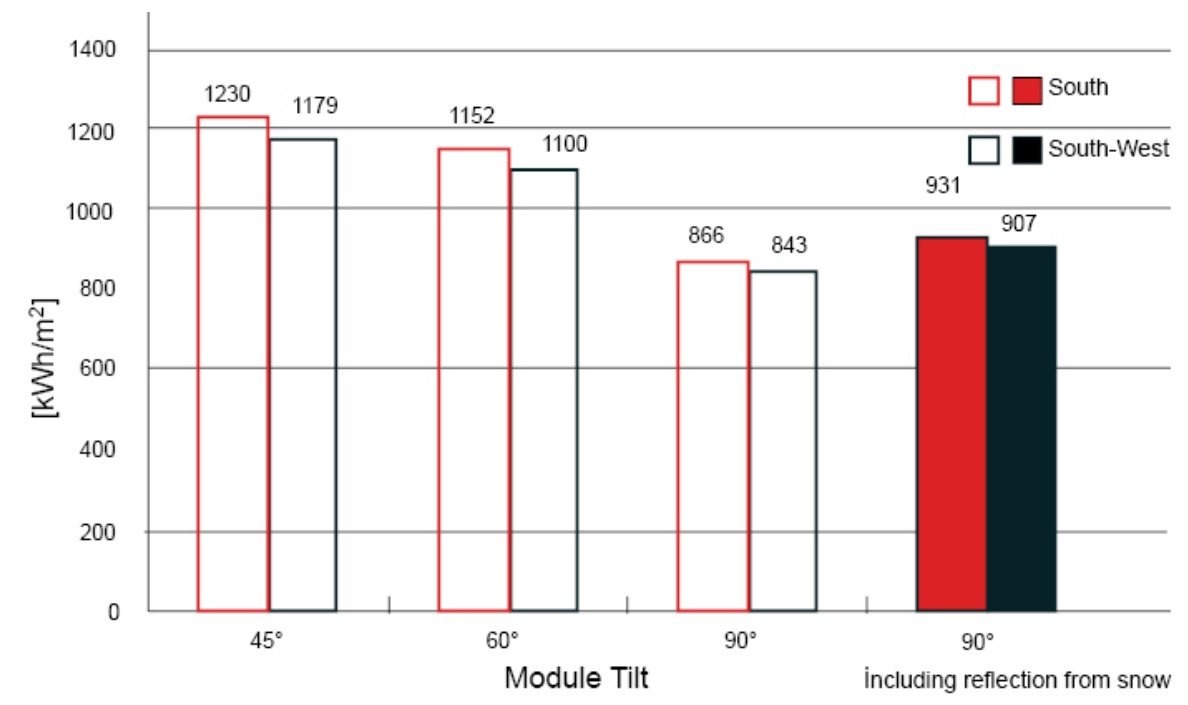

Figure 66: Annual solar radiation in Graz dependent on module tilt, snow reflection and azimuth

The second parameter necessary to derive the effective electricity output $Q_{\text {eff pv }}$ is the efficiency of the modules, which can be calculated based on the information provided in Table 17.

During testing (STC), modules are exposed to a power intensity equivalent to $1,000 \mathrm{~W} / \mathrm{m}^{2}$. Thus, the efficiency of the module Eff $\mathrm{fv}_{\mathrm{pv}}$ can be described as:

$\mathrm{Eff}_{\mathrm{pv}}=\frac{Q_{m p p}}{A_{p v} \cdot 1000 W / m^{2}}$

with

$Q_{\mathrm{mpp}} \quad$ Maximal power output according to STC $\quad[\mathrm{W}]$

$A_{p v}$

Area of the module

$\left[\mathrm{m}^{2}\right]$

Inserting values given in Table 17, the efficiency can be established as being $4 \%$.

By combining the output of the solar radiation model with the technical specification for the modules it is possible to determine the annual output of the system.

Table 23 shows the expected annual electricity generation of one Voltarlux panel and the window element of the multifunctional envelope. Given that overhead glazing was discussed as a more appropriate use of the PV window, the energy yield of glazing with a tilt of $45^{\circ}$ is indicated as well. 
Table 23: Total effective electrical output of the photovoltaic window, showing dependence on area and tilt

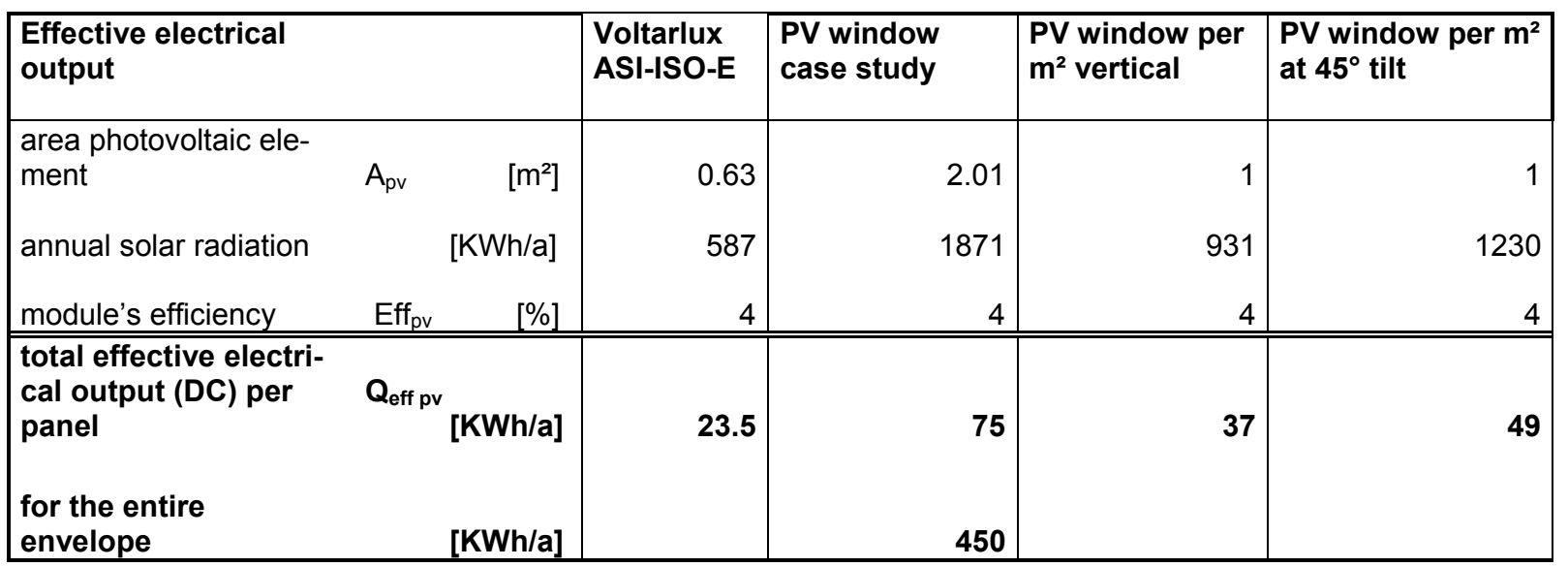

The total electricity output of the system in one year is $450 \mathrm{kWh}$.

\subsubsection{ENERGY REQUIREMENTS OF THE PUMPS}

As calculated, the four $20 \mathrm{~W}$ pumps in the solar thermal system require $352 \mathrm{KWh} / \mathrm{a}$ in total. The pump for the green wall was presumed to have the same wattage, resulting in an additional $88 \mathrm{KWh} / \mathrm{a}$. The total of $440 \mathrm{kWh} / \mathrm{a}$ could just be provided by the PV window, especially, as both the need for increased irrigation and high pump activity in the solar thermal system are correlated to high solar radiation and therefore in tune with the output of the PV window. As the chosen pump the Grundfos Solar $P M$ 15-80 can run on DC electricity and has a built in maximiser, conversion would not be needed and no additional losses would be produced. Should an electric supply surplus occur it could be used to provide hot water, while a surplus in demand could be met by relying on electricity sourced from the grid. 


\subsection{RESULTS: RESOURCE USE OF THE TWO CASE STUDIES}

Starting with an overview of the entire envelope, the following section describes and compares the results of the Material Intensity Analysis carried out for the case study. A detailed discussion of the results for the different elements of the envelope follows. The analysis uses the design and configuration as described in the section Materials, Functions and Elements above (1.11). As the analysis revealed that some of the chosen elements (both conventional and multifunctional) would significantly increase the total resource use of the two envelopes, resource-optimised alternatives for both envelopes have been developed and described where appropriate. Appendix 1.17 gives a detailed list of all materials used, their quantities, material intensities and estimated life span, which makes it possible to adopt the different parameters of the analysis to other studies.

\subsubsection{SCOPE, ASSUMPTIONS AND BOUNDARIES}

Specific assumptions made to derive the results presented, will in general be mentioned in the relevant sections. However, the following section lists the most important assumptions.

If not otherwise stated the data presented always refers to the $2 \mathrm{~m}$ wide section of the envelope (which is equal to a sixth of the total envelope in terms of volume, floor area and surface). The amount of energy required for heating, hot water and electricity as shown also represents a sixth of the overall consumption. If not otherwise stated the composition of the envelopes is identical with the discussion in section 1.11 .

The period of time taken into consideration for the material analysis was 60 years. Materials with shorter estimated life spans were accordingly counted several times.

A heating system is not included in the material analysis of the envelope. This means that the material intensities of electricity, space heating and hot water provision only refer to the energy carrier used and not to a secondary heating system including boiler, tanks cables, pumps etc. However, the additional components which are directly linked to the installation and that are necessary to run the solar heating system, the green wall or the photovoltaic window (stratified storage tank, pumps, additional pipes, cables) were counted towards the overall impact of the multifunctional wall elements and hence the envelope. This allows for a comparison of the direct and indirect resource use of the envelope, as both case studies require similar systems to provide heating, electricity and hot water but differ in the amount of energy that needs to be provided due to different thermal performance and energy generation by the multifunctional envelope.

For the overall comparison the energy carrier was presumed to be oil for hot water and space heating burned in a heating system with a conversion efficiency of $90 \%$. Oil was chosen as it is the main fuel source for heating in Graz (refer to Table 28, p.132). All electricity used was presumed to be sourced from the Austrian grid.

Earthwork, foundations and doors are not included in the case study. 


\subsubsection{OVERALL COMPARISON}

The following two diagrams show part of the most important findings of the material intensity analysis. Starting with a quantitative comparison of the direct resource use of the two envelopes, Figure 67 gives an indication of the resources used (self-weight and maintenance) during the time frame of 60 years.

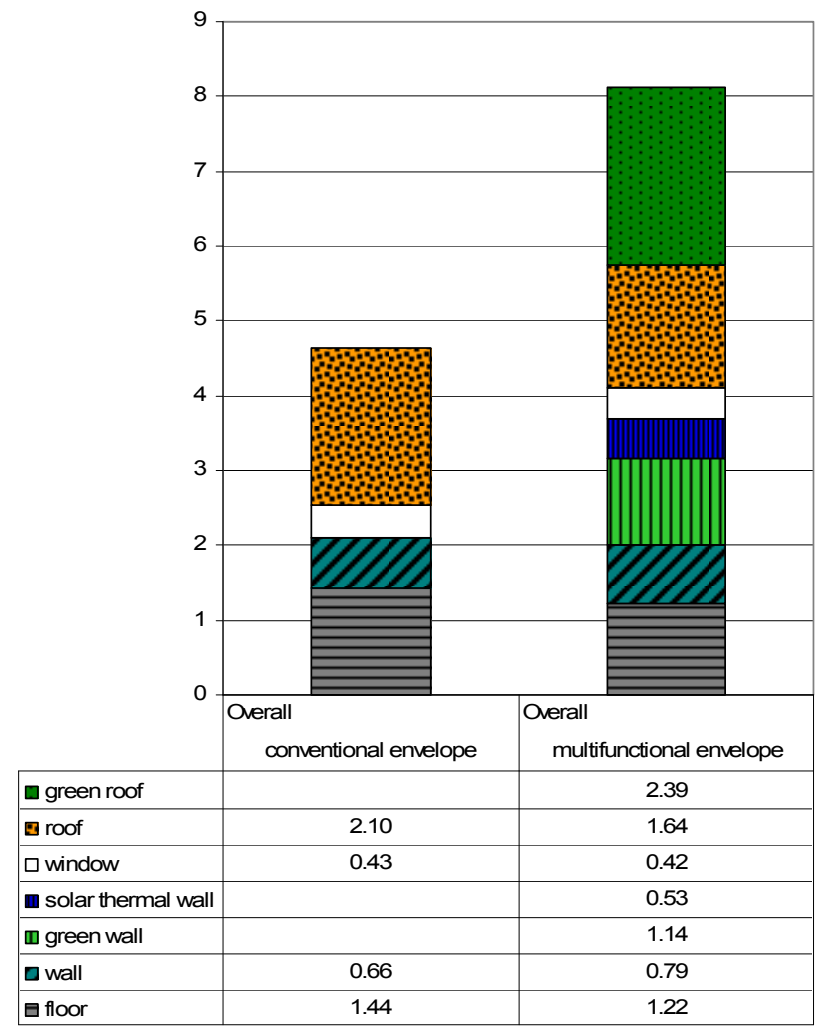

Figure 67: Direct resource use of the two envelopes

(in tonnes) over a 60 year period

It seems that the multifunctional elements, such as the green roof, the green wall or the solar thermal panels double the material flow of the multifunctional envelope in comparison to the conventional. The elements that exist in both envelopes such as floors, walls or the roof structure tend in general to be heavier in the conventional envelope. Therefore the multifunctional elements are really causing the bulk of the total weight of the multifunctional envelope (partly because they tend to be replaced more often due to their shorter lifespan).

However, as mentioned before, the direct resource use of an element is not an indicator of its overall resource consumption. Figure 68 therefore gives a more accurate impression as it reflects both the direct and the indirect resource use triggered by the two analysed envelopes. This time resource use is distinguished into abiotic, biotic, air and water use. 


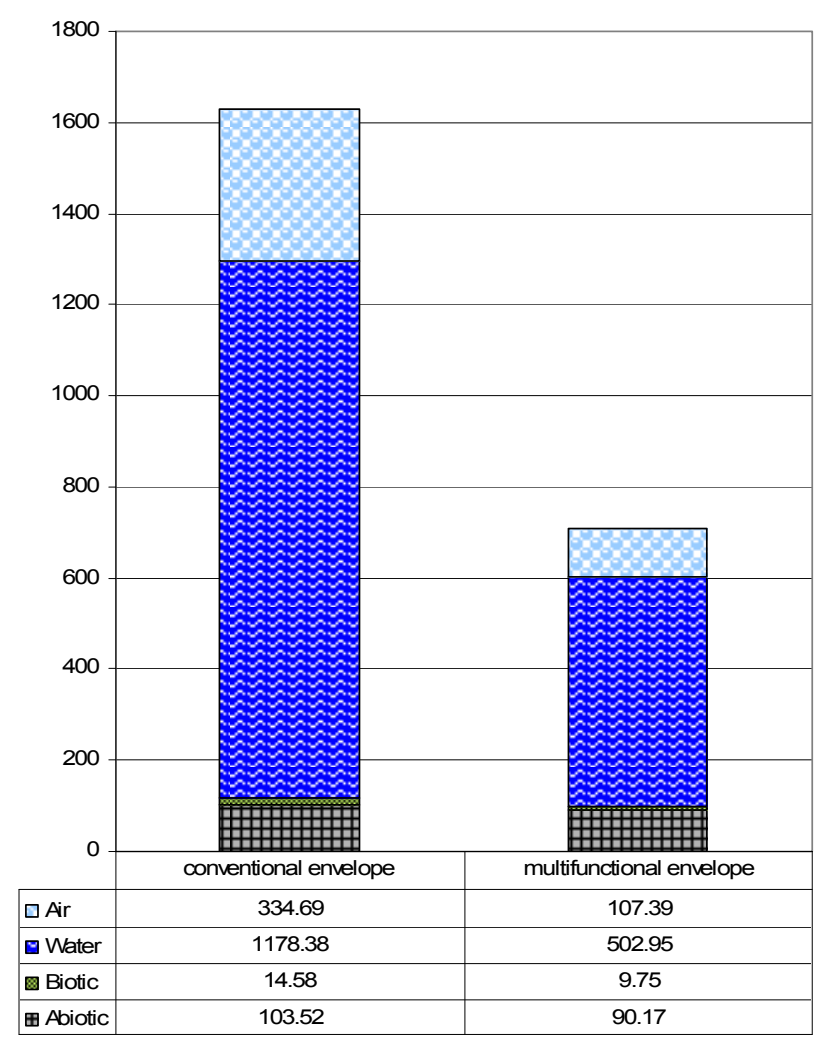

Figure 68: Overall resource use of the two envelopes

(in tonnes) taking both direct (self-weight) and indirect (ecological rucksack) material flows into account

It becomes apparent that the multifunctional envelope is more than twice as resource effective as the conventional envelope when all materials flows are taken into account. It hence seems a good example of effectiveness, as a bigger initial input results in a smaller global throughput.

From these two diagrams the following conclusions can be drawn:

- the direct resource use or self-weight of the envelope in itself cannot be used to predict the overall resource use (as already discussed in section 1.4.3.3.3.) A realistic picture ensues only if all the components that are directly involved or indirectly influenced by the envelope (such as heating requirements) are taken into account;

- the direct resource use of the two envelopes is only a small part $(0.3 \%$ for the conventional and $1.1 \%$ for the multifunctional envelope) of the overall resource use;

- water plays an important role in the material flows of envelopes;

- multifunctional elements seem to increase the resource productivity of the envelope significantly. However, looking at the different resource types, it is seen that some material flows are more effectively reduced than others.

The following diagram summarises the findings of this analysis. It indicates the overall resource use of the two envelopes distinguished both in types of resources used and the elements of the envelopes to which these relate. In the following sections the diagrams will be scaled to give better readability, here however the universal scale for all categories illustrates how the resource use is distributed. 


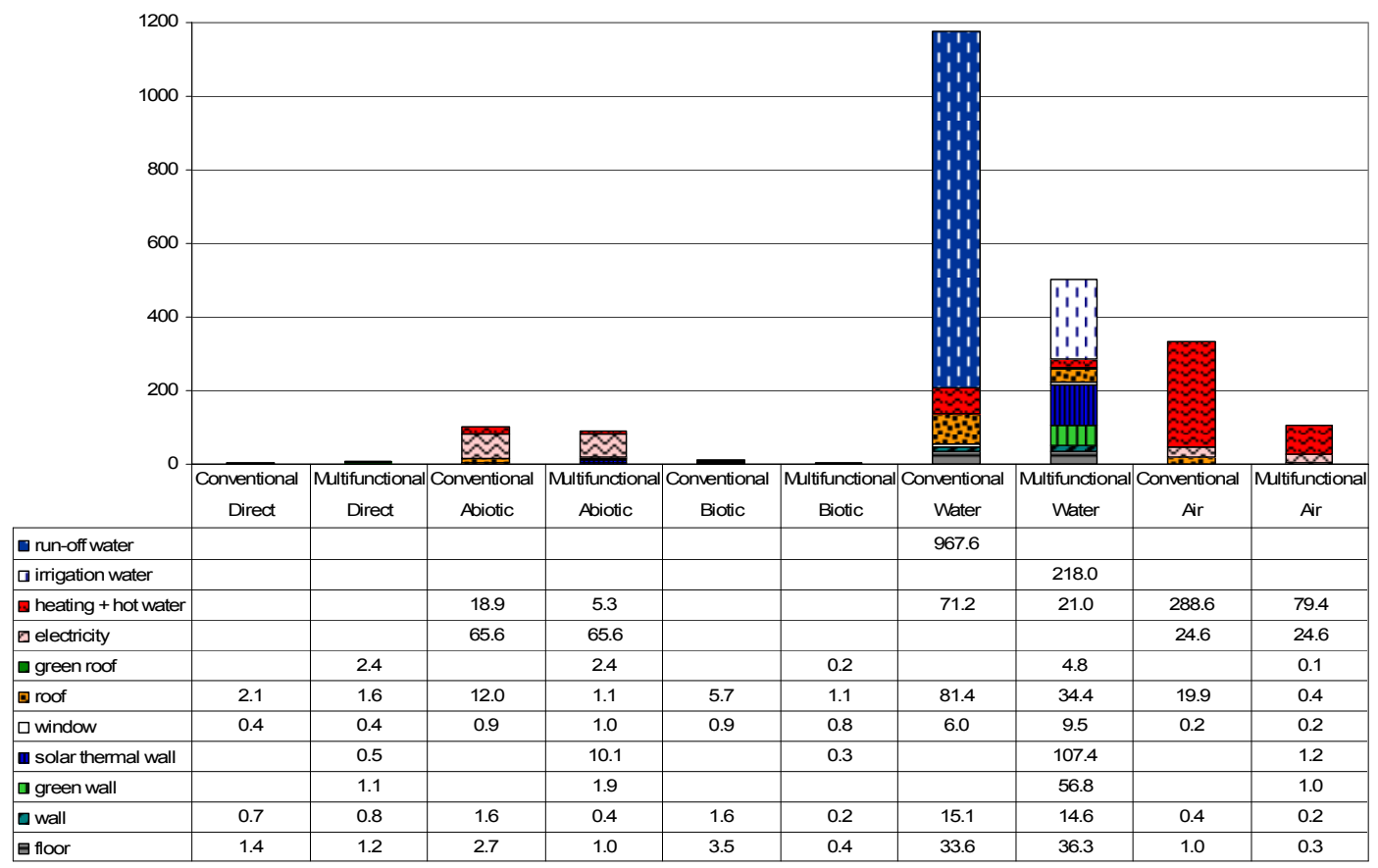

Figure 69: Overall resource use of the two envelopes

(in tonnes) distinguished by types of resources used and the elements of the envelopes

The source of material flows can be differentiated into external and internal components depending on whether they are part of the envelope or influenced by it indirectly.

The three major "external" contributors to material flows are explored below.

-Run-off water from the roof (968 tonnes)

The single largest contributor is the run-off water of the conventional roof that from the definition of the material intensity analysis (MIPS) is counted as a used resource (since it enters the technosphere when transported into the sewage system). The green roof of the multifunctional envelope minimises run-off and discharges the remaining water to the green wall

-Fuel used for space heating and hot water

The reduction of the material flows by $2 / 3$ for space heating and hot water can be almost entirely credited to the multifunctional solar thermal elements. As static insulation levels were similar for both envelopes (being in fact higher for the conventional), it becomes clear that the multifunctional elements successfully reduce the amount of resources used by both reducing the heat transmittance (of the wall and the roof) and by capturing solar heat for the heating system.

\section{-Electricity}

The contribution to the production of electricity of the multifunctional envelope was minimal (only $5.6 \%$ ). Although the production output could be expanded to a certain extend (both by more efficient panels and by covering a bigger area), photovoltaic window elements will probably not be sufficient to impact on the resource use to the level of the other multifunctional elements. Given the high material intensity of electricity, a greater leverage would probably lie in reducing the demand of the individual 
consumer. Multifunctionality can to a certain degree influence individual consumption patterns of electricity but for this case study it has to be noted that it clearly does not have a high leverage.

The major "internal" contributors of material flows were:

- the zinc roof of the conventional envelope;

- the solar thermal elements and the green wall panels of the multifunctional envelope.

As mentioned above, these elements were analysed and reviewed separately (refer to sections 1.13.1.5 and 1.13.1.7). This process was undertaken to derive a resource optimised version of the envelopes presented in the sections below. Having analysed possible improvements the following measures were taken.

- The zinc roof was replaced by a bituminous roof.

- The resource intensive elements (copper pipes and aluminium absorber) of the solar thermal elements were presumed to be made entirely from recycled materials rather than from half recycled as for the initial analysis.

- The fuel used for heating was presumed to be timber pellets.

- The use of a green wall was reconsidered entirely, as it did not contribute to quantitative improvements (e.g. insulation or cooling) but increased the resource use of the envelope as its most important function (retaining water) was already performed by the roof (e.g. the run-off of the green roof was not sufficient for the green wall, which in turn created a demand for irrigation water, as shown in Figure 69). It was therefore replaced by a simple plastic rain screen.

The resource use of these resource optimised versions of the two envelopes is shown in the figure below. 


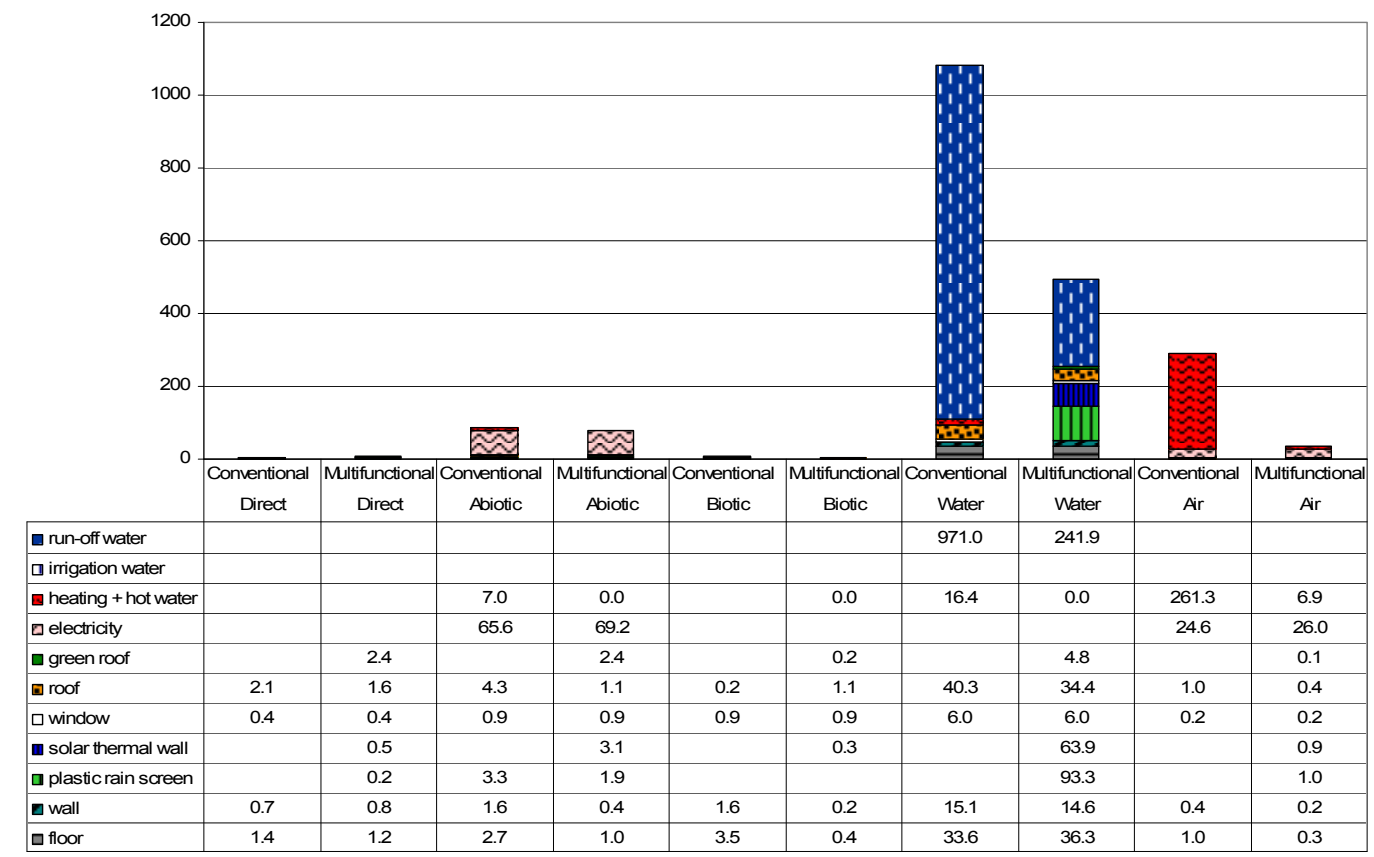

Figure 70: Overall resource use of the optimised versions of the two envelopes

(in tonnes) distinguished by types of resource used and the elements of the envelopes

By reconsidering design options, using recycled materials and not using multifunctional elements that increased the resource use, the material flows could be decreased by the following amounts (tonnes).

Table 24: Decline in material flows in tonnes after optimising the design of the two envelopes

\begin{tabular}{|l|l|l|l|l|l|}
\hline Envelope & Direct & Abiotic & Biotic & Water & Air \\
\hline Conventional & 0 & -16.39 & -5.49 & -96 & -46.17 \\
\hline Multifunctional & -0.97 & -8.74 & +0.13 & -7.78 & -71.6 \\
\hline
\end{tabular}

Before discussing the findings of the case study in more detail and the results of the material analysis of the different components of the envelopes and their alternatives (e.g. stainless steel, aluminium or plastic panels for green walls versus hydroponic wall), one other important aspect of the material analysis will be briefly introduced as it concerns the more detailed discussion that follows.

As will become clear in the following sections, one of the central findings of the analysis is that on an individual level most of the multifunctional elements have the potential to reduce a certain type of resource use, while increasing another. This is shown as using solar thermal elements in combination with an oil-fuelled secondary heating system, for example, decreases the material flow of air and abiotic resources in comparison to the exclusive use of an oil based system. At the same time it adds 50 tonnes of water usage which is almost twice as high as the water usage of the oil based system.

For some of the elements it is therefore impossible to produce a conclusive statement about their resource efficiency given that one resource use is not interchangeable with another in the material intensity analysis. On one hand the analysis enables informed decisions as it does not reduce all the different types of resources used to one single output as other analytical tools do, such as only indicating energy requirements for example. The material analysis does therefore allow for design or 
product choices based on user priorities or circumstances as it gives differentiated results. For example the high water consumption of some products might be considered a critical factor in many parts of the world or the reduction of abiotic material flow could be prioritised in order to reduce the reliance on non-renewable resources. On the other hand it seems to make choices rather complex when many components are involved and does not always allow for a quick answer on a component level. However the analysis clearly shows that overall the multifunctional elements working in conjunction are decreasing the resource use effectively (this points again to the discussion of eco-effectiveness versus eco-efficiency in section 1.4.3.2, p. 26).

To summarise the findings of the material analysis in regard to the question of effectiveness of multifunctionality to reduce resource use, it can be stated that multifunctionality works as a strategy that can decrease resource use (e.g. green roof) if used correctly. However, it can also have just a marginal leverage (e.g. influencing consumption patterns) or even increase resource use when synergistic effects are not produced or are insufficient to outweigh the higher initial inputs that often occur (e.g. green wall).

\subsection{DIRECT RESOURCE USE (SELF WEIGHT)}

The diagram on the right of Figure 71 shows the direct resource use of the two envelopes during their 60 years of operation. The multifunctional envelope, with its different resource intense components such as the green wall and the green roof, has a direct resource use of 8.13 tonnes, which is 1.7 times bigger than that of the conventional envelope with 4.63 tonnes.
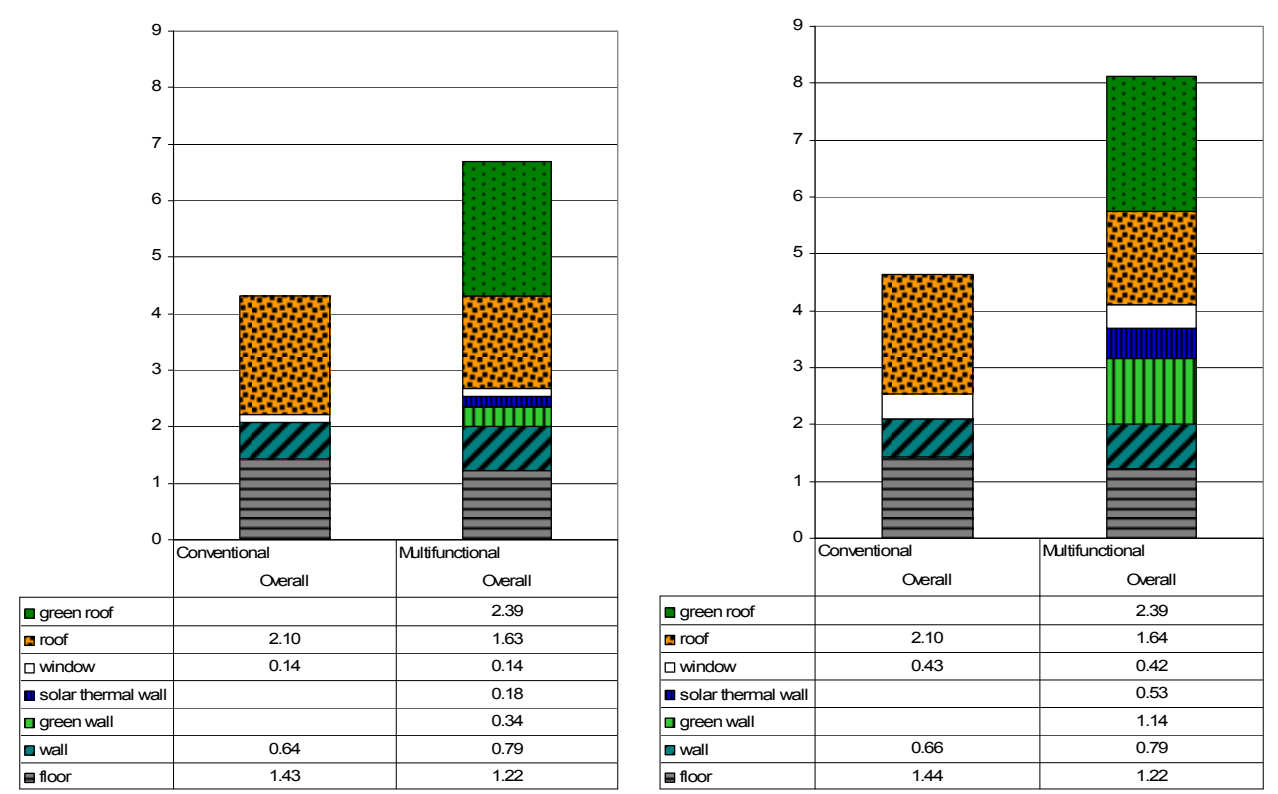

Figure 71: Initial direct resource use of the two envelopes

(left) and after 60 years of operation (right) (in tonnes), when several components have been replaced

The resource inputs of the roofs contribute the most to the total resources for both envelopes. The difference between the initial direct resource (left) and the direct resource use after 60 years (right) is larger for the multifunctional case study than for the conventional envelope as for example the wall elements (the solar thermal wall, the green wall as well as the photovoltaic window) have to be replaced several times during the 60 year period, as indicated in Table 11, p.85. 
While Figure 71 gives an indication of the overall direct resource use, Figure 72 does distinguish between resource types and reflects the composition of the materials used in the two envelopes. Composite materials such as MDF, chipboard or the straw-fibre panels were included under biotic materials, which means that the glue and resin components of these materials may have been ignored.
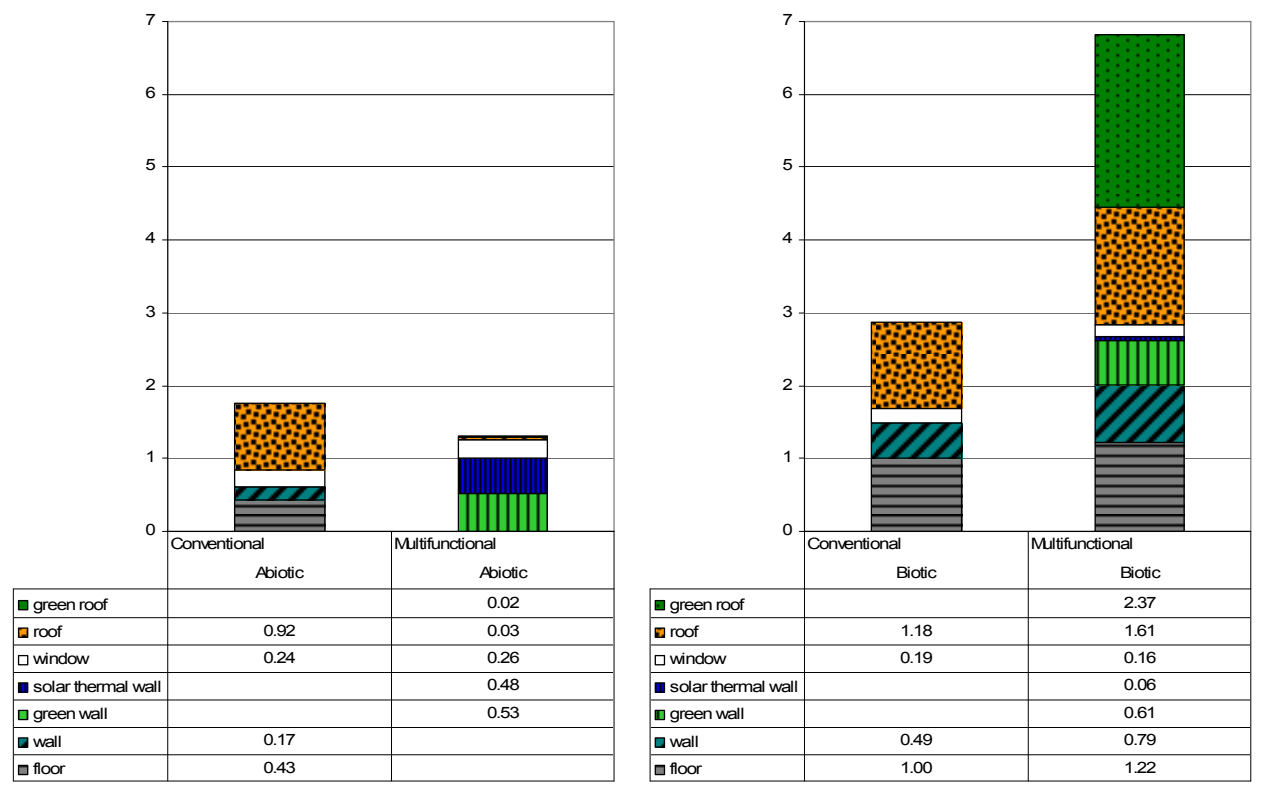

Figure 72: Direct resource use of the two envelopes over 60 years

(in tonnes) apportioned as abiotic and biotic materials

Although the diagram is therefore only a rough estimate (in terms of composition), it becomes clear that the multifunctional envelope uses a smaller amount of abiotic materials than the conventional envelope but has a larger resource use in terms of biotic materials. The green wall and roof alone with their large amounts of substrate contribute approximately three tonnes of biotic matter. The solar thermal elements ( 0.48 tonnes) and the green wall ( 0.53 tonnes) contribute the most to the abiotic resource use of the multifunctional envelope, while the zinc roof ( 0.92 tonnes) forms more than half of the abiotic resource use of the conventional envelope.

Table 25 summarises the findings of the figures above and indicates the direct resource use of the envelopes over a sixty year period.

Table 25: Direct resource use of the two envelopes over 60 years in tonnes (estimate)

\begin{tabular}{|c|c|c|c|c|c|c|}
\hline & \multicolumn{2}{|l|}{ Abiotic } & \multicolumn{2}{|l|}{ Biotic } & \multicolumn{2}{|l|}{ Overall } \\
\hline & Conventional & Multifunctional & Conventional & Multifunctional & Conventional & Multifunctional \\
\hline floor & 0.43 & & 1.00 & 1.22 & 1.44 & 1.22 \\
\hline wall & 0.17 & & 0.49 & 0.79 & 0.66 & 0.79 \\
\hline green wall & & 0.53 & & 0.61 & & 1.14 \\
\hline solar thermal wall & & 0.48 & & 0.06 & & 0.53 \\
\hline window & 0.24 & 0.26 & 0.19 & 0.16 & 0.43 & 0.42 \\
\hline
\end{tabular}




\begin{tabular}{|c|c|c|c|c|c|c|}
\hline roof & 0.92 & 0.03 & 1.18 & 1.61 & 2.1 & 1.64 \\
\hline green roof & & 0.02 & & 2.37 & & 2.39 \\
\hline total & 1.77 & 1.31 & 2.87 & 6.82 & 4.63 & 8.13 \\
\hline
\end{tabular}

\subsection{INDIRECT RESOURCE USE (ECOLOGICAL RUCKSACK)}

As discussed in section 1.4.3.3.4, the direct resource use alone is a poor indicator of the overall material flows triggered by building activities. The real impact can only be established by looking at direct use in conjunction with indirect resource use (or ecological rucksack).

Table 26 is the complement to Table 25, summarising the indirect resource use of the two envelopes according to the main types of resources: abiotic resources, biotic resources, water and air. Earth movement was excluded as it is currently not part of the MI data base.

Table 26: Indirect resource use of the two envelopes over 60 years in tonnes

\begin{tabular}{|c|c|c|c|c|c|c|c|c|}
\hline & \multicolumn{2}{|l|}{ Abiotic } & \multicolumn{2}{|l|}{ Biotic } & \multicolumn{2}{|l|}{ Water } & \multicolumn{2}{|l|}{ Air } \\
\hline & $\begin{array}{l}\text { Conven- } \\
\text { tional }\end{array}$ & $\begin{array}{l}\text { Multifunc- } \\
\text { tional }\end{array}$ & $\begin{array}{l}\text { Convention } \\
\text { al }\end{array}$ & $\begin{array}{l}\text { Multifunc- } \\
\text { tional }\end{array}$ & $\begin{array}{l}\text { Convention } \\
\text { al }\end{array}$ & $\begin{array}{l}\text { Multifunc- } \\
\text { tional }\end{array}$ & $\begin{array}{l}\text { Convention } \\
\text { al }\end{array}$ & $\begin{array}{l}\text { Multi- } \\
\text { func- } \\
\text { tional }\end{array}$ \\
\hline floor & 2.68 & 0.99 & 3.47 & 0.39 & 33.61 & 36.33 & 0.98 & 0.29 \\
\hline wall & 1.62 & 0.4 & 1.62 & 0.16 & 15.06 & 14.6 & 0.39 & 0.16 \\
\hline green wall & & 1.94 & & 0.00 & & 56.84 & & 0.98 \\
\hline $\begin{array}{l}\text { solar } \\
\text { thermal wall }\end{array}$ & & 10.13 & & 0.27 & & 107.39 & & 1.25 \\
\hline window & 0.93 & 0.97 & 0.9 & 0.77 & 6.02 & 9.54 & 0.22 & 0.24 \\
\hline roof & 11.98 & 1.09 & 5.72 & 1.09 & 81.4 & 34.43 & 19.93 & 0.39 \\
\hline green roof & & 2.43 & & 0.24 & & 4.78 & & 0.05 \\
\hline electricity & 65.6 & 65.6 & & & not known & $\begin{array}{l}\text { not } \\
\text { known }\end{array}$ & & 24.6 \\
\hline $\begin{array}{l}\text { heating + } \\
\text { hot water } \\
\text { (oil) }\end{array}$ & 18.94 & 5.32 & & & 71.24 & 21.05 & 288.57 & 79.43 \\
\hline $\begin{array}{l}\text { run-off } \\
\text { water }\end{array}$ & & & & & 971.04 & 0 & & \\
\hline irrigation & & & & & & 218 & & \\
\hline total & 101.75 & 88.87 & 11.72 & 2.95 & 1178.38 & 502.95 & 334.7 & 107.39 \\
\hline
\end{tabular}


Water is used in the largest quantity, followed by air and abiotic materials.

Given that both envelopes are largely made from biotic materials (timber and straw) it is interesting that biotic materials play the smallest role in the indirect resource use of the envelopes.

Table 27 indicates the ratio of direct and indirect resource use for biotic and abiotic materials over 60 years of operation. Although the distribution between abiotic and biotic materials in the direct resource use might be slightly different as all composite materials (chipboard, OSB, straw fibre-board) were counted as biotic materials, it is still apparent that the ecological rucksack of the abiotic materials used is far greater (accounting for around $98 \%$ of the material flows) than for biotic materials (accounting for $80 \%$ (conventional) and $29 \%$ (multifunctional) of the material flows). As a rule it seems that the higher the percentage of abiotic materials in the direct resource use of an element the higher its indirect resource.

Table 27: Overall resource use of the two case studies including direct and indirect resource use in tonnes

\begin{tabular}{|l|l|l|l|l|}
\hline \multicolumn{2}{|l|}{ Abiotic } & \multicolumn{2}{l|}{ Biotic } \\
\cline { 1 - 5 } & Conventional & Multifunctional & Conventional & Multifunctional \\
\cline { 1 - 5 } Direct & 1.8 & 1.3 & 2.9 & 6.8 \\
\cline { 1 - 5 } Indirect & 101.7 & 88.9 & 11.7 & 2.9 \\
\cline { 1 - 5 } Total & 103.5 & 90.2 & 14.6 & 9.7 \\
\cline { 1 - 5 } Ratio (direct/indirect) & $1 / 57$ & $1 / 68$ & $1 / 4$ & $2.3 / 1$ \\
\hline
\end{tabular}

Having analysed the ratio of direct and indirect resource flows triggered by the two envelopes, the following figures focus on the indirect resource use and analyse its implications.

Figure 73 illustrates the indirect abiotic and biotic resource use of the two case studies.
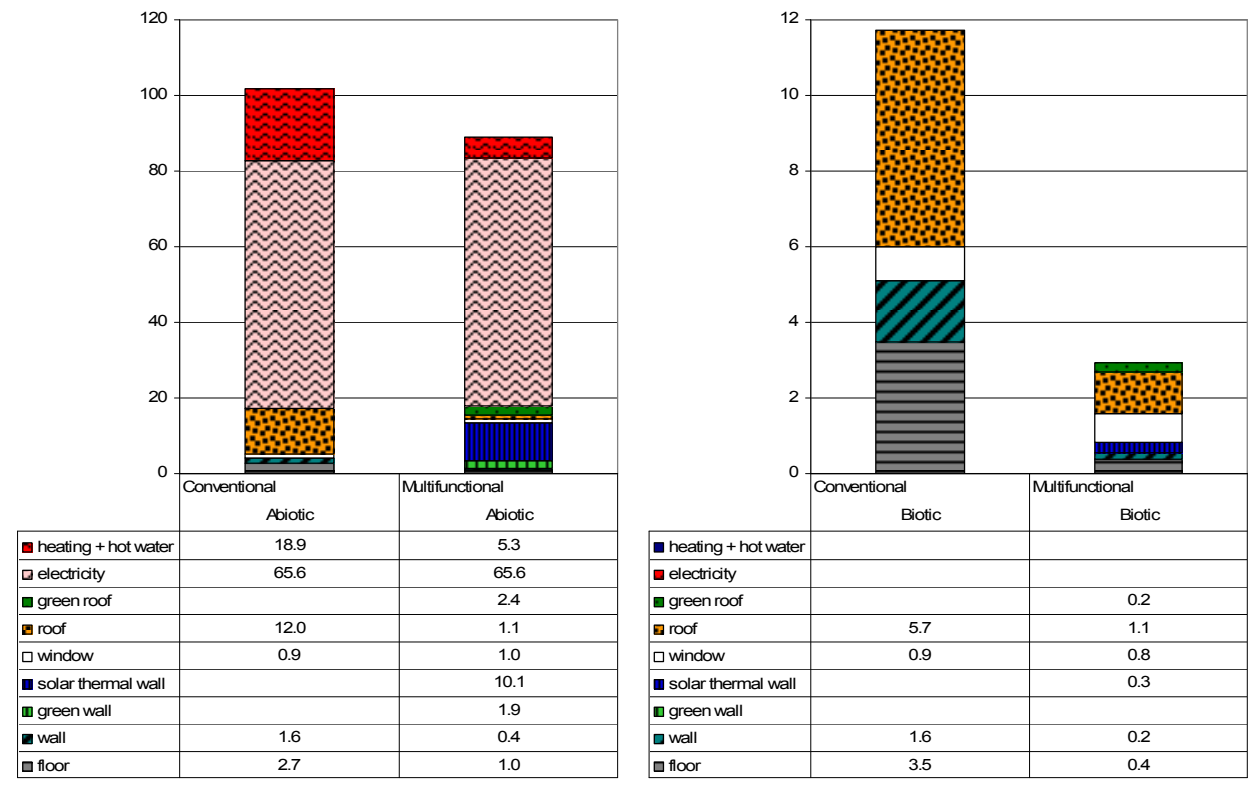

Figure 73: Abiotic and biotic indirect resource use of the two envelopes

(in tonnes) over 60 years 
The two diagrams highlight three facts:

- The abiotic resource use is mainly influenced by personal consumption patterns (consumption of electricity in a private household) and its size is roughly three times the indirect material flows triggered by the envelopes themselves. Compared to the abiotic resources from the provision of electricity (65 tonnes), all other material intensities combined seem small. This leads to the conclusion that leverage for decreasing resource use is greater through changes in personal behaviour than through multifunctionality, which is often limited to increasing the effectiveness of the components of the envelope (although it can impact on the behaviour of users). Indeed as, will be discussed below, saving electricity seems one of the most efficient ways to reduce resource flows in the domestic environment.

- Although multifunctionality does not have a major impact on personal consumption patterns in this case study, it largely influences the heating requirements and consequently the resulting resource use. While the conventional envelope has similar static U-values (or insulation levels) to the multifunctional envelope it still requires almost three times the abiotic resources for heating and hot water provision. The higher resource productivity of the multifunctional envelope is achieved by a combination of better insulation levels due to the green roof and the solar thermal panels (dynamic U-values) and the multifunctional solar thermal system that captures the solar heat.

- The data shown in Figure 73 underlines the importance of an integrated approach that includes good insulation levels, energy-efficient applications, a resource efficient heating system and above all the willingness of the consumer to use less energy.
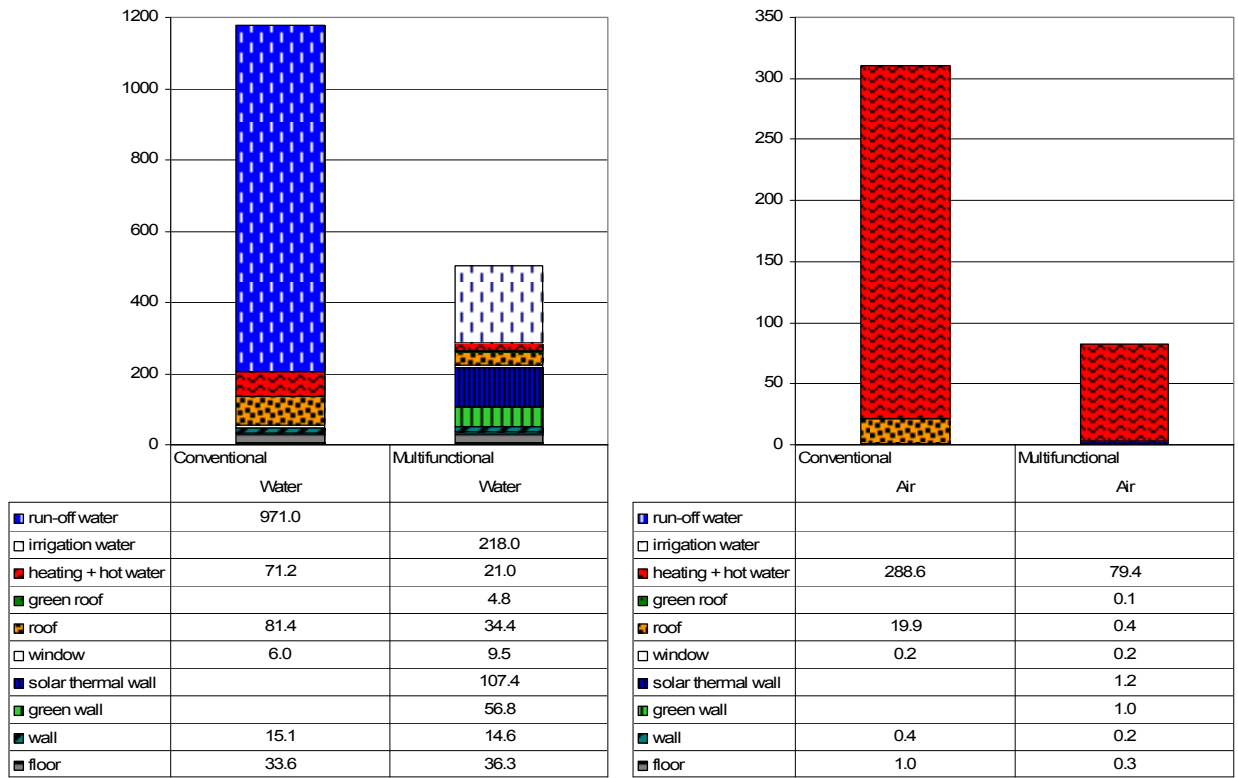

Figure 74: Indirect use of water and air

(in tonnes) over 60 years

Figure 74 indicates the indirect use of water and air by the two envelopes over 60 years. Again heating plays an important role especially in air consumption. As oil is the fuel for the heating system, it is not surprising that the emissions from its combustion make a large contribution to the use of air. The multifunctional case study is almost four times more efficient in terms of air use than the conventional 
even when the combustion air caused by the solar thermal system is taken into account. The air parameter cannot be equated one-to-one with harmful emissions (such as $\mathrm{CO}_{2}$ ) as combustion air includes harmless gases as well, but it can still act as a quantitative indicator that highlights ratios. The only other significant contributor in the diagram on the right is the zinc roof with its 20 tonnes of air. A bituminous roof as used for the optimised envelope would reduce this figure to 1 tonne (refer to Figure 70).

The water consumption of the conventional envelope is almost three times that of the multifunctional envelope. The heating system has some impact, but most of the consumed water is run-off water from the zinc roof and process water used during its manufacture.

In order to reduce water consumption, the most effective measure would be to collect the run-off water and to use it either in the household, the garden or to provide a natural retention area. If one of these measures were taken, the multifunctional envelope would have a higher level of water consumption in both the basic scenario and the optimised alternative shown in Figure 70, p. 126.

As discussed above the green roof reduces the amount of run-off water as does the green wall. However, the combination of green roof and green wall is a bit unfortunate in terms of water usage as it results in a lack of irrigation water for the green wall which increases the water consumption as tap water would be needed for irrigation purposes (refer to

Table 14).

\subsubsection{RESOURCE USE: HEATING AND HOT WATER}

For the case study it was presumed that the heating system was fuelled by oil as this is the most common fuel source in Graz, as indicated in Table 28 (Statistik Austria, 2009). However, it seemed useful to investigate how the case studies would perform if other fuel options were chosen.

Table 28: Composition of energy carriers to provide heating in private households in the Steirmark in 2007/2008

\begin{tabular}{|c|c|c|c|c|c|}
\hline \multirow[t]{2}{*}{ Energy carrier used in the Steirmark } & \multirow[t]{2}{*}{$\%$} & \multicolumn{4}{|c|}{ Material intensity } \\
\hline & & $\begin{array}{l}\text { abiotic } \\
\text { kg/kWh }\end{array}$ & \begin{tabular}{|l} 
biotic \\
$\mathrm{kg} / \mathrm{kWh}$
\end{tabular} & $\begin{array}{l}\text { water } \\
\mathrm{kg} / \mathrm{kWh}\end{array}$ & $\begin{array}{l}\text { air } \\
\mathrm{kg} / \mathrm{kWh}\end{array}$ \\
\hline oil & 29 & 0.21 & & 0.79 & 3.2 \\
\hline timber (not specified if fire logs, scraps or pellets) & 26 & & & & \\
\hline - fire wood & & 0.17 & 0.36 & 0.04 & 2.55 \\
\hline -pellets/scraps & & 0.01 & & 0.16 & 2.55 \\
\hline district heating & 25 & unknown & unknown & unknown & unknown \\
\hline gas & 9 & 0.1 & & 0.04 & 3.6 \\
\hline electricity & 8 & 0.8 & & unknown & 0.3 \\
\hline solar thermal/ heat pump & 1.3 & unknown & unknown & unknown & unknown \\
\hline
\end{tabular}

According to the Austrian statistical office oil is the most used fuel in the Steirmark, the county in which Graz is situated, with a share of $29 \%$, closely followed by timber $(26 \%)$ and district heating $(25 \%)$. Gas $(9 \%)$, electricity $(8 \%)$ and solar thermal heating are of less importance. Timber use for heating is currently on the rise in Austria having overtaken oil in 2008 for the first time since oil became available (Statistik Austria, 2009). The table also indicates the material intensities of the energy 
carriers. Timber scraps and pellets have the smallest resource use given that they are made from byproducts of the timber industry. Similar to the straw-fibre elements used in the case study, their material intensity does not include the sourcing of the timber, as this is allocated to the main product which is construction timber, fire wood or other timber products. By contrast, fire wood is not a by-product and therefore has a much larger material intensity in terms of abiotic materials. Förstner showed that the relatively high abiotic material intensity of timber of $0.18 \mathrm{~kg}$ per $\mathrm{kg}$ timber is caused by building forest roads and calculated that it is actually more resource efficient in the analysed case studies to use a helicopter to transport the timber to the mill so the construction of forest roads can be avoided (0.0007kg/kg timber) (Schmidt-Bleek, F., Manstein, C. 1999, p.68).

Figure 75 indicates the abiotic and biotic resource use as well as the water use of the main energy carriers used in the case study. Unfortunately no data could be obtained for district heating. The left hand diagram shows the resources needed to provide heating and hot water for the conventional envelope depending on the energy carrier used. The right hand diagram shows the resource use of the multifunctional envelope including all components of the solar thermal system (e.g. collector, absorber, pipes, stratified storage tanks, pumps etc.) and the resource use of the energy carrier that would be needed in a secondary or back-up heating system. For both diagrams, only the energy carriers were taken into account (no hardware for the space heating was included). As mentioned above the solar thermal system does change the resource use caused by space heating and hot water provision, reducing it in absolute numbers. However water usage it higher for the multifunctional envelope independent of the fuel used for the heating system, as the solar thermal panels, which are largely made from aluminium and copper pipes, have a big influence on the water consumption.

In Austria electricity is the least resource productive possible fuel resource. Unfortunately the water consumption caused by Austrian electricity generation could not be established.
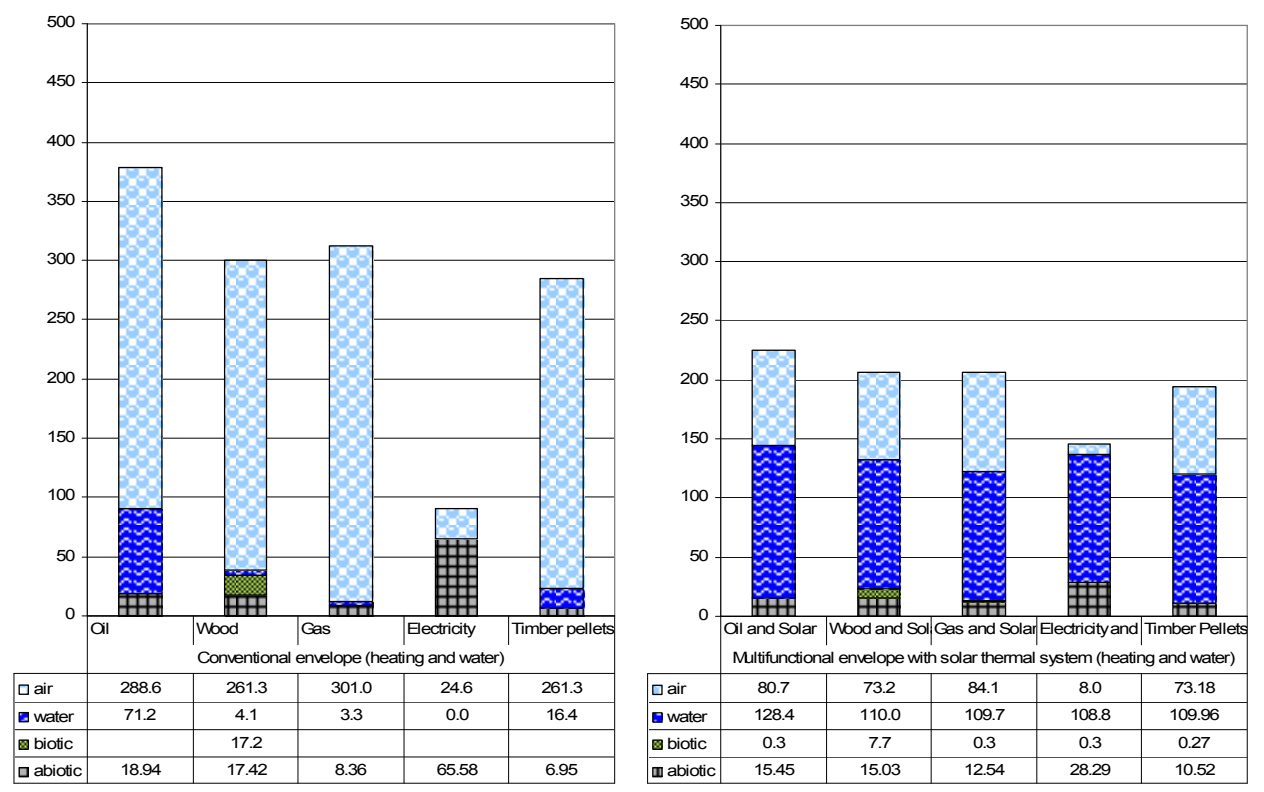

Figure 75: Resource use of different fuel options

based on the energy requirements of the two envelopes for hot water and heating over 60 years (in tonnes). The right diagram indicates the resource use of the solar thermal element in combination with the fuel needed for the secondary heating system

Figure 76 compares the resource use of the multifunctional envelope including its solar thermal system with the same multifunctional envelope when the solar thermal panel is omitted. This analysis was 
done to decide if a resource-optimised version should include a solar thermal system or not. The removal of the solar thermal system does increase the amount of heating that has to be provided by the normal heating system but does on the other hand exclude all the resources otherwise needed for the solar thermal system and its components over 60 years. As the solar thermal envelope also increases the thermal resistance of the wall, a different heat load had to be taken into account (Transmission loss index $L_{T}$ rose from 64 to 69 , refer to section 1.16.1.1).
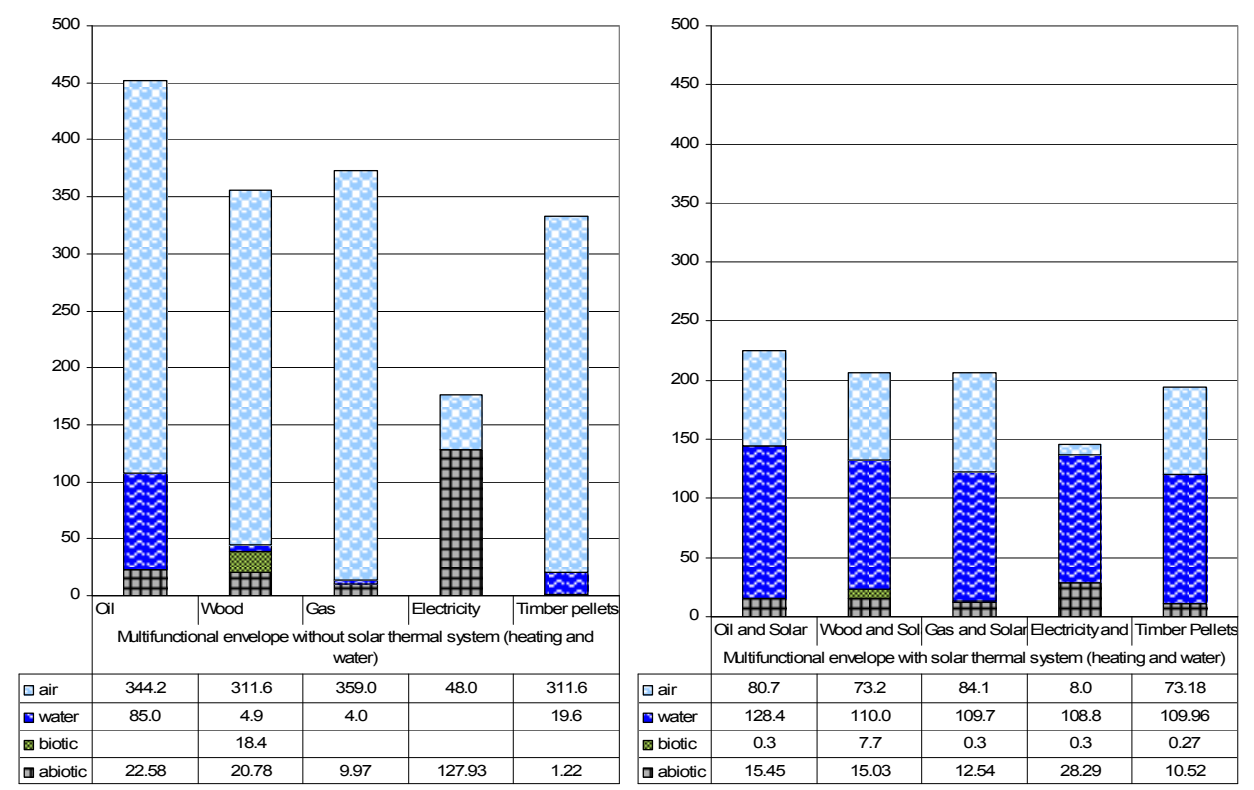

Figure 76: Resource use of the multifunctional envelope with (right) and without (left) solar thermal elements over 60 years depending on energy carrier used in the heating system for space heating and hot water provision (in tonnes).

The comparison actually shows that the overall resource use is decreased by having the solar thermal system integrated in the wall. However, some combinations are better than others. While a solar thermal system can decrease all materials flows except water, when oil is used as fuel for space heating and hot water provision, it actually increases all material flows except air use when compared with a system fuelled by gas or timber pellets.

Bergmann, who came to similar conclusions, therefore stated that: "it can be concluded that the resource-efficiency of a heating system fuelled by timber pellets, which represents a particularly efficient system, is not achievable with solar thermal panels." (Bergmann, I., Weiss, W. 2002, p. A83).

According to Bergmann a similar solar thermal system would have to have a life span of 67 years in order to become as resource efficient as a heating system fuelled by timber pellets. Current solar systems have a life span of 20-25 years.

One way to improve the performance of the solar thermal system is by using recycled materials. Figure 77 shows the improved resource efficiency of such a system (right hand diagram) in combination with different fuels used for space heating and hot water. A combination of a solar thermal heating system and a secondary oil based system (right hand diagram) is now more resource effective in all resource categories than using oil as the only source of heating and hot water (left hand diagram). When oil is used, the multifunctional option with solar panels outperforms the multifunctional option without solar panels and can decrease the resource use effectively. Compared and combined with wood or gas based systems, it reduces the abiotic, biotic and air consumption but increases the water 
consumption. However, compared with a heating system fuelled by timber pellets, it remains less efficient.
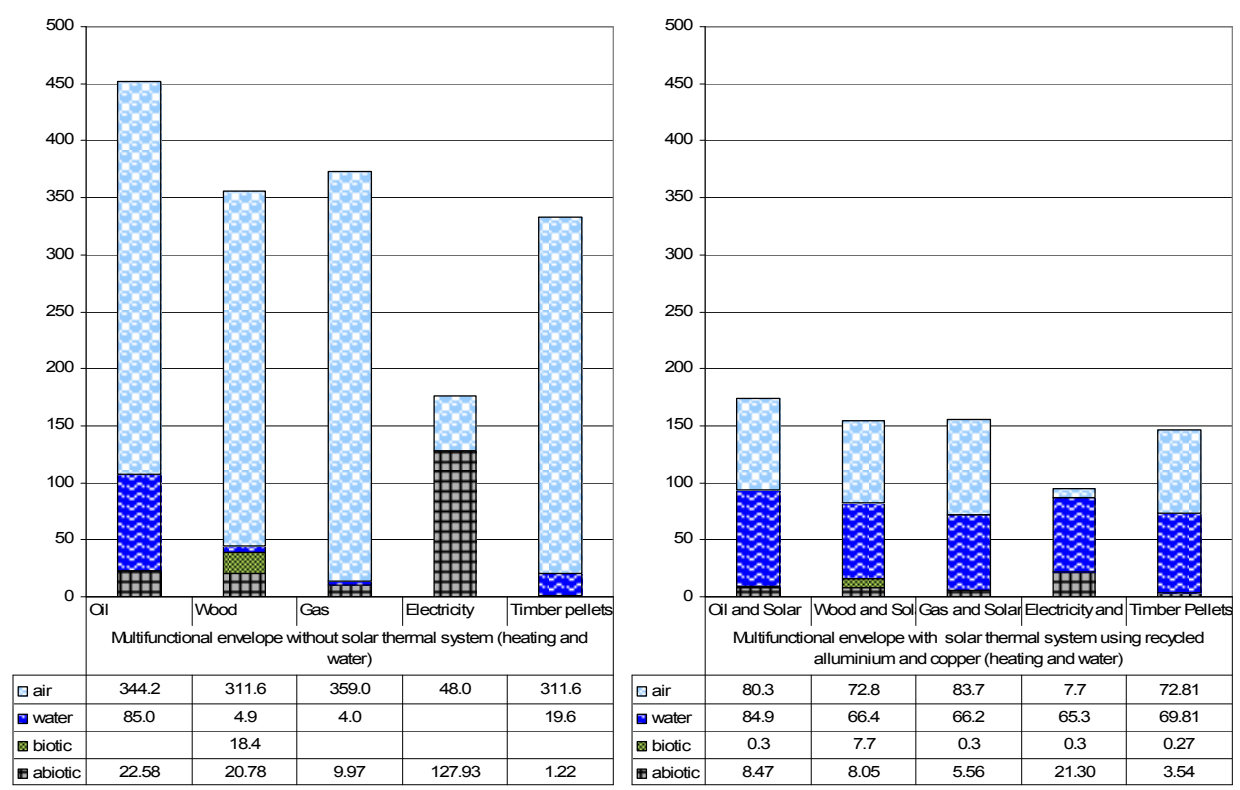

Figure 77: Resource use of the multifunctional envelope (in tonnes) with solar thermal elements

using recycled materials (right hand diagram) over 60 years compared with the multifunctional envelope not using a solar thermal system.

Although these findings might seem disappointing at first, given that solar thermal panels are often presented as one of the most environmentally friendly and efficient technologies in residential housing, it should be underlined that the resource use of abiotic and biotic materials should not be the only factor taken into account when weighing up the performance of the panels. The solar thermal element can reduce the amount of air that is involved by at least a factor of four, as shown in Figure 77.

\subsubsection{RESOURCE USE: ELECTRICITY}

As shown in section 1.13.1.1.2, electricity is the major contributor to the resource use of both case studies. This is due to the fact that electricity is resource intensive in production as well as in distribution. However, the material intensity of electricity can vary widely depending on the resource and method used to generate it. Table 29 indicates the resource use of electricity in different parts of the world. While Austrian electricity is relatively resource productive as it is sourced mainly from hydropower which has a low operational resource input, other countries such as Germany have a high input due to the continuous use of coal or other resource intense energy carriers to generate power. The potential to minimise resource use by saving electricity is therefore not only true of Austria, but has an even bigger leverage in some other countries. 
Table 29: Material Intensities of electricity

\begin{tabular}{|c|c|c|c|}
\hline Country & $\begin{array}{l}\text { Abiotic } \\
\mathrm{kg} / \mathrm{kWh}\end{array}$ & $\begin{array}{l}\text { Water } \\
\text { kg/kWh }\end{array}$ & $\begin{array}{l}\text { Air } \\
\mathrm{kg} / \mathrm{kWh}\end{array}$ \\
\hline World ${ }^{* *}$ & 1.55 & 66.7 & 0.535 \\
\hline OCDE** & 1.58 & 63.8 & 0.425 \\
\hline Austria* & 0.8 & unknown & 0.3 \\
\hline Germany** & 4.7 & 83.1 & 0.6 \\
\hline
\end{tabular}

*(Schmidt-Bleek, F., Manstein, C., 1999, p. 20) **(Wuppertal Institute, 2003-2009)

\section{IS THE USE OF THE PHOTOVOLTAIC WINDOW ELEMENTS RESOURCE-EFFICIENT?}

As discussed in section 1.11.1.5, the multifunctional case study produces electricity with the help of its photovoltaic windows. At the same time the photovoltaic elements reduce the amount of passive heat gains and thereby increase the need for space heating in winter. Therefore the question arises whether their electricity output offsets the resources for the additional space heating.

The electric output of the PV windows for the entire envelope was established as $450 \mathrm{kWh} / \mathrm{a}$ (or 75 $\mathrm{KWh} / \mathrm{a}$ for the $2 \mathrm{~m}$ wide section) in section 1.12.3.1. Compared to the estimated overall consumption of $8000 \mathrm{kWh} / \mathrm{a}$ for all four occupants of the case study (or $1333 \mathrm{kWh} / \mathrm{a}$ relative to the $2 \mathrm{~m}$ wide section), this represents $5.6 \%$ of total.

Table 30 summarises the givens of the multifunctional envelope and breaks them down into the 2 metre wide section.

Table 30: Comparison of production of electricity and additional heating requirements caused by the PV window over a 60 year period when only the $2 \mathrm{~m}$ wide section of the envelope is considered

\begin{tabular}{|l|l|l|}
\hline Energy type & with PV window & $\begin{array}{l}\text { with conventional } \\
\text { window }\end{array}$ \\
\hline Heat gains & 477 KWh/a $(2860 \mathrm{KWh} / \mathrm{a} / 6)$ & $816 \mathrm{KWh} / \mathrm{a}(4896 \mathrm{KWh} / \mathrm{a}$ \\
$/ 6)$
\end{tabular}

While producing electricity, the photovoltaic cells in the windows reduce the amount of solar radiation that penetrates the building resulting in a reduction in usable heat gains $Q_{\text {annum }}$ in winter from 4896 $\mathrm{kWh} / \mathrm{a}$ to $2860 \mathrm{kWh} / \mathrm{a}$. The required warmth must therefore be provided by the space heating. In 60 years $122160 \mathrm{kWh}$ of passive heat gains will be lost due to the photovoltaic elements and will have to be provided by the heating system.

To answer the question whether it is preferable (from a resource point of view) to abandon the photovoltaic windows and replace the $4500 \mathrm{kWh}$ of electricity they produce by electricity sourced from the grid but gain more passive heating in winter (an additional $20340 \mathrm{kWh}$ ) and therefore reduce the amount of heating that has to be provided, all inputs (including those of the conventional or the photovoltaic windows) have to be taken into account. In order to remain consistent with all other parts of the material intensity analysis this calculation was again broken down to the 2 metre wide section. The results of this weighing of options are illustrated in the two figures below. 
Figure 78 quantifies the resources needed to provide $20340 \mathrm{KWh}$ of heating (to replace 60 years of theoretically accumulated passive heat gains lost due to the photovoltaic elements partly shading the windows) and the resource use of the photovoltaic window elements during that period of time. The diagram takes different fuel options into account.

The results shown are ambiguous, as in terms of abiotic material flows, a heating system fuelled by oil or fire wood would make abandoning the photovoltaic windows a reasonable option as these fuels require more resources than the use of electricity from the grid. For timber pellets and gas, the use of a photovoltaic window does decrease the overall abiotic resource use. However, in terms of air consumption and the resulting production of greenhouse gases, the use of electricity from the grid is up to 47 times more resource efficient than installing the photovoltaic windows, which indirectly causes the combustion of between 65 and 74.9 tonnes of air for the extra space heating. In terms of water usage no statement can be made given that the water usage of Austrian electricity was not obtainable.
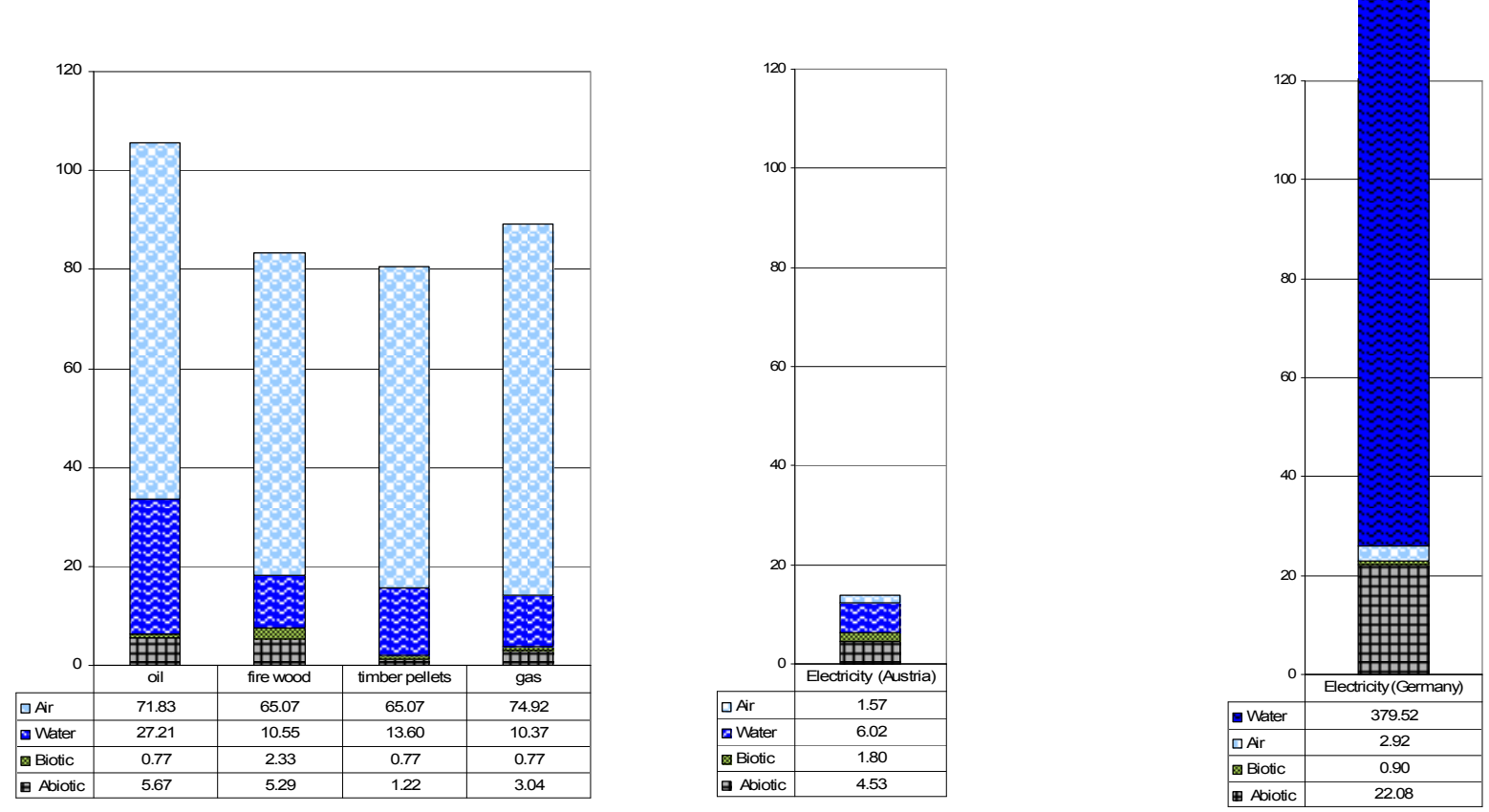

Figure 78: Comparison of the material flows

(in tonnes) triggered by the provision of $20340 \mathrm{kWh}$ of heating (left) with $4500 \mathrm{kWh}$ of electricity in Austria (middle) and Germany(right). The left diagram includes the resource use of the PV windows, while the middle and right diagrams take the resources triggered by the conventional windows into account. 
However, if the case study were situated in a different country the outcome could be tipped in favour of the photovoltaic elements as the diagram on the right clearly shows. German data was used as material intensity data was known. While the air use remains lower than for any of the other types of space heating considered here, the abiotic material flows become much larger if German electricity were to be used. The highest increase can be seen in the amount of water used.

As mentioned in section 1.13.1, the material flows below only take the resource use of the fuels into account, not the heating systems themselves.

\subsubsection{RESOURCE USE: STRUCTURAL SYSTEM AND FLOORS}

This section deals with the question of whether the conventional structure or the insulated straw-fibre panels are more effective in terms of resource use. The figures below show the resource use of the floor of the conventional envelope (timber frame) and the straw-fibre floor of the multifunctional envelope. They are only indicative as the material intensity of the straw-fibre element had to be estimated based on data relating to the production of chipboard that was provided by the Wuppertal Institute. After gathering as much information as possible about the production process of straw-fibre panels and with the help of researchers of the Wuppertal Institute, the resource use of straw was lowered to the following figures (Ritthoff, M., 01.07.2009).

\begin{tabular}{|l|l|l|l|l|}
\hline Material & $\begin{array}{l}\text { Abiotic } \\
\mathbf{k g} / \mathbf{k g}\end{array}$ & $\begin{array}{l}\text { Biotic } \\
\mathbf{k g} / \mathbf{k g}\end{array}$ & $\begin{array}{l}\text { Water } \\
\mathbf{k g} / \mathbf{k g}\end{array}$ & $\begin{array}{l}\text { Air } \\
\mathbf{k g} / \mathbf{k g}\end{array}$ \\
\hline Chipboard & 0.68 & 0.65 & 18.4 & 0.29 \\
\hline Straw fibre & 0.5 & 0.2 & 18.4 & 0.2 \\
\hline
\end{tabular}

The abiotic material flows in both manufacturing processes derive from transportation and machinery as well as from products used in the process such as glues and process water. Overall the straw-fibre was assumed to be less material intensive given its high volume to weight ratio which makes long transportation distances uneconomic and its fast growth rate as well as the fact it needs less treatment to be usable for the panels. 

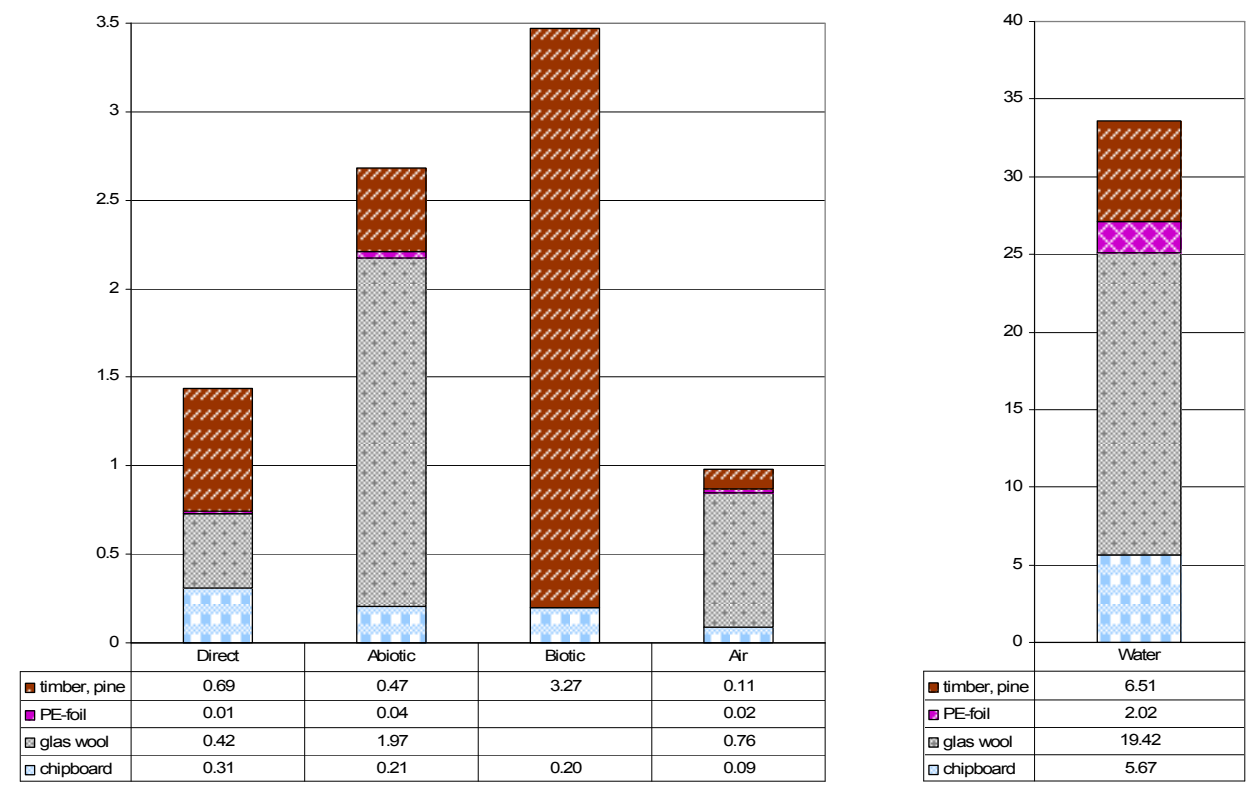

Figure 79: Resource use of the timber floor structure

(in tonnes) over 60 years

Although the exact resource use of the straw might be a bit different from the estimated amounts, it becomes clear that the advantage of the structural insulated panel lies only partly in the smaller footprint of the straw compared to the timber. It seems to be much more appropriate to decrease the resource use of the insulating layer in the timber frame wall. In terms of abiotic materials as well as air use, the straw insulation is much more efficient than the glass wool, as the latter uses more than twice the amount of resources.
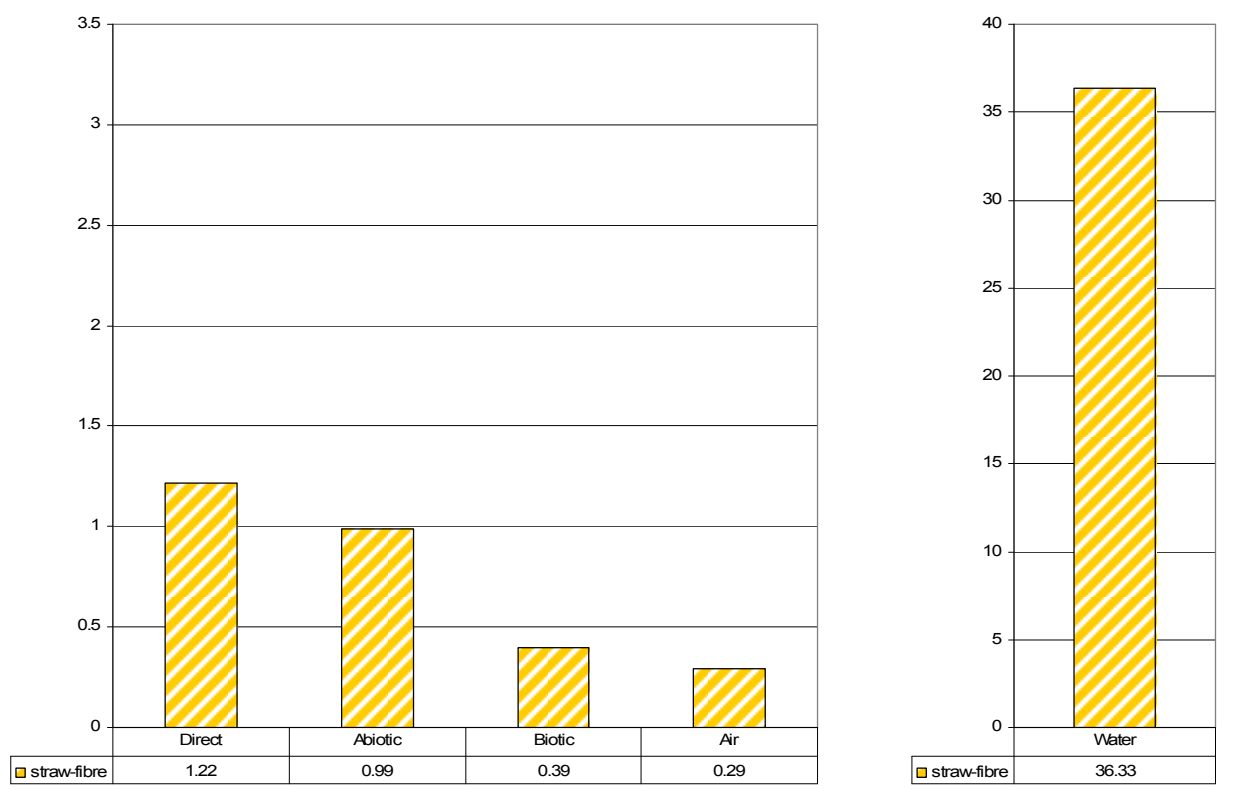

Figure 80: Resource use of the insulated straw/fibre panel

(in tonnes) during 60 years

Apart from water consumption, the structural insulating straw-panels seem to be a good way to reduce the resource use of the structural elements of the envelope. However, as discussed in section 1.11 .1 .1 , p. 87 , it has to be noted that the multifunctional aspect of the structural insulating panel can limit the effectiveness of the element as well. Given that both structural requirements and insulation 
levels are determining the amount of resources used in a given building, one function will influence the performance of the other when interlocked, as is the case here.

\subsubsection{RESOURCE USE: WALLS}

The comparison of the conventional wall with the two different multifunctional walls is one of the most complex parts of the material intensity analysis carried out here. This is partly the result of looking at three different wall types (the conventional timber-framed wall, the insulated straw-fibre wall structure clad with the solar thermal heating system and the green wall elements) and partly due to the fact that both multifunctional wall elements have additional components such as water storage, pumps and pipes that do not necessarily form part of the wall, but nevertheless have to be taken into account.

\subsection{CONVENTIONAL WALL}

Figure 81 shows the resource use of the conventional wall.
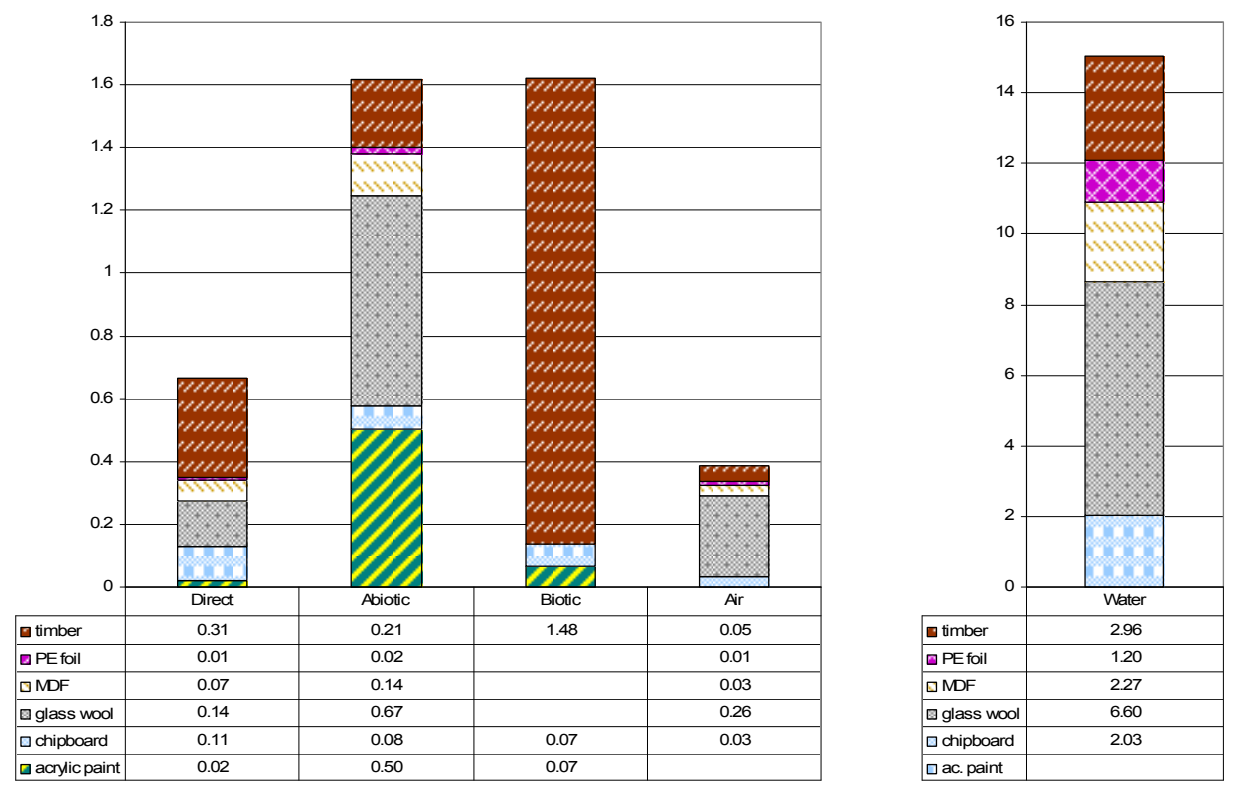

Figure 81: Resource use of the conventional wall (in tonnes)

The direct resource use is roughly five times smaller than the indirect resource use of abiotic and biotic materials, while the water consumption is almost 23 times larger. It is remarkable how the different materials of the wall, trigger different resource flows. Timber for example is the major contributor to total biotic material flows accounting for $91 \%$, while glass wool has a big impact on both abiotic resources $(41 \%)$ and water consumption $(44 \%)$.

\subsection{SOLAR THERMAL WALL}

Figure 82 shows the resource use of the solar thermal wall and its components. The wall structure itself (in orange) only contributes a small amount to the indirect resource use. It can be compared with the input of the wall structure in the conventional wall (Figure 81), although the fact that the structural insulated panel would need some sort of finish in order to work as an external wall should be taken into account. In terms of input this would probably be similar to the paint used in the conventional en- 
velope. If the paint issue is set aside, it becomes clear that the structural insulated panel is much less resource-intensive and the use of straw as an insulating material instead of glass wool seems to be a resource-effective method. Only the water consumption of the straw-fibre elements is comparable to that of the conventional envelope.

It can be observed that the straw wall makes the biggest direct contribution but has the smallest ecological rucksack. By contrast the absorber, with the second biggest direct weight, is the most important contributor to indirect resource flows. As with most other elements it can be observed that water consumption is the main resource use, outweighing the direct resource use of the solar thermal wall by a factor of 90 .
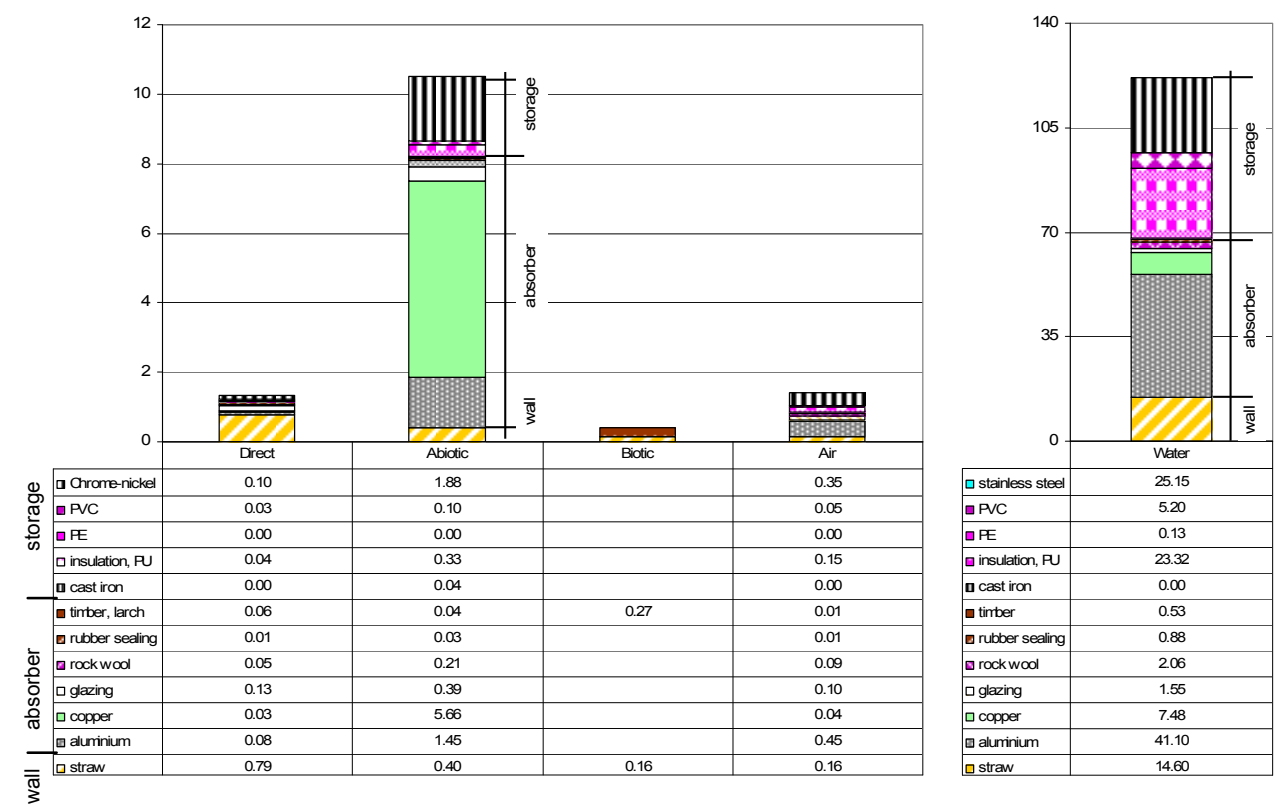

Figure 82: Direct and indirect resource use of the solar thermal wall

(in tonnes) including the straw-fibre wall structure

Aluminium and copper play an important role in indirect resource use, as their material intensity is high. Initially it was presumed that half of the metal used was recycled. For the resource optimised version of the multifunctional envelope a solar thermal wall made from recycled aluminium was proposed. The results are shown in Figure 78. The diagram shows the resource use of the solar thermal wall if the aluminium and copper are completely sourced from recycled materials. While the direct resource use obviously stays the same, the indirect resource use of abiotic materials is roughly halved, the amount of air is 1.4 times smaller, and water consumption is reduced by a factor of 1.6. This underlines the importance of circular materials flows for metals which tend to have high initial material intensities making their recycling worthwhile. 

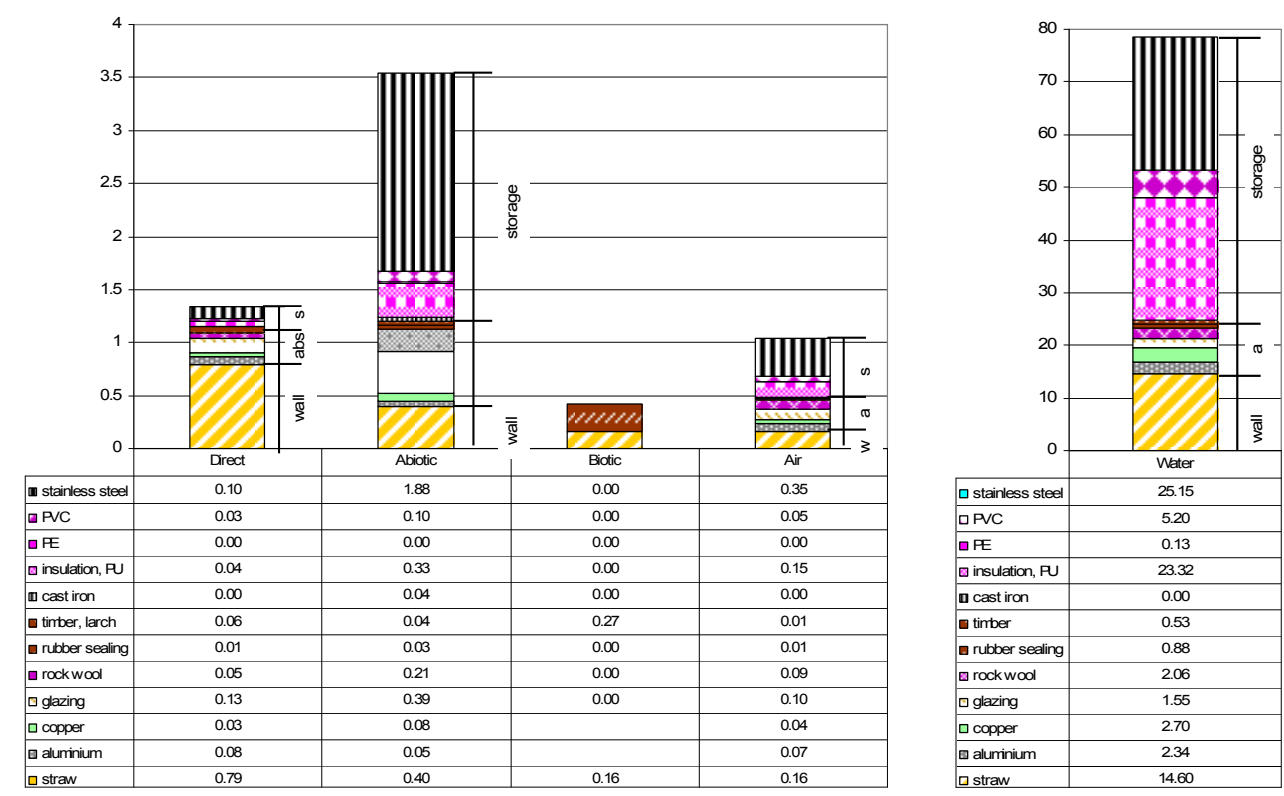

Figure 83: Direct and indirect resource use of the solar thermal wall

(in tonnes) including the straw-fibre wall structure if all the aluminium and copper is recycled

\subsection{GREEN WALL}

Four green wall systems were analysed for the Material Intensity Analysis. Three of them were panel based systems made from, respectively, polyethylene, aluminium (decorative use) and stainless steel (food production). The fourth system was a hydroponic felt system. As described in section 1.11.1.3 , the additional elements including pumps, water storage tanks and irrigation systems were presumed to be the same for all four. Figure 84 indicates the resource use (excluding water consumption) of the four systems and their additional elements as well as the resource use of a simple plastic rain screen (and fixings) that could be used as an alternative facade cladding.

Looking at the analysed green walls, it seems of less importance which type of system is used (hydroponic or substrate-based). The material choice plays a much more significant role. The stainless steel panels, for example, have a direct resource use (self-weight) of 2.53 tonnes which trigger 19.88 tonnes of abiotic material flows during production, while aluminium with a similar direct resource use of 2.1 tonnes only triggers 2.08 tonnes of abiotic resources. The huge difference between the resource use of the aluminium panels and the stainless steel panels is partly caused by the fact that the manufacturer uses recycled aluminium but new stainless steel elements (as this is not recyclable). 


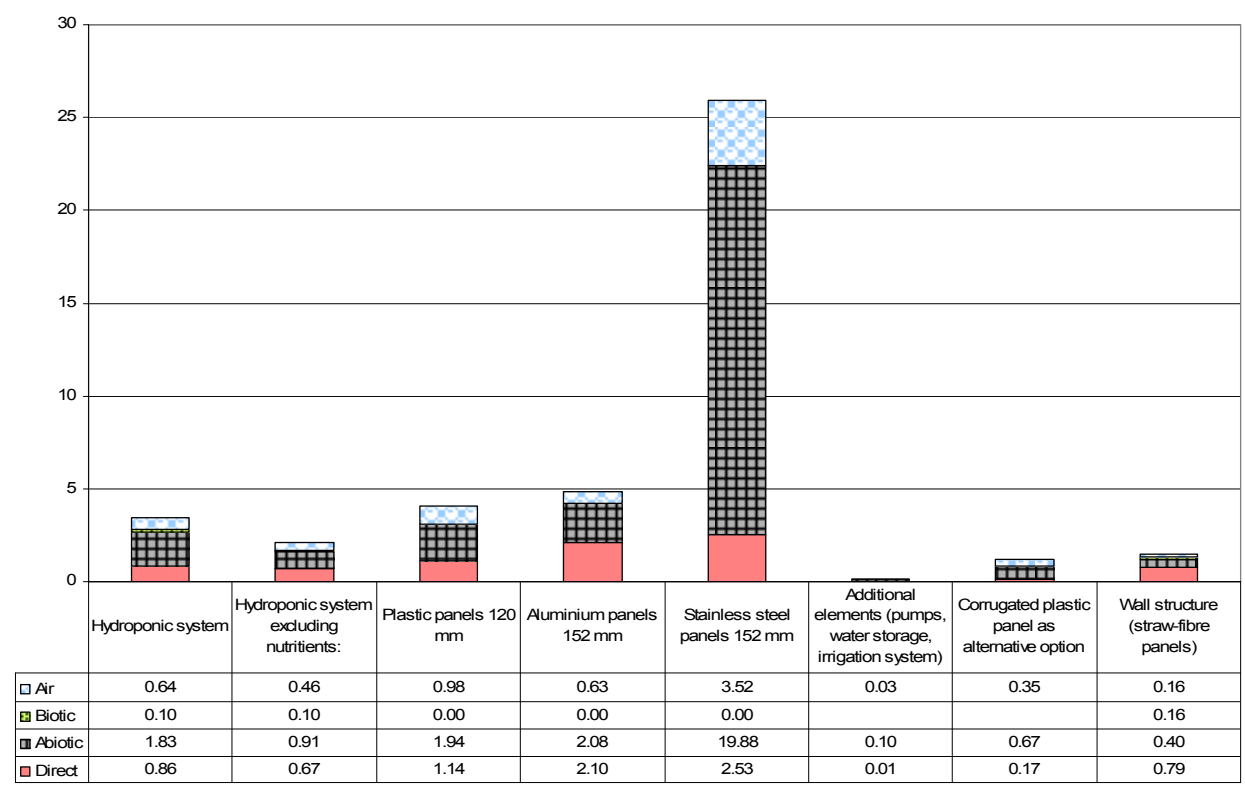

Figure 84: Direct and indirect resource use of the four green wall systems

additional support elements and an alternative plastic rain screen

The hydroponic system seems to be the least resource intensive green wall option analysed (if water is not taken into account), although it accumulates almost the same direct weight as the plastic panels (filled with substrate) simply as it has to be replaced more often during the 60 year period. In terms of indirect resources it performs similar to or slightly better than the other systems. Among the substrate based systems, the plastic polyethylene system clearly outperforms all the others, as its components are less resource intensive. The material intensity analysis revealed that the additional elements such as pumps and water tanks had only a minor influence on the overall resource use of the green wall systems analysed.

The diagram also indicates that the promotion of food production in vertical gardens should be limited to food grown in plastic panels and should certainly not be done in the stainless steel system which requires up to 10 times the resources of the plastic system. Food production (given that even the plastic system requires $0.94 \mathrm{t}$ of resources per $\mathrm{m}^{2}$ of system of which one 0.1 tonnes are caused by the substrate itself) will be further discussed in section 1.13.1.8 .

Looking at the water usage illustrated in Figure 85, a different picture in terms of efficiencies ensues. Although the stainless steel panels remain the least efficient option by requiring 250 tonnes of water during production, the felt panel requires more water for irrigation due to higher evaporation levels and this therefore creates the highest water demand overall. 


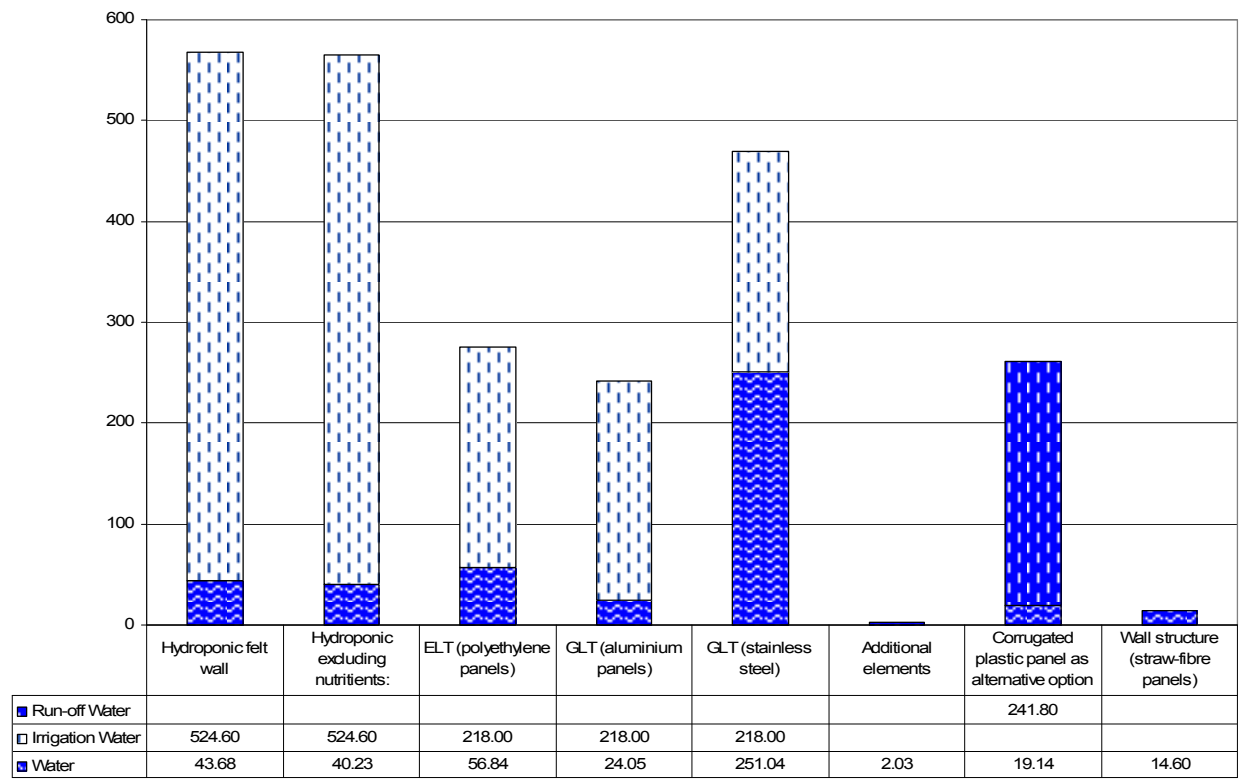

Figure 85: Water consumption of the four green wall systems

additional support elements and an alternative plastic rain screen (in tonnes)

The water consumption for the substrate based wall was estimated based on recommendations from manufacturers of around $3 \mathrm{l} / \mathrm{m}^{2} /$ day. The hydroponic wall was estimated to need $5 \mathrm{l} / \mathrm{m}^{2} /$ day as it has a higher evaporation loss, cannot retain water in large quantities and needs regular irrigation all year round, to supply nutrients to the roots. The absolute quantity is dependent on factors such as climate, plant species, shading by neighbouring buildings, and orientation to the sun (Labeur, 2007), (Irwin, G., 30.06.2009).

The run-off water shown in the diagram, which only appears for corrugated plastic panels, relates to the water that would be lost as storm water if the green wall of the multifunctional envelope was replaced by a simple plastic rain screen, as this would not be able to retain the water released from the green roof. Although it is similar in quantity to the water used for irrigation of the substrate based panels, it is qualitatively different given that it is rain water, while irrigation would probably be done with drinking water of higher quality. The combination of the green roof with the green wall therefore seems not always beneficial, given that can lead to a shortage of irrigation water as in the case study (refer to Table 14 ). 


\begin{tabular}{|c|c|c|c|}
\hline & Conventional roof & Green roof & Green wall \\
\hline area $\left[\mathrm{m}^{2}\right]$ & $\begin{array}{l}18.6 \text { (including over- } \\
\text { hang) }\end{array}$ & $\begin{array}{l}15.5 \text { (excluding para- } \\
\text { pet) }\end{array}$ & 7 \\
\hline $\begin{array}{l}\text { litres per year in Graz } \\
\text { depending on roof size }\end{array}$ & $\begin{array}{l}867 \mathrm{l} / \mathrm{m}^{2} \times 18.6 \mathrm{~m}^{2}= \\
16126 \mathrm{I}\end{array}$ & $\begin{array}{l}867 \mathrm{l} / \mathrm{m}^{2} \times 15.5 \mathrm{~m}^{2} \\
=13438 \mathrm{I}\end{array}$ & \\
\hline $\begin{array}{l}\text { amount of water re- } \\
\text { tained/ needed }\end{array}$ & 01 & 9407 I (70\%) & $\begin{array}{l}7665 \mathrm{I}\left(3 \mathrm{l} / \mathrm{m}^{2} / \mathrm{d}\right) \text { for substrate } \\
\text { panels } \\
12775 \mathrm{I}\left(5 \mathrm{l} / \mathrm{m}^{2} / \mathrm{d}\right) \text { for hydroponic } \\
\text { system }\end{array}$ \\
\hline $\begin{array}{l}\text { amount of water re- } \\
\text { leased / lost }\end{array}$ & 16126 I (storm water) & $\begin{array}{l}4031 \text { I ( } 30 \%) \text { (used for } \\
\text { green wall) }\end{array}$ & $\begin{array}{l}\text { in combination with conventional } \\
\text { roof: } \\
16126|-7665|=8461 \mid \text { (sub.p) } \\
16126 \mid-12775 \text { I=3351 I (hydro.) }\end{array}$ \\
\hline $\begin{array}{l}\text { amount of additional } \\
\text { irrigation water required }\end{array}$ & & & $\begin{array}{l}\text { in combination with green roof: } \\
4031 \mid-7665 \text { I=3634 I (sub.p) } \\
4031 \mid-12775 \text { I=8744 I (hydro.) }\end{array}$ \\
\hline
\end{tabular}

The green wall was hence excluded from the optimised version of the multifunctional envelope as it was felt that its quantitative advantages (water retention) were fulfilled by the green roof which also had additional benefits over the green wall because of its thermal performance improvements. A more detailed discussion of the advantages of green roofs and green walls can be found in section 1.13.1.8

\subsubsection{WINDOWS}

The following figures show the overall resource use of the conventional and the photovoltaic windows over a sixty year period. The underlying geometry and data can be found in Appendix 1.17.2. The material flows produced by the windows are almost identical for all categories apart from water consumption. 

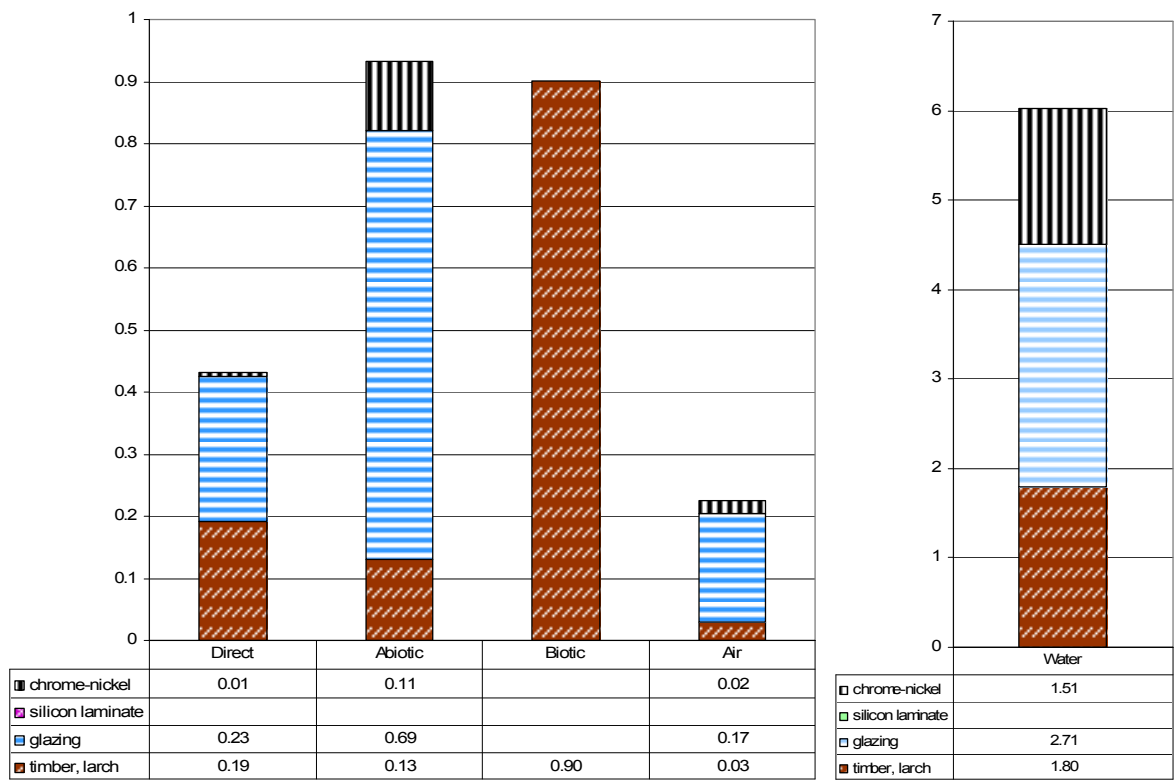

Figure 86: Resource use of the conventional window over 60 years (in tonnes)

The use of the photovoltaic elements has a very small impact on the overall resource use of the window. On one hand, the amorphous silicon only contributes 500 grams to the self-weight of the window which makes its material intensity a less dominant factor, and on the other hand the synergistic effect of placing the amorphous silicon into the glazing diminishes the amount of support structure needed to a minimum, which further decreases the impact of the solar components.
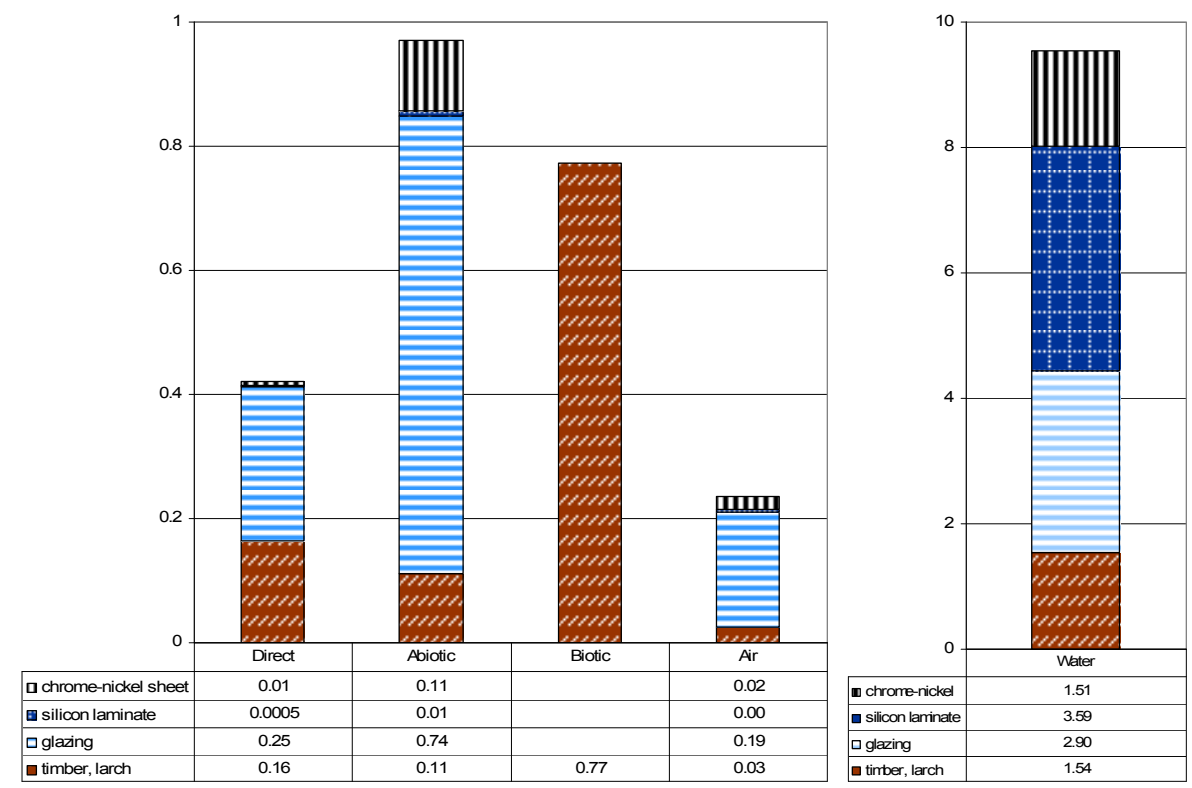

Figure 87: Resource use of the photovoltaic window (in tonnes) over 60 years

The 500 grams of amorphous silicone provide $4500 \mathrm{kWh}$ of electricity in 60 years at the cost of 3.59 tonnes of water. To put this into perspective the water use resulting from sourcing $4500 \mathrm{kWh}$ from the grid is roughly 379 tonnes (German data is used as water usage of the Austrian grid was not known, refer to Figure 77). The water consumption of the photovoltaic window is therefore very small in comparison. 
The question of whether the photovoltaic window decreases the resource use of the envelope is not answered easily. As discussed in section 1.13.1.3 the provision of electricity by the photovoltaic windows is not resource efficient (in terms of abiotic materials) if an oil based heating system is used to provide the heat to make up the lost solar gains from having the photovoltaic cells. All other analysed fuel options are more efficient. However in terms of other materials such as air, the use of a photovoltaic window is not preferential as it results in a steep increase in air consumption.

This dilemma is very specific to the photovoltaic window element and its multifunctional nature and does not apply to conventional photovoltaic elements in general. Here the synergistic effect is certainly decreasing the resource use of the photovoltaic panels in terms of their initial installation etc. as the glazing of the window provides the structural frame for the photovoltaic element, but there is a conflict with possible heat gains the glazing could otherwise secure. As the likelihood of overheating in summer was ruled out during the calculation of the heating requirements of the envelopes, potential disadvantages might outweigh the benefits of decreasing the abiotic resource use in this case by including qualitative aspects such as the visual and aesthetical constraints produced by the photovoltaic windows. It could be concluded that the appropriate balance discussed in section 1.8.3, between all of the functions of the photovoltaic window is not entirely found.

\subsubsection{RESOURCE USE: ROOF}

This section starts with the resource use of the conventional zinc roof, looks at a bituminous roof (as a more resource efficient alternative) and compares both options with the green roof of the multifunctional envelope.

Figure 88 shows the resource use of the conventional zinc roof over 60 years of operation. The underlying geometry and data can be found in Appendix 1.17.2. The roof of the conventional envelope has a self weight of 2.1 tonnes. Although the zinc cladding only contributes $20 \%$ of the direct resource use, it triggers $72 \%$ of the indirect abiotic material flows and accounts for roughly half of the water consumption. As the zinc was already identified as one of the resource intensive elements in the conventional envelope, the decision to choose the zinc roof (for its long life span and therefore presumed smaller resource use) was reconsidered. An analysis of a roof type with less resource intense materials but with a shorter life span was carried out in order to see which option provided the better tradeoff. As discussed in section 1.13.1.5.3, the use of a less resource intensive roof that has a shorter life span positively influences the overall resource use of the conventional case study. 

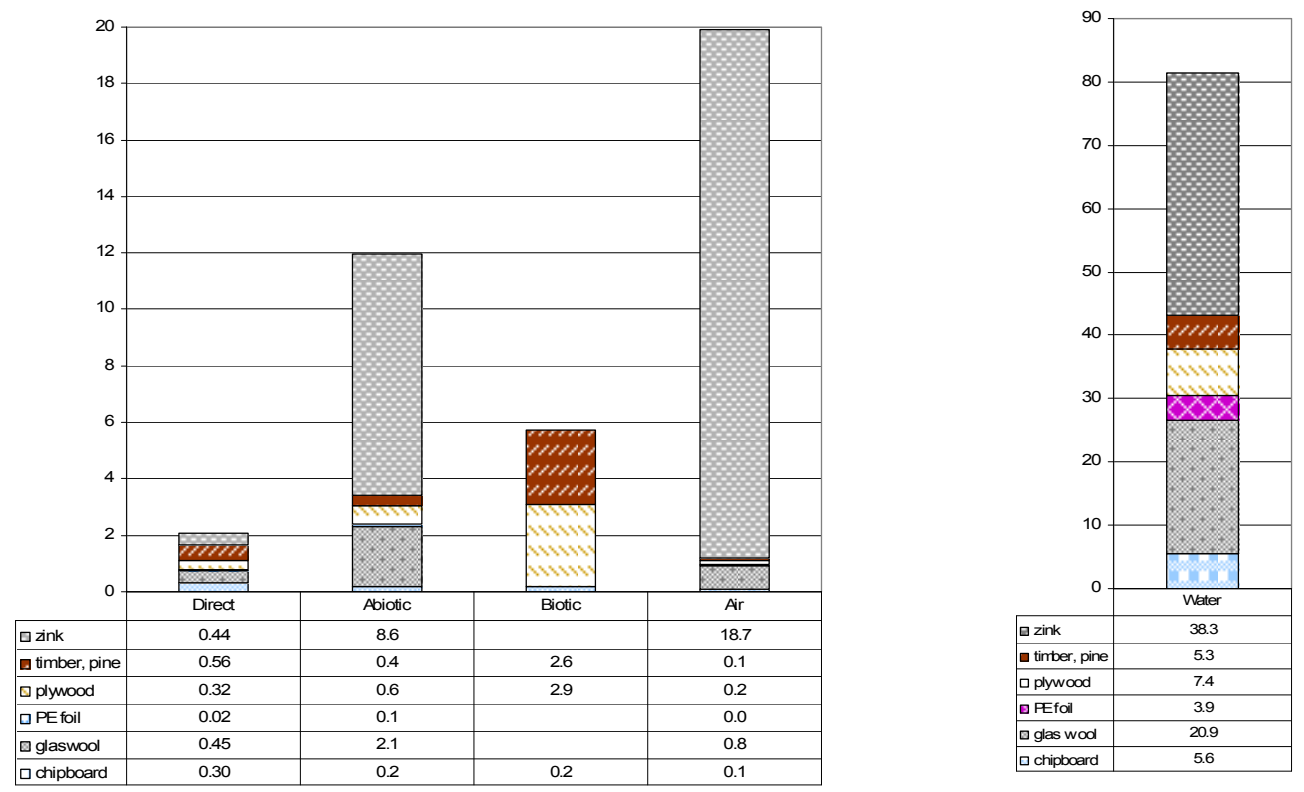

Figure 88: Resource use of the conventional roof with zinc-cladding

over 60 years in tonnes (excluding run-off water)

The alternative roof has a construction similar to the multifunctional roof. The roof has a parapet and is sealed with bituminous layers which are covered in $50 \mathrm{~mm}$ gravel. Figure 99 in Appendix 1.14 gives an overview on the design of the alternative as well as its geometry and parameters.

Figure 89 shows that although the direct resource use of the alternative is higher (2.9 tonnes compared to 2.1 tonnes for the zinc roof), the indirect resource use over 60 years of the alternative is at least half of that of the zinc roof and, depending on the category, up to 20 times smaller.
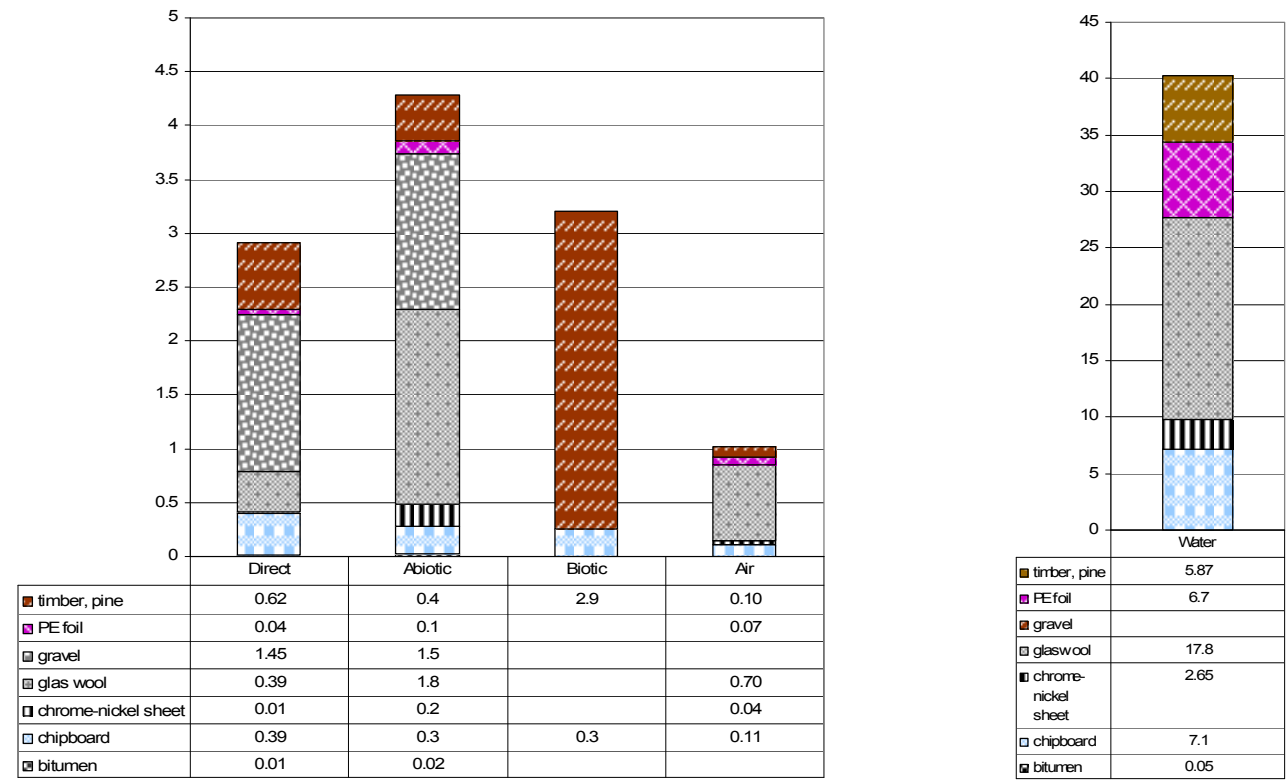

Figure 89: Resource use of the alternative conventional bituminous roof over 60 years in tonnes (excluding run-off water)

The resource use of the multifunctional roof is shown separately for the roof structure and the green roof in Figure 90 and Figure 91. Unfortunately both major contributors to the multifunctional roof structure and the green roof, the straw-fibre and the substrate, do not have precisely calculated material intensities but are estimated on the basis of similar materials. The material intensity of the substrate is 
highly dependent on its sourcing (e.g. if the topsoil layer of the building footprint is used even in part, it would be very small). All unknown material intensities were estimated conservatively which means that they are probably rather too large.
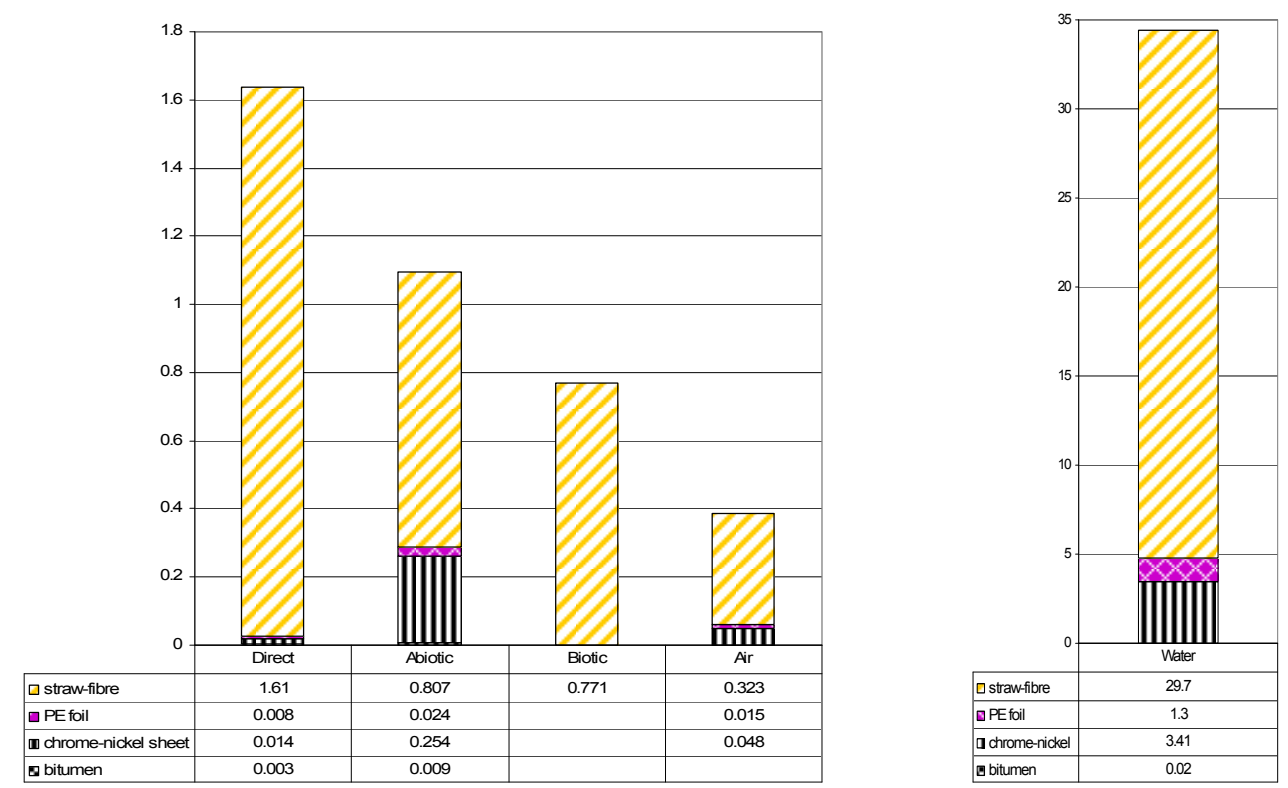

Figure 90: Resource use of the roof structure of the multifunctional envelope without the green roof over 60 years (in tonnes)

Figure 90 shows again that the only substantial amount of metal in the construction (the stainless steel lining of the parapet) has an ecological rucksack that outweights its self-weight by 16 times (abiotic materials), 3.3 times (air) and 226 times (water).
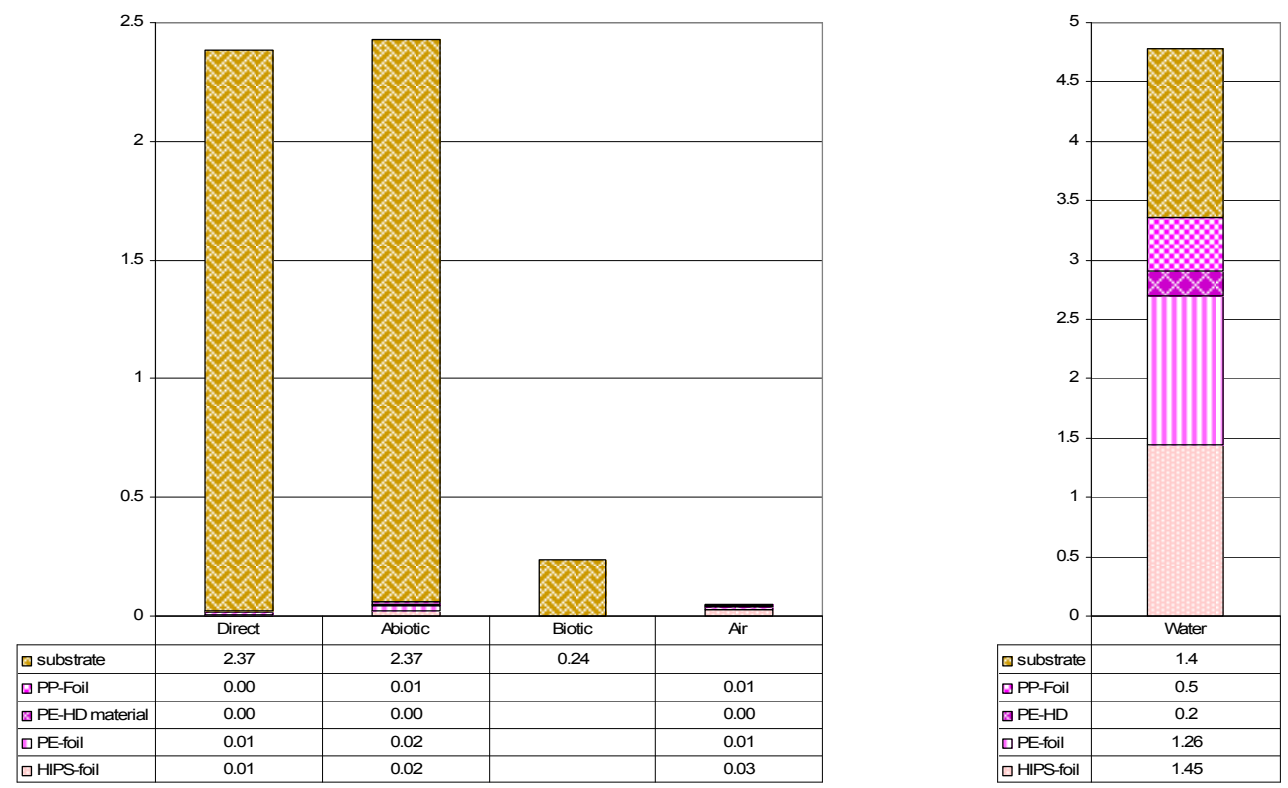

Figure 91: Resource use of the green roof of the multifunctional envelope

(excluding roof structure) over 60 years (in tonnes)

Figure 91 reveals that apart from the substrate the green roof does not contribute significantly to the resource use of the multifunctional envelope. Only the water category is influenced by the different plastic components of the roof. However, compared to the water consumption of the conventional options the green roof is favourable. This is even more the case if the increase in storm water reten- 
tion is also considered. As shown in Figure 74, p.131, the run-off water of the conventional roof accounts for roughly $80 \%$ of the total water used by the installation and maintenance of the conventional envelope.

Table 31 summarises the resource use of the three roofs. As the zinc roof was initially chosen for having a similar life span to the green roof, the data this time refers to a period of 80 years. Compared to Figure 88 and Figure 89, the difference between the direct resource use of the two conventional roof types increases when a longer life span is considered. This is caused by the bituminous roof that has to be replaced and repaired more often during the 80 year period.

Table 31: Direct and indirect resource use of the three roofs (in tonnes) over 80 years ${ }^{\star}$ including run-off water

\begin{tabular}{|c|c|c|c|c|c|c|c|c|c|c|c|c|c|c|c|c|c|c|}
\hline Roof & \multicolumn{3}{|c|}{ Self-weight } & \multicolumn{3}{|c|}{ Abiotic } & \multicolumn{3}{|c|}{ Biotic } & \multicolumn{3}{|c|}{ Water } & \multicolumn{3}{|c|}{$\begin{array}{l}\text { Run-off } \\
\text { water }\end{array}$} & \multicolumn{3}{|l|}{ Air } \\
\hline conventional zinc roof & \multicolumn{3}{|c|}{2.1} & \multicolumn{3}{|c|}{11.9} & \multicolumn{3}{|c|}{5.7} & \multicolumn{3}{|c|}{81.4} & \multicolumn{3}{|c|}{971} & \multicolumn{3}{|c|}{19.9} \\
\hline conventional alternative roof & \multicolumn{3}{|c|}{2.9} & \multicolumn{3}{|c|}{4.3} & \multicolumn{3}{|c|}{3.2} & \multicolumn{3}{|c|}{40.2} & \multicolumn{3}{|c|}{806} & \multicolumn{3}{|c|}{1.02} \\
\hline $\begin{array}{l}\text { multifunctional roof } \\
\text {-roof structure } \\
\text {-green roof }\end{array}$ & \multicolumn{3}{|c|}{$\begin{array}{r}4.03 \\
1.64 \\
2.39 \\
\end{array}$} & \multicolumn{3}{|c|}{$\begin{array}{r}3.5 \\
1.09 \\
2.43\end{array}$} & \multicolumn{3}{|c|}{$\begin{array}{l}1.01 \\
0.77 \\
0.24\end{array}$} & \multicolumn{3}{|c|}{$\begin{array}{r}39.2 \\
34.4 \\
4.78 \\
\end{array}$} & \multicolumn{3}{|c|}{$242^{* *}$} & \multicolumn{3}{|c|}{$\begin{array}{r}0.44 \\
0.4 \\
0.04 \\
\end{array}$} \\
\hline ratio & 1 & 1.4 & 2 & 3.4 & 1.2 & 1 & 5.6 & 3.2 & 1 & 2 & 1 & 1 & 4 & 3.3 & 1 & 45 & 2.3 & 1 \\
\hline
\end{tabular}

*Presumed life spans are indicated in the relevant tables in Appendix 1.17. ${ }^{* *}$ runoff with no green wall (refer to p.30) 


\begin{tabular}{|c|c|c|c|}
\hline & Conventional roof & Green roof & Green wall \\
\hline area $\left[\mathrm{m}^{2}\right]$ & $\begin{array}{l}18.6 \text { (including over- } \\
\text { hang) }\end{array}$ & $\begin{array}{l}15.5 \text { (excluding para- } \\
\text { pet) }\end{array}$ & 7 \\
\hline $\begin{array}{l}\text { litres per year in } \\
\text { Graz depending on } \\
\text { roof size }\end{array}$ & $\begin{array}{l}867 \mathrm{l} / \mathrm{m}^{2} \times 18.6 \mathrm{~m}^{2}= \\
16126 \mathrm{I}\end{array}$ & $\begin{array}{l}867 \mathrm{l} / \mathrm{m}^{2} \times 15.5 \mathrm{~m}^{2} \\
=13438 \mathrm{I}\end{array}$ & \\
\hline $\begin{array}{l}\text { amount of water } \\
\text { retained/ needed }\end{array}$ & 01 & 9407 I (70\%) & $\begin{array}{l}7665 \text { I }\left(3 \mathrm{l} / \mathrm{m}^{2} / \mathrm{d}\right) \text { for sub- } \\
\text { strate panels } \\
12775 \mathrm{I}\left(5 \mathrm{l} / \mathrm{m}^{2} / \mathrm{d}\right) \text { for hydro- } \\
\text { ponic system }\end{array}$ \\
\hline $\begin{array}{l}\text { amount of water } \\
\text { released / lost }\end{array}$ & 16126 I (storm water) & $\begin{array}{l}4031 \text { I }(30 \%) \text { (used for } \\
\text { green wall) }\end{array}$ & $\begin{array}{l}\text { in combination with con- } \\
\text { ventional roof: } \\
16126 \text { I-7665 I=8461 I (sub.p) } \\
16126 \text { I-12775 I=3351 I (hy- } \\
\text { dro.) }\end{array}$ \\
\hline $\begin{array}{l}\text { amount of additional } \\
\text { irrigation water re- } \\
\text { quired }\end{array}$ & & & $\begin{array}{l}\text { in combination with green } \\
\text { roof: } \\
4031 \text { I-7665 I=3634 I (sub.p) } \\
4031 \text { I-12775 I=8744 I (hy- } \\
\text { dro.) }\end{array}$ \\
\hline
\end{tabular}

The table indicates that the bituminous roof is more resource efficient than the zinc roof although parts of it have to be replaced up to four times during the 80 years. The green roof remains the most resource efficient option in all categories but the direct resource use. The ratio of abiotic resource use would be even better when taking the superior thermal performance of the green roof into account, as it indirectly reduces the heating and cooling required as discussed in section 1.11.1.2 . Comparing the roof structure of the multifunctional envelope (which is effectively a fully functioning water-proof roof in itself) with the two conventional options, it becomes clear that the reduction in resource use is partly achieved by the roof structure. The quantitative reduction of the resource input is hence partly achieved by using the straw-fibre panels as structural elements and partly by using a green vegetated roof, which furthermore provides qualitative benefits for the urban environment, such as increased biodiversity, as well as the individual issues discussed above. 


\subsubsection{COMPARISON OF RESOURCE AND SURFACE USE: GREEN WALL, GREEN ROOF, GREENED FAÇADE AND GARDEN}

This section seeks to establish the advantages and disadvantages of green walls, roofs, greened facades and a garden in terms of resource as well as surface use. It compares $1 \mathrm{~m}^{2}$ of each enclosure.

\section{SURFACE USE}

One of the problems occurring in conjunction with increased material flows is the simultaneous increase in surface use (land) by human activities. In the built environment both the green roof and wall can to a certain extent offset the impacts caused by sealing-off land in the development process. In this context, the green wall seems to provide a special advantage as the green space does not compete for horizontal land area but occupies a vertical element and thereby increases the amount of surface available for planting. Figure 92 illustrates the advantage of the green wall over the green roof in terms of ratio of surface use to created green space.

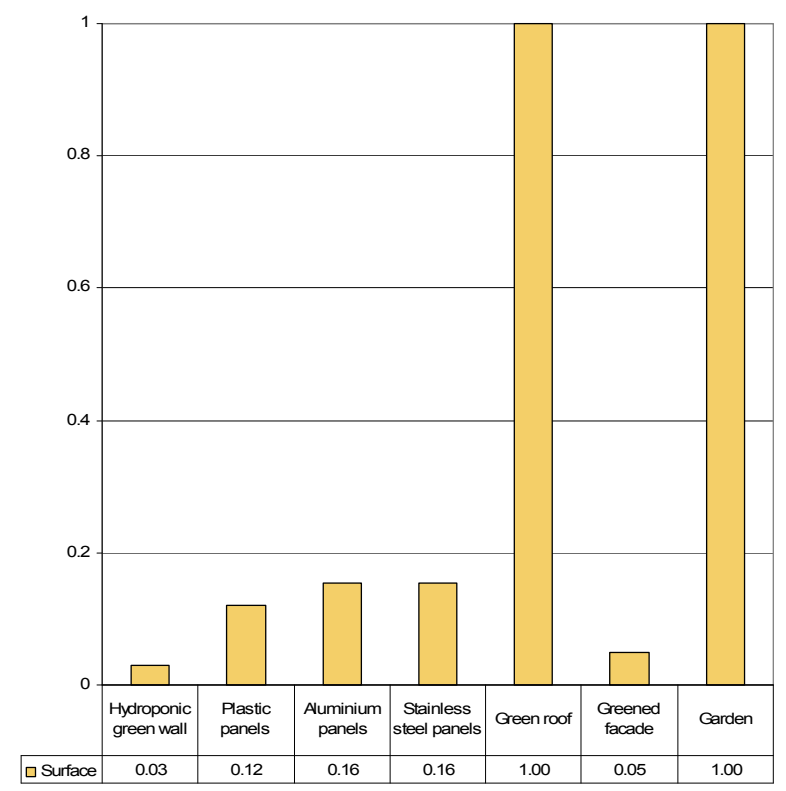

Figure 92: Surface use per square metre greened area of green wall systems, roofs and gardens

While green roofs or gardens create at best the same amount of green space as they occupy, the green wall has a much smaller footprint in terms of surface use. As discussed in section 1.11.1.3 this finding raised the hopes of many people that the green wall or "vertical garden" could provide a vital and sustainable alternative green space for a largely urbanised human population and would even allow for improved resilience in the urban context, as the new found vertical green space could provide local food. Green walls in this context would probably not replace green spaces, but add more greenery and food production areas into the existing urban space. In reality, the productive vertical garden would hence compete with other "sustainable" elements, as the green roof does. Many elements such as solar thermal heating systems or PV panels or even well positioned glazing all rely on high solar radiation levels, as do vegetables, and therefore all need to be positioned on the same building face for maximal benefit. 


\section{RESOURCE USE}

The first question raised in this context was whether it makes sense from a resource point of view to grow vegetables on the wall.

The following picture emerges from comparing the resource use of vegetables grown on one square metre of green wall with a square metre of commercially grown vegetables. Presuming that the yield of the wall is $75 \%$ of the yield of horizontal agricultural land (as more radiation reaches the horizontal), each square metre of wall would produce $2.7 \mathrm{~kg}$ vegetables per year or 0.166 tonnes in 60 years (Statistik Austria, 2008, p. 11). This figure is similar to the estimates of $2.6 \mathrm{~kg} / \mathrm{m}^{2} / \mathrm{a}$ of one of the manufacturers of food-grade stainless steel panels (Wong, 2008). The material intensity of the wall grown vegetables (excluding irrigation) can now be calculated as the resource use of a square metre of the plastic and (stainless steel) green wall systems including proportional material flows triggered by pumps, water storage and irrigation system is known. These are 0.16 tonnes $(0.36)$ direct resource use, 0.29 tonnes (2.85) of abiotic resource use, 0.14 tonnes (0.51) of air and 8.41 tonnes (36.15) of water as can be seen in Figure 93. Table 32 shows the material intensity of one tonne of vegetables grown on a green wall in both plastic and stainless steel panels and compares it with commercially grown vegetables. It includes the material intensity of a $2.8 \mathrm{t}$ lorry per kilometre and transported tonne.

Table 32: Material intensity of wall grown vegetables, commercially grown vegetables and home grown vegetables

\begin{tabular}{|l|r|r|l|r|r|}
\hline Material & \multicolumn{3}{l|}{ Material intensity [t/t], [t/tkm] } \\
\hline & Abiotic & Biotic & Water & \multicolumn{1}{l|}{ Air } & \multicolumn{1}{l|}{$\begin{array}{l}\text { Surface } \\
{[\mathrm{m} / \mathrm{m}]}\end{array}$} \\
\hline Wall grown vegetables (plastic panels) & 1.75 & 0 & 50.7 & 0.84 & \\
\hline Wall grown vegetables (stainless steel panels) & 17.16 & 0 & 217 & 3.07 & 0.15 \\
\hline Vegetables grown commercially (excl. transport) & $1.4^{*}$ & $1.4^{*}$ & $8.89^{* *}$ & $0.104^{* *}$ & 0.15 \\
\hline Transport (Lorry, 2.8t) & 0.00045 & 0 & 0.004124 & 0.00144 & 1 \\
\hline
\end{tabular}

${ }^{*}\left(\right.$ Loske, R. et al., 1996, p. 104) ${ }^{* *(K a i s e r, ~ C . ~ e t ~ a l ., ~ 2009), ~(R i t t h o f, ~ M ., ~ 19.10 .2009) ~}{ }^{* * *(W u p p e r t a l ~ I n s t i t u t e, ~ 2003) ~}$

The table does not include the water needed to irrigate the green wall but includes the water needed to irrigate the commercially grown vegetables so that the data is not completely comparable. It also does not take cooling and storing of commercially grown vegetables into account which would increase their material intensity. Nevertheless it gives a first indication of whether green walls can reduce or even compete with the resource use of commercially grown vegetables. Table 32 shows that growing vegetables in stainless steel panels increases the resource use significantly. Using the data from the table, a lorry could transport commercially grown vegetables for over $2000 \mathrm{~km}$ before reaching the same air consumption as the vegetables grown in stainless steel panels. In terms of abiotic and water usage the distances would be over 35000 and $50000 \mathrm{~km}$. For the plastic panels the boundary value would be a transport distance of $500 \mathrm{~km}$ (air), $777 \mathrm{~km}$ (abiotic) or $10000 \mathrm{~km}$ (water). This suggests that vertical farming is not going to be an answer to a growing, hungry world population nor an alternative to supplying urban population with fresh food transported over long distances.

The second question raised was if the green wall has a similar resource use to the green roofs or greened facades and does it therefore provide a good alternative for bringing greenery into the envelope. Figure 93 shows the resource use (excluding water) of one square metre of the different green wall systems, the extensive green roof and the greened façade. In order to indicate the ratio between the resource use of the green wall itself to the resource use of the additional common elements re- 
quired, such as pumps, water storage tanks and irrigation systems, these are shown in a separate column.

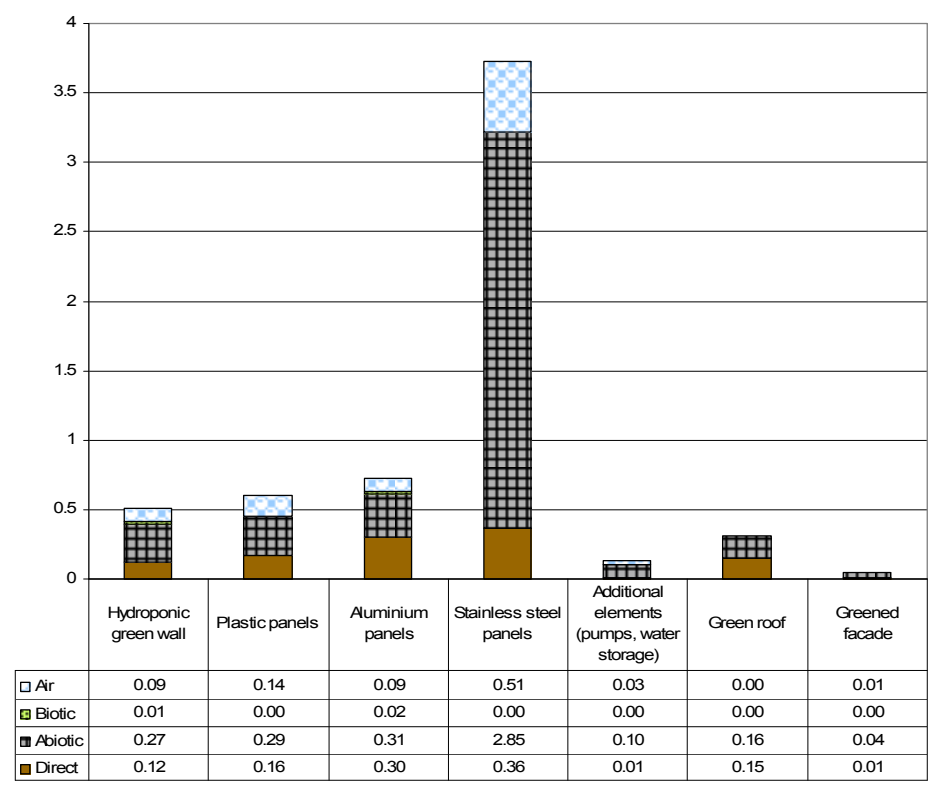

Figure 93: Resource use in tonnes of 1 square metre of green wall panels, green roof and greened façade over 60 years without taking irrigation, water or planting into account

As can be seen, the greened facade provides the most resource efficient option by far in all categories. The green roof and the greened facade use fewer resources than any of the green wall systems analysed. The analysis shows that there is no fixed ratio between direct and indirect resource use, but that this is highly dependent on the materials used.

Looking at the water usage illustrated in Figure 94, a different picture in terms of efficiencies ensues. The diagram shows the water consumption during production of the analysed systems and for the irrigation water to water and feed the plants.

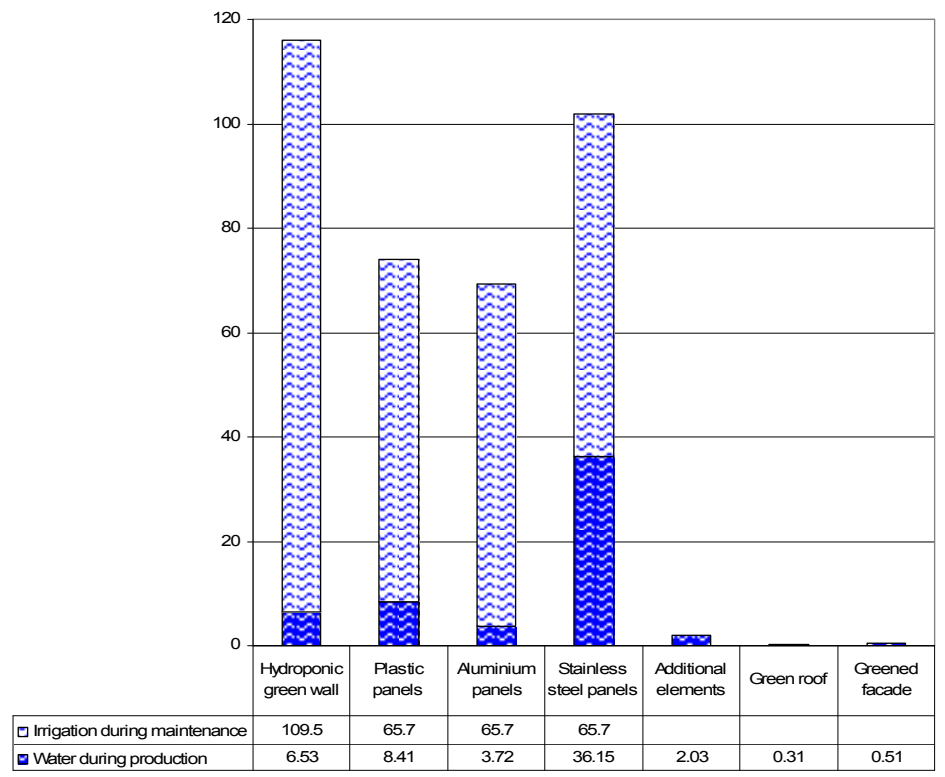

Figure 94: Water use in tonnes during production and maintenance of 1 square metre of green wall panels green roof and greened façade (in tonnes) over 60 years 
Overall the green roof has the lowest water consumption, being similar to that of the greened façade. If irrigation is not taken into account, the green roof only needs $5 \%$ of the water required for the most efficient wall system (aluminium). With irrigation it needs only $0.4 \%$ of the water required for the aluminium system.

While the green roof and the greened façade are dependent only on rainfall, all green wall systems require constant irrigation. Although the stainless steel panels are the least efficient option considering production by requiring 36.15 tonnes of water during manufacture, the felt panels require more water for irrigation due to higher evaporation levels and this creates the highest water demand overall. If the water demand can be satisfied by the use of storm-water this is not too critical, although peaks in water demand and precipitation are unlikely to occur at the same time making bigger storage facilities necessary.

Given that the green roof can retain a large quantity of water in contrast to the greened façade, it seems that the roof remains the best option in this context. 


\section{CONCLUSION}

This thesis investigated the potential of multifunctionality to reduce the resource use of building envelopes with the help of a material intensity analysis using the MIPS approach. The following section will describe the conclusions that can be drawn from the theoretical discussion in Part 1 and the case study in Part 2 in terms of the success of multifunctionality to reduce resource use, its potentials and the benefits and limits of the material intensity analysis used.

The most general conclusion of the research is that it is important to be aware of the hidden impact (design) choices have. Life-cycle wide resource use and especially the biological rucksack of products and services need to be taken into consideration by architects and planners especially if sustainable building practice is one of their declared priorities.

To summarise the findings of the research in regard to the question of effectiveness of multifunctionality to reduce resource use, it can be stated that multifunctionality can decrease resource use (e.g. green roof) if used correctly. As for most strategies, its success depends on a complex set of conditions and especially on careful planning and awareness of the material flows. If multifunctionality involves materials with very high intensities it can also have only a marginal leverage or even increase resource use when synergistic effects are not produced or are insufficient to outweigh the higher initial inputs that often occur (e.g. green wall). Furthermore as a strategy that influences material flows, it has only a limited leverage if another overriding parameter (e.g. consumption patterns) remain unsustainable (refer to section 1.3). While the achievable reductions seem to be of minor importance on a global scale, multifunctionality certainly should be considered in conjunction with other strategies if the material flows triggered by the building sector are to be reduced.

For the case study, the material intensity analysis proves to be a tool that facilitates the uncovering of these hidden material flows as it is easy and practical to use and yet provides a differentiated output.

Its output, which does not reduce all the different types of resources used to one single output, enables informed decisions and allows for prioritising of certain types of material flows. In water stressed regions for example materials with higher biotic material flows could be weighed against those with lower water consumption, which could be easily identified. The material analysis does therefore allow for design or product choices based on user priorities or circumstances.

On the other hand by not breaking the resource use down to one figure as other analytical tools do, (e.g. by only indicating life-cycle-wide energy requirements), choosing the "right" material can sometimes become harder especially when many components are involved each showing a slightly different resource profile.

The ease of data collection possible through the Material Intensity database therefore can stand in contrast with complex weighing of options. However, it was felt that this differentiation enables the designer to see the real impact of resource use more clearly and more realistically (just as the impact on the environment is a complex issue), while remaining a tool that is simple to handle. One shortcoming of the system is that is does not indicate toxicity, which has to be analysed separately by the designer. 
However, for the case study the material intensity analysis shows clearly that overall multifunctional elements working in conjunction do decrease the resource use effectively (this points again to the discussion of eco-effectiveness versus eco-efficiency in section 1.4.3.2, p. 26). As the two envelopes analysed in this thesis were both relatively resource-efficient and sustainable, given their medium to high level of insulation and the use of renewable resources such as timber and straw for the bulk of materials, the leverage of multifunctionality could even be bigger in less optimised examples.

The potential of multifunctionality to reduce resource use was therefore shown. However, the case study also underlined that if resource efficient materials are used from the start the leverage of decreasing resource use is greater through changes in personal behaviour (less electricity consumption), than through multifunctionality. The latter, in this case, is often limited to increasing the effectiveness of the components of the envelope (refer to section 1.13.1.1.2). 


\section{APPENDICES}

\subsection{APPENDIX 1: DRAWINGS}
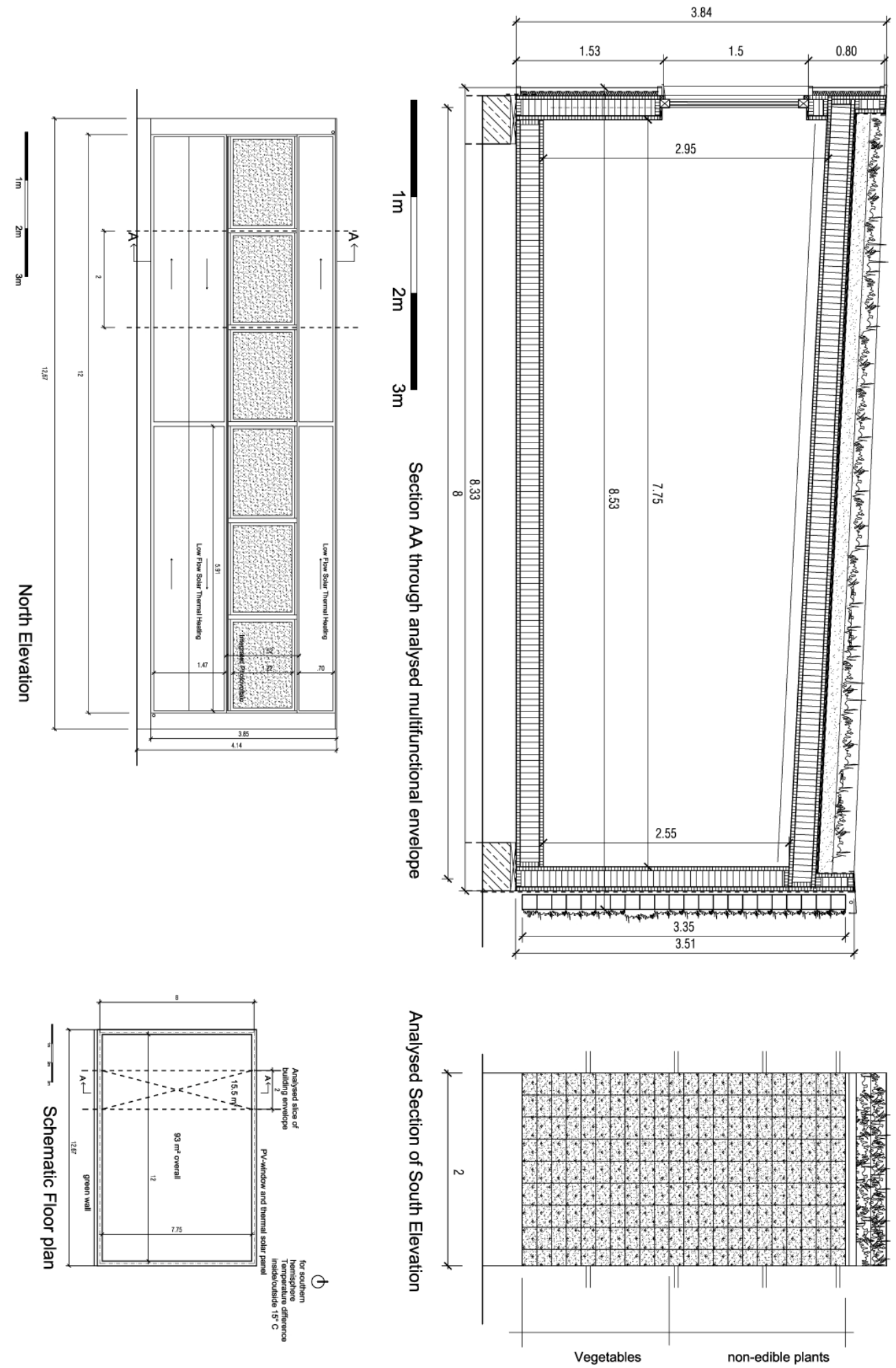

Figure 95: Section and schematic Floor Plan of the multifunctional envelope 

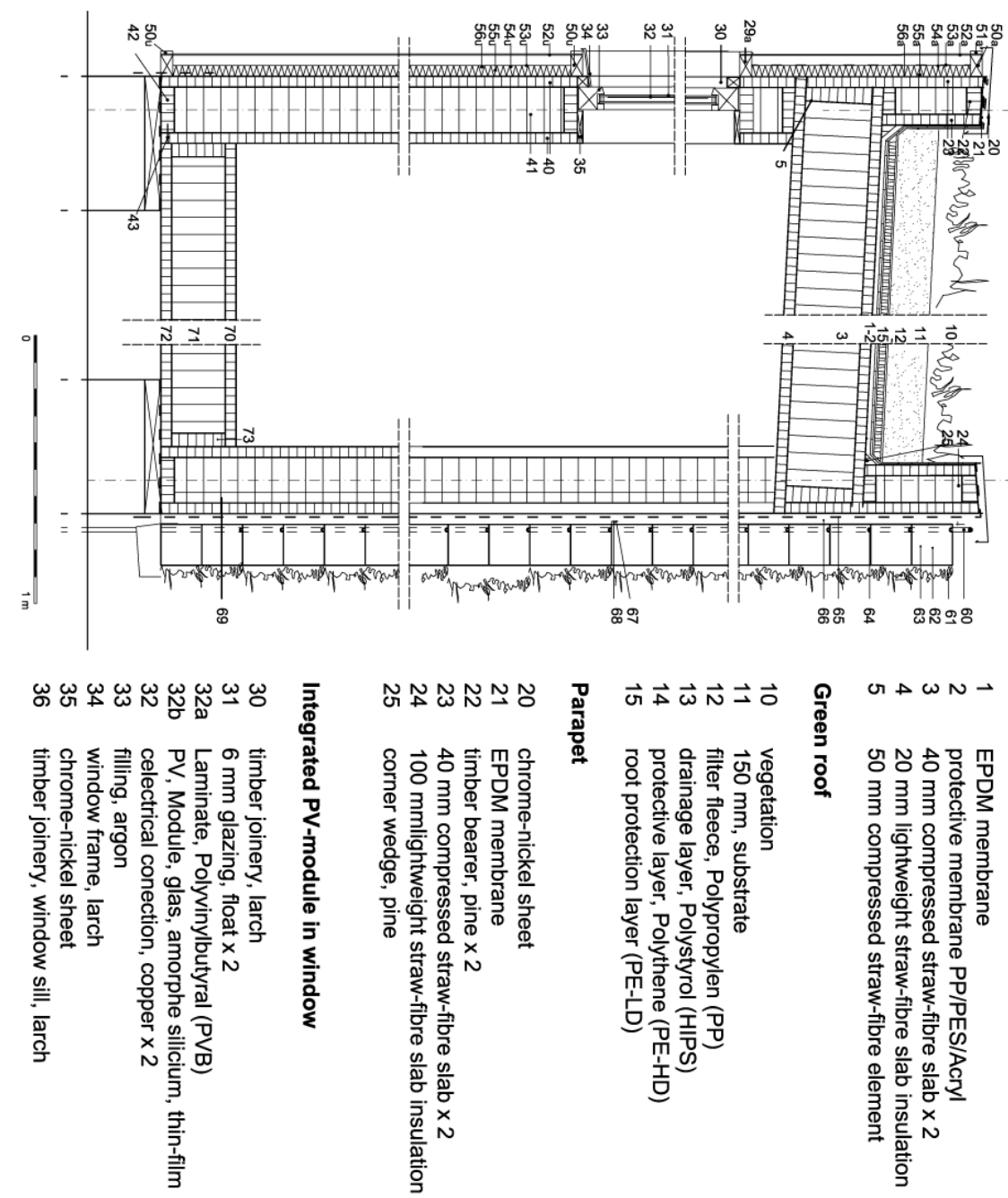

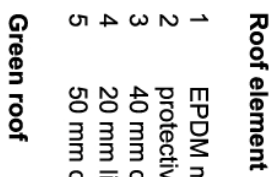
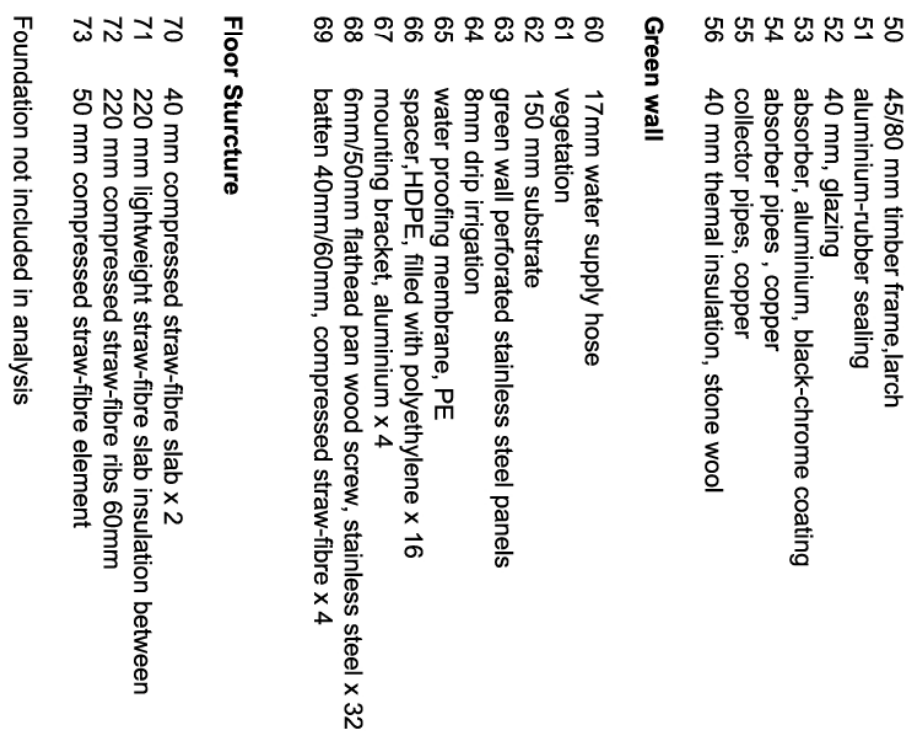

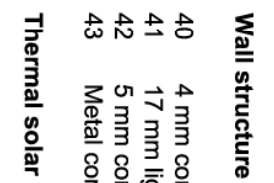

Figure 96: Detailed section and reference numbers of the multifunctional envelope 

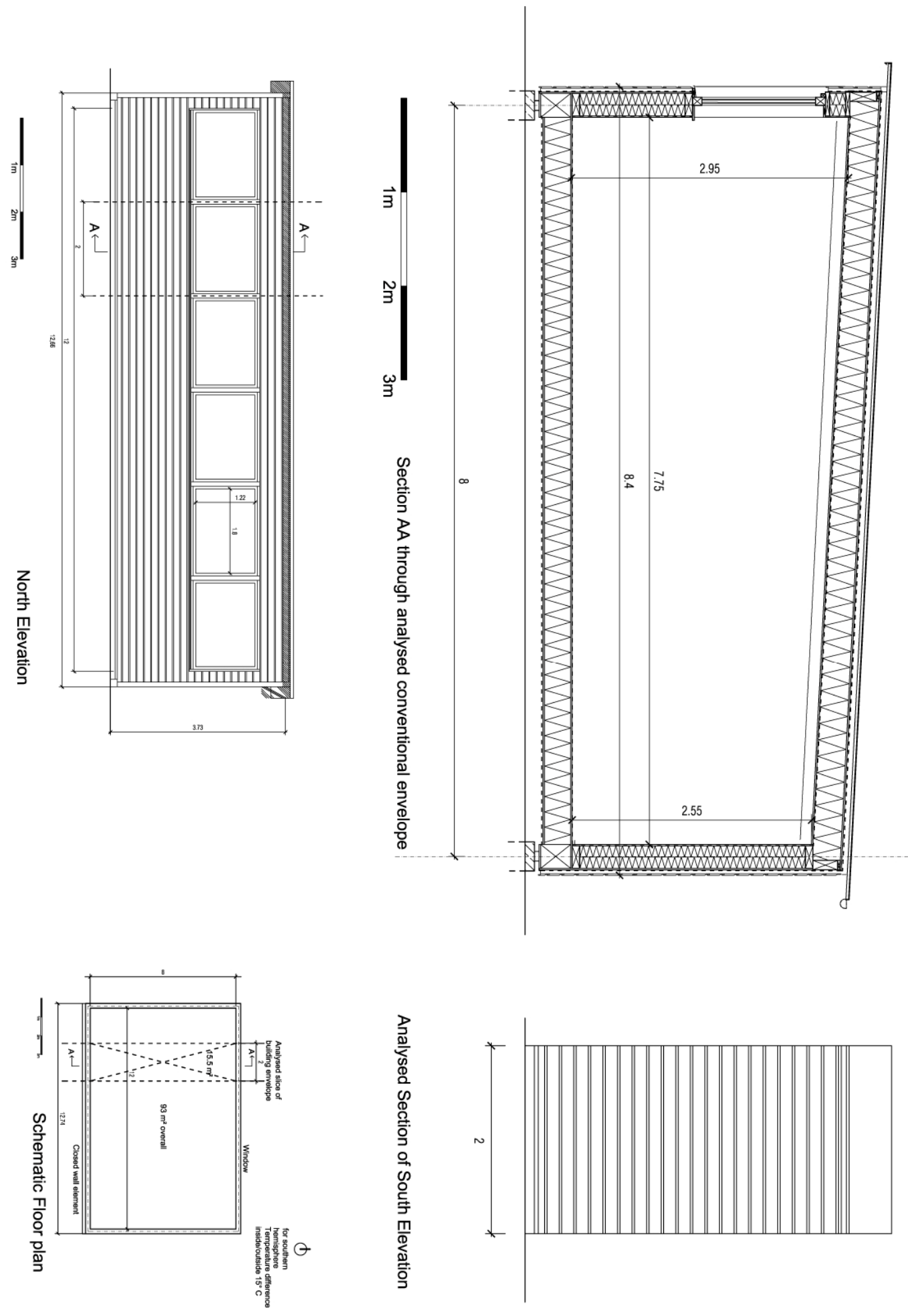

Figure 97: Section and schematic Floor Plan of the conventional envelope 

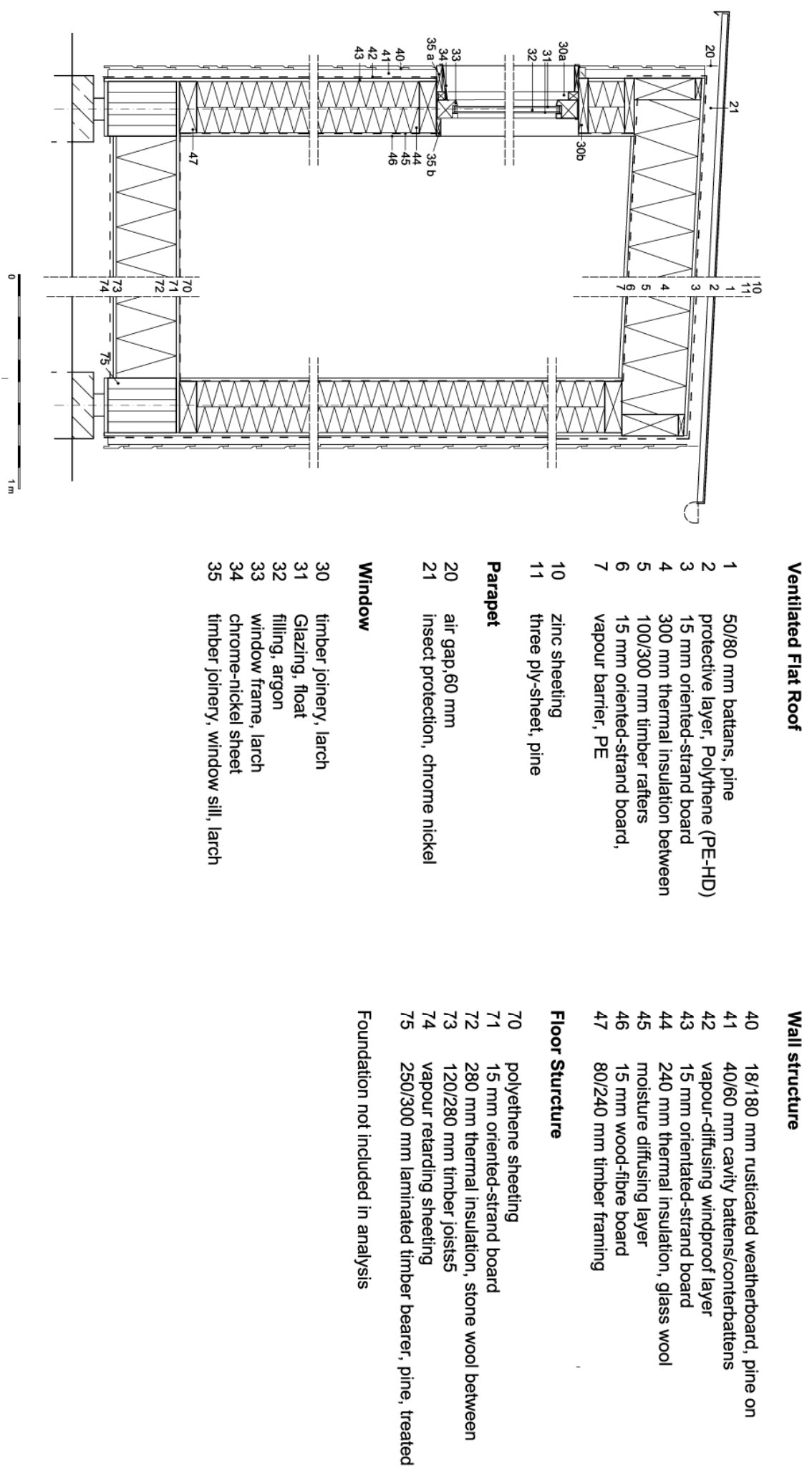

Figure 98: Detailed section and reference numbers of the multifunctional envelope 

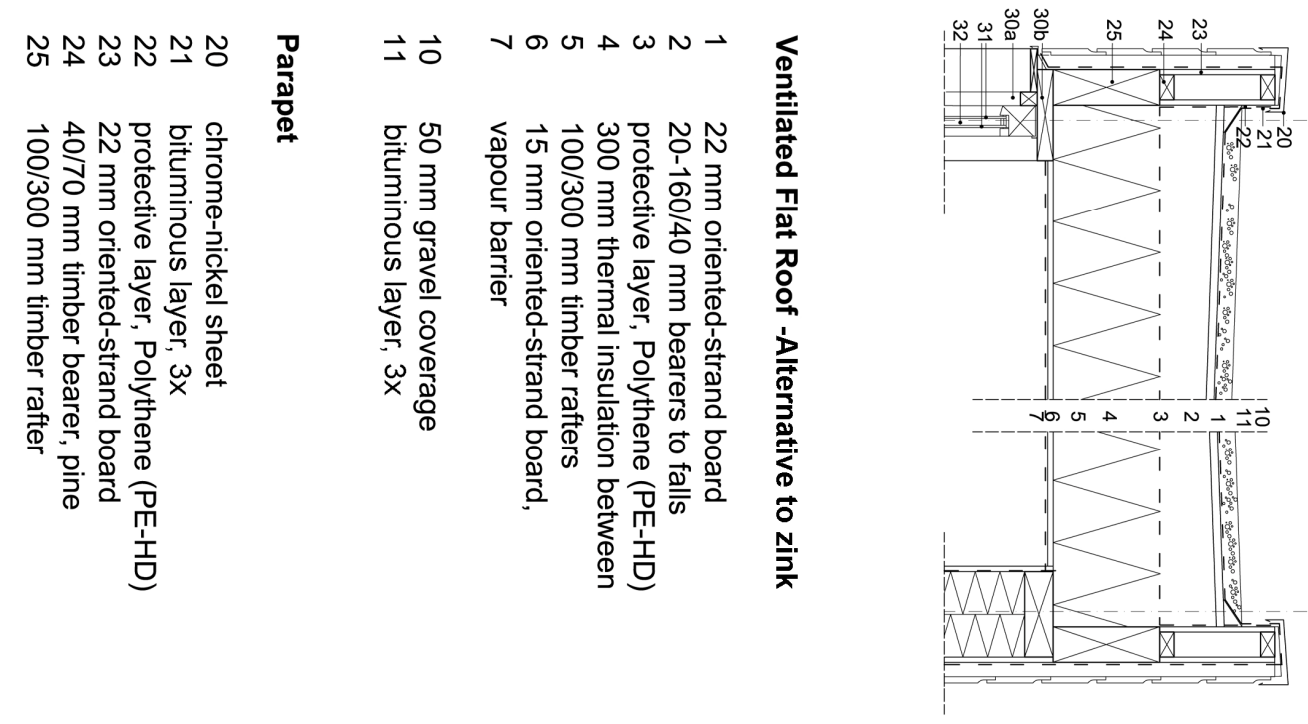

\begin{tabular}{|c|c|c|}
\hline $\mathcal{N} \sim \mathcal{N} N N$ & $\overrightarrow{0}$ & $V \sigma G A \omega N \rightarrow$ \\
\hline 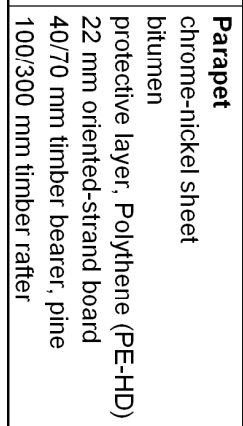 & 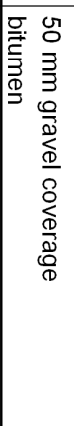 & 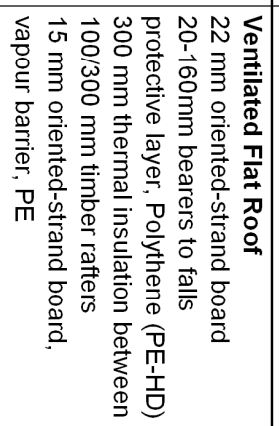 \\
\hline 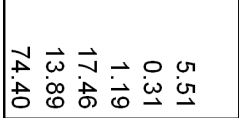 & 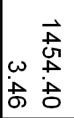 & 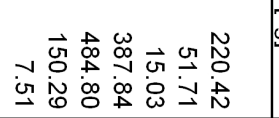 \\
\hline
\end{tabular}

Figure 99: Alternative roof solution, conventional envelope Instead of zinc roofing, the roof is covered with gravel and has a parapet 


\subsection{APPENDIX 2: GEOMETRIC DATA}

\subsubsection{THE MULTIFUNCTIONAL ENVELOPE}

The following tables summarise the most important geometric settings and material properties of the different elements of the multifunctional envelope. The numbers in the first row refer to the numbers used in the drawings.

Table 33: geometric information of the roof structure and the extensive green roof

\begin{tabular}{|c|c|c|c|c|c|c|c|c|}
\hline No. & Elements: & Amount & \begin{tabular}{|l|} 
Layer \\
thickness \\
[m] \\
\end{tabular} & \begin{tabular}{|l|} 
Running \\
metre [m]
\end{tabular} & \begin{tabular}{|l|} 
Cross \\
sectional \\
area $\left[\mathrm{m}^{2}\right]$ \\
\end{tabular} & \begin{tabular}{|l|} 
Density \\
{$\left[\mathrm{kg} / \mathrm{m}^{3}\right]$}
\end{tabular} & \begin{tabular}{|l|} 
Thermal \\
conductivity k \\
{$[\mathrm{W} /(\mathrm{mK})]$} \\
\end{tabular} & Source \\
\hline $\begin{array}{l}1 \\
2 \\
3 \\
4 \\
5\end{array}$ & $\begin{array}{l}\text { Roof structure and sheeting } \\
\text { EPDM membrane } \\
\text { protective membrane PP, root protection } \\
\text { compressed straw-fibre slab } \\
\text { lightweight straw-fibre slab insulation } \\
\text { compressed straw-fibre slab }\end{array}$ & 2 & $\begin{array}{r}0.0015 \\
0.004 \\
0.04 \\
0.25 \\
0.05 \\
\end{array}$ & & 0.01 & $\begin{array}{r}1300 \\
125 \\
600 \\
208 \\
600 \\
\end{array}$ & \begin{tabular}{|l}
0.25 \\
0.22 \\
0.12 \\
0.04 \\
\end{tabular} & $\begin{array}{l}1 \\
1 \\
2 \\
2 \\
2\end{array}$ \\
\hline $\begin{array}{l}10 \\
11 \\
12 \\
13 \\
14 \\
15\end{array}$ & $\begin{array}{l}\text { Green Roof } \\
\text { vegetation } \\
\text { substrate } \\
\text { filter fleece, Polypropylen (PP) } \\
\text { drainage layer, Polystyrol (HIPS) } \\
\text { protective layer, Polythene (PP) } \\
\text { root protection layer (PE-LD) }\end{array}$ & & $\begin{array}{r}0.15 \\
0.15 \\
0.002 \\
0.025 \\
0.001 \\
0.0005\end{array}$ & & & $\begin{array}{r}1000 \\
70 \\
47,5 \\
125 \\
950\end{array}$ & $\begin{array}{l}0.17 \\
0.6 \\
0.6 / 0.026\end{array}$ & $\begin{array}{l}1 \\
1 \\
1 \\
1 \\
1\end{array}$ \\
\hline $\begin{array}{l}20 \\
21 \\
22 \\
23 \\
24 \\
25\end{array}$ & $\begin{array}{l}\text { Parapet } \\
\text { chrome-nickel sheet } \\
\text { EPDM membrane } \\
\text { compressed straw-fibre slab } \\
\text { compressed straw-fibre slab } \\
\text { lightweight straw-fibre slab insulation } \\
\text { corner wedge, compressed straw }\end{array}$ & $\begin{array}{l}2 \\
2 \\
4 \\
2 \\
2 \\
2\end{array}$ & $\begin{array}{r}0.0005 \\
0.0015 \\
\\
0.04 \\
0.1\end{array}$ & 1.1 & $\begin{array}{r}0.000225 \\
0.00087 \\
0.0005 \\
\\
\\
0.000625\end{array}$ & $\begin{array}{r}7874 \\
1300 \\
600 \\
600 \\
208 \\
600\end{array}$ & & $\begin{array}{l}1 \\
2 \\
2 \\
2 \\
2\end{array}$ \\
\hline
\end{tabular}

Table 34: Geometric information for the wall structure and the different wall elements

\begin{tabular}{|c|c|c|c|c|c|c|c|c|c|}
\hline No. & & Elements: & Amount & $\begin{array}{l}\text { Layer } \\
\text { thickness } \\
{[\mathrm{m}]}\end{array}$ & $\begin{array}{l}\text { Running } \\
\text { metre } \\
{[\mathrm{m}]}\end{array}$ & $\begin{array}{l}\text { Cross } \\
\text { sectional } \\
\text { area }\left[\mathrm{m}^{2}\right]\end{array}$ & $\begin{array}{l}\text { Density } \\
{\left[\mathrm{kg} / \mathrm{m}^{3}\right]}\end{array}$ & $\begin{array}{l}\text { Thermal } \\
\text { conductivity k } \\
{[\mathrm{W} /(\mathrm{mK})]}\end{array}$ & Source \\
\hline & & Window with integrated PV & \multirow{6}{*}{2} & & \multirow{6}{*}{6.38} & & & & \multirow[b]{6}{*}{3} \\
\hline 30 & & timber joinery, larch & & & & 0.002 & 620 & & \\
\hline 31 & & Glazing & & 0.006 & & 2.23 & 2500 & & \\
\hline 32 & a & Laminate, Polyvinylbutyral (PVB) & & 0.0076 & & 2.17 & 1.1 & & \\
\hline 32 & $\mathrm{~b}$ & PV, Module, amorphous silicone & & 0.0000004 & & 2.17 & 2330 & & \\
\hline 32 & \multirow[t]{4}{*}{$\mathrm{C}$} & glazing, substrate & & 0.003 & & 2.17 & 2500 & & \\
\hline 33 & & window frame, larch & & \multirow{3}{*}{$\begin{array}{l}0.003 \\
0.025\end{array}$} & \multirow[b]{3}{*}{4} & \multirow[t]{2}{*}{0.0072} & 620 & & \\
\hline 34 & & chrome-nickel sheet & & & & & 7874 & & \\
\hline 35 & & timber joinery, window sill, larch & & & & 0.0024 & 620 & & \\
\hline
\end{tabular}




\begin{tabular}{|c|c|c|c|c|c|c|c|c|c|}
\hline 36 & & timber joinery, window sill, larch & & 0.095 & 1.66 & 0.0108 & 620 & & \\
\hline $\begin{array}{l}40 \\
41 \\
42 \\
43\end{array}$ & & $\begin{array}{l}\text { Wall element } \\
\text { compressed straw-fibre slab } \\
\text { lightweight straw-fibre slab insulation } \\
\text { compressed straw-fibre slab } \\
\text { Metal connections } \\
\end{array}$ & 6 & $\begin{array}{l}0.04 \\
0.17 \\
0.05\end{array}$ & 9.02 & $\begin{array}{l}18.04 \\
8.46 \\
0.0085\end{array}$ & $\begin{array}{l}600 \\
208 \\
600\end{array}$ & $\begin{array}{l}0.12 \\
0.04 \\
0.12\end{array}$ & $\begin{array}{l}1 \\
1\end{array}$ \\
\hline $\begin{array}{l}50 \\
51 \\
52 \\
53 \\
54 \\
55 \\
56\end{array}$ & & $\begin{array}{l}\text { Solar heating } \\
\text { timber frame, larch } \\
\text { aluminium-rubber sealing } \\
\text { glazing } \\
\text { absorber, aluminium } \\
\text { absorber pipes, copper } \\
\text { collector pipes, copper } \\
\text { thermal insulation, rock wool }\end{array}$ & & $\begin{array}{l}0.045 \\
0.004 \\
0.002 \\
\\
0.04 \\
\end{array}$ & $\begin{array}{l}8.4 \\
8.4\end{array}$ & $\begin{array}{l}0.0036 \\
0.00018 \\
4.46 \\
4.32 \\
0.000002 \\
3 \\
0.000004 \\
8 \\
4.32 \\
\end{array}$ & $\begin{array}{r}620 \\
2700 \\
2500 \\
2700 \\
8920 \\
8920 \\
100 \\
\end{array}$ & $\begin{array}{l}1.5 \\
1.1 / 0.026 \\
0.045\end{array}$ & 4 \\
\hline \multicolumn{10}{|c|}{ Additional elements solar heating excluded } \\
\hline $\begin{array}{l}60 \\
61 \\
62 \\
63 \\
64 \\
64 \\
65 \\
66 \\
66 \\
67 \\
68\end{array}$ & $\begin{array}{l}a \\
b\end{array}$ & $\begin{array}{l}\text { Green wall, panel, stainless steel } \\
16 \mathrm{~mm} \text { water supply hose, polyethyl- } \\
\text { ene } \\
\text { vegetation } \\
150 \mathrm{~mm} \text { substrate } \\
\text { green wall perforated stainless steel } \\
\text { panels } \\
\text { drip line, 8mm, polyethylene } \\
\text { drip line insert, acetyl } \\
\text { protective layer, polythene (PE-HD) } \\
\text { spacer, HDPE } \\
\text { filled with polyurethane } \\
\text { mounting bracket, aluminium } \\
\text { flathead pan wood screw, stainless } \\
\text { steel }\end{array}$ & $\begin{array}{c}22 \\
286 \\
16 \\
16 \\
4 \\
32\end{array}$ & $\begin{array}{r}0.1524 \\
0.1524 \\
\\
0.04 \\
0.001 \\
0.013 \\
0.013 \\
0.005 \\
\text { see }\end{array}$ & $\begin{array}{l}8.37 \\
8.37\end{array}$ & $\begin{array}{l}0.000009 \\
8 \\
\\
0.000001 \\
5 \\
0.0002 \\
0.00014 \\
0.00018 \\
0.00025 \\
\end{array}$ & $\begin{array}{r}915 \\
\\
623 \\
48 \\
915 \\
1420 \\
930 \\
941 \\
105 \\
2700 \\
\end{array}$ & & 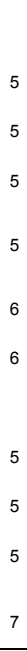 \\
\hline & & Additional elements green wall & & xcluded & & & & & \\
\hline
\end{tabular}

Table 35: Geometric information for the floor structure

\begin{tabular}{|c|c|c|c|c|c|c|c|c|}
\hline No. & Elements: & Amount & \begin{tabular}{|l|} 
Layer \\
thickness \\
{$[\mathrm{m}]$}
\end{tabular} & \begin{tabular}{|l|} 
Running \\
metre [m]
\end{tabular} & \begin{tabular}{|l} 
Cross \\
sectional \\
area $\left[\mathrm{m}^{2}\right]$
\end{tabular} & $\begin{array}{l}\text { Density } \\
{\left[\mathrm{kg} / \mathrm{m}^{3}\right]}\end{array}$ & \begin{tabular}{|l|} 
Thermal \\
conductivity \\
$\mathrm{k}$ \\
{$[\mathrm{W} /(\mathrm{mK})]$} \\
\end{tabular} & Source \\
\hline 70 & $\begin{array}{l}\text { Floor structure } \\
\text { compressed straw-fibre slab }\end{array}$ & 2 & 0.04 & & & 600 & 0.12 & \\
\hline 71 & lightweight straw-fibre slab insulation & & 0.22 & & & 208 & 0.04 & \\
\hline 72 & compressed straw-fibre ribs & 4 & 0.22 & & 0.0132 & 600 & 0.12 & \\
\hline 73 & compressed straw-fibre element & 2 & 0.05 & & 0.11 & 600 & 0.12 & \\
\hline
\end{tabular}

${ }^{1}$ (Symma, M. 19.04. 2009)

${ }^{5}$ (Irwin, G., 08.06. 2009)

2 (Stropoly, 2007), (Detail, 2006), (Buchan, D., 29.04. 2009)

${ }^{6}$ (Rainbird Ltd., 2009)

${ }^{3}$ (Arnold Glaswerke, Voltarlux, 2009)

${ }^{7}$ (Stoll, H., 08.05. 2009)

${ }^{4}$ (Bergmann, I.; Weiss, W., 2003) 


\subsubsection{THE CONVENTIONAL ENVELOPE}

The following tables summarise the most important geometric and material properties of the different elements of the conventional envelope. The numbers in the first row refer to the numbers used in the drawings.

Table 36: Geometric information for the roof structure

\begin{tabular}{|c|c|c|c|c|c|c|c|}
\hline No. & Elements: & Amount & $\begin{array}{l}\text { Layer } \\
\text { thickness } \\
{[\mathrm{m}]}\end{array}$ & $\begin{array}{l}\text { Running } \\
\text { metre [m] }\end{array}$ & $\begin{array}{l}\text { Cross } \\
\text { sectional } \\
\text { area }\left[\mathrm{m}^{2}\right]\end{array}$ & $\begin{array}{l}\text { Density } \\
{\left[\mathrm{kg} / \mathrm{m}^{3}\right]}\end{array}$ & $\begin{array}{l}\text { Thermal } \\
\text { conductivity k } \\
{[\mathrm{W} /(\mathrm{mK})]}\end{array}$ \\
\hline & Ventilated Flat Roof & \multirow{8}{*}{4} & & & \multirow{8}{*}{0.004} & & \multirow{4}{*}{0.13} \\
\hline 1 & $50 / 80 \mathrm{~mm}$ battens, pine & & & & & 500 & \\
\hline 2 & protective layer, polythene (PE-HD) & & 0.001 & & & 930 & \\
\hline 3 & oriented-strand board & & 0.015 & & & 620 & \\
\hline 4 & $300 \mathrm{~mm}$ thermal insulation, glass wool & & 0.3 & & & 100 & 0.04 \\
\hline 5 & $100 / 300 \mathrm{~mm}$ timber rafters & & & & & 500 & 0.13 \\
\hline 6 & $15 \mathrm{~mm}$ oriented-strand board & & 0.015 & & & 620 & \\
\hline 7 & vapour barrier, PE & & 0.0005 & & & 930 & 0.13 \\
\hline 8 & zinc sheeting & & 0.03 & & 20.67 & 7140 & \\
\hline 9 & three ply-sheet, pine & & 0.027 & & 18.83 & 620 & \\
\hline
\end{tabular}

Table 37: Geometric information for the wall structure and windows

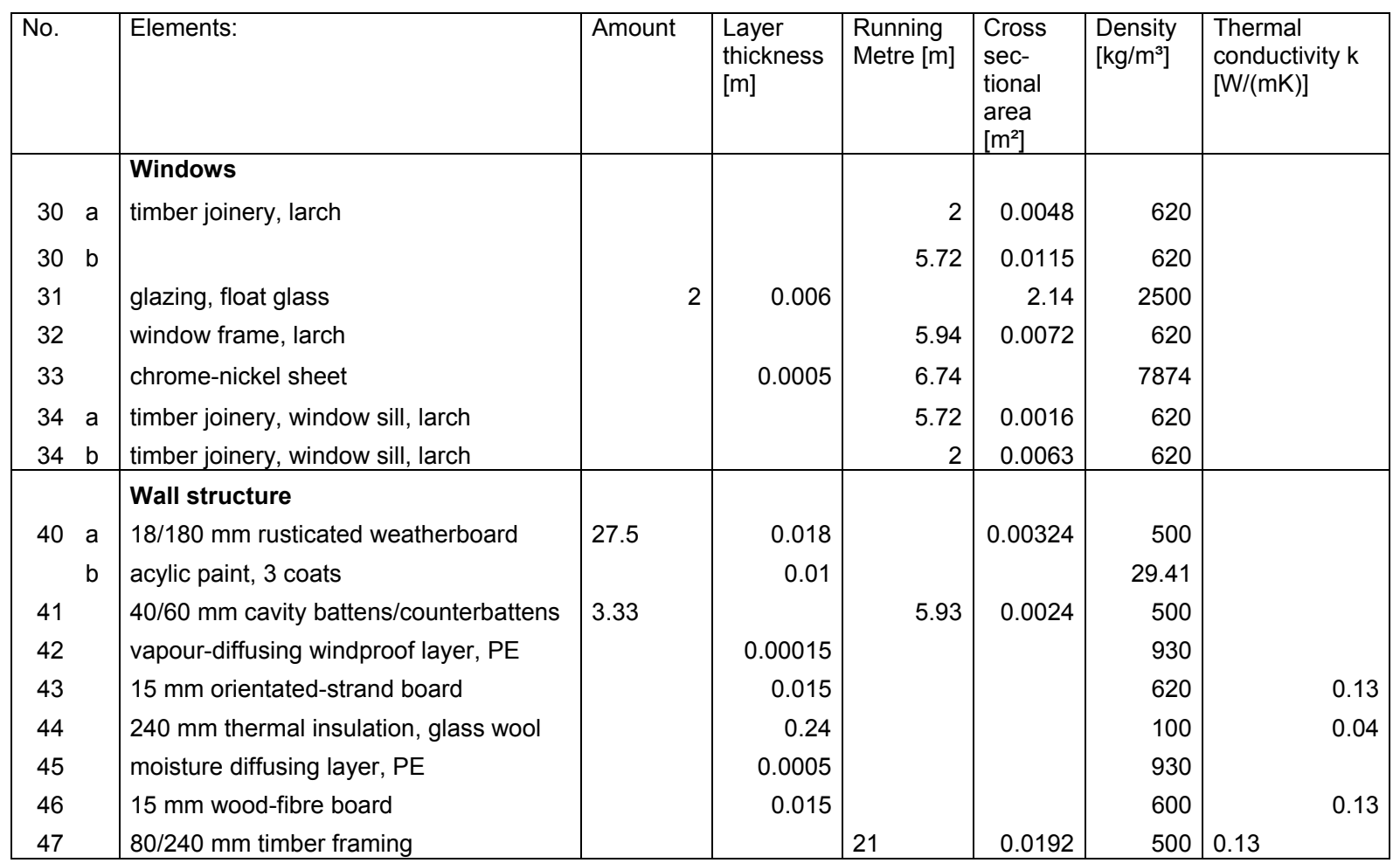


Table 38: Geometric information for the floor structure

\begin{tabular}{|c|c|c|c|c|c|c|c|}
\hline No. & Elements: & Amount & $\begin{array}{l}\text { ILayer } \\
\text { thickness } \\
\text { [m] }\end{array}$ & $\begin{array}{l}\text { Running } \\
\text { metre [m] }\end{array}$ & $\begin{array}{l}\text { Cross } \\
\text { sec- } \\
\text { tional } \\
\text { area } \\
{\left[\mathrm{m}^{2}\right]} \\
\end{array}$ & $\begin{array}{l}\text { Density } \\
{\left[\mathrm{kg} / \mathrm{m}^{3}\right]}\end{array}$ & $\begin{array}{l}\text { Thermal } \\
\text { conductivity k } \\
{[\mathrm{W} /(\mathrm{mK})]}\end{array}$ \\
\hline & Floor strucutre & & & & & & \\
\hline 70 & polyethylene sheeting & & 0.0005 & & & 930 & \\
\hline 71 & $15 \mathrm{~mm}$ orientated-strand board & 2 & 0.015 & & & 620 & 0.13 \\
\hline 72 & $280 \mathrm{~mm}$ thermal insulation, rock wool & & 0.28 & & & 100 & 0.04 \\
\hline 73 & $120 / 280 \mathrm{~mm}$ timber joists & 4 & & & 0.034 & 500 & 0.13 \\
\hline 74 & vapour retarding sheeting & & 0.00015 & & & 930 & \\
\hline 75 & $250 / 300 \mathrm{~mm}$ laminated timber bearer & 2 & & & 0.075 & 500 & 0.13 \\
\hline
\end{tabular}




\subsection{APPENDIX 3: CALCULATION OF ENERGY REQUIREMENTS}

The following section establishes the annual energy required for space heating, hot water and electricity of the two envelopes and their occupants. Similar to section 1.12, p.115, it is organised in three parts: space heating, hot water provision and electrical energy.

The calculations in part 1.16.1, Space heating, are based on the Austrian Standard ÖNORM B 8110-1 and its equivalent, the European Standard EN 832, Thermal performance of buildings - Calculation of energy use for heating - Residential buildings (OIB, 1999), (CEN, 1999). A complete list of all indices and terms used can be found in the list of Notations. The figures below relate to the entire building (93 $\mathrm{m}^{2}$ ) and not to the two metre wide section $\left(15.5 \mathrm{~m}^{2}\right)$ used for the Material Intensity analysis as the heating requirements have to be calculated for an enclosed volume.

General data relevant for the calculation of energy requirements of both envelopes is summarised in Table 39. All data, except the marked items, was sourced from the standard mentioned above.

Table 39: Climatic, geometric and other relevant general data for calculating the energy index of the two case studies

\begin{tabular}{|c|c|c|c|}
\hline air changes per hour & $\mathrm{n}$ & 0.6 & {$[1 / \mathrm{h}]$} \\
\hline \multirow[t]{6}{*}{ correction factor heat loss f } & \multirow{6}{*}{$\begin{array}{l}\text { for floor tangent to soil } \\
\text { for walls tangent to soil } \\
\text { to unheated basement } \\
\text { for windows } \\
\text { for external walls } \\
\text { for roofs }\end{array}$} & 0.15 & {$[-]$} \\
\hline & & 0.5 & \\
\hline & & 0.5 & \\
\hline & & 1 & \\
\hline & & 1 & \\
\hline & & 1 & \\
\hline correction for shading and dirt & $f_{s}$ & 0.9 & {$[-]$} \\
\hline density of air & $\mathrm{Pa}_{\mathrm{a}}$ & 1.2 & {$\left[\mathrm{~kg} / \mathrm{m}^{3}\right]$} \\
\hline electrical energy used per capita in household & $\mathrm{E}_{\text {elec } p}$ & 2050 & {$[\mathrm{kWh} / \mathrm{a}]$} \\
\hline energy production photovoltaics * & $Q_{p v}$ & 35 & {$\left[\mathrm{kWh} /\left(\mathrm{m}^{2} \mathrm{a}\right)\right]$} \\
\hline \multirow{2}{*}{$\begin{array}{l}\text { solar thermal element } \\
\text { solar fraction space heating } \\
\text { solar fraction hot water }\end{array}$} & \multirow[b]{2}{*}{$\begin{array}{l}\text { sf heating } \\
\text { sf hw }\end{array}$} & & \\
\hline & & & \\
\hline gross floor area & 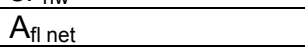 & 93 & {$\left[\mathrm{~m}^{2}\right]$} \\
\hline heat gain from appliances & $Q_{\text {appl }}$ & 60 & [W/person] \\
\hline heat gain from people with $12 \mathrm{~h} / 24 \mathrm{~h}$ absence & $Q_{\text {peo }}$ & 40 & [W/person] \\
\hline heat loss cold water pipes & $P_{\text {pip }}$ & -30 & [W/person] \\
\hline heating degree days & HGT $-12 / 20$ & 3515 & {$[\mathrm{~K} \mathrm{~d}]$} \\
\hline light transmission coefficient conventional glazing ${ }^{* * *}$ & $g_{w}$ con & 0.61 & {$[-]$} \\
\hline light transmission coefficient PV glazing * & $g_{w ~ p v}$ & 0.1 & {$[-]$} \\
\hline load factor & $\eta$ & 0.9 & $\begin{array}{l}\text { for light-weight } \\
\text { buildings }\end{array}$ \\
\hline mass of hot water provided & $\mathrm{M}_{\mathrm{hw}}$ & 160 & {$[\mathrm{~kg}]$} \\
\hline net glazed area & $A_{g}$ & 11.66 & {$\left[\mathrm{~m}^{2}\right]$} \\
\hline net collector area & $A_{\text {th }}$ & 24.04 & {$\left[\mathrm{~m}^{2}\right]$} \\
\hline normalised inside temperature & $\mathrm{t}_{\text {iint }}$ & 20 & {$\left[{ }^{\circ} \mathrm{C}\right]$} \\
\hline normalised outside temperature & $\mathrm{t}_{\mathrm{ne}}$ & -12 & {$\left[{ }^{\circ} \mathrm{C}\right]$} \\
\hline number of persons in household & & 3 & $\mathrm{p}$ \\
\hline solar radiation on vertical plane (oriented south) heating period & $\mathrm{I}_{\mathrm{S}}$ & 456 & {$\left[\mathrm{kWh} / \mathrm{m}^{2} \mathrm{a}\right]$} \\
\hline specific heat capacity of air & $\mathrm{C}_{\mathrm{a}}$ & 1000 & {$[\mathrm{~J} / \mathrm{kgK}]$} \\
\hline
\end{tabular}




\begin{tabular}{|l|l|l|l|}
\hline temperature difference & $\Delta \mathrm{t}=\mathrm{t}_{\mathrm{i}} \mathrm{t}_{\mathrm{ne}}$ & 32 & {$[\mathrm{~K}]$} \\
\hline temperature tap water (average) & $\mathrm{t}_{\mathrm{w}}$ & 12 & {$\left[{ }^{\circ} \mathrm{C}\right]$} \\
\hline temperature hot water (required) & $\mathrm{t}_{\mathrm{hw}}$ & 55 & {$\left[{ }^{\circ} \mathrm{C}\right]$} \\
\hline temperature difference water & $\Delta \mathrm{t}_{\mathrm{hw}}=\mathrm{t}_{\mathrm{hw}}-\mathrm{t}_{\mathrm{w}}$ & 43 & {$[\mathrm{~K}]$} \\
\hline
\end{tabular}

*(Voltarlux-ASI-T-ISO-E, by manufactuer)

**( Bergmann, I., Weiss, W., 2002, p.86) $\quad{ }^{* * *}($ OIB, 1999, p.16)

\subsubsection{SPACE HEATING}

\subsubsection{SPACE HEATING OF THE MULTIFUNCTIONAL ENVELOPE}

In order to establish the heating requirement of the multifunctional envelope during one heating period, heat loss and gains were calculated. Table 40 summarises the thermal transmittance of the elements of the envelope and establishes the ratio of their area and their specific heat transmittance (Uvalues). The underlying geometric data can be found in Appendix 1.15, Table 33-Table 35. Thermal bridges were taken into account.

Table 40: U-Values of the different elements of the multifunctional envelope

\begin{tabular}{|c|c|c|c|c|c|c|}
\hline $\begin{array}{l}\text { gross heated volume }\left[\mathrm{m}^{3}\right] \\
\text { net ventilated volume }\left[\mathrm{m}^{3}\right]\end{array}$ & $\begin{array}{l}\mathrm{V} \\
\mathrm{V}_{\mathrm{N}}\end{array}$ & $\begin{array}{l}368 \\
255\end{array}$ & & & & \\
\hline area surface of envelope $\left[\mathrm{m}^{2}\right]$ & $A_{B}$ & 316.33 & & & & \\
\hline Element Area $\mathrm{A}\left[\mathrm{m}^{2}\right]$ & & & $\mathrm{U}$-value $\left[\mathrm{W} / \mathrm{m}^{2} \mathrm{~K}\right]$ & & Correction $\mathbf{f}$ & $A \times U[W / K]$ \\
\hline roof & & 94.8 & & 0.13 & 1.00 & 12.7 \\
\hline roof structure and extensive green roof & & 94.8 & & 0.11 & 1.00 & 10.8 \\
\hline roof structure and intensive green roof & & 94.8 & & 0.12 & 1.00 & 11.4 \\
\hline window & & 16.4 & & 1.30 & 1.00 & 21.3 \\
\hline wall element (west \&east faces) & & 50 & & 0.18 & 1.00 & 9 \\
\hline wall element and thermal heating & & 28.3 & (effective & 0.04 & 1.00 & 1.1 \\
\hline wall element and green wall & & 33.8 & & 0.18 & 1.00 & 6.1 \\
\hline floor & & 93 & & 0.17 & 1.00 & 15.6 \\
\hline
\end{tabular}

The annual energy use for heating $E_{\text {heating }}$ of the multifunctional envelope is $731.6 \mathrm{KWh} / \mathrm{a}$. It is the sum of all heat loss through ventilation and transmittance $P_{\text {annum }}$ minus all usable heat gains through internal sources and solar gains $Q_{a n n u m}$ and minus the heat provided by the solar thermal element of the envelope $Q_{\text {th space }}$.

$E_{\text {heating }}=P_{\text {annum }}-Q_{\text {annum }}-Q_{\text {th space }}$

to derive $E_{\text {heating }}$ the following calculation had to be carried out: 


\subsection{CALCULATION OF HEAT LOSS}

The overall heat loss of the envelope $P_{\text {tot }}$ consists of heat loss from transmission $P_{0}$ and heat loss from ventilation $\mathrm{P}_{\mathrm{A}}$.

$\mathbf{P}_{\text {tot }}=\mathbf{P}_{0}+\mathbf{P}_{\mathrm{A}}$

with $P_{0}=P_{t} \cdot V \cdot \Delta T$ and $P_{A}=\rho_{A} \cdot V_{N} \cdot a c \cdot c_{p} \cdot \Delta T$

transmission loss index

$\mathrm{L}_{\mathrm{T}}=\Sigma(\mathrm{A} \cdot \mathrm{U} \cdot \mathrm{f})$

$64[\mathrm{~W} / \mathrm{K}]$

specific heat loss through transmission

$$
\mathrm{P}_{\mathrm{t}}=\mathrm{L}_{\mathrm{t}} / \mathrm{V}
$$

$0.17\left[\mathrm{~W} / \mathrm{m}^{3} \mathrm{~K}\right]$

heat loss through transmission $\mathrm{P}_{0}$

$\mathrm{P}_{0}=\mathrm{P}_{\mathrm{t}} \cdot \mathrm{V} \cdot \Delta \mathrm{T}$

$2047.6[\mathrm{~W}]$

specific heat loss through ventilation

$P_{A}=\rho_{A} \cdot V_{N} \cdot a c \cdot c_{p} \cdot \Delta T$

$1634.6[\mathrm{~W}]$

Inserting the values from Table 39, p.169, the following results are obtained:

The overall heat loss of the envelope $P_{\text {tot }}$ or heating load is $3682.2 \mathrm{~W}$, which translates to an annual energy requirement excluding heat gains $P_{\text {annum }}$ of $9707.2 \mathrm{KWh} / \mathrm{a}$

$P_{\text {annum }}=P_{\text {spec }} \cdot V \cdot H_{G} T_{-12 / 20}$

with

overall specific heat loss

energy use per annum

or

$$
\begin{aligned}
& P_{\text {spec }}=\left(P_{0}+P_{A}\right) /\left(\begin{array}{ll}
V & \Delta T
\end{array}\right) \\
& P_{\text {annum }}=P_{\text {spec }} \cdot V \cdot H G T_{-12 / 20}
\end{aligned}
$$

$0.31\left[\mathrm{~W} / \mathrm{m}^{3} \mathrm{~K}\right]$

$34945.7[\mathrm{MJ} / \mathrm{a}]$

$9707.2[\mathrm{KWh} / \mathrm{a}]$

\subsection{CALCULATION OF HEAT GAINS}

Overall heat gains $Q_{2}$ can be separated into internal heat gains $Q_{\text {int }}$ and solar heat gains $Q_{s}$. The former are calculated by adding heat sources such as appliances and people and subtracting cold water pipes within the building. It was presumed that four people would inhabit the case studies with an average of 12 hours spent in the house.

$Q_{2}=Q_{\text {int }}+Q_{s}$

with

$Q_{\text {int }}=Q_{\text {peo }}+Q_{\text {appl. }} \cdot P_{\text {pip }}$ and $Q_{s}=A_{g} \cdot I_{s} \cdot f_{s} \cdot g_{w}$

Inserting the values from Table 39 the overall heat gains $Q_{2}$ become $2966.6[\mathrm{kWh} / \mathrm{a}]$.

The amount of heat that can be stored inside the building and is therefore available for use depends on the thermal mass or thermal capacity $C$ of the building components. Only those components that are inside the insulation layer can store the heat gains. As the building is a light-weight construction and no heavy mass is included, the usable heat gains $Q_{a n n u m}$ are smaller then the overall heat gains. According to the Austrian standard $Q_{a n n u m}$ can be calculated as follows:

$\mathbf{Q}_{\text {annum }}=\mathbf{Q}_{2} \cdot \boldsymbol{\eta}$ 
with

ratio of heat gains and heat loss

$\mathrm{Y}=\mathrm{Q}_{2} / \mathrm{P}_{\text {annum }} \quad 0.31[-]$

time constant of thermal inertia

$\mathrm{T}=\mathrm{C} /\left(\mathrm{L}_{\mathrm{v}}+\mathrm{L}_{\mathrm{T}}\right) \quad 47.9[\mathrm{~h}]$

ventilation loss index

$L_{v}=\rho_{A} \cdot C_{p} \cdot a c \cdot V_{N}$

$51.1[\mathrm{~W} / \mathrm{k}]$

numerical parameter to calculate usable heat gains

$a=0,8+(\mathrm{T} / 28)$

$2.51[-]$

relevant thermal capacity

$\mathrm{C}=\mathrm{V} \cdot 15 \mathrm{Wh} / \mathrm{m}^{3} \mathrm{~K}$

$5515\left[\mathrm{Wh} / \mathrm{m}^{3} \mathrm{~K}\right]$

factor of usable heat gains

$\eta=1-y^{a} / y^{a+1}$

$0.96[-]$

The usable heat gains per annum $\mathrm{Q}_{\mathrm{annum}}$ add up to 2860.8 [kWh/a].

The effective energy use per annum $\mathrm{P}_{\text {eff }}$ is the sum of the total heat loss and the usable heat gains. It is comparable with $P_{\text {tot }}$ of the conventional envelope.

$\mathbf{P}_{\text {eff }}=\mathbf{P}_{\text {annum }}-\mathbf{Q}_{\text {annum }}$

$P_{\text {eff }}$ is $6847.14 \mathrm{KWh} / \mathrm{a}$ for the multifunctional envelope.

\subsection{ENERGY GAINS FROM SOLAR THERMAL HEATING}

The total energy produced by the solar thermal elements per year $Q_{\text {th solar }}$ is dependent on the solar fraction of the system. It is directly dependent on the area of the collector and the heat load $P_{\text {tot }}$ and the resulting energy that has to be provided for space heating $P_{\text {annum }}$ of the building. As discussed in section 0, p. 103 , the solar fraction for space heating was established at $63 \%$.

$Q_{\text {th space }}=P_{\text {annum }} \cdot 0.63$

$Q_{\text {th space }}$ is therefore $6115.6 \mathrm{KWh} / \mathrm{a}$.

\subsubsection{SPACE HEATING OF THE CONVENTIONAL ENVELOPE}

Just as for the multifunctional envelope, the heating requirement of the conventional envelope during one heating period depends on heat losses and gains. Table 41 summarises the thermal transmittance of the elements of the envelope and establishes the ratio of their area and their specific heat transmittance (U-values). The underlying geometric data can be found in Appendix 1.15, Table 33Table 35. Thermal bridges were taken into account. 
Table 41: U-Values of the different elements of the conventional envelope

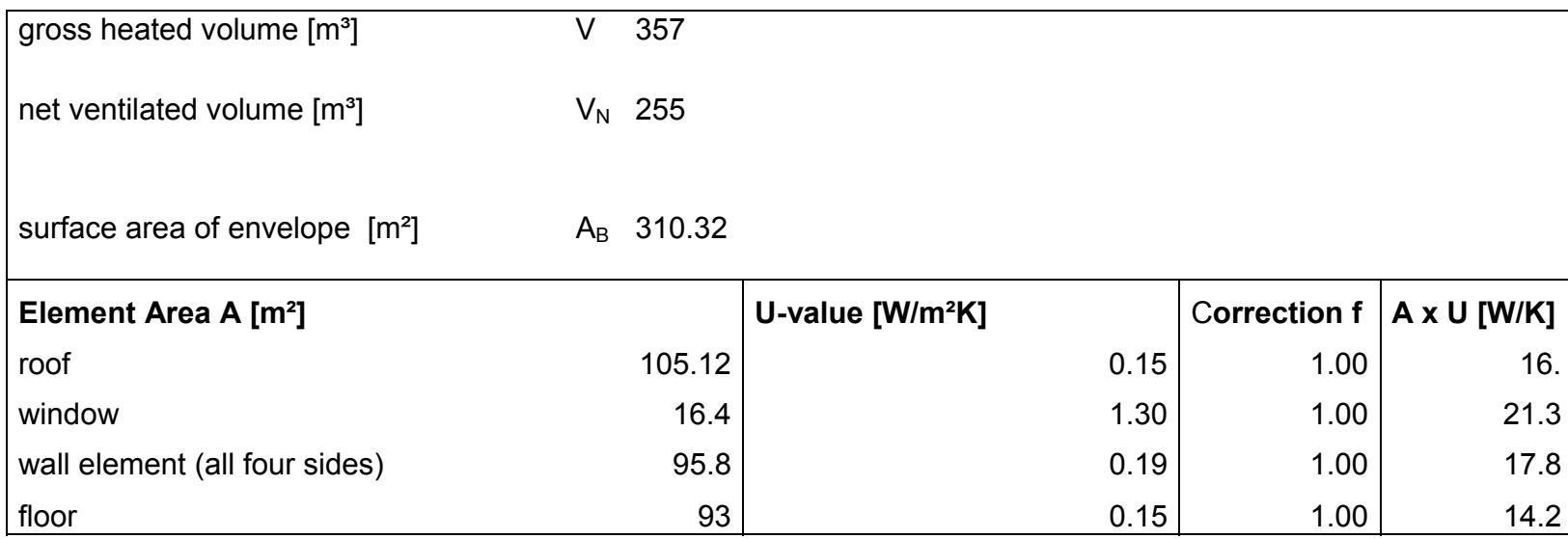

The annual energy use for heating $E_{\text {heating }}$ of the conventional envelope is $5268.3 \mathrm{KWh} / \mathrm{a}$. It is the sum of all heat losses through ventilation and transmittance $P_{\text {annum }}$ minus all usable heat gains through internal sources and solar gains $Q_{a n n u m}$. As the envelope does not actively produce heat no additional heat gains (solar thermal) can be added.

$E_{\text {heating }}=P_{\text {annum }}-Q_{\text {annum }}$

To derive $E_{\text {heating }}$ the following calculation had to be carried out.

\subsection{CALCULATION OF HEAT LOSS}

The overall heat loss of the envelope $\mathrm{P}_{\text {tot }}$ consists of heat loss from transmission $\mathrm{P}_{0}$ and heat loss from ventilation $\mathrm{P}_{\mathrm{A}}$.

$\mathbf{P}_{\text {tot }}=\mathbf{P}_{0}+\mathbf{P}_{\mathrm{A}}$

with $\mathrm{P}_{0}=\mathrm{P}_{\mathrm{t}} \cdot \mathrm{V} \cdot \Delta \mathrm{T}$ and $\mathrm{P}_{\mathrm{A}}=\rho_{\mathrm{A}} \cdot \mathrm{V}_{\mathrm{N}} \cdot \mathrm{ac} \cdot \mathrm{c}_{\mathrm{p}} \cdot \Delta \mathrm{T}$

transmission loss index

specific heat loss through transmission

heat loss through transmission $\mathrm{P}_{0}$

specific heat loss through ventilation

$$
\begin{array}{lrl}
\mathrm{L}_{\mathrm{T}}=\sum(\mathrm{A} \cdot \mathrm{U} \cdot \mathrm{f}) & 69.3[\mathrm{~W} / \mathrm{K}] \\
\mathrm{P}_{\mathrm{t}}=\mathrm{L}_{\mathrm{t}} / \mathrm{V} & 0.19\left[\mathrm{~W} / \mathrm{m}^{3} \mathrm{~K}\right] \\
\mathrm{P}_{0}=\mathrm{P}_{\mathrm{t}} \cdot \mathrm{V} \cdot \Delta \mathrm{T} & 2217[\mathrm{~W}] \\
\mathrm{P}_{\mathrm{A}}=\rho_{\mathrm{A}} \cdot \mathrm{V}_{\mathrm{N}} \cdot \mathrm{ac} \cdot \mathrm{c}_{\mathrm{p}} \cdot \Delta \mathrm{T} & 1634.6[\mathrm{~W}]
\end{array}
$$

Inserting the values from Table 39, p.169, the following results are obtained:

The overall heat loss of the envelope $P_{\text {tot }}$ or heating load is $3851.6 \mathrm{~W}$, which translates to an annual energy requirement excluding heat gains $\mathrm{P}_{\text {annum }}$ of 10161.8 [KWh/a ]

$P_{\text {annum }}=P_{\text {spec }} \cdot \mathbf{V} \cdot$ HGT $_{-12 / 20}$

with 
overall specific heat loss

energy use per annum

or

$$
\mathrm{P}_{\mathrm{spec}}=\left(\mathrm{P}_{0}+\mathrm{P}_{\mathrm{A}}\right) /(\mathrm{V} \Delta \mathrm{T})
$$$$
\mathrm{P}_{\text {annum }}=\mathrm{P}_{\text {spec }} \cdot \mathrm{V} \cdot \mathrm{HGT}_{-12 / 20}
$$

$0.34\left[\mathrm{~W} / \mathrm{m}^{3} \mathrm{~K}\right]$

36553.32 [MJ/a]

10161.8 [KWh/a ]

\subsection{CALCULATION OF HEAT GAIN}

Overall heat gains $Q_{2}$ can be separated into internal heat gains $Q_{\text {int }}$ and solar heat gains $Q_{s}$. The former are calculated by adding heat sources such as appliances and people and subtracting cold water pipes within the building. It was presumed that four people would inhabit the case studies with an average of 12 hours spent in the house.

$Q_{2}=Q_{i n t}+Q_{s}$

with

$Q_{\text {int }}=Q_{\text {peo }}+Q_{\text {appl. }} \cdot P_{\text {pip }}$ and $Q_{s}=A_{g} \cdot l_{s} \cdot f_{s} \cdot g_{w}$

Inserting the values from Table 39 the overall heat gains $Q_{2}$ become 5587 [kWh/a]. This is much larger than for the multifunctional envelope as the photovoltaic windows reduce the penetration of solar radiation from $\mathrm{g}=0.61$ for the conventional window to $\mathrm{g}=0.1$ for the photovoltaic window.

The amount of heat that can be stored inside the building and is therefore available for use depends on the thermal mass or thermal capacity $\mathrm{C}$ of the building components. Only those components that are inside the insulation layer can store the heat gains. As the building is a light-weight construction and no heavy mass is included, the usable heat gains $Q_{\text {annum }}$ are smaller then the overall heat gains. According to the Austrian standard $Q_{a n n u m}$ can be calculated as follows:

$\mathbf{Q}_{\mathrm{annum}}=\mathbf{Q}_{\mathbf{2}} \cdot \boldsymbol{\eta}$

with

ratio of heat gains and heat loss

$\mathrm{Y}=\mathrm{Q}_{2} / \mathrm{P}_{\text {annum }} \quad 0.55[-]$

time constant of thermal inertia

$\mathrm{T}=\mathrm{C} /\left(\mathrm{L}_{\mathrm{V}}+\mathrm{L}_{\mathrm{T}}\right)$

$44.5[\mathrm{~h}]$

ventilation loss index

numerical parameter to calculate usable heat

gains

$L_{V}=\rho_{A} \cdot C_{p} \cdot a c \cdot V_{N}$

$51.8[\mathrm{~W} / \mathrm{k}]$

relevant thermal capacity

$\mathrm{a}=0,8+(\mathrm{T} / 28)$

$2.4[-]$

factor of usable heat gains

$\mathrm{C}=\mathrm{V} \cdot 15 \mathrm{Wh} / \mathrm{m}^{3} \mathrm{~K}$

$5357\left[\mathrm{Wh} / \mathrm{m}^{3} \mathrm{~K}\right]$

$\eta=1-y^{a} / y^{a+1}$

$0.88[-]$

The usable heat gains per annum $Q_{\text {annum }}$ add up to 4894 [kWh/a].

The effective energy use per annum $P_{\text {eff }}$ is the sum of the total heat loss and the usable heat gains.

For the conventional envelope it is identical with $\mathrm{P}_{\text {tot }}$

$P_{\text {eff }}=P_{\text {tot }}=P_{\text {annum }}-Q_{\text {annum }}$ 
$P_{\text {eff }}$ is $5268.3 \mathrm{KWh} / \mathrm{a}$ for the conventional envelope.

\subsubsection{HOT WATER GENERATION}

The amount of hot water required within 24 hours was estimated to be 160 litres for four people. Cold tap water would enter the boiler at around $12^{\circ} \mathrm{C}$ and would then be heated up to $55^{\circ} \mathrm{C}$. Figure 100 shows part of the heating system. The boiler has a higher storage capacity than 160 I to allow for the provision of smaller amounts of hot water at frequent intervals e.g. mornings and evenings.

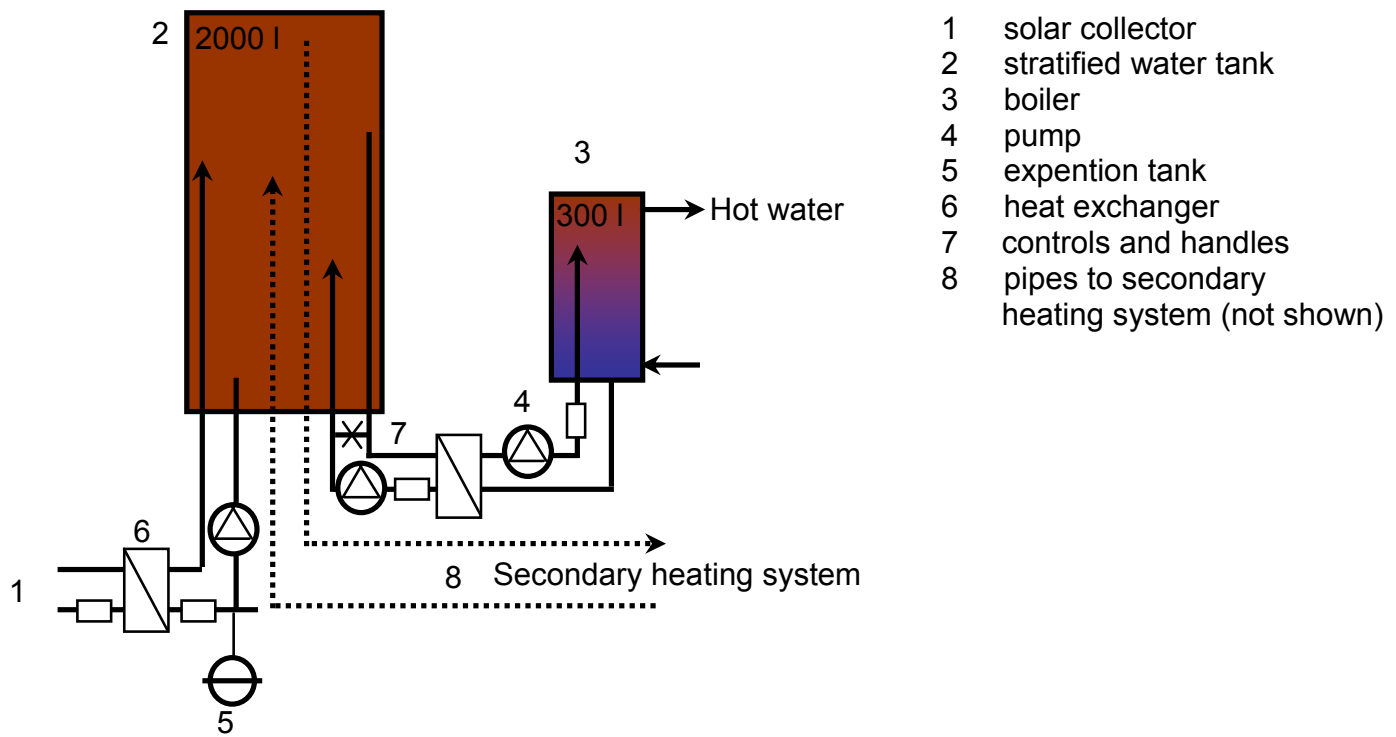

Figure 100: Part of the heating system providing hot water and space heating

The total energy $E_{h w}$ required to provide hot water can be described as the sum of all energy $P_{h w}$ required to heat the cold tap water to $55^{\circ} \mathrm{C}$ and keep it at that temperature minus the sum of all energy $Q_{\text {th hw }}$ provided by the solar thermal system to do this.

$E_{h w}=P_{h w}-Q_{\text {th hw }}$

$\mathrm{P}_{\mathrm{hw}}$ can be calculated as a product of the temperature difference between hot and cold water $\Delta_{\text {thw, }}$ the mass of water heated $\mathrm{M}_{\mathrm{hw}}$ and the specific heat capacity of water $\mathrm{C}_{\mathrm{w}}$

$\mathrm{P}_{\mathrm{hw}}=\mathrm{c}_{\mathrm{w}} \cdot \Delta_{\mathrm{thw}} \cdot \mathrm{M}_{\mathrm{hw}}$

Inserting the values from Table $39 \mathrm{P}_{\mathrm{hw}}$ becomes $2929.7 \mathrm{kWh} / \mathrm{a}$. This is identical for both envelopes.

However, the multifunctional envelope can provide $48 \%$ of the required energy for hot water with its solar thermal system (refer to section 0, p.103).

The energy gains from the solar thermal system therefore can be calculated as: 
$Q_{\text {th hw }}=P_{\text {hw }} \cdot 0.48$

which gives a reduction of $1406.3 \mathrm{kWh} / \mathrm{a}$.

The total amount of energy $E_{h w}$ required to provide hot water stays at $2929.7 \mathrm{KWh} / \mathrm{a}$ for the conventional envelope and is reduced to $1523.4 \mathrm{kWh} / \mathrm{a}$ as can be seen in Table 42.

Table 42: Energy requirements for hot water generation for the two envelopes

\begin{tabular}{|c|c|c|c|}
\hline Hot Water generation & & $\begin{array}{l}\text { Multifunctional } \\
\text { envelope }\end{array}$ & $\begin{array}{l}\text { Conventional } \\
\text { envelope }\end{array}$ \\
\hline $\begin{array}{l}\text { Energy use for the provision of } \\
\text { hot water per year }\end{array}$ & $\mathrm{P}_{\mathrm{hw}}=\mathrm{c}_{\mathrm{w}} \cdot \Delta$ thw $\cdot \mathrm{M}_{\mathrm{hw}}$ & $\begin{aligned} & 10547.04 {[\mathrm{MJ} / \mathrm{a}] } \\
& 2929.73[\mathrm{KWh} / \mathrm{a}]\end{aligned}$ & $\begin{aligned} & 10547.04 {[\mathrm{MJ} / \mathrm{a}] } \\
& 2929.73 \quad[\mathrm{KWh} / \mathrm{a}]\end{aligned}$ \\
\hline $\begin{array}{l}\text { Energy gains from solar thermal } \\
\text { heating }\end{array}$ & $\mathrm{Q}_{\mathrm{th} \mathrm{hw}}=\mathrm{P}_{\mathrm{hw}} \cdot 0,48$ & $1406.27[\mathrm{kWh} / \mathrm{a}]$ & $0.00[\mathrm{kWh} / \mathrm{a}]$ \\
\hline $\begin{array}{l}\text { Total Energy use per year for } \\
\text { hot water provision }\end{array}$ & $E_{h w}=P_{h w}-Q_{t h ~ h w}$ & $1523.46[\mathrm{KWh} / \mathrm{a}]$ & $2929.73[\mathrm{KWh} / \mathrm{a}]$ \\
\hline
\end{tabular}




\subsection{APPENDIX 4: UNDERLYING MATERIAL INTENSITY DATA}

The data shown in this section refers to initial resource use of the $2 \mathrm{~m}$ wide section of the envelope and and does not take the sixty year period into account.

MATERIAL INTENSITY SOURCES USED IN THE TABLES BELOW:

$\begin{array}{ll}* 1 & \text { (Wuppertal Institut, 2003) } \\ * 2 & \text { (Hegger, M. et al., 2005) } \\ { }^{*} 3 & \text { (Kötz, D., 2009) } \\ { }^{*} 4 & \text { (Schmidt-Bleek, F., Manstein, C., 1999) } \\ * 5 & \text { (Bergmann, I.; Weiss, U., 2002) } \\ * 6 & \text { (Minke, G., 2006) } \\ { }^{*} 7 & \text { (Ritthoff, M., 26.04.2009, 13.10.2009) } \\ * 8 & \text { (Pacca, S. et al., 2006) } \\ * 9 & \text { (Mercaldo, L. et al., 2009, p.1840) } \\ * 10 & \text { (MFL Edderitz, 2009, personal communication) } \\ * 11 & \text { (Sinivuoria, P., Saarib, A., 2006) }\end{array}$




\subsubsection{THE MULTIFUNCTIONAL ENVELOPE}

Table 43: Material Intensity Data, multifunctional envelope-FLOOR STRUCTURE

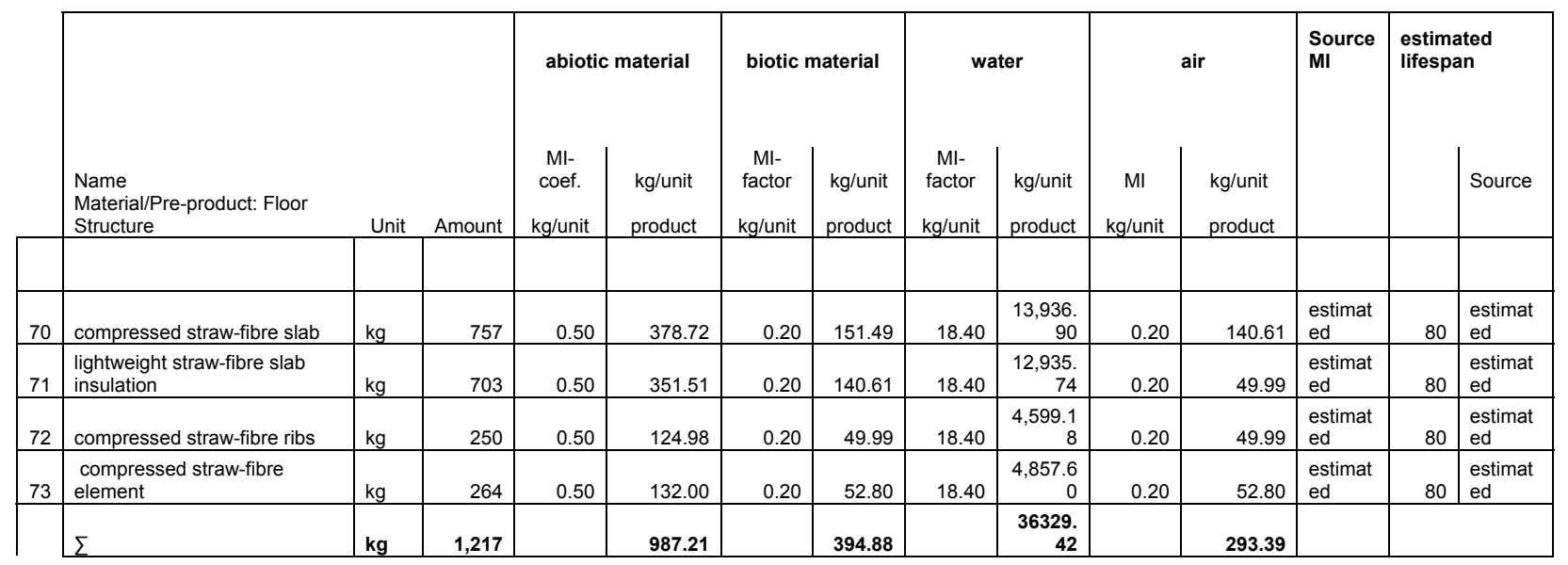

Table 44: Material Intensity Data, multifunctional envelope-WALL STRUCTURE

\begin{tabular}{|c|c|c|c|c|c|c|c|c|c|c|c|c|c|}
\hline \multirow{2}{*}{\multicolumn{3}{|c|}{ Name }} & \multicolumn{2}{|c|}{ abiotic material } & \multicolumn{2}{|c|}{ biotic material } & \multicolumn{2}{|c|}{ water } & \multicolumn{2}{|c|}{ air } & \multirow[t]{2}{*}{$\begin{array}{l}\text { Source } \\
\text { MI }\end{array}$} & \multicolumn{2}{|c|}{$\begin{array}{l}\text { estimated } \\
\text { lifespan }\end{array}$} \\
\hline & & & $\begin{array}{c}\text { MI-coeff. } \\
\text { kg/unit }\end{array}$ & $\begin{array}{l}\mathrm{kg} / \mathrm{unit} \\
\text { product }\end{array}$ & $\begin{array}{c}\begin{array}{c}\mathrm{Ml}- \\
\text { factor }\end{array} \\
\mathrm{kg} / \mathrm{unit}\end{array}$ & $\begin{array}{l}\mathrm{kg} / \mathrm{unit} \\
\text { product }\end{array}$ & $\begin{array}{c}\text { Ml- } \\
\text { factor } \\
\text { kg/unit }\end{array}$ & $\begin{array}{l}\mathrm{kg} / \mathrm{unit} \\
\text { product }\end{array}$ & $\begin{array}{l}\mathrm{Ml}- \\
\text { factor } \\
\mathrm{kg} / \mathrm{unit}\end{array}$ & $\begin{array}{l}\mathrm{kg} / \mathrm{unit} \\
\text { product }\end{array}$ & & & Source \\
\hline $\begin{array}{l}\text { compressed straw- } \\
\text { fibre slab }\end{array}$ & $\mathrm{kg}$ & 432.96 & 0.50 & 216.48 & 0.20 & 86.59 & 18.40 & $7,966.46$ & 0.20 & 86.59 & $\begin{array}{l}\text { estimat } \\
\text { ed }\end{array}$ & 60 & $\begin{array}{l}\text { estimate } \\
\text { d }\end{array}$ \\
\hline $\begin{array}{l}\text { lightweight straw-fibre } \\
\text { slab insulation }\end{array}$ & $\mathrm{kg}$ & 299.15 & 0.50 & 149.57 & 0.20 & 59.83 & 18.40 & $5,504.28$ & 0.20 & 59.83 & $\begin{array}{l}\text { estimat } \\
\text { ed }\end{array}$ & 60 & $\begin{array}{l}\text { estimate } \\
\text { d }\end{array}$ \\
\hline $\begin{array}{l}\text { compressed straw- } \\
\text { fibre slab }\end{array}$ & $\mathrm{kg}$ & 61.20 & 0.50 & 30.60 & 0.20 & 12.24 & 18.40 & $1,126.08$ & 0.20 & 12.24 & $\begin{array}{l}\text { estimat } \\
\text { ed }\end{array}$ & 60 & $\begin{array}{l}\text { estimate } \\
d\end{array}$ \\
\hline$\Sigma$ & $\mathrm{kg}$ & 793.31 & & 396.65 & & 158.66 & & 14596.82 & & 158.66 & & & \\
\hline
\end{tabular}


Table 45: Material Intensity Data, multifunctional envelope-SOLAR THERMAL PANELS

\begin{tabular}{|c|c|c|c|c|c|c|c|c|c|c|c|c|c|c|}
\hline & $\begin{array}{l}\text { Name } \\
\text { Material/Pre-product: }\end{array}$ & $\begin{array}{c}U \\
\text { nit } \\
\end{array}$ & $\underset{t}{\operatorname{Amoun}}$ & $\begin{array}{c}\text { abiotic } \\
\\
\text { Ml- } \\
\text { coefficient } \\
\text { kg/unit } \\
\end{array}$ & $\begin{array}{c}\text { material } \\
\text { kg/unit } \\
\text { main } \\
\text { product }\end{array}$ & $\begin{array}{c}\begin{array}{c}\text { biot } \\
\text { ic }\end{array} \\
\text { Ml- } \\
\text { fact } \\
\text { or } \\
\mathrm{kg} / \mathrm{u} \\
\text { nit }\end{array}$ & $\begin{array}{l}\text { material } \\
\text { kg/unit } \\
\text { main } \\
\text { product }\end{array}$ & $\begin{array}{c}\text { water } \\
\text { MI-factor } \\
\text { kg/unit }\end{array}$ & $\begin{array}{c}\mathrm{kg} / \mathrm{unit} \\
\text { main product }\end{array}$ & $\begin{array}{c}\text { air } \\
\text { Ml- } \\
\text { factor } \\
\text { kg/unit } \\
\end{array}$ & $\begin{array}{c}\mathrm{kg} / \mathrm{unit} \\
\text { main } \\
\text { product }\end{array}$ & $\begin{array}{l}\text { Sour } \\
\text { ce MI }\end{array}$ & $\begin{array}{l}\text { estim } \\
\text { lifesp }\end{array}$ & $\begin{array}{l}\text { ated } \\
\text { an }\end{array}$ \\
\hline $\begin{array}{l}5 \\
0 \\
\end{array}$ & timber frame, larch & $\mathrm{kg}$ & 18.75 & 0.68 & 12.75 & $\begin{array}{r}4.7 \\
2 \\
\end{array}$ & 88.49 & 9.40 & 176.24 & 0.16 & 2.92 & *1 & 20 & $\begin{array}{l}* 5 \mathrm{p} . \\
\text { A } 74\end{array}$ \\
\hline $\begin{array}{l}5 \\
1 \\
\end{array}$ & $\begin{array}{l}\text { aluminium sealing (50\% prim./50\% } \\
\text { sec.) }\end{array}$ & $\mathrm{kg}$ & 2.08 & 18.98 & 39.48 & & & 539.20 & $1,121.54$ & 5.91 & 12.29 & *1 & 20 & $\begin{array}{l}* 5 \mathrm{p} \\
\text { A } 74\end{array}$ \\
\hline $\begin{array}{l}5 \\
1\end{array}$ & $\begin{array}{l}\text { rubber sealing (styrol buradien } \\
\text { rubber) }\end{array}$ & $\mathrm{kg}$ & 2.00 & 5.70 & 11.40 & & & 146.00 & 292.00 & 1.65 & 3.30 & *1 & 20 & $\begin{array}{l}* 5 \mathrm{p} . \\
\text { A } 74\end{array}$ \\
\hline $\begin{array}{l}5 \\
2 \\
\end{array}$ & glazing & $\mathrm{kg}$ & 44.60 & 2.95 & 131.57 & & & 11.60 & 517.36 & 0.74 & 33.14 & *1 & 20 & $\begin{array}{l}* 5 \mathrm{p} . \\
\mathrm{A} 74\end{array}$ \\
\hline $\begin{array}{l}5 \\
3 \\
\end{array}$ & $\begin{array}{l}\text { absorber, aluminium(50\% prim. } / 50 \% \\
\text { sec.) }\end{array}$ & $\mathrm{kg}$ & 23.33 & 18.98 & 442.77 & & & 539.20 & $12,578.46$ & 5.91 & 137.85 & *1 & 20 & $\begin{array}{l}* 5 \mathrm{p} . \\
\text { A } 74\end{array}$ \\
\hline $\begin{array}{l}5 \\
4 \\
\end{array}$ & $\begin{array}{l}\text { absorber pipes , copper }(50 \% \\
\text { prim. } / 50 \% \text { sec.) }\end{array}$ & $\mathrm{kg}$ & 8.66 & 179.07 & $1,551.19$ & & & 236.39 & $2,047.72$ & 1.16 & 10.05 & *1 & 20 & $\begin{array}{l}* 5 \mathrm{p} . \\
\mathrm{A} 74\end{array}$ \\
\hline $\begin{array}{l}5 \\
5 \\
\end{array}$ & $\begin{array}{l}\text { collector pipes, copper }(50 \% \\
\text { prim. } / 50 \% \text { sec.) }\end{array}$ & $\mathrm{kg}$ & 1.88 & 179.07 & 337.13 & & & 236.39 & 445.05 & 1.16 & 2.18 & *1 & 20 & $\begin{array}{l}* 5 \mathrm{p} \\
\mathrm{A} 74 \\
\end{array}$ \\
\hline $\begin{array}{l}5 \\
6 \\
\end{array}$ & thermal insulation, rock wool & $\mathrm{kg}$ & 17.28 & 4.00 & 69.12 & & & 39.70 & 686.02 & 1.69 & 29.20 & *1 & 20 & $\begin{array}{l}* 5 \mathrm{p} . \\
\text { A } 74\end{array}$ \\
\hline $\begin{array}{l}5 \\
7 \\
\end{array}$ & $\begin{array}{l}\text { stratified buffer storage } 2000 \text { (partial } \\
1 / 6)\end{array}$ & $\mathrm{kg}$ & & & & & & & & & & *1 & 20 & $\begin{array}{l}\text { estim } \\
\text { ated }\end{array}$ \\
\hline $\begin{array}{l}5 \\
7 \\
a\end{array}$ & stainless steel & $\mathrm{kg}$ & 34.76 & 17.94 & 623.55 & & & 240.30 & $8,352.25$ & 3.38 & 117.55 & *1 & 20 & $\begin{array}{l}\text { estim } \\
\text { ated }\end{array}$ \\
\hline $\begin{array}{l}5 \\
7 \\
\mathrm{~b}\end{array}$ & insulation, PU & $\mathrm{kg}$ & 14.60 & 7.52 & 109.79 & & & 532.40 & $7,772.75$ & 3.42 & 49.93 & *1 & 20 & $\begin{array}{l}\text { estim } \\
\text { ated }\end{array}$ \\
\hline $\begin{array}{l}5 \\
7 \\
\mathrm{c} \\
\end{array}$ & cabinet, PVC & $\mathrm{kg}$ & 9.81 & 3.33 & 32.67 & & & 176.60 & $1,732.38$ & 1.69 & 16.61 & *1 & 20 & $\begin{array}{l}\text { estim } \\
\text { ated }\end{array}$ \\
\hline $\begin{array}{l}5 \\
8 \\
\end{array}$ & $\begin{array}{l}\text { controls and instruments (stainless } \\
\text { steel) }\end{array}$ & $\mathrm{kg}$ & 2.00 & 17.94 & 35.88 & & & 240.30 & 480.60 & 3.38 & 6.76 & & 20 & $\begin{array}{l}\text { estim } \\
\text { ated }\end{array}$ \\
\hline $\begin{array}{l}5 \\
9 \\
\end{array}$ & pumps & & & & 0.00 & & & & & & & & 20 & $\begin{array}{l}\text { estim } \\
\text { ated }\end{array}$ \\
\hline $\begin{array}{l}5 \\
9 \\
\mathrm{a}\end{array}$ & cast iron etc. & $\mathrm{kg}$ & 1.30 & 9.32 & 12.12 & & & 81.90 & 106.47 & 0.77 & 1.00 & & 20 & $\begin{array}{l}\text { estim } \\
\text { ated }\end{array}$ \\
\hline $\begin{array}{l}5 \\
9 \\
\mathrm{~b}\end{array}$ & stainless steel & $\mathrm{kg}$ & 0.13 & 17.94 & 2.33 & & & 240.30 & 31.24 & 3.38 & 0.44 & & 20 & $\begin{array}{l}\text { estim } \\
\text { ated }\end{array}$ \\
\hline $\begin{array}{l}5 \\
9 \\
\mathrm{c} \\
\end{array}$ & plastics (PE) & $\mathrm{kg}$ & 0.40 & 2.52 & 1.01 & & & 105.90 & 42.36 & 1.90 & 0.76 & & 20 & $\begin{array}{l}\text { estim } \\
\text { ated }\end{array}$ \\
\hline & $\Sigma$ & kg & 181.58 & & 3412.75 & & 88.49 & & 36382.43 & & 423.99 & & & \\
\hline
\end{tabular}

Table 46: Material Intensity Data, multifunctional envelope-SOLAR THERMAL PANELS-OPTIMISED, RECYCLED 


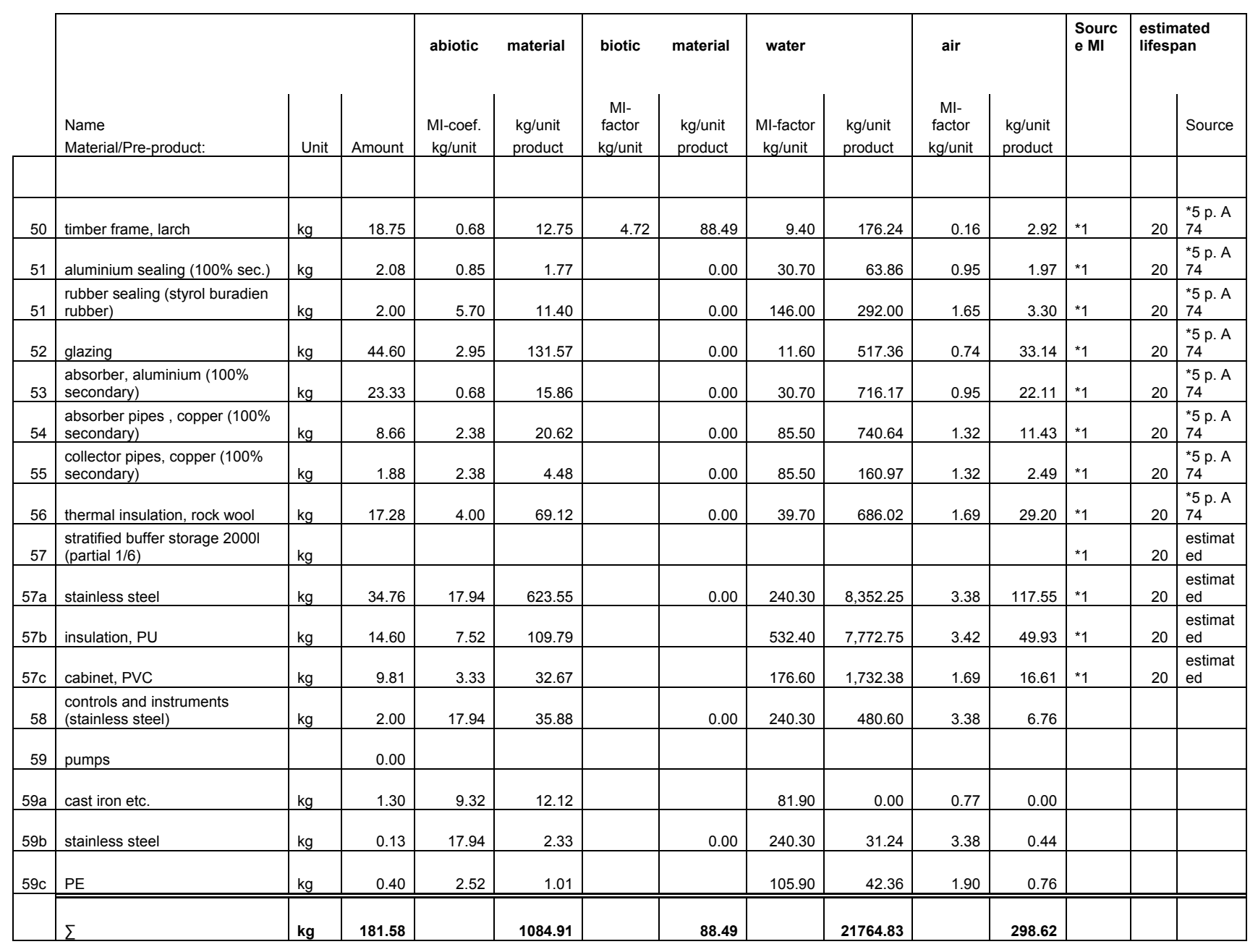

Table 47: Material Intensity Data, multifunctional envelope-GREEN WALL, HYDROPONIC SYSTEM 


\begin{tabular}{|c|c|c|c|c|c|c|c|c|c|c|}
\hline & \multirow[b]{2}{*}{$\begin{array}{l}\text { Name } \\
\text { Material/Pre-product: }\end{array}$} & \multirow{2}{*}{\multicolumn{2}{|c|}{$\begin{array}{c}\text { Amoun } \\
t\end{array}$}} & \multirow[b]{2}{*}{$\begin{array}{c}\begin{array}{c}\text { Ml- } \\
\text { coefficient }\end{array} \\
\text { kg/unit }\end{array}$} & \multirow[b]{2}{*}{$\begin{array}{c}\mathrm{kg} / \mathrm{unit} \\
\text { main } \\
\text { product }\end{array}$} & \multirow[b]{2}{*}{$\begin{array}{c}\text { MI- } \\
\text { factor } \\
\text { kg/unit }\end{array}$} & \multirow[b]{2}{*}{$\begin{array}{l}\mathrm{kg} / \mathrm{unit} \\
\text { main } \\
\text { product }\end{array}$} & \multirow[b]{2}{*}{$\begin{array}{c}\begin{array}{c}\text { Ml- } \\
\text { factor }\end{array} \\
\text { kg/unit }\end{array}$} & \multirow{2}{*}{$\begin{array}{l}\text { ir } \\
\text { kg/unit } \\
\text { main } \\
\text { product }\end{array}$} & \multirow[t]{2}{*}{$\begin{array}{l}\text { Source } \\
\text { MI }\end{array}$} \\
\hline & & & & & & & & & & \\
\hline 60 & $16 \mathrm{~mm}$ water supply hose, polyethylene & $\mathrm{kg}$ & 0.18 & 2.49 & 0.45 & 122.20 & 22.14 & \multicolumn{2}{|l|}{1.62} & *1 \\
\hline a & $20 \mathrm{~mm}$ compressed straw & $\mathrm{kg}$ & 84.00 & 0.50 & 42.00 & 0.20 & 16.80 & \multicolumn{2}{|l|}{0.20} & *7 \\
\hline $\mathrm{b}$ & root protection layer, $\mathrm{PE}$ & $\mathrm{kg}$ & 6.51 & 2.52 & 16.41 & 105.90 & 689.41 & 1.90 & 12.40 & *1 \\
\hline c & $5 \mathrm{~mm}$ felt layer, polyester & $\mathrm{kg}$ & 4.34 & 8.10 & 35.15 & 278.00 & 1206.52 & \multicolumn{2}{|r|}{16.19} & *1 \\
\hline d & $60 \mathrm{~d}$ drainage membrane, $\mathrm{PE}$ & $\mathrm{kg}$ & 6.51 & 2.52 & 16.41 & 105.90 & 689.41 & 1.90 & 12.40 & *1 \\
\hline 61 & vegetation & $\mathrm{kg}$ & & & 0.00 & & 0.00 & & 0.00 & ${ }^{* 1}$ \\
\hline $\begin{array}{l}64 \\
a \\
\end{array}$ & drip line, $8 \mathrm{~mm}$, polyethylene & $\mathrm{kg}$ & 0.63 & 2.52 & 1.59 & 105.90 & 66.97 & 1.90 & 1.20 & ${ }^{* 1} 1$ \\
\hline $\begin{array}{l}64 \\
\mathrm{~b}\end{array}$ & drip line insert, acetyl & $\mathrm{kg}$ & 3.27 & 3.33 & 10.88 & 176.60 & 576.81 & 1.69 & 5.53 & *1 \\
\hline 65 & $\begin{array}{l}\begin{array}{l}\text { protective layer, Polythene } \\
\text { membrane }\end{array} \\
\end{array}$ & $\mathrm{kg}$ & 6.51 & 2.52 & 16.41 & 105.90 & 689.41 & 1.90 & 12.40 & *1 \\
\hline 68 & $\begin{array}{l}6 \mathrm{~mm} / 50 \mathrm{mmwood} \text { screw, stainless } \\
\text { steel }(17 \% \mathrm{Cr}, 12 \% \mathrm{Ni})\end{array}$ & $\mathrm{kg}$ & 0.17 & 17.94 & 3.05 & 240.30 & 40.85 & 3.38 & 0.57 & ${ }^{* 1} 1$ \\
\hline & $\begin{array}{l}\text { fertiliser,phosphate }(8 \%), \mathrm{K}_{2} \mathrm{O} \\
(24 \%) ; \mathrm{CACO}_{2}(20 \%), \mathrm{NH}_{4} \mathrm{NO}_{3}(31 \%)^{*}\end{array}$ & & 3.06 & 5.00 & 15.28 & 18.84 & 57.59 & 0.98 & 3.00 & *2 \\
\hline
\end{tabular}

Table 48: Material Intensity Data, multifunctional envelope-GREEN WALL; PE-PANEL SYSTEM

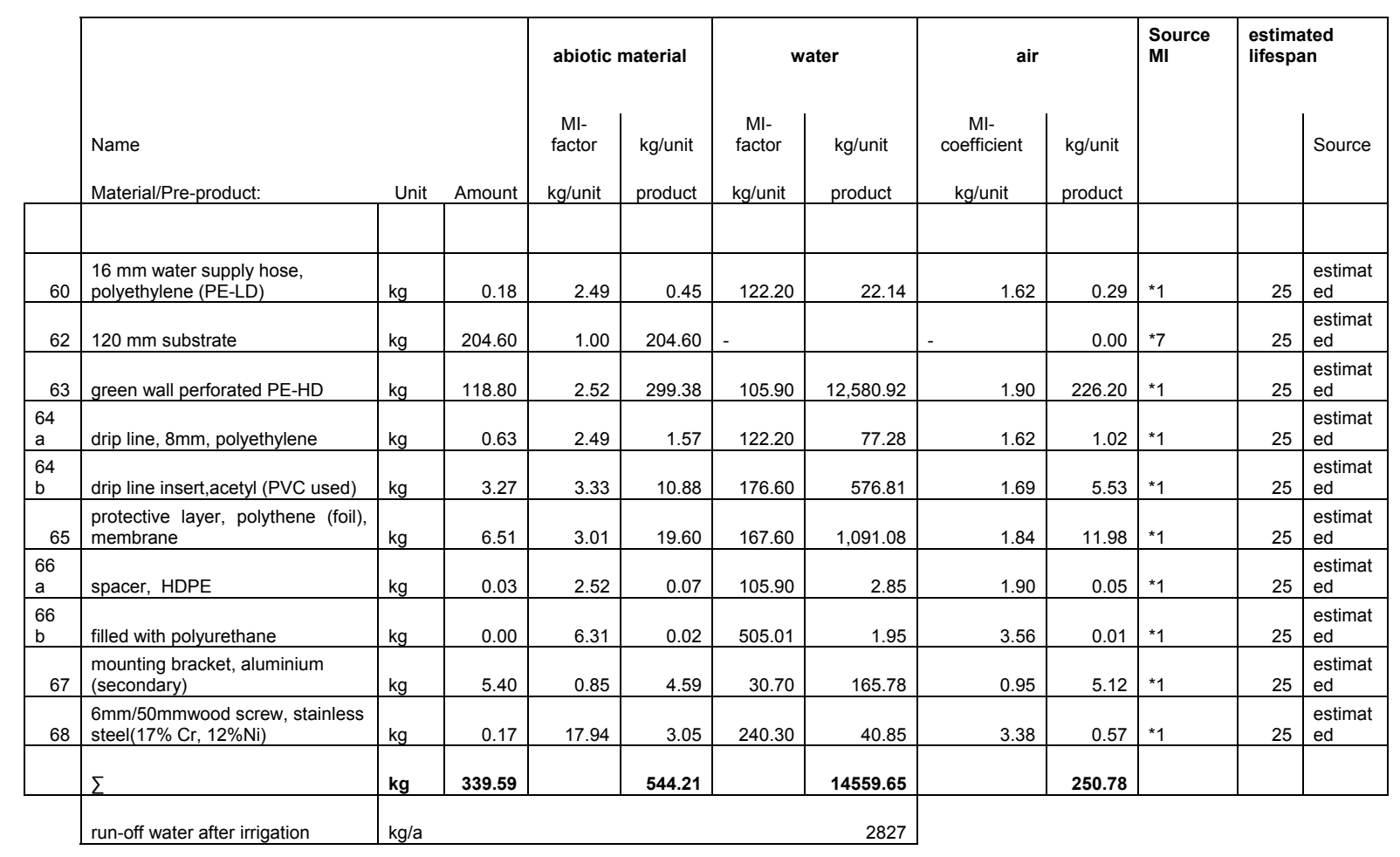

Table 49: Material Intensity Data, multifunctional envelope-GREEN WALL, ALUMINIUM-PANEL SYSTEM 


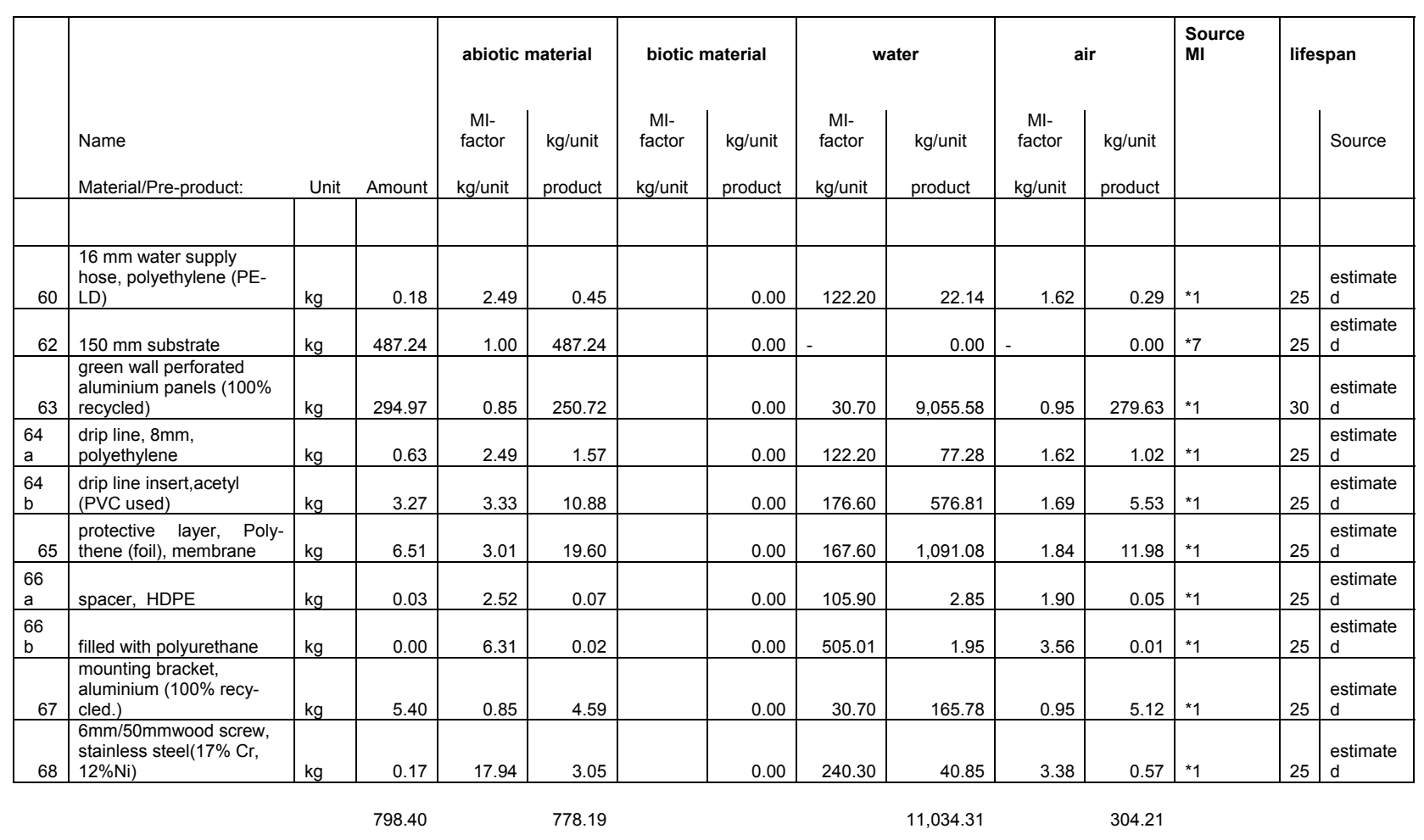

Table 50: Material Intensity Data, multifunctional envelope-GREEN WALL, STAINLESS STEEL-PANEL SYSTEM

\begin{tabular}{|c|c|c|c|c|c|c|c|c|c|c|c|c|c|c|}
\hline & & & & abiotic & naterial & biotic & aterial & & & & ir & $\begin{array}{l}\text { Source } \\
\text { MI }\end{array}$ & & $\begin{array}{l}\text { lifesp } \\
\text { an }\end{array}$ \\
\hline & $\begin{array}{l}\text { Name } \\
\text { Material/Pre-product: }\end{array}$ & Unit & Amount & $\begin{array}{c}\begin{array}{c}\text { Ml- } \\
\text { factor }\end{array} \\
\mathrm{kg} / \mathrm{unit}\end{array}$ & $\begin{array}{l}\mathrm{kg} / \mathrm{unit} \\
\text { product }\end{array}$ & $\begin{array}{c}\text { Ml- } \\
\text { factor }\end{array}$ & $\begin{array}{l}\mathrm{kg} / \mathrm{unit} \\
\text { product }\end{array}$ & $\begin{array}{c}\text { Ml- } \\
\text { factor } \\
\mathrm{kg} / \mathrm{unit}\end{array}$ & $\begin{array}{l}\mathrm{kg} / \mathrm{unit} \\
\text { product }\end{array}$ & $\begin{array}{c}\begin{array}{c}\text { Ml- } \\
\text { factor }\end{array} \\
\text { kg/unit }\end{array}$ & $\begin{array}{l}\mathrm{kg} / \mathrm{unit} \\
\text { product }\end{array}$ & & & $\begin{array}{l}\text { Sourc } \\
\text { e }\end{array}$ \\
\hline 60 & $\begin{array}{l}16 \mathrm{~mm} \text { water supply } \\
\text { hose, polyethylene (PE- } \\
\text { LD) }\end{array}$ & $\mathrm{kg}$ & 0.18 & 2.49 & 0.45 & & 0.00 & 122.20 & 22.14 & 1.62 & 0.29 & ${ }^{* 1}$ & 25 & $\begin{array}{l}\text { estim } \\
\text { ated }\end{array}$ \\
\hline 62 & $150 \mathrm{~mm}$ substrate & $\mathrm{kg}$ & 487.00 & 1.00 & 487.00 & & 0.00 & - & 0.00 & - & 0.00 & ${ }^{*} 7$ & 25 & $\begin{array}{l}\text { estim } \\
\text { ated }\end{array}$ \\
\hline 63 & $\begin{array}{l}\text { green wall stainless steel } \\
\text { panels }(17 \% \mathrm{Cr}, 12 \% \mathrm{Ni})\end{array}$ & $\mathrm{kg}$ & 510.00 & 17.94 & $9,149.40$ & & 0.00 & 240.30 & $\begin{array}{r}122,553.0 \\
0 \\
\end{array}$ & 3.38 & $1,724.82$ & *1 & 30 & $\begin{array}{l}\text { estim } \\
\text { ated }\end{array}$ \\
\hline $\begin{array}{l}64 \\
\mathrm{a} \\
\end{array}$ & $\begin{array}{l}\text { drip line, } 8 \mathrm{~mm} \text {, } \\
\text { polyethylene }\end{array}$ & $\mathrm{kg}$ & 0.63 & 2.49 & 1.57 & & 0.00 & 122.20 & 77.28 & 1.62 & 1.02 & ${ }^{* 1}$ & 25 & $\begin{array}{l}\text { estim } \\
\text { ated }\end{array}$ \\
\hline $\begin{array}{l}64 \\
b\end{array}$ & $\begin{array}{l}\text { drip line insert,acetyl } \\
\text { (PVC used) }\end{array}$ & $\mathrm{kg}$ & 3.27 & 3.33 & 10.88 & & 0.00 & 176.60 & 576.81 & 1.69 & 5.53 & *1 & 25 & $\begin{array}{l}\text { estim } \\
\text { ated }\end{array}$ \\
\hline 65 & $\begin{array}{l}\text { protective layer, poly- } \\
\text { thene (foil), membrane }\end{array}$ & $\mathrm{kg}$ & 6.51 & 3.01 & 19.60 & & 0.00 & 167.60 & $1,091.08$ & 1.84 & 11.98 & *1 & 25 & $\begin{array}{l}\text { estim } \\
\text { ated }\end{array}$ \\
\hline $\begin{array}{l}66 \\
a \\
\end{array}$ & spacer, HDPE & $\mathrm{kg}$ & 0.03 & 2.52 & 0.07 & & 0.00 & 105.90 & 2.85 & 1.90 & 0.05 & *1 & 25 & $\begin{array}{l}\text { estim } \\
\text { ated }\end{array}$ \\
\hline $\begin{array}{l}66 \\
b \\
\end{array}$ & filled with polyurethane & $\mathrm{kg}$ & 0.00 & 6.31 & 0.02 & & 0.00 & 505.01 & 1.95 & 3.56 & 0.01 & *1 & 25 & $\begin{array}{l}\text { estim } \\
\text { ated }\end{array}$ \\
\hline 67 & $\begin{array}{l}\text { mounting bracket, } \\
\text { aluminium ( } 100 \% \text { recyl..) }\end{array}$ & $\mathrm{kg}$ & 5.40 & 0.85 & 4.59 & & 0.00 & 30.70 & 165.78 & 0.95 & 5.12 & *1 & 25 & $\begin{array}{l}\text { estim } \\
\text { ated }\end{array}$ \\
\hline 68 & $\begin{array}{l}6 \mathrm{~mm} / 50 \mathrm{mmscrew}, \\
\text { stainless steel }(17 \% \mathrm{Cr} \text {, } \\
12 \% \mathrm{Ni})\end{array}$ & $\mathrm{kg}$ & 0.17 & 17.94 & 3.05 & & 0.00 & 240.30 & 40.85 & 3.38 & 0.57 & *1 & 25 & $\begin{array}{l}\text { estim } \\
\text { ated }\end{array}$ \\
\hline
\end{tabular}


Table 51: Material Intensity Data, multifunctional envelope-GREEN WALL, ADDITIONAL ELEMENTS

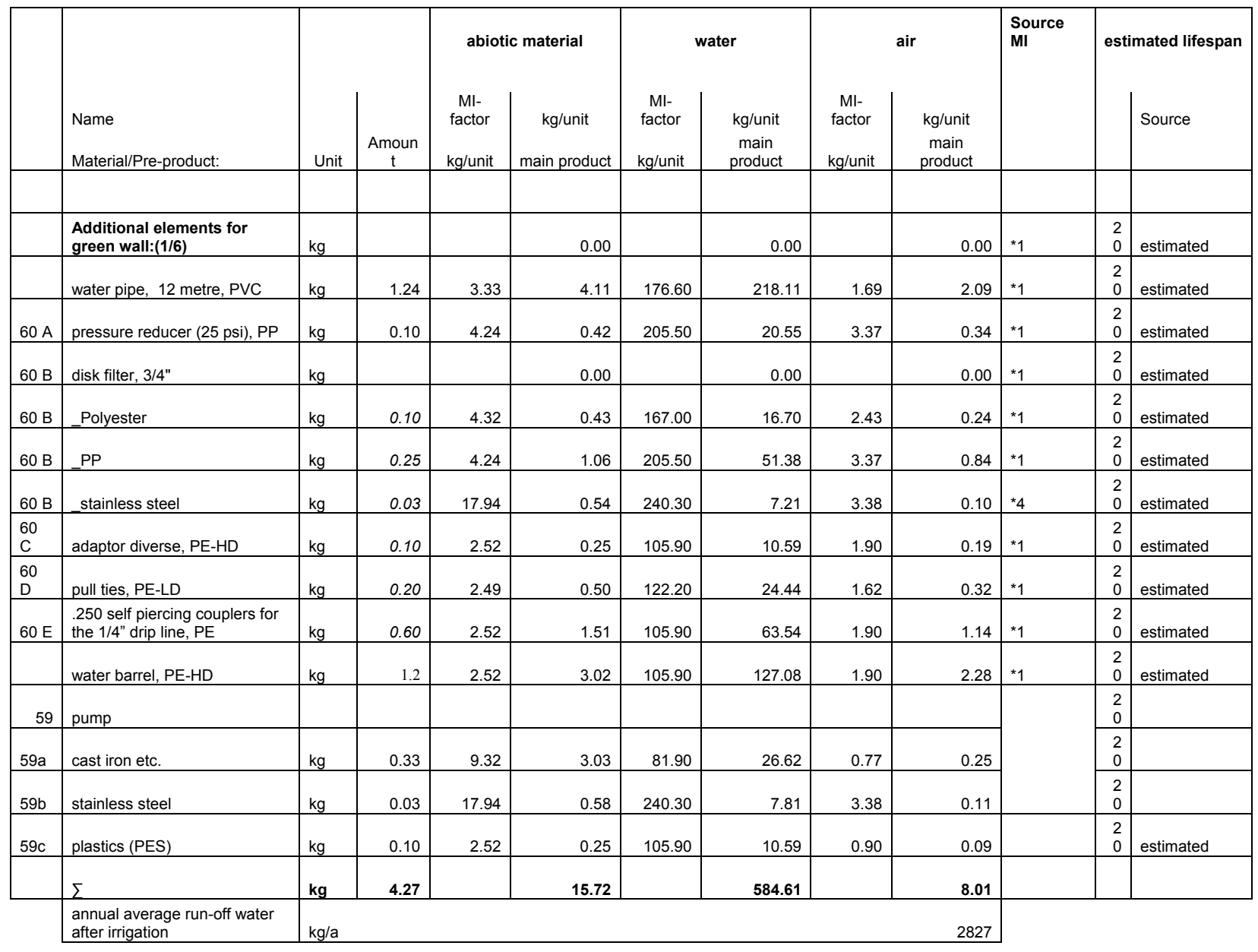

Table 52: Material Intensity Data, multifunctional envelope-PHOTOVOLTAIC WINDOW

\begin{tabular}{|c|c|c|c|c|c|c|c|c|c|c|c|c|c|c|}
\hline & $\begin{array}{l}\text { Name } \\
\text { Material/Pre-product: }\end{array}$ & Unit & $\begin{array}{c}\text { Amoun } \\
t\end{array}$ & 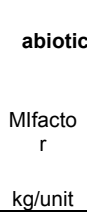 & $\begin{array}{l}\text { naterial } \\
\mathrm{kg} / \mathrm{unit} \\
\text { product } \\
\end{array}$ & $\begin{array}{c}\text { biotic } \\
\text { Ml- } \\
\text { factor } \\
\text { kg/unit } \\
\end{array}$ & $\begin{array}{l}\mathrm{kg} / \mathrm{unit} \\
\text { product }\end{array}$ & $\begin{array}{c}\text { MI- } \\
\text { factor } \\
\text { kg/unit }\end{array}$ & $\begin{array}{l}\mathrm{kg} / \mathrm{unit} \\
\text { product }\end{array}$ & $\begin{array}{c}\text { Ml- } \\
\text { factor } \\
\mathrm{kg} / \mathrm{unit}\end{array}$ & $\begin{array}{l}\mathrm{kg} / \mathrm{unit} \\
\text { product }\end{array}$ & $\begin{array}{l}\text { Sourc } \\
\text { e MI }\end{array}$ & $\begin{array}{l}\text { estimate } \\
\text { lifespan }\end{array}$ & Source \\
\hline 30 & timber joinery, larch & $\mathrm{kg}$ & 7.71 & 0.68 & 5.24 & 4.72 & 36.40 & 9.40 & 72.50 & 0.16 & 1.20 & *1 & 20 & \\
\hline 31 & glazing & $\mathrm{kg}$ & 66.98 & 2.95 & 197.59 & & 0.00 & 11.60 & 776.94 & 0.74 & 49.76 & ${ }^{* 1}$ & 20 & $\begin{array}{l}* 9 \\
\text { p.1840 }\end{array}$ \\
\hline 32 & \begin{tabular}{|l|} 
laminate, \\
polyvinylbutyral \\
(PVB) $^{\star}$ \\
\end{tabular} & $\mathrm{kg}$ & 0.02 & & 0.00 & & 0.00 & & 0.00 & & 0.00 & ${ }^{* 1}$ & 20 & $\begin{array}{l}* 9 \\
\text { p.1840 }\end{array}$ \\
\hline 32 & $\begin{array}{l}\text { PV, module, glass, } \\
\text { amorphous silicone }\end{array}$ & $\mathrm{kg}$ & 0.15 & 19.13 & 2.87 & & 0.00 & 7800.60 & $1,170.09$ & 6.60 & 0.99 & $\begin{array}{l}\text { based } \\
\text { on } * 8\end{array}$ & 20 & $* 11$ \\
\hline 32 & glazing & $\mathrm{kg}$ & 16.29 & 2.95 & 48.06 & & 0.00 & 11.60 & 188.96 & 0.74 & 12.10 & ${ }^{* 1}$ & 20 & \\
\hline 33 & window frame, larch & $\mathrm{kg}$ & 29.73 & 0.68 & 20.22 & 4.72 & 140.33 & 9.40 & 279.46 & 0.16 & 4.64 & ${ }^{* 1}$ & 20 & \\
\hline 34 & chrome-nickel sheet & $\mathrm{kg}$ & 3.15 & 17.94 & 56.51 & & 0.00 & 240.30 & 756.95 & 3.38 & 10.65 & $* 1$ & 50 & \\
\hline 35 & $\begin{array}{l}\text { timber joinery, window } \\
\text { sill, larch }\end{array}$ & $\mathrm{kg}$ & 5.95 & 0.68 & 4.05 & 4.72 & 28.09 & 9.40 & 55.95 & 0.16 & 0.93 & *1 & 20 & \\
\hline 36 & $\begin{array}{l}\text { timber joinery, window } \\
\text { sill, larch }\end{array}$ & $\mathrm{kg}$ & 11.12 & 0.68 & 7.56 & 4.72 & 52.46 & 9.40 & 104.48 & 0.16 & 1.73 & $* 1$ & 20 & \\
\hline & $\Sigma$ & $\mathbf{k g}$ & 141.10 & & 342.09 & & 257.29 & & 3405.34 & & 82.02 & & & \\
\hline
\end{tabular}


Table 53: Material Intensity Data, multifunctional envelope-ROOF STRUCTURE

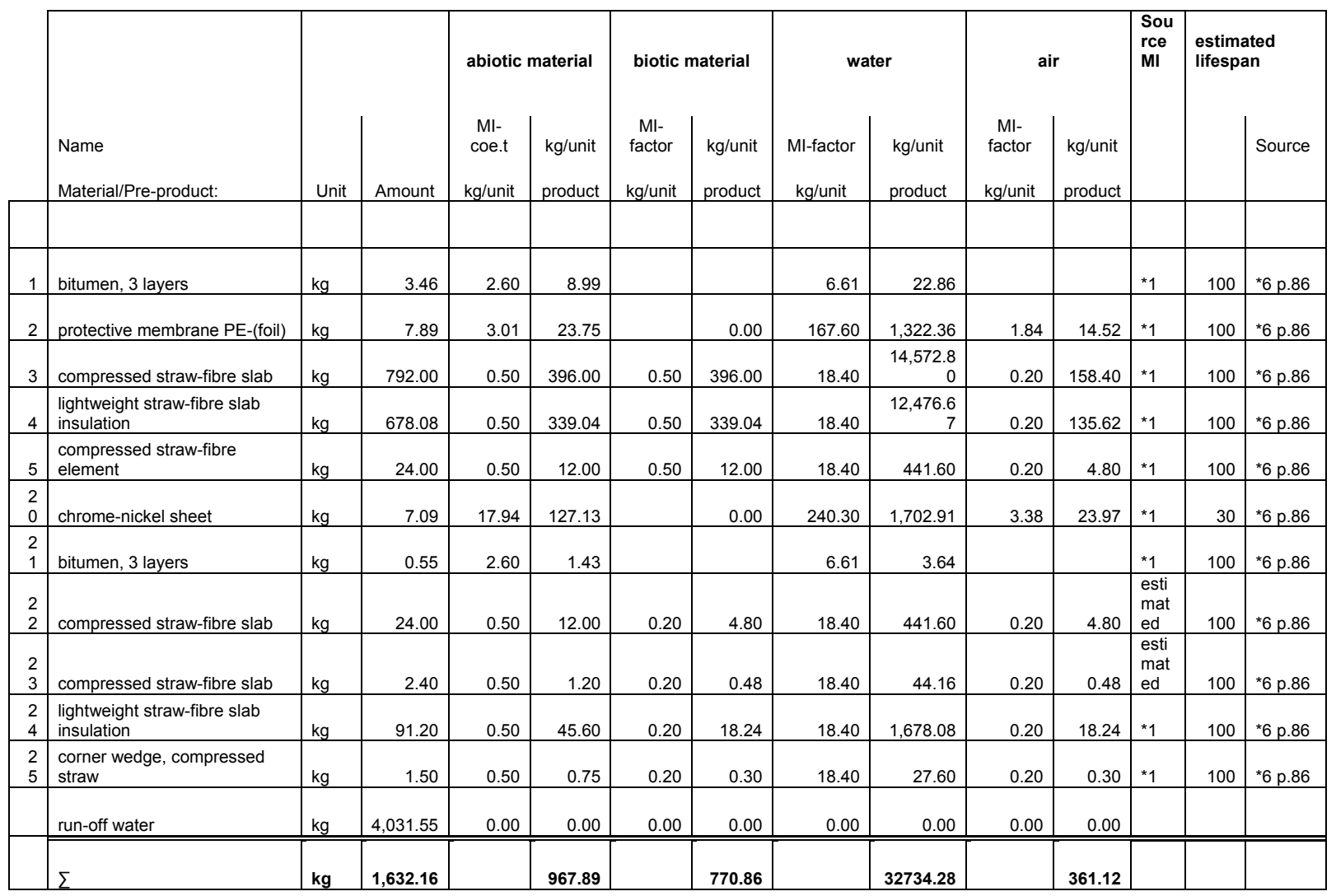

Table 54: Material Intensity Data, multifunctional envelope-GREEN ROOF

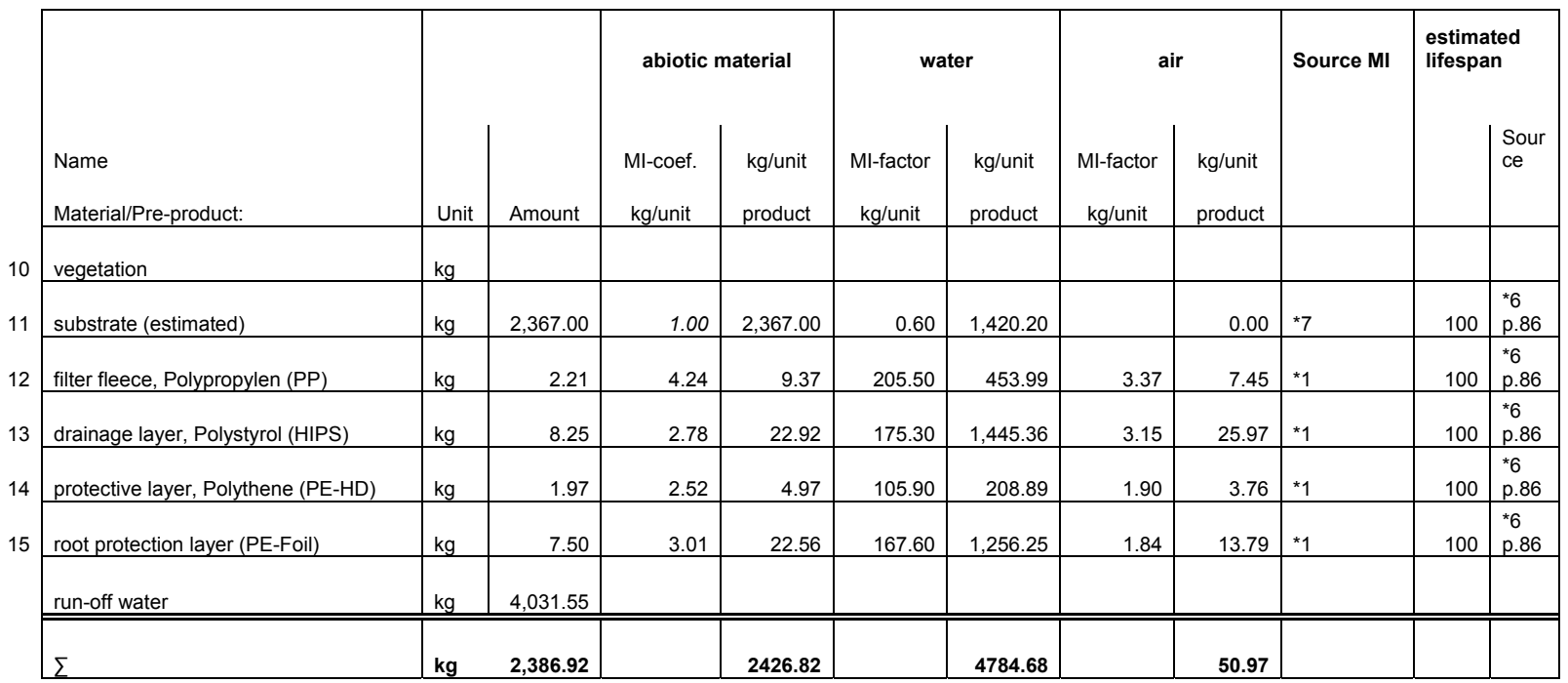




\begin{tabular}{|l|l|}
\hline electricity & $1367 \mathrm{kWh}$ \\
space heating & $122 \mathrm{kWh}$ \\
hot water provision & $254 \mathrm{kWh}$ \\
\hline
\end{tabular}

Table 55: Material Intensity Data, multifunctional envelope-ELECTRICITY

Data for: ELECTRICITY Conventional - annual energy requirements

\begin{tabular}{|c|c|c|c|c|c|c|c|}
\hline \multirow[b]{2}{*}{$\begin{array}{l}\text { Name } \\
\text { Material/Pre-product: }\end{array}$} & \multirow[b]{2}{*}{ Unit } & \multirow[b]{2}{*}{ Amount } & \multirow[b]{2}{*}{$\begin{array}{c}\text { Ml-coefficient } \\
\text { kg/kWh }\end{array}$} & \multirow[b]{2}{*}{$\begin{array}{c}\text { kg/unit } \\
\text { main product }\end{array}$} & \multirow[b]{2}{*}{$\begin{array}{c}\text { Ml-factor } \\
\text { kg/unit } \\
\end{array}$} & \multirow{2}{*}{$\begin{array}{l}\text { air } \\
\text { kg/unit } \\
\text { main product }\end{array}$} & \multirow[t]{2}{*}{ Source MI } \\
\hline & & & & & & & \\
\hline electricity (Austrian grid) & kWh & $1,366.67$ & 0.80 & $1,093.33$ & 0.30 & 410.00 & *4 p. 20 \\
\hline$\Sigma$ & kWh & $1,366.67$ & & 1093.33 & & 410.00 & \\
\hline
\end{tabular}


Table 56: Material Intensity Data, multifunctional envelope-HEATING WITH OIL

Data for:OIL Conventional - annual energy requirements

\begin{tabular}{|c|c|c|c|c|c|c|c|c|c|}
\hline \multirow[b]{2}{*}{$\begin{array}{l}\text { Name } \\
\text { Material/Pre-product: }\end{array}$} & \multirow[b]{2}{*}{ Unit } & \multirow[b]{2}{*}{ Amount } & \multirow[b]{2}{*}{$\begin{array}{c}\text { Ml-coefficient } \\
\mathrm{kg} / \mathrm{kWh} \\
\end{array}$} & \multirow[b]{2}{*}{$\begin{array}{l}\mathrm{kg} / \mathrm{unit} \\
\text { product }\end{array}$} & \multirow[b]{2}{*}{$\begin{array}{c}\text { Ml-factor } \\
\text { kg/unit }\end{array}$} & \multirow[b]{2}{*}{$\begin{array}{l}\mathrm{kg} / \mathrm{unit} \\
\text { product }\end{array}$} & \multirow[b]{2}{*}{$\begin{array}{c}\text { Ml-factor } \\
\text { kg/unit }\end{array}$} & \multirow[b]{2}{*}{$\begin{array}{l}\mathrm{kg} / \mathrm{unit} \\
\text { product }\end{array}$} & \multirow{2}{*}{\begin{tabular}{|l|}
$\begin{array}{l}\text { Source } \\
\text { MI }\end{array}$ \\
\\
\\
\end{tabular}} \\
\hline & & & & & & & & & \\
\hline space heating & kWh & 122.00 & & & & & & & \\
\hline$(42,8 \mathrm{MJ} / \mathrm{kg})(90 \%$ effi. $)$ & $\mathrm{kWh}$ & 134.20 & 0.21 & 28.18 & 0.79 & 106.018 & 3.20 & 429.44 & ${ }^{*} 5$ p. $\mathrm{A} 73$ \\
\hline hot water provision & kWh & 254.00 & & & & & & & *4 p.20 \\
\hline with oil & $\mathrm{kWh}$ & 279.40 & 0.21 & 58.67 & 0.79 & 220.726 & 3.20 & 894.08 & \\
\hline$\Sigma$ & kWh & 376.00 & & 86.86 & & 326.74 & & 1323.52 & \\
\hline
\end{tabular}

\begin{tabular}{|l|l|l|l|l|l|l|l|l|}
\hline in 60 years & 22,560 & $\mathrm{kwh}$ & $\mathbf{5 2 1 1 . 4}$ & $\mathrm{kg}$ & $\mathbf{1 9 6 0 4 . 6}$ & $\mathrm{kg}$ & $\mathbf{7 9 4 1 1 . 2}$ & $\mathrm{kg}$ \\
\hline
\end{tabular}

\begin{tabular}{|l|r|r|r|r|}
\hline \multirow{2}{*}{ OIL +solar } & abiotic material [kg] & biotic material [kg] & water [kg] & air [kg] \\
\hline 60 years & 15449.60 & 265.48 & 128432.51 & 80680.16 \\
\hline $\begin{array}{l}\text { Recycled solar system } \\
60 \text { years }\end{array}$ & & & & \\
\cline { 2 - 5 } & 8466.09 & 265.48 & 84899.13 & 80307.05 \\
\hline
\end{tabular}


Table 57: Material Intensity Data, multifunctional envelope-HEATING WITH GAS

Data for: GAS Conventional - annual energy requirements

\begin{tabular}{|c|c|c|c|c|c|c|c|c|c|}
\hline \multirow[b]{2}{*}{$\begin{array}{l}\text { Name } \\
\text { Material/Pre-product: }\end{array}$} & \multirow[b]{2}{*}{ Unit } & \multirow[b]{2}{*}{ Amount } & \multicolumn{2}{|c|}{ abiotic material } & \multicolumn{2}{|c|}{ water } & \multicolumn{2}{|c|}{ air } & \multirow[t]{2}{*}{$\begin{array}{l}\text { Source } \\
\text { MI }\end{array}$} \\
\hline & & & $\begin{array}{l}\text { Ml-coef. } \\
\text { kg/kWh }\end{array}$ & $\begin{array}{l}\mathrm{kg} / \mathrm{unit} \\
\text { product }\end{array}$ & $\begin{array}{l}\text { Ml-factor } \\
\text { kg/unit }\end{array}$ & $\begin{array}{l}\mathrm{kg} / \mathrm{unit} \\
\text { product }\end{array}$ & $\begin{array}{l}\text { Ml- } \\
\text { factor } \\
\text { kg/unit }\end{array}$ & $\begin{array}{l}\mathrm{kg} / \mathrm{unit} \\
\text { product }\end{array}$ & \\
\hline space heating & $\mathrm{kWh}$ & 122 & & & & & & & \\
\hline with gas ( $98 \%$ efficiency) & $\mathrm{kWh}$ & 124 & 0.10 & 12.44 & 0.04 & 4.9776 & 3.60 & 447.984 & * \\
\hline hot water provision & kWh & 254 & & & & & & & \\
\hline with gas & $\mathrm{kWh}$ & 259 & 0.10 & 25.91 & 0.04 & 10.3632 & 3.60 & 932.688 & * \\
\hline$\Sigma$ & kWh & 376 & & 38.35 & & 15.34 & & 1380.7 & \\
\hline in 60 years & 60.00 & 22,560 & kwh & 2301.12 & $\mathrm{~kg}$ & 920.45 & $\mathrm{~kg}$ & 82840.32 & $\mathrm{~kg}$ \\
\hline
\end{tabular}

\begin{tabular}{|l|r|r|r|r|}
\hline GAS +solar & abiotic material [kg] & biotic material [kg] & water [kg] & air [kg] \\
\hline $\begin{array}{l}60 \text { years } \\
\text { recycled } \\
60 \text { years }\end{array}$ & 12539.36 & 265.48 & 109748.32 & 84109.28 \\
\cline { 2 - 5 } & & & & \\
\hline
\end{tabular}


Table 58: Material Intensity Data, multifunctional envelope-HEATING WITH ELECTRICITY

Data for: Electrical heat

Conventional - annual energy requirements

\begin{tabular}{|c|c|c|c|c|c|c|c|}
\hline \multirow[b]{2}{*}{$\begin{array}{l}\text { Name } \\
\text { Material/Pre-product: }\end{array}$} & \multirow[b]{2}{*}{ Unit } & \multirow[b]{2}{*}{ Amount } & \multirow[b]{2}{*}{$\begin{array}{c}\text { Ml-coefficient } \\
\mathrm{kg} / \mathrm{kWh} \\
\end{array}$} & \multirow[b]{2}{*}{$\begin{array}{l}\mathrm{kg} / \mathrm{unit} \\
\text { product }\end{array}$} & \multirow[b]{2}{*}{$\begin{array}{c}\text { Ml-factor } \\
\text { kg/unit }\end{array}$} & \multirow[b]{2}{*}{$\begin{array}{l}\mathrm{kg} / \mathrm{unit} \\
\text { product }\end{array}$} & \multirow{2}{*}{ Source MI } \\
\hline & & & & & & & \\
\hline \multirow{2}{*}{$\begin{array}{l}\text { space heating } \\
\text { with electricity (Austrian grid) } \\
\text { ( } 100 \% \text { efficiency) }\end{array}$} & kWh & 122.00 & & & & & \\
\hline & $\mathrm{kWh}$ & 122.00 & 0.80 & 97.60 & 0.30 & 36.60 & *4 \\
\hline \multirow{3}{*}{$\begin{array}{l}\text { hot water provision } \\
\text { with electricity (Austrian grid) } \\
\Sigma\end{array}$} & $\mathrm{kWh}$ & 254.00 & & & & & \\
\hline & $\mathrm{kWh}$ & 254.00 & 0.80 & 203.20 & 0.30 & 76.20 & *4 \\
\hline & kWh & 376.00 & & 300.80 & & 112.80 & \\
\hline in 60 years & 60.00 & $22,560.00$ & kwh & 18048.00 & $\mathrm{~kg}$ & 6768.00 & $\mathrm{~kg}$ \\
\hline
\end{tabular}

\begin{tabular}{|l|r|r|r|r|}
\hline \multirow{2}{*}{ ELE + solar } & abiotic material [kg] & biotic material [kg] & water [kg] & air [kg] \\
\hline & & & & \\
\cline { 2 - 5 } & & & & \\
\hline $\begin{array}{l}\text { recycled } \\
60 \text { years }\end{array}$ & 28286.24 & 265.48 & 108827.87 & 8036.96 \\
\cline { 2 - 5 } & 21302.73 & & & 7663.85 \\
\hline
\end{tabular}


Table 59: Material Intensity Data, multifunctional envelope-HEATING WITH WOOD

Data for:FIRE WOOD Conventional - annual energy requirements

\begin{tabular}{|c|c|c|c|c|c|c|c|c|c|c|}
\hline \multirow[b]{2}{*}{$\begin{array}{l}\text { Name } \\
\text { Material/Pre-product: }\end{array}$} & \multirow[b]{2}{*}{ Unit } & \multirow[b]{2}{*}{ Amount } & \multicolumn{2}{|c|}{ abiotic material } & \multicolumn{2}{|c|}{ biotic material } & \multicolumn{2}{|c|}{ water } & \multicolumn{2}{|c|}{ air } \\
\hline & & & $\begin{array}{l}\text { Ml-coef. } \\
\mathrm{kg} / \mathrm{kWh}\end{array}$ & $\begin{array}{l}\mathrm{kg} / \mathrm{unit} \\
\text { product }\end{array}$ & $\begin{array}{l}\text { Ml-coeff. } \\
\mathrm{kg} / \mathrm{kWh}\end{array}$ & $\begin{array}{l}\mathrm{kg} / \mathrm{unit} \\
\text { product }\end{array}$ & $\begin{array}{c}\text { Ml- } \\
\text { factor } \\
\text { kg/unit }\end{array}$ & $\begin{array}{c}\mathrm{kg} / \mathrm{unit} \\
\text { produ } \\
\mathrm{ct}\end{array}$ & $\begin{array}{c}\text { Ml-factor } \\
\text { kg/unit } \\
\end{array}$ & $\begin{array}{l}\mathrm{kg} / \mathrm{unit} \\
\text { product }\end{array}$ \\
\hline space heating & $\mathrm{kWh}$ & 122. & & & & & & & & \\
\hline $\begin{array}{l}\text { oven } 75 \%) \\
\text { pine, fuel value } 4.41 \\
\mathrm{kWh} / \mathrm{kg}\end{array}$ & kWh & 152.5 & 0.17 & 25.93 & 0.36 & 9.33 & 0.04 & 6.1 & 2.55 & 388.88 \\
\hline hot water provision & $\mathrm{kWh}$ & 254 & & & & & & & & \\
\hline with timber scraps & $\mathrm{kWh}$ & 317.5 & 0.17 & 53.98 & 0.36 & 114.30 & 0.04 & 12.7 & 2.55 & 809.63 \\
\hline$\Sigma$ & kWh & 376. & & 79.90 & & 123.63 & & 18.8 & & 1198.5 \\
\hline in 60 years & 60.00 & 22,560 & kwh & 4794 & $\mathrm{~kg}$ & 7417.98 & $\mathrm{~kg}$ & 1128 & $\mathrm{~kg}$ & 71910 \\
\hline
\end{tabular}

\begin{tabular}{|c|c|c|c|c|}
\hline WOOD +solar & abiotic material [kg] & biotic material [kg] & water [kg] & air [kg] \\
\hline 60 years & 15032.24 & 7683.46 & 109955.87 & 73178.96 \\
\hline \multicolumn{5}{|l|}{ recycled } \\
\hline 60 years & 8048.73 & 7683.46 & 66422.49 & 72805.85 \\
\hline
\end{tabular}


Table 60: Material Intensity Data, multifunctional envelope-HEATING WITH TIMBER SCRAPS

\begin{tabular}{|c|c|c|c|c|c|c|c|c|c|c|}
\hline \multicolumn{11}{|c|}{ Conventional - annual energy requirements } \\
\hline $\begin{array}{l}\text { Name } \\
\text { Material/Pre-product: }\end{array}$ & Unit & Amount & $\begin{array}{l}\text { abiotic } \\
\text { Ml-coef. } \\
\text { kg/kWh }\end{array}$ & \begin{tabular}{|c|} 
naterial \\
kg/unit \\
produ \\
ct
\end{tabular} & $\begin{array}{c}\text { biotic } \\
\text { Ml-f. } \\
\mathrm{kg} / \mathrm{kW} \\
\mathrm{h} \\
\end{array}$ & $\begin{array}{l}\text { naterial } \\
\text { kg/unit } \\
\text { product }\end{array}$ & $\begin{array}{l}\text { Ml-factor } \\
\text { kg/unit } \\
\end{array}$ & $\begin{array}{c}\mathrm{kg} / \mathrm{uni} \\
\mathrm{t} \\
\mathrm{produ} \\
\mathrm{ct}\end{array}$ & $\begin{array}{l}\text { Ml- } \\
\text { factor } \\
\text { kg/unit }\end{array}$ & $\begin{array}{l}\mathrm{kg} / \mathrm{unit} \\
\text { product }\end{array}$ \\
\hline \multirow{2}{*}{$\begin{array}{l}\text { space heating } \\
\text { with fire wood (eff.oven } \\
75 \% \text { ), } \\
\text { pine, fuel value } 4.41 \\
\text { kWh/kg }\end{array}$} & kWh & 122 & & & & & & & & \\
\hline & kWh & 152.5 & 0.01 & 1.53 & & & 0.16 & 24.4 & 2.55 & 388.88 \\
\hline \multirow{3}{*}{$\begin{array}{l}\text { hot water provision } \\
\text { with timber scraps } \\
\Sigma\end{array}$} & $\mathrm{kWh}$ & 254 & & & & & & & & \\
\hline & $\mathrm{kWh}$ & 317.5 & 0.01 & 3.18 & & & 0.16 & 50.8 & 2.55 & 809.63 \\
\hline & kWh & 376 & & 4.7 & & 0.00 & & 75.20 & & 1198.5 \\
\hline in 60 years & 60.00 & 22,560 & kwh & 282 & $\mathrm{~kg}$ & 0.00 & $\mathrm{~kg}$ & $\begin{array}{r}4512 . \\
00 \\
\end{array}$ & $\mathrm{~kg}$ & 71910.00 \\
\hline
\end{tabular}

\begin{tabular}{|c|c|c|c|c|}
\hline TIMBER +solar & abiotic material [kg] & biotic material [kg] & water [kg] & air [kg] \\
\hline 60 years & 10520.24 & 265.48 & 113339.87 & 73178.96 \\
\hline \multicolumn{5}{|l|}{ recycled } \\
\hline 60 years & 3536.73 & 265.48 & 69806.49 & 72805.85 \\
\hline
\end{tabular}




\subsubsection{THE CONVENTIONAL ENVELOPE}

Table 61: Material Intensity Data, conventional envelope-FLOOR

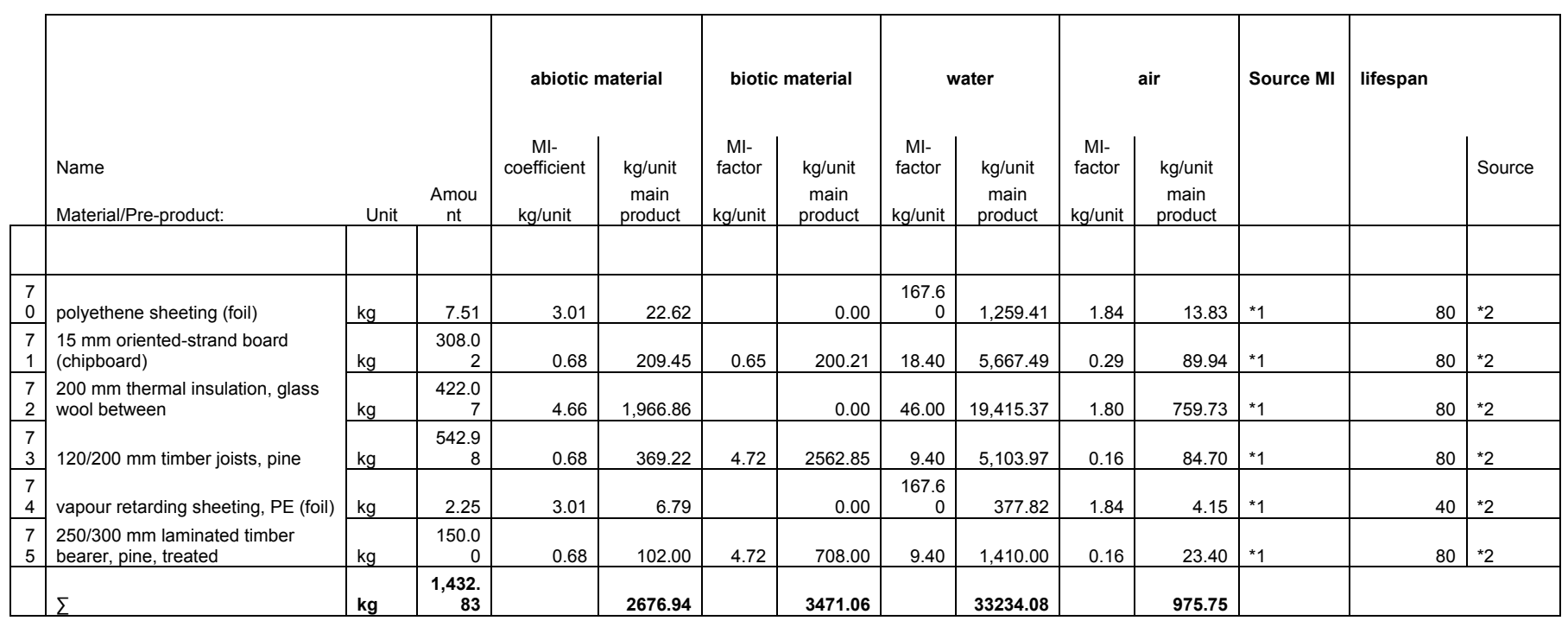

Table 62: Material Intensity Data, conventional envelope-WALL

\begin{tabular}{|c|c|c|c|c|c|c|c|c|c|c|c|c|c|c|}
\hline & \multirow{3}{*}{$\begin{array}{l}\text { Data for: } \\
\text { Name } \\
\text { Material/Pre-product: }\end{array}$} & \multicolumn{13}{|c|}{ Conventional - wall structure } \\
\hline & & \multirow[b]{2}{*}{ Unit } & \multirow[b]{2}{*}{ Amount } & \multirow[b]{2}{*}{$\begin{array}{c}\text { Ml-coef.t } \\
\text { kg/unit }\end{array}$} & \multirow[b]{2}{*}{$\begin{array}{l}\mathrm{kg} / \mathrm{unit} \\
\text { product }\end{array}$} & \multirow{2}{*}{$\begin{array}{r}\text { Bic } \\
\text { mat } \\
\text { Ml-factor } \\
\text { kg/unit } \\
\end{array}$} & \multirow{2}{*}{$\begin{array}{l}\text { teric } \\
\text { terial } \\
\mathrm{kg} / \mathrm{unit} \\
\text { product }\end{array}$} & \multirow[b]{2}{*}{$\begin{array}{c}\text { Ml-factor } \\
\text { kg/unit }\end{array}$} & ter & \multicolumn{2}{|c|}{ air } & \multirow[t]{2}{*}{$\begin{array}{l}\text { Source } \\
\text { MI }\end{array}$} & \multirow[t]{2}{*}{ lifespan } & \multirow[b]{2}{*}{ Source } \\
\hline & & & & & & & & & $\begin{array}{l}\mathrm{kg} / \mathrm{unit} \\
\text { product }\end{array}$ & $\begin{array}{l}\text { Ml-factor } \\
\text { kg/unit }\end{array}$ & $\begin{array}{l}\text { kg/unit } \\
\text { product }\end{array}$ & & & \\
\hline $40 \mathrm{a}$ & $\begin{array}{l}\text { 18/180 mm rusticated } \\
\text { weatherboard, pine on }\end{array}$ & $\mathrm{kg}$ & 89.10 & 0.68 & 60.59 & 4.72 & 420.55 & 9.40 & 837.54 & 0.16 & 13.90 & *1 & 60 & estimated \\
\hline $40 \mathrm{~b}$ & acrylic paint & $\mathrm{m}^{2}$ & 11.18 & 3.74 & 41.81 & 0.50 & 5.59 & & & & & *4 & 5 & estimated \\
\hline 41 & $\begin{array}{l}40 / 60 \mathrm{~mm} \text { cavity battens/ } \\
\text { counterbattens, pine }\end{array}$ & $\mathrm{kg}$ & 23.70 & 0.68 & 16.11 & 4.72 & 111.85 & 9.40 & 222.75 & 0.16 & 3.70 & *1 & 60 & estimated \\
\hline 42 & $\begin{array}{l}\text { vapour-diffusing win } \\
\text { dproof layer, PE (foil) }\end{array}$ & $\mathrm{kg}$ & 1.65 & 3.01 & 4.98 & & 0.00 & 167.60 & 277.29 & 1.84 & 3.04 & *1 & 60 & estimated \\
\hline 43 & $\begin{array}{l}15 \mathrm{~mm} \text { orientated-strand } \\
\text { board (chipboard) }\end{array}$ & $\mathrm{kg}$ & 110.30 & 0.68 & 75.00 & 0.65 & 71.69 & 18.40 & $2,029.48$ & 0.29 & 32.21 & *1 & 60 & estimated \\
\hline 44 & $\begin{array}{l}240 \mathrm{~mm} \text { thermal ins } \\
\text { ulation, glass wool }\end{array}$ & $\mathrm{kg}$ & 143.52 & 4.66 & 668.80 & & 0.00 & 46.00 & $6,601.92$ & 1.80 & 258.34 & *1 & 60 & estimated \\
\hline 45 & $\begin{array}{l}\text { moisture diffusing } \\
\text { layer, PE (foil) }\end{array}$ & $\mathrm{kg}$ & 5.51 & 3.01 & 16.60 & & 0.00 & 167.60 & 924.30 & 1.84 & 10.15 & *1 & 60 & estimated \\
\hline 46 & $\begin{array}{l}15 \mathrm{~mm} \text { wood-fibre } \\
\text { board (MDF) }\end{array}$ & $\mathrm{kg}$ & 68.94 & 1.96 & 135.12 & & 0.00 & 32.90 & $2,268.13$ & 0.48 & 33.16 & *1 & 60 & estimated \\
\hline 47 & $\begin{array}{l}80 / 240 \mathrm{~mm} \text { timber } \\
\text { framing, pine }\end{array}$ & $\mathrm{kg}$ & 201.60 & 0.68 & 137.09 & 4.72 & 951.55 & 9.40 & $1,895.04$ & 0.16 & 31.45 & & 60 & estimated \\
\hline & $\Sigma$ & $\mathbf{k g}$ & 644.32 & & 1156.11 & & 1561.23 & & 15056.44 & & 385.94 & & & \\
\hline
\end{tabular}


Table 63: Material Intensity Data, conventional envelope-WINDOW

\begin{tabular}{|c|c|c|c|c|c|c|c|c|c|c|c|c|c|c|}
\hline & Data for: & \multicolumn{13}{|c|}{ Conventional - window } \\
\hline & \multirow[b]{2}{*}{\begin{tabular}{|l} 
Name \\
Material/Pre-product:
\end{tabular}} & \multirow[b]{2}{*}{ Unit } & \multirow[b]{2}{*}{ Amount } & \multicolumn{2}{|c|}{ abiotic material } & \multicolumn{2}{|c|}{ biotic material } & \multicolumn{2}{|c|}{ water } & \multicolumn{2}{|c|}{ air } & \multirow[t]{2}{*}{ Source MI } & \multicolumn{2}{|c|}{ estimated lifespan } \\
\hline & & & & $\begin{array}{c}\text { MI-coef. } \\
\text { kg/unit }\end{array}$ & $\begin{array}{l}\mathrm{kg} / \mathrm{unit} \\
\text { product }\end{array}$ & $\begin{array}{l}\text { Ml-factor } \\
\text { kg/unit }\end{array}$ & $\begin{array}{l}\mathrm{kg} / \mathrm{unit} \\
\text { product }\end{array}$ & $\begin{array}{c}\text { Ml-factor } \\
\mathrm{kg} / \mathrm{unit}\end{array}$ & $\begin{array}{l}\mathrm{kg} / \mathrm{unit} \\
\text { product }\end{array}$ & $\begin{array}{c}\text { Ml-factor } \\
\text { kg/unit }\end{array}$ & $\begin{array}{l}\mathrm{kg} / \mathrm{unit} \\
\text { product }\end{array}$ & & & Source \\
\hline 30 & $\begin{array}{l}\text { timber joinery, larch (pine } \\
\text { used) }\end{array}$ & $\mathrm{kg}$ & 20.18 & 0.68 & 13.72 & 4.72 & 95.25 & 9.40 & 189.70 & 0.16 & 3.15 & *1 & 25 & ${ }^{*} 3, \mathrm{p} .8$ \\
\hline 31 & glazing & $\mathrm{kg}$ & 78.00 & 2.95 & 230.10 & & 0.00 & 11.60 & 904.80 & 0.74 & 57.95 & *1 & 25 & ${ }^{*} 3, \mathrm{p} .8$ \\
\hline 32 & window frame, larch & $\mathrm{kg}$ & 30.09 & 0.68 & 20.46 & 4.72 & 142.01 & 9.40 & 282.82 & 0.16 & 4.69 & $*_{1}$ & 25 & ${ }^{\star} 3, \mathrm{p} .8$ \\
\hline 33 & \begin{tabular}{|l|} 
chrome-nickel sheet $(17 \%$ \\
$\mathrm{Cr}, 12 \% \mathrm{Ni})$
\end{tabular} & $\mathrm{kg}$ & 3.15 & 17.94 & 56.50 & & 0.00 & 240.30 & 756.85 & 3.38 & 10.65 & *1 & 50 & \\
\hline 34 & $\begin{array}{l}\text { timber joinery, window sill, } \\
\text { larch }\end{array}$ & $\mathrm{kg}$ & 13.42 & 0.68 & 9.13 & 4.72 & 63.36 & 9.40 & 126.19 & 0.16 & 2.09 & $*_{1}$ & 25 & ${ }^{*} 3, \mathrm{p} .8$ \\
\hline & $\Sigma$ & $\mathbf{k g}$ & 144.84 & & 329.91 & & 300.63 & & 2260.36 & & 78.54 & & & \\
\hline
\end{tabular}

Table 64: Material Intensity Data, conventional envelope- ZINC ROOF

\begin{tabular}{|c|c|c|c|c|c|c|c|c|c|c|c|c|c|c|}
\hline & \multicolumn{14}{|c|}{ Conventional - roof structure } \\
\hline & \multirow{3}{*}{$\begin{array}{l}\text { Name } \\
\text { Material/Pre-product: }\end{array}$} & \multirow[b]{3}{*}{ Unit } & \multirow[b]{3}{*}{ Amount } & \multicolumn{2}{|c|}{ abiotic material } & \multicolumn{2}{|c|}{ biotic material } & \multicolumn{2}{|c|}{ water } & \multicolumn{2}{|c|}{ air } & \multirow[t]{3}{*}{$\begin{array}{l}\text { Source } \\
\text { MI }\end{array}$} & \multicolumn{2}{|c|}{$\begin{array}{l}\text { estimated } \\
\text { lifespan }\end{array}$} \\
\hline & & & & $\begin{array}{c}\text { Ml- } \\
\text { coeff. }\end{array}$ & $\mathrm{kg} / \mathrm{unit}$ & Ml-factor & $\mathrm{kg} / \mathrm{unit}$ & Ml-factor & kg/unit & MI-factor & kg/unit & & & Source \\
\hline & & & & $\mathrm{kg} / \mathrm{unit}$ & product & $\mathrm{kg} / \mathrm{unit}$ & product & kg/unit & product & $\mathrm{kg} / \mathrm{unit}$ & product & & & \\
\hline \multirow[b]{2}{*}{2} & \multirow{3}{*}{$\begin{array}{l}50 / 80 \mathrm{~mm} \text { battans, pine } \\
\text { protective layer, Polythene (foil) } \\
\text { oriented-strand board } \\
\text { (chipboard) }\end{array}$} & $\mathrm{kg}$ & 64.00 & 0.68 & 43.52 & 4.72 & 302.08 & 9.40 & 601.60 & 0.16 & 9.98 & *1 & 80 & *2, p.131 \\
\hline & & $\mathrm{kg}$ & 15.40 & 3.01 & 46.36 & & 0.00 & 167.60 & $2,581.17$ & 1.84 & 28.34 & *1 & 80 & *2, p.131 \\
\hline 3 & & $\mathrm{~kg}$ & 154.01 & 0.68 & 104.73 & 0.65 & 100.11 & 18.40 & $2,833.75$ & 0.29 & 44.97 & *1 & 80 & *2, p.131 \\
\hline 4 & \multirow{4}{*}{$\begin{array}{l}300 \mathrm{~mm} \text { thermal insulation, } \\
\text { glass wool, between } \\
100 / 300 \mathrm{~mm} \text { timber rafters } \\
15 \mathrm{~mm} \text { oriented-strand board, } \\
\text { vapour barrier, PE }\end{array}$} & $\mathrm{kg}$ & 454.99 & 4.66 & $2,120.26$ & & 0.00 & 46.00 & $20,929.63$ & 1.80 & 818.99 & *1 & 80 & *2, p.131 \\
\hline 5 & & $\mathrm{~kg}$ & 496.80 & 0.68 & 337.82 & 4.72 & 2344.90 & 9.40 & $4,669.92$ & 0.16 & 77.50 & *1 & 80 & *2, p. 131 \\
\hline 6 & & $\mathrm{~kg}$ & 150.29 & 0.68 & 102.20 & 0.65 & 97.69 & 18.40 & $2,765.30$ & 0.29 & 43.88 & *1 & 80 & ${ }^{*} 2$, p. 131 \\
\hline 7 & & $\mathrm{~kg}$ & 7.70 & 3.01 & 23.18 & & 0.00 & 167.60 & $1,290.59$ & 1.84 & 14.17 & *1 & 80 & *2, p. 131 \\
\hline \multirow[t]{2}{*}{8} & \multirow{2}{*}{$\begin{array}{l}\text { zinc sheeting (secondary) } \\
\text { three-ply sheet (plywood) }\end{array}$} & $\mathrm{kg}$ & 442.68 & 19.36 & $8,570.28$ & & 0.00 & 86.50 & $38,291.82$ & 42.29 & $\begin{array}{r}18,720.9 \\
4 \\
\end{array}$ & *1 & 80 & *2, p.131 \\
\hline & & $\mathrm{kg}$ & 315.27 & 2.00 & 630.54 & 9.13 & 2878.42 & 23.60 & $7,440.37$ & 0.54 & 170.56 & *1 & 80 & *2, p. 131 \\
\hline & run-off water & $\mathrm{kg}$ & $15,476.00$ & & & & & 1.00 & 16,184 & & & & & \\
\hline & $\Sigma$ & $\mathbf{k g}$ & $2,101.14$ & & 11978.89 & & 5723.18 & & 97588.15 & & 19929.33 & & & \\
\hline
\end{tabular}


Table 65: Material Intensity Data, conventional envelope- BITUMEN ROOF

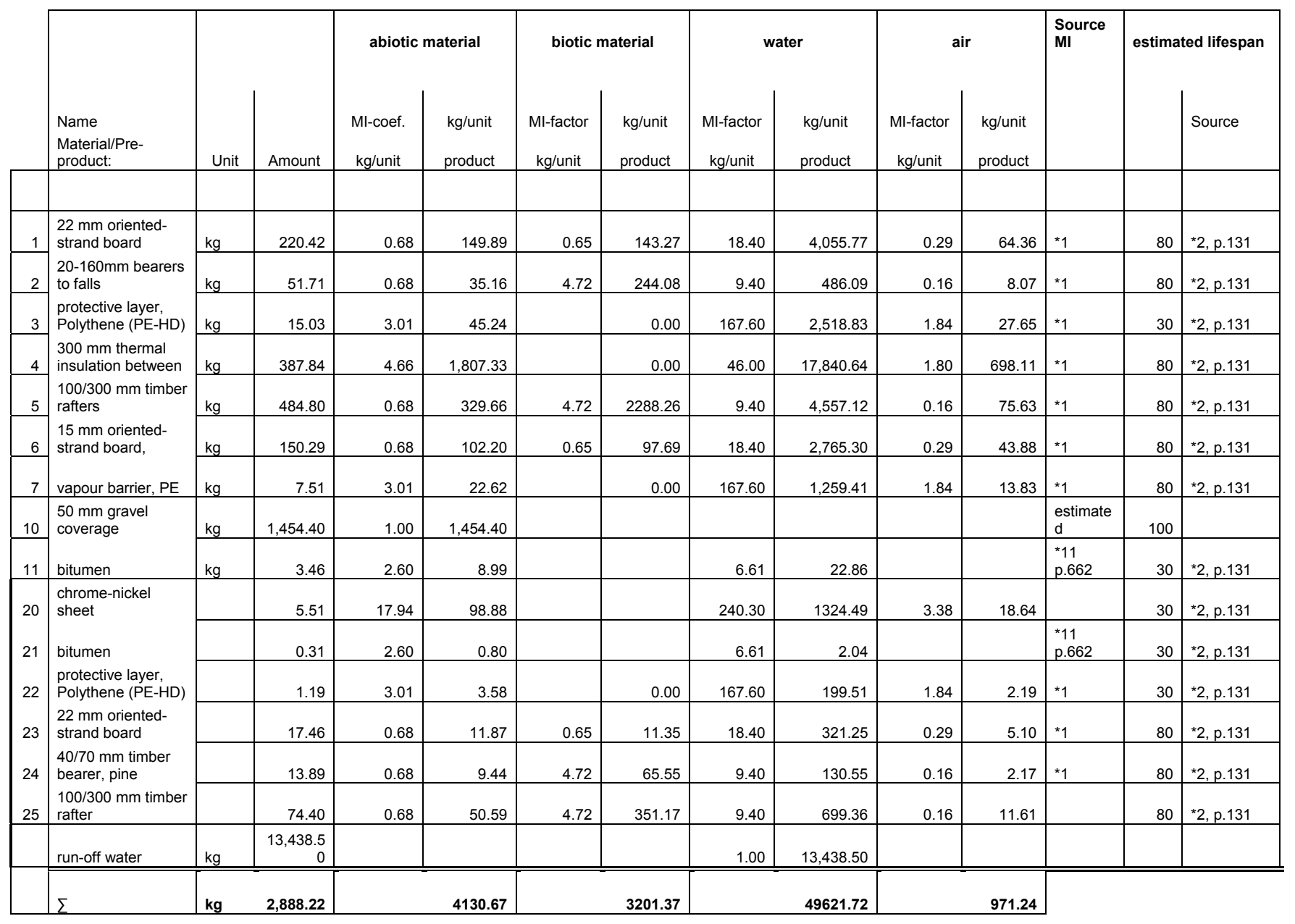


Table 66: Material Intensity Data, conventional envelope-ENERGY REQUIREMENTS

\begin{tabular}{|lr|}
\hline Annual requirement: & divided by 6 \\
\hline electricity & 1366.7 kWh \\
space heating & 878 kWh \\
hot water provision & $488.33 \quad \mathrm{kWh}$ \\
\hline
\end{tabular}

Table 67: Material Intensity Data, conventional envelope-ELECTRICITY

\begin{tabular}{|c|c|c|c|c|c|c|c|}
\hline \multirow[b]{3}{*}{$\begin{array}{l}\text { Name } \\
\text { Material/Pre-product: }\end{array}$} & \multicolumn{7}{|c|}{ Conventional - annual energy requirements } \\
\hline & & & abiotic & naterial & & air & Source M \\
\hline & Unit & Amount & $\begin{array}{c}\text { Ml-coefficient } \\
\text { kg/kWh }\end{array}$ & $\begin{array}{c}\mathrm{kg} / \mathrm{unit} \\
\text { main product }\end{array}$ & $\begin{array}{c}\text { Ml-factor } \\
\text { kg/unit }\end{array}$ & $\begin{array}{c}\mathrm{kg} / \mathrm{unit} \\
\text { main product }\end{array}$ & \\
\hline electricity (Austrian grid) & $\mathrm{kWh}$ & $1,366.67$ & 0.80 & $1,093.33$ & 0.30 & 410.00 & *4 p. 20 \\
\hline$\Sigma$ & kWh & $1,366.67$ & & 1093.33 & & 410.00 & \\
\hline
\end{tabular}

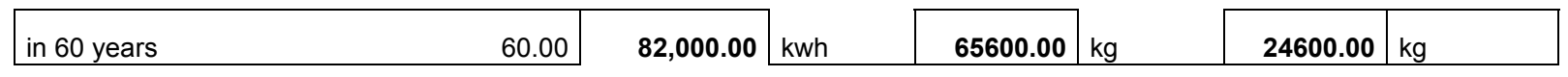

Table 68: Material Intensity Data, conventional envelope-HEATING WITH OIL

\begin{tabular}{|c|c|c|c|c|c|c|c|c|c|}
\hline \multirow[b]{3}{*}{$\begin{array}{l}\text { Name } \\
\text { Material/Pre-product: }\end{array}$} & \multicolumn{9}{|c|}{ Conventional - annual energy requirements } \\
\hline & \multirow[b]{2}{*}{ Unit } & \multirow[b]{2}{*}{ Amount } & \multicolumn{2}{|c|}{ abiotic material } & \multicolumn{2}{|c|}{ water } & \multicolumn{2}{|c|}{ air } & \multirow[t]{2}{*}{$\begin{array}{l}\text { Source } \\
\text { MI }\end{array}$} \\
\hline & & & $\begin{array}{c}\text { Ml-factor } \\
\mathrm{kg} / \mathrm{kWh}\end{array}$ & $\begin{array}{l}\mathrm{kg} / \mathrm{unit} \\
\text { product }\end{array}$ & $\begin{array}{c}\text { MI-factor } \\
\text { kg/unit }\end{array}$ & $\begin{array}{l}\mathrm{kg} / \mathrm{unit} \\
\text { product }\end{array}$ & $\begin{array}{c}\text { Ml-factor } \\
\text { kg/unit }\end{array}$ & $\begin{array}{l}\mathrm{kg} / \mathrm{unit} \\
\text { product }\end{array}$ & \\
\hline \multirow{4}{*}{$\begin{array}{l}\text { space heating } \\
\text { with oil } \mathrm{H}_{\mathrm{u}} \text { el } \\
(42,8 \mathrm{MJ} / \mathrm{kg})(90 \% \text { effi. }) \\
\text { hot water provision } \\
\text { with oil }\end{array}$} & $\mathrm{kWh}$ & 878.00 & & & & & & & \\
\hline & $\mathrm{kWh}$ & 965.80 & 0.21 & 202.82 & 0.79 & 762.982 & 3.20 & 3090.56 & ${ }^{*} 5$ p.A73 \\
\hline & $\mathrm{kWh}$ & 488.33 & & & & & & & *4 p. 20 \\
\hline & $\mathrm{kWh}$ & 537.17 & 0.21 & 112.81 & 0.79 & 424.3617 & 3.20 & $\begin{array}{r}1718.9333 \\
33 \\
\end{array}$ & \\
\hline$\Sigma$ & kWh & $1,366.33$ & & 315.62 & & 1187.34 & & 4809.49 & \\
\hline
\end{tabular}

\begin{tabular}{|c|c|c|c|c|c|c|c|}
\hline in 60 years & 60.00 & $81,980.00$ & kwh & 18937.38 & $\mathrm{~kg}$ & $71240.62 \mathrm{~kg}$ & 288569.60 \\
\hline
\end{tabular}




\begin{tabular}{|c|c|c|c|c|c|c|c|c|c|}
\hline Data for: GAS & Conve & onal - annue & energy require & ents & & & & & \\
\hline \multirow[b]{2}{*}{$\begin{array}{l}\text { Name } \\
\text { Material/Pre-product: }\end{array}$} & \multirow[b]{2}{*}{ Unit } & \multirow[b]{2}{*}{ Amount } & \multicolumn{2}{|c|}{ abiotic material } & \multicolumn{2}{|c|}{ water } & \multicolumn{2}{|c|}{ air } & \multirow[t]{2}{*}{ Source MI } \\
\hline & & & $\begin{array}{c}\text { Ml-coefficient } \\
\mathrm{kg} / \mathrm{kWh}\end{array}$ & $\begin{array}{l}\mathrm{kg} / \mathrm{unit} \\
\text { product }\end{array}$ & $\begin{array}{c}\text { Ml-factor } \\
\text { kg/unit }\end{array}$ & $\begin{array}{l}\mathrm{kg} / \mathrm{unit} \\
\text { product }\end{array}$ & $\begin{array}{c}\text { Ml-factor } \\
\text { kg/unit }\end{array}$ & $\begin{array}{l}\mathrm{kg} / \mathrm{unit} \\
\text { product }\end{array}$ & \\
\hline \multirow{4}{*}{$\begin{array}{l}\text { space heating } \\
\text { with gas } \\
\text { ( } 98 \% \text { efficiency) } \\
\text { hot water provision } \\
\text { with gas }\end{array}$} & $\mathrm{kWh}$ & 878.00 & & & & & & & \\
\hline & kWh & 895.56 & 0.10 & 89.56 & 0.04 & 35.8224 & 3.60 & 3224.02 & *5 p.A73 \\
\hline & kWh & 488.33 & & & & & & & *4 p. 20 \\
\hline & $\mathrm{kWh}$ & 498.10 & 0.10 & 49.81 & 0.04 & 19.924 & 3.60 & 1793.2 & * \\
\hline$\Sigma$ & kWh & $1,366.33$ & & 139.37 & & 55.75 & & 5017.2 & \\
\hline
\end{tabular}

\begin{tabular}{|l|l|l|l|l|l|l|l|}
\hline in 60 years & & & & 301030. & & & \\
\hline
\end{tabular}

Table 70: Material Intensity Data, conventional envelope-HEATING WITH ELECTRICITY

Data for: Electricity

Conventional - annual energy requirements

\begin{tabular}{|c|c|c|c|c|c|c|c|}
\hline \multirow[b]{2}{*}{$\begin{array}{l}\text { Name } \\
\text { Material/Pre-product: }\end{array}$} & \multicolumn{7}{|c|}{ Conventional - annual energy requirements } \\
\hline & Unit & Amount & $\begin{array}{r}\text { abiotic } n \\
\text { Ml-coefficient } \\
\mathrm{kg} / \mathrm{kWh} \\
\end{array}$ & $\begin{array}{l}\text { naterial } \\
\text { kg/unit } \\
\text { main product }\end{array}$ & $\begin{array}{c}\text { Ml-factor } \\
\text { kg/unit }\end{array}$ & $\begin{array}{l}\text { air } \\
\mathrm{kg} / \mathrm{unit} \\
\text { main product }\end{array}$ & Source MI \\
\hline \multirow{4}{*}{$\begin{array}{l}\text { space heating } \\
\text { with electricity (Austrian grid) } \\
\text { (100\% efficiency) } \\
\text { hot water provision } \\
\text { with electricity (Austrian grid) }\end{array}$} & $\mathrm{kWh}$ & 878.00 & & & & & \\
\hline & $\mathrm{kWh}$ & 878.00 & 0.80 & 702.40 & 0.30 & 263.40 & *4 \\
\hline & $\mathrm{kWh}$ & 488.33 & & & & & \\
\hline & $\mathrm{kWh}$ & 488.33 & 0.80 & 390.67 & 0.30 & 146.50 & *4 \\
\hline$\Sigma$ & kWh & $1,366.33$ & & $1,093.07$ & & 409.90 & \\
\hline
\end{tabular}

\begin{tabular}{|ll|l|l|l|l|l|l|}
\hline in 60 years & 60.00 & $\mathbf{8 1 , 9 8 0 . 0 0}$ & $\mathrm{kwh}$ & $\mathbf{6 5 5 8 4 . 0 0}$ & $\mathrm{kg}$ & $\mathbf{2 4 5 9 4 . 0 0}$ & $\mathrm{kg}$ \\
\hline
\end{tabular}


Table 71: Material Intensity Data, conventional envelope-HEATING WITH WOOD

Data for:FIRE WOOD Conventional - annual energy requirements

\begin{tabular}{|c|c|c|c|c|c|c|c|c|c|c|}
\hline \multirow[b]{2}{*}{$\begin{array}{l}\text { Name } \\
\text { Material/Pre-product: }\end{array}$} & \multirow[b]{2}{*}{ Unit } & \multirow[b]{2}{*}{ Amount } & \multicolumn{2}{|c|}{ abiotic material } & \multicolumn{2}{|c|}{ biotic material } & \multicolumn{2}{|c|}{ water } & \multicolumn{2}{|c|}{ air } \\
\hline & & & $\begin{array}{l}\text { Ml-coeff. } \\
\text { kg/kWh }\end{array}$ & $\begin{array}{l}\text { kg/unit } \\
\text { product }\end{array}$ & $\begin{array}{l}\text { Ml-coef. } \\
\text { kg/kWh }\end{array}$ & $\begin{array}{l}\mathrm{kg} / \mathrm{unit} \\
\text { product }\end{array}$ & $\begin{array}{c}\text { Ml-factor } \\
\text { kg/unit }\end{array}$ & $\begin{array}{l}\mathrm{kg} / \mathrm{unit} \\
\text { product }\end{array}$ & $\begin{array}{c}\text { Ml-factor } \\
\text { kg/unit }\end{array}$ & $\begin{array}{l}\mathrm{kg} / \mathrm{unit} \\
\text { product }\end{array}$ \\
\hline space heating & $\mathrm{kWh}$ & 878 & & & & & & & & \\
\hline $\begin{array}{l}\text { (efficiency oven } 75 \%) \text {, } \\
\text { pine }^{*},\end{array}$ & kWh & $1,097.5$ & 0.17 & 186.58 & 0.36 & 67.17 & 0.04 & 43.9 & 2.55 & 2798.6 \\
\hline hot water provision & $\mathrm{kWh}$ & 488.3 & & & & & & & & \\
\hline with timber scraps & kWh & 610.4 & 0.17 & 103.77 & 0.36 & 219.75 & 0.04 & 24.417 & 2.55 & 1556.56 \\
\hline$\Sigma$ & kWh & \begin{tabular}{r|}
$1,366.3$ \\
3 \\
\end{tabular} & & 290.35 & & 286.92 & & 68.32 & & 4355.19 \\
\hline
\end{tabular}

* fuel $4.41 \mathrm{kWh} / \mathrm{kg}$,

efficiency oven $75 \%$

pine

\begin{tabular}{|c|c|c|c|c|c|c|c|c|c|c|}
\hline in 60 years & 60.00 & 81,980 & kwh & 17420.75 & $\mathrm{~kg}$ & 17215.02 & $\mathrm{~kg}$ & 4099 & $\mathrm{~kg}$ & 261311.2 \\
\hline
\end{tabular}




\section{REFERENCES}

Alcorn, A., Embodied Energy Coefficients of Building Materials. 1998, Centre for Building Performance Research, School of Architecture, Victoria University of Wellington, Wellington.

Allix, G., Patrick Blanc, quand la nature fait le mur. Le Monde, 2005. 28(15.01.).

Alsema, E., Energy Pay-back Time and CO2 Emissions of PV Systems. Progress in Photovoltaics: Research and Application, 2000. 8.

Alsema, E. et al., Energy pay-back, Time of Photovoltaic Energy Systems: Present Status and Prospects, in 2nd Word Conference and Exhibition on Photovoltaic Solar Energy Conversion. 1998, p. 2125-2130: Vienna.

Arnold Glaswerke, manufacturer, online resources, accessed 05/2009:

http://www.glaswerke-arnold.de/cms.asp?AE=1\&IDN=95\&Plugin=\&H=\%27175\%27\&T=0\&Sprache=en

Ashby, M., Materials selection in mechanical design. 1992, Pergamon Press, Oxford.

Australian Bureau of Statistics, Household and Family Projections, 2004 (3236.0), online database, accessed May 2009:http://www.abs.gov.au/ausstats/abs@.nsf/mf/3236.0

Bargigli, S. et al., Mass Accounting and Mass-based Indicators, in Handbook of ecological indicators for assessment of ecosystem health, Jørgensen, S., Costanza, R, Xu, F., Editor. 2005, CRC Press: Boca Raton, Florida.

Bartlett, R., Our dependency on foreign oil, House of Representatives, 20.04.2005, Washington, online:http://www.energybulletin.net/node/5519

Bass, B., Baskaran, B., Evaluating Rooftop and Vertical Gardens as an Adaptation Strategy for Urban Areas, NRCC-46737, 2001, National Research Council Canada, Institute for Research in Construction, Toronto.

Bastian, M., Dengel, U., Abschätzung der Gebrauchsdauer von EPDM-Bahnen. 2004, SKZ, Süddeutsches Kunstoffzentrum: Würzburg. Available at: http://www.skz.de/

Bendiksen, J., The Places We live. 2008, New York: Aperture Foundation, Inc.

Berghahn, V., Globalization, Americanization and Europeanization, the Globalist, daily online magazine, 2007(13.-15. 11.)

http://www.theglobalist.com/Storyld.aspx?Storyld=6558

Bergmann, I., Weiss, W., Fassadenintegration von thermischen Sonnenkollektoren ohne Hinterlüftung, in Berichte aus der Energie- und Umweltforschung. 2002, Bundesministerium für Verkehr, Innovation und Technologie, Wien.

Baird, G., et al., The energy embodied in building materials - updated New Zealand coefficients and their significance. IPENZ Transactions, 1997. 24(1/CE, 1997): p. 46-54.

Brandwein, T., Hedera helix und Hedera colchica,Efeu - Arten und Sorten des Efeus. 2009. Online database: http://www.biotekt.de/kletterpflanzen/hedera.htm

Braungart, M., Eco-Effectiveness, Environmental Protection and Encouragement Agency (EPEA), online database: http://www.epea.com/english/cradle_methodology/ecoeffectiveness.htm

Brock, L., Designing the exterior wall. 2005, Wiley\&Sons Inc., Hoboken 
Brunskill, R., Illustrated handbook of vernacular architecture. 1978,

Faber and Faber, London.

Buchan, D., manufacturer, Agriboard, personal communication, 2009 and website: http://www.agriboard.com/

Buckminster-Fuller, R., Operating Manual for Spaceship Earth. 1969, Aeonian Press, Mattituck.

Callenbach, E., Living poor with style. 1973, Pantam, New York.

Cantor, S., Green Roofs in Sustainable Landscape Design. 2008, W. W. Norton \& Company, New York, London.

Catton, W. Jr., Overshoot, the ecological basis of revolutionary change. 1982: University of Illinois Press.

CEN, Thermal performance of buildings - Calculation of energy use for heating - Residential buildings. 1999, European Committee for Standardization.

Chu, S., speech at the St. James Nobel Laureate Symposium, Media release, 26.-28-05.2009, Cambridge: http://www.nobelcause.org/press/Pages/default.aspx

CIA, The World Fact Book, online database: https://www.cia.gov/library/publications/the-world-factbook/

Clifton-Taylor, A., The Pattern of English Building. 4th ed. 1987, Faber and Faber, London, Boston.

Crapper, D. et al., Aluminium, neurofibrillary degeneration and Alzheimer's disease. Brain, 1976. 99: p. $67-80$.

Daly, H., Special report: Economics blind spot is a disaster for the planet. New Scientist, 2008(2678): p. 46-47.

Daly, H., Steady-state economics, 2nd ed. With new essays, Island Press, 1991, Washington, D.C.

Daly, H., Toward some operational principles of sustainable development. Ecological Economics 1990. 2(1): p. 1-6

DANIDA Workshop papers: Improving the Urban Environment and Reducing Poverty, ed. Danish International Development Assistance. 2000, Copenhagen, Denmark.

Davies, M., A wall for all seasons. RIBA Journal, 1981. 88(02).

Detail, Straw House in Eschenz. Detail, 2006(6): p. 642-646.

Deutscher Bundestag, Energieeinsparverordnung-EnEV 2007-Verordnung über energiesparenden Wärmeschutz und energiesparende Anlagetechnik bei Gebäuden. 2007, Bundesjustizministerium.

Diamond, J., Collapse: How Societies Choose to Fail or Succeed. 2005, Viking, New York.

Diehl, M., Ternus, T., Dünnschicht oder kristalline Module ?,(06)2009. Online database accessed July 2009:http://www.photovoltaikbuero.de/PVBueroBlog/tabid/128/Entryld/31/D-uuml-nnschicht-oder-kristalline-Module.aspx

DIN 1946-6. Raumlufttechnik - Teil 6: Lüftung von Wohnungen; Anforderungen, Ausführung, Abnahme (VDI-Lüftungsregeln) Norm. 2006, Deutsche Institut fuer Normierung e. V.

Dunnett, N., Kingsbury, N., Planting green roofs and living walls. 2004, Timber Press, Portland.

Dürr, A., Dachbegrünung. 2005, Wiesbaden: Bauverlag.

Eichmeyer, H., ed. Neuwertwirtschaft: Eine Perspektive für Wirtschaft und Ökologie. 1996, Blottner 
Verlag.

Energiesparhaus, Klimadaten für Orte in Österreich. 2009:

http://www.energiesparhaus.at/denkwerkstatt/klimadatensuche.asp

EnEV 2009, will be published in November 2009-05-27, online database:

http://www.enev-online.org/index.htm

Fay, R., et al. Assessing the Importance of Design Decisions on Life Cycle Energy and Environmental Impact. in PLEA. 2000. James + James Ltd., London.

Fischer-Kowalski, M., Interview Marina Fischer-Kowalski: Die Bewegung von Material ist eine Funktion von Energie 2006, Aachener Stiftung Kathy Beys, online database: http://www.faktorx.info/zukuenfte/energie-triggert-stoffstroemebroktober-2006/interview-fischer-kowalski/

German Federal Statistical Office, Bevölkerungs- und Haushaltsentwicklung im Bund und in den Ländern, in Demografischer Wandel in Deutschland. 2007, Statistische Ämter des Bundes und der Länder, Wiesbaden.

German Federal Statistical Office, Press release 419. 11/ 2008, online database:

http://www.destatis.de/08/

Giljum, S. et al., Overconsumption? Our use of the world's natural resources, Friends of the Earth, SERI, Global 2000, Editor. 2009.

Global Foot Print Network, online database: accessed January 2009:

http://www.footprintnetwork.org/en/index.php/GFN/page/earth_overshoot_day/\#WOD

GRAIN, Seized: The 2008 land grab for food and financial security. 2008, GRAIN NGO: Barcelona, online database: accessed December 2008: http://www. grain.org/briefings/?id=212

Haerig, S., et al.; Technologie der Baustoffe, 2003, C.F. Müller Verlag, Karlsruhe.

Halliday, S., Sustainable Construction. 2008, Elsevier, Oxford.

Halls, S., The building and construction sector: cornerstone of sustainability. UNEP Industry and Environment, 2003(2).

Hamilton, C., Affluenza in Australia. ECOS, 2005. 126(9/10): p. 16-17.

Hausladen, G. et al., ClimateSkin, Building-skin, Concepts that Can Do More with Less Energy. 2006, Birkhäuser, Basel, Boston, Berlin.

Hawthorne, C., Sustainability needs star architects, media coverage, and a few great buildings. Metropolis magazine, 2001 (10).

Hayes, M., Agricultural Residues: A promising alternative to virgin timber. Online database on resource conservation, accessed April 2009: http://www.woodconsumption.org/alts/meghanhayes.html

Hegger, M. et al., Baustoffatlas, ed. Detail. 2005, Institut für internationale Architektur-Dokumentation, Munich.

Hegger, M. et al. ed. Energie Atlas Nachhaltige Architektur. 1 ed., ed. Detail. 2007, Institut für internationale Architektur-Dokumentation, Munich.

Herwig, O., Feigenblatt-Fassaden. Süddeutsche Zeitung, 2008(14.05.).

Herzog, T. et al., ed. Facade Construction Manual. Edition Detail. 2004, Birkhäuser: Munich. 
Hindrichs, D., Heusler, W., ed. Facades - Building envelopes for the 21st Century. 2 ed. 2006, Birkhäuser, Basel.

Hinte v., E. et al., Superuse - Constructing new architecture by shortcutting material flows. 2007, OIO Publishers, Rotterdam.

Hoffmann-Mueller, R., Lauber, U., Umwelt und Nachhaltigkeit, in Datenreport 2008. 2008, Statistisches Bundesamt, Wiesbaden.

Hopkins, R., The Transition Handbook: from oil dependency to local resilience. 2008, Green Books, Totnes.

Huber, J., Industrielle Ökologie. Konsistenz, Effizienz und Suffizienz in zyklusanalytischer Betrachtung, in Global Change, , U. Simonis, Editor. 2000, Nomos, Baden-Baden.

Huurdeman, A., The Worldwide History of Telecommunications. 2003, Wiley-Interscience Pub., Hoboken.

IFS, Pro-Kopf-Fläche weiter gestiegen - Deutschland international im Mittelfeld, in Hausbau Information. 2/2006, Institut für Städtebau, Wohnungswirtschaft und Bausparwesen:http://www.ifsstaedtebauinstitut.de/hi/hi2006/hi02.pdf

Irwin, G., personal communication, 08.05.2009

Jackson, T., New Scientist, Special report: Why politicians dare not to limit economic growth. New Scientist, 2008(2678)

Jackson, T., Prosperity without growth? The transition to a sustainable economy. 2009, Sustainable Development Commission, UK : http://www.sd-commission.org.uk/publications.php?id=914

Jerusalem, F., personal communication, 20.05.2009

Jevons, W., The Coal Question: An Inquiry Concerning the Progress of the Nation and the Probable Exhaustion of our Coal-Mines, 1866, Macmillan, London.

Kaiser, C. et al., Wie viel Natur kostet unsere Nahrung? Ein Beitrag zur Materialintensität ausgewählter Produkte aus Landwirtschaft und Ernährung. Wuppertal Paper, 2009, to be published.

Kaltenbach, F., Living Walls, Vertical Gardens-from the Flower Pot to the Planted System Facade. Detail, 2009(12): p. 1454-66.

Kaufmann et al., Das Passivhaus - Energie-Effizientes-Bauen. Holzbau Handbuch, 2002. 1(3 /10).

Kirschbaum, C., ed. Biopsychologie von A bis Z. 2008, Springer, Heidelberg, online database: accessed February 2009: http://www.biologische-psychologie.de/entries/989

Knaack, K. et al., ed. Facades Principles Of Construction. 2007, Birkhäuser, Basel, Boston, Berlin.

König, H., Wege zum Gesunden Bauen. 1997, Ökobuch Staufen, Freiberg.

Kötz, D., Baulicher Schallschutz gegen Verkehrslärm-Wissenswertes über die Schalldämmung von Fenstern, 2009, German Ministry for the Environment, Umweltbundesamt, Berlin.

Koch, R., The 80/20 Principle; the Secret of Achieving More with Less. 1997, Nicholas Brealey, London.

Koch, W., Americans are moving on up to smaller, smarter homes. USA TODAY, 17.04.2009. Online database, accessed: May 2009: http://www.usatoday.com/life/lifestyle/home/2009-03-16-small-homes_N.htm 
Kuchelmeister, G., Wüstenbekämpfung in China -ein Erfolgsrezept? The international journal of rural development, 2006(4): p. 16-19.

Labeur, J.-B., 2007, Les murs se mettent au vert. Metro France(04.10.), online magazine:http://www.metrofrance.com/fr/article/2007/10/04/08/4952-37/index.xml

Layard, R., Happiness, Lessons from a New Science. 2005, Penguin Books, London.

LEARN - Low Energy Architecture Research Unit, Comfortable low energy architecture (CLEAR). 2004, London Metropolitan University. online database: accessed February 2009: http://www.learn.londonmet.ac.uk/packages/clear/index.html

Le Corbusier, Precisions on the present state of architecture and city planning. 1930, the MIT press, Cambridge, Massachusetts.

Lehmann, H., Stanetzky, C., Zukunftsfähiges Bauen heißt Ressourcennutzung optimieren, in Das Wuppertal Haus. 1999, Birkhäuser, Basel.

Loske, R. et al., Zukunftsfähiges Deutschland, ein Beitrag zu einer global nachhaltigen Entwicklung. ed. BUND/MISEREOR. 1996, Birkhäuser, Basel, Boston, Berlin.

Lstiburek, J., Insight Vocabulary. Insight, Building Science, 2009. 24: p. 1-5.

Mathiason, N., World vows to curb sub-Saharan land grab. The Guardian Weekly, 06.11.2009.

Mc Donough, W., Braungart, M., Cradle to Cradle, the way we make things. 2002, North Point Press, New York.

Mc Granahan, G., Satterthwaite, D., Environmental Health or Ecological Sustainability: Reconciling the brown and green agendas in urban development, in Sustainable cities in developing countries: theory and practice at the millennium, C. Pugh, Editor. 2000, Earthscan Publications, London.

Mc Leod, B., California Agriboard LLC. Journal of Industrial Ecology, 2004. 7(3-4): p. 205-208.

Meadows, D. H., Leverage Points, Places to intervene in a system. 1999, Sustainability Institute, Hartland.

Meadows, D.H. et al., Limits to Growth-The 30-Year Update. 2004, Chelsea Green Publishing, Vermont.

Meadows, D.H. et al., The Limits to Growth: a Report for the Club of Rome's Project on the Predicament of Mankind. 1974, Universe Books, Earth Island Ltd., New York, London.

Mercaldo, L., et al., Thin film silicon photovoltaics: Architectural perspectives and technological issues. Applied Energy, 2009(86): p. 1836-1844.

Minke, G., Dächer begrünen -einfach und wirkungsvoll. 2006, Ökobuch, Staufen.

Minke, G., private communication, 2009.

Ministry for the Environment, Section 1-The waste problem, in The New Zealand Waste Strategy: Towards zero waste and a sustainable New Zealand. 2002. p. 8. Online database: accessed January 2009: http://www.mfe.govt.nz/publications/waste/waste-strategy-mar02/section1-mar02.pdf 
Mithraratne et al, Sustainable living: the role of the whole life costs and value, 2007, ButterworthHeinemann, Amsterdam, London.

NAHB, Single Family square footage by location. 2008, National Association of Home Builders. Online database, accessed May 2009: http://www.nahb.org/category. aspx?sectionlD=819\&channelID=311

Netter, P. et al., Does aluminium have a pathogenic role in dialysis associated arthropathy? Annals of the Rheumatic Diseases, 1989. 49(8).

NZZ, Steigende Fläche, geringe Belegungsdichte - Wie sich die Schweizer Wohnlandschaft verändert. Neue Züricher Zeitung, 2008(30.03.).Online

database:http://www.nzz.ch/nachrichten/startseite/steigende_flaeche_geringere_belegungsdichte_1.697743.html

Oberrauch, B., Bauphysikalische Daten über Lehm, Wohnung + Gesundheit 9/92 Nr. 64, 1992

OECD. Measuring Material Flow and Resource Productivity, Organisation for Economic Co-operation and Development, 2008, online database: accessed January 2009: www.oecd.org

OIB, -Österreichisches Institut für Bautechnik, Leitfaden für die Berechnung von Energiekennzahlen. OIB-382-010/99, 1999, OIB, Wien.

OIB, -Österreichisches Institut für Bautechnik, Klimadaten, Anhang zum Leitfaden für die Berechnung von Energiekennzahlen. OIB-382-011/99, 1999, OIB, Wien.

OIB, -Österreichisches Institut für Bautechnik, Energieeinsparung und Wärmeschutz. 2007, OIB, Wien.

Olgyay, V., Design with climate. 1963, Princeton University Press, Princeton.

Pacca, S., et al., Life Cycle Assessment of the $33 \mathrm{~kW}$ Photovoltaic System on the Dana Building at the University of Michigan: Thin Film Laminates, Multi-crystalline Modules, and Balance of System Components. 2006, University of Michigan, Ann Abor.

Peck, S., et al., Greenbacks from Green roofs: Forging a new Industry in Canada. 1999, Canada Mortgage and Housing Corporation, Toronto.

Peryman, T., personal communication, 2009

Polimeni, J., Ed. The Jevons paradox and the myth of resource efficiency improvements, 2008, Earthscan, London.

Pommer, R., Revising Modernist History: The Architecture of the 1920s and 1930s: The Flat Roof: A Modernist Controversy in Germany. Art Journal, 1983. 43(2)

Purvis, M., Grainger, A., ed. Exploring Sustainable Development-Geographical Perspectives. 2004, Earthscan, London.

Rainbird Ltd., manufacturer, online resources accessed 05.2009: http://www.rainbird.com/ag/index.htm

Rael, R., Earth Architecture, Princeton Architectural Press, 2008, New York.

Reed, B., Shifting our Mental Model - "Sustainability" to Regeneration', in Rethinking Sustainable Construction 2006: Next Generation Green Buildings 2006

Ritthoff, M., personal communication, 02.05.2009, 01.07.2009

Ritthoff, M. et al., Calculating MIPS -Resource productivity and services. Wuppertal Spezial 27 e, ed. Wuppertal Institute for Climate, Environment and Energy, Vol. 1. 2002, Wuppertal. 
Rivoli, P., The Travels of a T-Shirt in the Global Economy: An Economist Examines the Markets, Power, and Politics of World Trade, 2005, Wiley, Hoboken.

Roper, J., Encountering America: Altered States, in Americanisation and the transformation of world cultures- Melting Pot or Cultural Chernobyl?, P. Melling, Roper, J., Editor. 1996, The Edwin Mellen Press, Lampeter.

Sack, M., Zukunft bauen in Verlockungen der Architektur, 2003, Quart, Luzerne.

Sustainable Aotearoa New Zealand Inc.(SANZ), UNESCO, Strong Sustainability for New Zealand Principles and Scenarios, W. Cartwright, Editor. 2009.

Scherhorn, G., Über Effizienz hinaus, in Ressourceneffizienz im Kontext der Nachhaltigkeitsdebatte, Schaffer, Hartard, Giegrich, Editor. 2008, Nomos Verlag, Baden-Baden.

Schmidheiny, S., Business Council for Sustainable Development, Changing Course, 1992, MIT Press, London, Cambridge, Massachusetts.

Schmidt-Bleek, F. et al., Das Wuppertal Haus-Bauen und Wohnen nach dem MIPS-Konzept. 1999, Birkhäuser, Basel.

Schmidt-Bleek, F. et al, MAIA, Einführung in die Material-Intensitäts-Analyse nach dem MIPSKonzept, 1998, Birkhäuser, Basel, Boston, Berlin.

Schmidt-Bleek, F. Factor 10 Manifesto. 2000a, online database: accessed November 2008: http://www.factor10-institute.org/

Schmidt-Bleek, F., The Factor 10/MIPS-Concept, Bridging Ecological, Economic, and Social Dimensions with Sustainability Indicators, 2000b, online database: accessed November 2008: http://www.factor10-institute.org/

Schmidt-Bleek, F., Manstein, C., Klagenfurt Innovation- neue Wege einer umweltgerechten Produktgestaltung. 1999, Alekto Verlag, Klagenfurt. http://www.faktor10.at/sites/default/files/Klagenfurtlnnovation_de.pdf

Schmidt-Bleek: F., The fossil makers, -English translation of: Wieviel Umwelt braucht der Mensch? MIPS, das Maß für ökologisches Wirtschaften 1993, Birkhäuser, Basel, Boston, Berlin. Online database: accessed November 2008: http://www.factor10-institute.org/publications.htm|\#factor10_1993_1995

Schumacher, E.F., Small is beautiful. 1973, Blond and Briggs, London.

Schuhmann, H.; Hygrische und thermische Phänomene bei Natursteinen, 1987, Online database: accessed February 2009: http://www.baufachinformation.de/denkmalpflege.jsp?md=1988067123135

SIA, Schweizer Ingenieur- und Architektenverein, SIA 380/1; SN 520380/1. Thermische Energie im Hochbau. 2009, Verlag SIA Zürich.

Simms, A. et al, The UK Interdependence Report, M. Murphy, Editor. 2006, new economics foundation, London. Online resource: http://www.neweconomics.org/gen/z_sys_PublicationDetail.aspx?pid=220

Simms, A., Special report: Does growth really help the poor?, New Scientist, 2008(2678): p. 49-50

Sinivuoria, P., Saarib, A., MIPS analysis of natural resource consumption in two university buildings. Building and Environment, 2006.(41): p. 657-668.

Spash, C., Economics, Ethics and Long-term Environmental Damages. Environmental Ethics, 1993. 10(1): p. 117-32. 
STATISTIK AUSTRIA, Heizungen 2007/2008 nach Bundesländern, verwendetem Energieträger und Art der Heizung, Ergebnisse für die Steiermark, 2009, online data base:

http://www.statistik.at/web_de/statistiken/energie_und_umwelt/energie/energieeinsatz_der_haushalte/index.html

STATISTIK AUSTRIA, Gemüseernte 2008, endgültige Ergebnisse, online data base:

http://www.statistik.at/web_de/statistiken/land und forstwirtschaft/agrarstruktur flaechen ertraege/gemuese/index.html

Stoll, H., Spax GmbH, personal communication 2009, manufacturer webpage: http://www.spax.com/

Sullivan, L., The tall office building artistically considered. Lippincott's Magazine 1896. 57(3).

Symma, M., OBS-Dachsysteme, manufacturer, personal communication and website: http://www.obs.de/

Taut, B., Siedlungsmemoiren, (1936). 1980, Akademie der Künste, Berlin.

Thomas, W., Man's Role in Changing the Face of the Earth. 1956, Vol.2. University of Chicago Press, Chicago.

Tischner, U., FRIA, Leaping Ahead in Efficient Cooling INEM BULLETIN, 1993. 2(3).

Turner, R., Pearce, D., Sustainable Development: Ethics and Economics, Working Paper PA 9209,Centre for Social and Economic Research on the Global Environment. 1992, Norwich, London.

Ulrich, J., Nicht von Pappe. Focus Money, 2005. 2005(27).

UNEP, ed. Global Environmental Outlook 3 - past, present and future perspectives. 2002, Earthscan Publications Ltd., London.

Vale, B., Vale, R., The New Autonomous House. 2000, Thames+Hudson, New York.

Vringer, K., Blok, K., The energy requirement of cut flowers and consumer options to reduce it. Resources, Conservation and Recycling, 2000. 28: p. 3-28.

Wackernagel, M., 2009/07, letter to friends of the Global footprint network.

Wala, T., Lechner, J., Wohnbauförderung im Überblick. Besser Wohnen, 2006. 2006(9): p. 47-54. http://www.vwbf.at/content/publik/publikpdf/wala_lechner.pdf

Ward, S., Learning from the US: The Americanisation of Western Urban Planning, in Urbanism: Imported or Exported?, J. Nasr, Volait, M., Editor. 2003, Wiley-Academy: Chichester.

WBCSD, Eco-efficiency: creating more value with less impact. 2000a, World Business Council for Sustainable Development: Geneva.

WBCSD, Measuring eco-efficiency: a guide to measure company performance. 2000b, World Business Council for Sustainable Development.

Weizsäcker v., E., Factor four: doubling wealth - halving resource use: a new report to the Club of Rome. 1997: Allen \& Unwin, St. Leonard.

Wilson, A., Straw: The Next Great Building Material? Environmental Building News, 2005(5).

Winchip, S., Sustainable design for interior environments. 2007, Fairchild Inc., New York. 
Winterfeld, v., U. Keine Nachhaltigkeit ohne Suffizienz. Vorgänge, 2007. Nr. 179(3): p. 46-54.

Wong, H., Eat my wall, a vertical urban farm will seed community farming in a graffiti-scarred L.A. neighbourhood. CNN online,08.08. 2008. Online at:

http://money.cnn.com/2008/07/14/smallbusiness/giving_back_wall.fsb/index.htm

World Commission on Environment and Development (WCED), Our Common Future, G.-H.

Brundtland, Editor. 1987, Oxford.

World Trade organisation (WTO), online database: accessed January 2009:

http://www.wto.org/english/thewto_e/glossary_e/multifunctionality_e.htm

Wuppertal Institute for Climate, Environment and Energy. Material intensity of materials, fuels, transport services. 2003-2009, online document:http://www.wupperinst.org/de/info/entwd/uploads/tx_wibeitrag/MIT_v2.pdf

WWF, Living Planet Report 2008, World Wide Fund for Nature, Global Footprint Network, Zoographical Society London, Editor. 2008, Gland. 


\section{PICTURE CREDITS}

Figure 1: Image 1: http://upload.wikimedia.org/wikipedia/en/8/83/Udachnaya_pipe.JPG

Image 2: http://alloverasia.wordpress.com/

Figure 2 after Simms, A. et al, The UK Interdependence Report, p. 34, M. Murphy, Editor. 2006, new economics foundation: London.

Figure 3 after WWF, Living Planet Report 2008, p. 2. World Wide Fund for Nature, Global Footprint Network, Zoographical Society London, Editor. 2008: Gland and with permission of Global Footprint Network.

Figure 4 World Bank development indicators, 2008

Figure 5 by the author

Figure 6 by the author

Figure 7 by the author

Figure 8 by the author

Figure 9 Image 1: http://www.student.uni-augsburg.de/ retterjo/schleching.htm Image 2: http://www.ekir.de/ebersgoens/contenido/cms/front_content.php?idcat=86

Figure 10 Image 1: Icon no.065. "Activist Architects: Teddy Cruz, Nov 2008.

Image 2: http://theinspirationroom.com/daily/2007/adbusters-posters-for-buy-nothingday/

Figure 11 with permission of: http://www.ambossmeister.de

Figure 12 after Reed, B., Shifting our Mental Model - "Sustainability" to Regeneration', p.13, in Rethinking Sustainable Construction 2006: Next Generation Green Buildings 2006.

Figure 13 by the author

Figure 14 Images by Reuters news agency.

Figure 15 by Leatherman Itd.

Figure 16 Giljum, S. et al., Overconsumption? Our use of the world's natural resources, Friends 
of the Earth, SERI, Global 2000, Editor. 2009, p.21.

Figure 17 Images by N. Hilal

Figure 18 by the author

Figure 19 based on

Hegger, M. et al. ed. Energie Atlas Nachhaltige Architektur. 1 ed., ed. Detail. 2007, Institut für internationale Architektur-Dokumentation: Munich, p.83 and

Herzog, T. et al., ed. Facade Construction Manual. Edition Detail. 2004, Birkhäuser: Munich, p. 18.

Figure 20 Images by Murcutt, G.

Olgyay, V., Design with climate. 1963, Princeton: Princeton University Press, p.4.

Figure 22 Image 1:http://www.britannica.com/EBchecked/topic-art/202468/96423/Tomb-ofChishti-Fatehpur-Sikri-Uttar-Pradesh-India Image 2:http://rubens.anu.edu.au/raider7/islam_and_marble/images/fatehpur_chishti /DSCN4881.JPG

Figure 23 Bendiksen, J., The Places We live. 2008, New York: Aperture Foundation, Inc.

Figure 24 Images by Jasmax Ltd.

Figure 25 Image 1: Sartor

Image 2: Clausing

$\begin{array}{lllll}\text { Figure } 26 & \text { Image } & \text { 1: } & \text { Schlieper, } & \text { R., }\end{array}$ www.fotogemeinschaft.de/v/motive/architektur/bahnhof/_bahnhofkoeln.jpg.html Image 2: http://www.allgaeu-aktuell.de/schloss.html

Figure 27 Images: http://www.eikongraphia.com

Figure 28 Image 1: Artspace, http://www.arcspace.com/architects/sejima_nishizawa/zollverein_school/zollverein_s chool.html Image 2: http://www.neublack.com/art-design/gmp-architekten-church-beijing-china/ 
Figure 29 Images: http://www.as-p.de/projects/urban-planning/9199.html

Figure 30 based on

Hegger, M. et al. ed. Energie Atlas Nachhaltige Architektur. 1 ed., ed. Detail. 2007, Institut für internationale Architektur-Dokumentation: Munich, p.83 and

Herzog, T. et al., ed. Facade Construction Manual. Edition Detail. 2004, Birkhäuser: Munich, p. 18.

Figure 31 by the author

Figure 32

Hegger, M. et al., Baustoffatlas, ed. Detail. 2005, Institut für internationale Architektur-Dokumentation: Munich, p.105.

Figure 33 Image by Mayang

Figure 34 by the author

Figure 35 by LEARN - Low Energy Architecture Research Unit, Comfortable low energy architecture (CLEAR). 2004, London Metropolitan University.

http://www.learn.londonmet.ac.uk/packages/clear/index.html

Figure 36 Image 1: Kilian

Image 2: Gommer

Figure 37 Image 1: Virella, D.

Image 2: Rauch, M.

Figure 38 by the author

Figure 38 by the author

Figure 40 by the author

Figure 41 Aerni, with permission of Jerusalem, F.

Figure 42 Aerni, with permission of Jerusalem, F.

Figure 43 by the author 
Figure 43 Minke, G., Dächer begrünen -einfach und wirkungsvoll. 2006, Staufen: Ökobuch, p.13.

Figure 45 Image 1: with permission of United States Environmental Protection Agency Image 2: Levenston, M., http://www.cityfarmer.info/?cat=28\&paged=2

Figure 46 Image 1: Köhler Image 2: Neda, http://picasaweb.google.com/lh/photo/RWnNq6Gq90k4aJvgqyaRWg

Figure 47 Image 1: with permission of Yong-Kwan Image 2: Kramer, L.

Figure 48 Image 1: Nagase

Image 2: by the author

Figure 49 Image 1: http://www.flickr.com/photos/sustainablebuildingcentre/217949817/ Image 2: http://www.buildinggreentv.com/keywords/living-wall

Figure 50 Images:

http://www.agreenroof.com/Standard\%20Green\%20Living\%20Wall\%20Panels.pdf

Figure 51 Images: http://www.buildinggreentv.com/keywords/living-wall

Figure 52 Image 1: Sharp, R., http://www.sharpdiamond.com/

Image 2: by the author

Figure 53 with permission of De Geus, M.

Figure 54 Image 1: with permission of De Geus, M.

Image 2. by the author

Figure 55 after Kaltenbach, F., Living Walls, Vertical Gardens -from the Flower Pot to the Planted System Facade. Detail, 2009(12): p. 1454-66.

Figure 56 by the author

Figure 57 by the author

Figure 58 by the author 
Figure 59 based on:

Bergmann, I., Weiss, W., Fassadenintegration von thermischen Sonnenkollektoren ohne Hinterlüftung, in Berichte aus der Energie- und Umweltforschung. 2002, Bundesministerium für Verkehr, Innovation und Technologie: Wien, p. 69, Figure 5.30

Figure 60 by the author

Figure 61 by the author

Figure 62 Image by Voltarlux

Image 1: Voltarlux

Figure 63

Figure 64 by the author

Figure 65 Image 1: by the author

Image 2: Aerni, with permission of Jerusalem, F.

Figure 66 based on:

Bergmann, I., Weiss, W., Fassadenintegration von thermischen Sonnenkollektoren ohne Hinterlüftung, in Berichte aus der Energie- und Umweltforschung. 2002, Bundesministerium für Verkehr, Innovation und Technologie: Wien, p. 56.

Figure 67

by the author

Figure 100 
